\title{
Análise do comportamento de blocos de concreto armado sobre estacas submetidos à ação de força centrada
}

\author{
Fabiana Stripari Munhoz \\ Dissertação apresentada ao Departamento de \\ Engenharia da EESC-USP, como parte dos \\ requisitos necessários à obtenção do título de Mestre \\ em Engenharia de Estruturas.
}

Orientador: José Samuel Giongo 


\section{AGRADECIMENTOS}

Ao Professor José Samuel Giongo pela orientação dedicada e pela oportunidade de realização deste trabalho.

Ao colega Eng. Rodrigo Gustavo Delalibera pelas sugestões e orientações na elaboração das várias fases deste trabalho.

Ao Professor Libânio Miranda Pinheiro pela amizade e pelo encaminhamento no início do Programa de Mestrado.

Aos amigos do Departamento de Engenharia de Estruturas EESC/USP: Daniane, Larissa, Luciana, Sandra e Wesley pela confiança e paciência dedicadas.

Meus sinceros agradecimentos aos funcionários, colegas e professores do Departamento de Engenharia de Estruturas EESC/USP que colaboraram para a realização deste trabalho.

A Capes (Coordenação de Aperfeiçoamento de Pessoal de Nível Superior) pela bolsa concedida.

E finalmente aos meus pais e ao meu noivo pela paciência e confiança desprendidas durante a elaboração deste trabalho. 


\section{RESUMO}

MUNHOZ, F. S. (2004). Análise do comportamento de blocos de concreto armado sobre estacas submetidos à ação de força centrada. Dissertação (Mestrado) - Escola de Engenharia de São Carlos, Universidade de São Paulo.

Este trabalho estuda o comportamento de blocos rígidos de concreto armado sobre uma, duas, três, quatro e cinco estacas, submetidos à ação de força centrada. Com o objetivo de contribuir para critérios de projeto, utilizaram-se resultados obtidos por meio de modelos analíticos e realizou-se análise numérica utilizando-se programa baseado no Método dos Elementos Finitos. Foi desenvolvida, ainda, uma análise comparativa entre os processos de dimensionamento adotados em projeto, na qual se verificou grande variabilidade dos resultados. Para análise numérica adotou-se comportamento do material como elástico linear e os resultados de interesse foram os fluxos de tensões em suas direções principais. Nos modelos adotados variaram-se os diâmetros de estacas e dimensões de pilar, a fim de se verificar as diferenças na formação dos campos e trajetórias de tensões. Concluiu-se que o modelo de treliça utilizado em projetos é simplificado e foram feitas algumas sugestões para a utilização de um modelo de Bielas e Tirantes mais refinado. Foi possível a verificação da influência da variação da geometria de estacas e de pilares no projeto de blocos sobre e a revisão dos critérios para os arranjos das armaduras principais. Para os modelos de blocos sobre cinco estacas adotados concluiu-se que o comportamento não é exatamente como considerado na prática.

Palavras-chave: blocos sobre estacas, fundações, concreto armado, bielas e tirantes. 


\section{ABSTRACT}

MUNHOZ, F. S. (2004). Analysis of reinforced concrete pile-caps behaviour subjected to center top surfaces loading. Dissertação (Mestrado) - Escola de Engenharia de São Carlos, Universidade de São Paulo.

This work describes the behavior of rigid reinforced concrete pile-caps with one, two, three, four and five piles subjected to patches of loading on the center top surfaces of the column. Programs based on Finite Elements Method were used to obtain numerical results and results obtained by means of analytic models were used. A comparative analysis was developed among the processes adopted in design, which large variability of the results was verified. An elastic linear behavior of the material was adopted for numerical analysis and interest results were stress paths along main directions. Piles diameters and column dimensions of the models were been varied, in order to verify the differences in the formation of the regions and trajectories of stress. It is ended that used the truss model is simplified. Some suggestions were made for the use of a more refined Strut-and-Tie Model than the one used in design and it was possible the verification of the variation geometry of piles and columns influence. It was still made a revision of the reinforcement layouts. The conclusion for adopted five-pile-caps was that the behavior is not exactly as considered in the practice.

Keywords: pile-caps, footings, reinforced concrete, strut-and-tie. 


\section{SUMÁRIO}

AGRADECIMENTOS ..........................................................................

RESUMO ..........................................................................................

ABSTRACT .......................................................................................

LISTA DE FIGURAS ..........................................................................viii

LISTA DE TABELAS .............................................................................xii

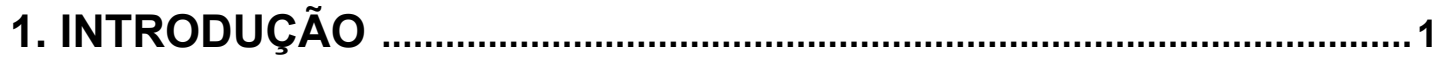

1.1. Considerações iniciais........................................................... 1

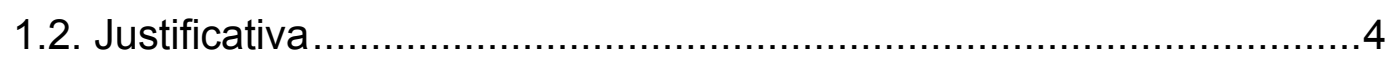

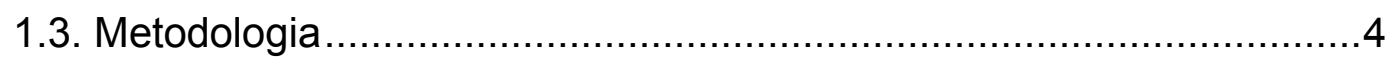

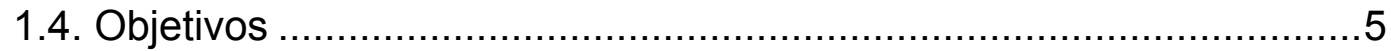

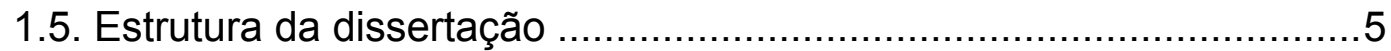

2. REVISÃO BIBLIOGRÁFICA ................................................... 7

2.1. Considerações iniciais...........................................................

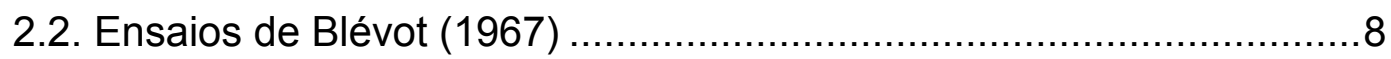

2.3. Ensaios de Mautoni (1972) f.................................................. 10

2.4. Ensaios de Taylor e Clarke (1976) ........................................ 12

2.5. Ensaios de Adebar, Kuchma e Collins (1990) ..............................13

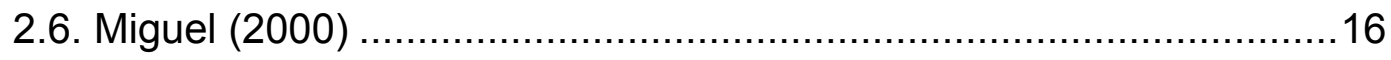

2.7. Trabalhos com ênfase na análise numérica ................................ 18

3. PROJETO DE BLOCOS SOBRE ESTACA................................... 22

3.1. Considerações iniciais........................................................... 22

3.2. Critérios de projeto para blocos sobre estacas .............................22

3.2.1. Procedimentos gerais de projeto.................................................22 
3.2.2. Distância entre eixos de estacas. 24

3.2.3. Método da superposição para blocos submetidos à força vertical e momento fletor 25

3.2.4. Classificação de blocos sobre estaca...........................................26

3.2.5. Recomendações para a altura dos blocos...................................... 28

3.2.6. Distância do eixo da estaca até a face do bloco...............................29

3.2.7. Ligação da estaca com o bloco .................................................... 29

3.2.8. Recomendações sobre excentricidades acidentais.......................... 30

3.2.9. Ancoragem das barras de armadura principal dos blocos.................. 30

3.2.10. Detalhamento das Armaduras Secundárias.................................. 33

3.2.10.1. Método do CEB-FIP - Boletim 73 (1970).......................................33

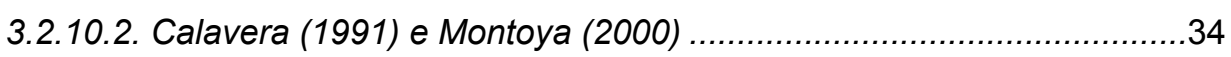

3.2.10.3. Recomendações da NBR 6118 2003...........................................34

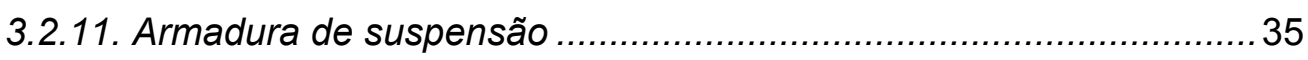

3.3. Métodos para dimensionamento de blocos sobre estacas................36

3.3.1. Método das Bielas ................................................................. 36

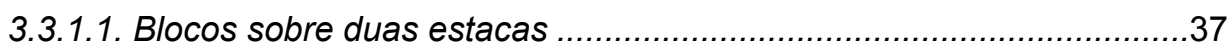

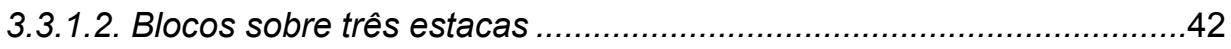

3.3.1.3. Blocos sobre quatro estacas .......................................................4

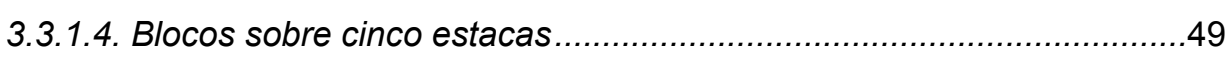

3.3.2. Processo do CEB-FIP - Boletim 73 (1970)................................. 51

3.3.2.1. Dimensionamento da armadura inferior ..........................................52

3.3.2.2. Disposição da armadura inferior .....................................................53

3.3.2.3. Condição de aderência das barras da armadura principal ..................55

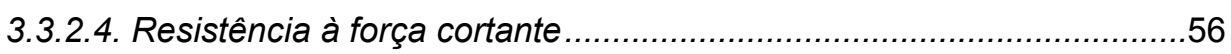

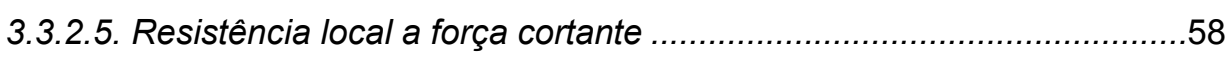

3.3.3. Critérios adotados por Calavera (1991)..........................................58

3.3.4. Critérios adotados por Montoya (2000) ..........................................62

3.3.5. Critérios adotados pelo ACl (1994).............................................. 65

3.3.6. Critérios para blocos sobre 1 estaca .........................................66

4. MODELO DE BIELAS E TIRANTES ....................................... 71

4.1. Considerações Iniciais .......................................................... 71

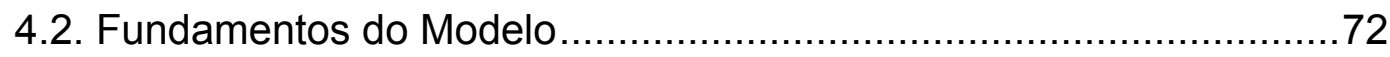

4.2.1. Aplicação de Modelos de Bielas e Tirantes ...................................73

4.3. Projeto considerando o Modelo de Bielas e Tirantes ........................75

4.4. Dificuldades e Desafios em Modelos de Bielas e Tirantes................84

5. ANÁLISE DE BLOCOS SOBRE ESTACAS.................................90 


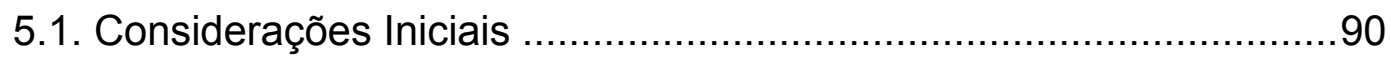

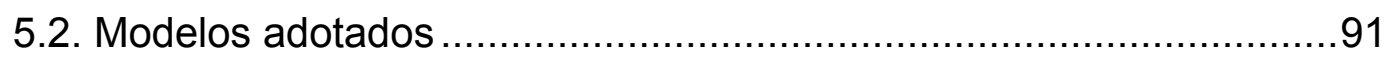

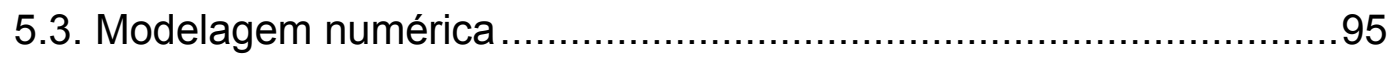

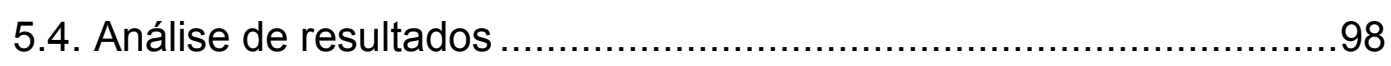

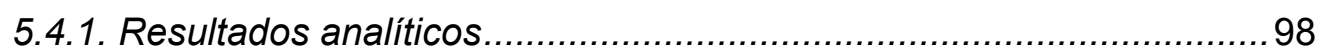

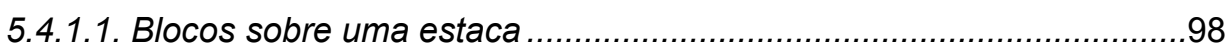

5.4.1.2. Blocos sobre duas, três, quatro e cinco estacas...............................99

5.4.2. Resultados numéricos ................................................ 103

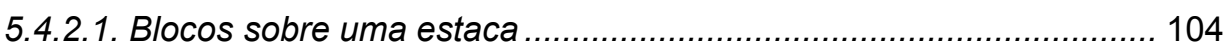

5.4.2.2. Blocos sobre duas estacas .................................................... 107

5.4.2.3. Blocos sobre três estacas ........................................................ 112

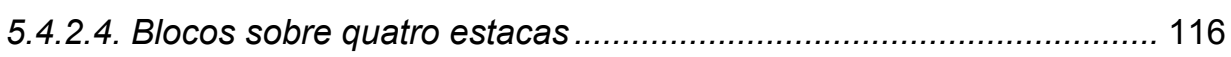

5.4.2.5. Blocos sobre cinco estacas..................................................... 120

5.5. Modelagem utilizando Bielas e Tirantes....................................127

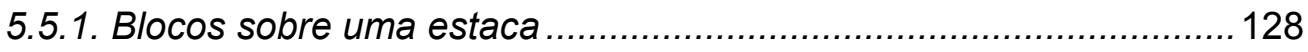

5.5.2. Blocos sobre duas estacas ........................................................ 129

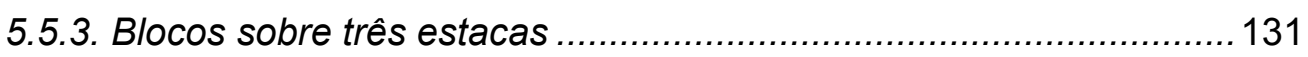

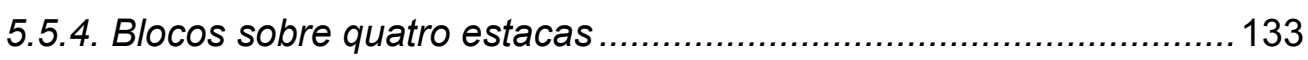

5.6. Exemplo de Aplicação para blocos sobre duas estacas .................135

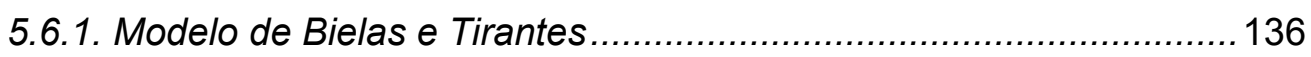

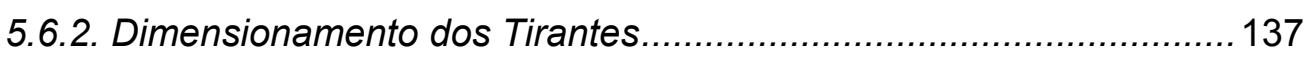

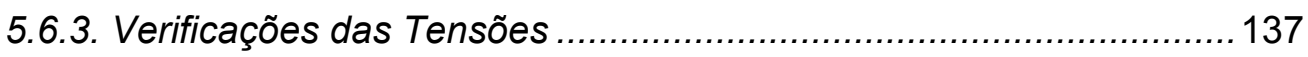

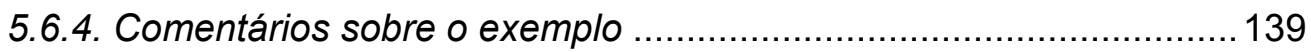

6. CONCLUSÃO

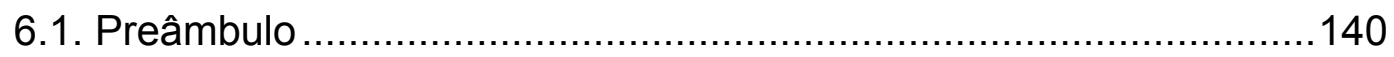

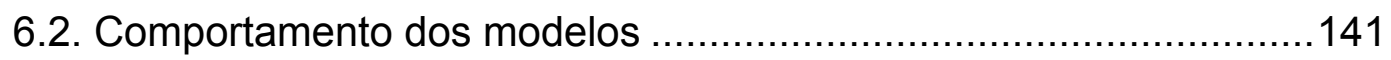

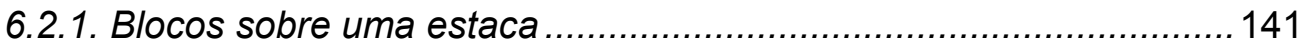

6.2.2. Blocos sobre duas, três e quatro estacas ..................................... 141

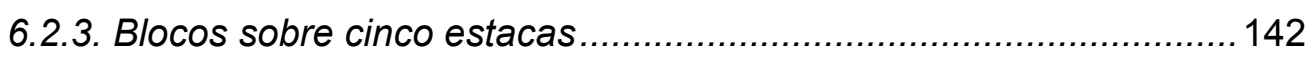

6.3. Sugestões para trabalhos futuros............................................. 142

REFERÊNCIAS BIBLIOGRÁFICAS ........................................... 144 


\section{LISTA DE FIGURAS}

Figura 1.1 - Bloco sobre quatro estacas. 1

Figura 2.1 - Modelos de blocos sobre duas estacas ensaiados por Blévot (1967) ... 8

Figura 2.2 - Modelos de blocos sobre três estacas ensaiados por Blévot (1967) .....9

Figura 2.3 - Modelos de blocos sobre quatro estacas ensaiados por Blévot (1967)10

Figura 2.4 - Modelo adotado nos ensaios de Mautoni (1972) com armadura "em bigode"

Figura 2.5 - Tipos de armadura e ancoragem utilizadas nos blocos ensaiados por Taylor e Clarke (1976). 12

Figura 2.6 - Tipos de ruptura em blocos ensaiados por Taylor e Clarke (1976) ..... 13

Figura 2.7 - Modelos de blocos ensaiados por Adebar et al. (1990) 14

Figura 2.8 - Trajetórias de tensões elástico-lineares e Modelo refinado de Bielas e

Tirantes sugerido por Adebar et al. (1990). 15

Figura 2.9 - Numeração das estacas dos modelos ensaiados por Miguel (2000)... 17

Figura 2.10 - Bloco sobre três estacas analisado por IYER e SAM (1991).... 19

Figura 3.1 - Blocos padronizados sobre estacas. 24

Figura 3.2 - Nomenclatura adotada para aplicação do Método da Superposição... 25

Figura 3.3 -Parâmetros para classificação do bloco. 27

Figura 3.4 - União de bloco e estaca (Calavera, 1991) 29

Figura 3.5 - Excentricidade acidental em blocos sobre uma e duas estacas (Calavera, 1991). 30

Figura 3.6 - Comprimento de ancoragem em blocos sobre estacas(Calavera, 1991)

Figura 3.7 - Armaduras secundárias (CEB-FIP, 1970) 
Figura 3.8 - Esquema para colocação de armadura de suspensão em casos de armadura disposta entre as estacas (Leonhardt e Monning, 1978) ........................35

Figura 3.9 - Modelo de cálculo para blocos sobre duas estacas...........................37

Figura 3.10 - Polígono de Forças .................................................................... 38

Figura 3.11 - Área de verificação das bielas, junto à estaca e junto ao pilar (bloco sobre duas estacas) .................................................................................... 40

Figura 3.12 - Modelo de cálculo para blocos sobre três estacas .......................... 42

Figura 3.13 - Arranjo de armadura segundos as medianas e segundo os lados do

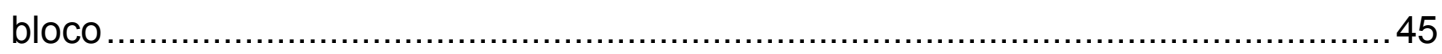

Figura 3.14 - Arranjo de armadura em malha...................................................... 46

Figura 3.15 - Modelo de cálculo para blocos sobre quatro estacas ...................... 47

Figura 3.16 - Modelo de cálculo para blocos sobre cinco estacas ........................ 49

Figura 3.17 - Relação entre a aba $\ell_{\mathrm{c}}$ e altura h................................................ 52

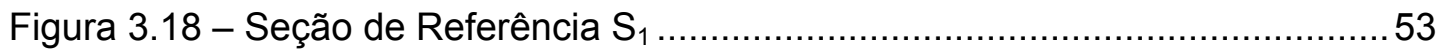

Figura 3.19 - Disposição das armaduras ....................................................... 54

Figura 3.20 - Recomendação para ancoragem da armadura principal em blocos

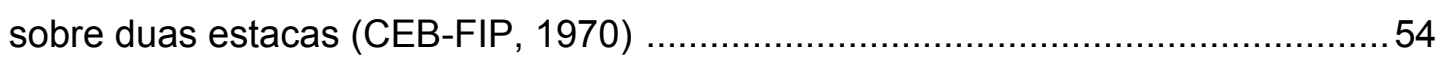

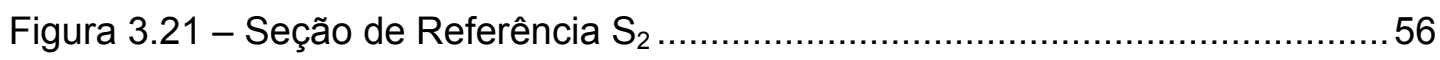

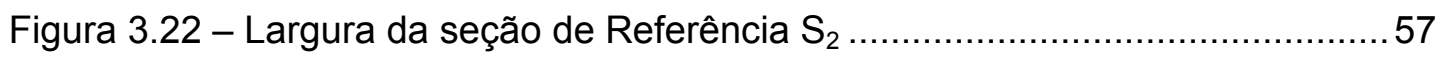

Figura 3.23 - Verificação da força cortante em regiões próximas às estacas de canto .58

Figura 3.24 - Modelo de cálculo para blocos sobre três estacas sugerido por Calavera (1991). 60

Figura 3.25 - Seção de referência para verificação à força cortante

(Calavera, 1991).

Figura 3.26 - Modelo de cálculo para blocos sobre quatro estacas sugerido por Calavera (1991). 62

Figura 3.27 - Modelo de cálculo para blocos sobre duas estacas (EHE, 2001)......63

Figura 3.28 - Modelo de cálculo para blocos sobre três estacas (EHE, 2001). .......64

Figura 3.29 - Disposição de armadura em blocos sobre quatro estacas (EHE, 2001)

Figura 3.30 - Trajetória de Tensões Principais de Compressão 66

Figura 3.31 - Modelo para determinação de força transversal de tração $\left(R_{t t}\right)$ proposto

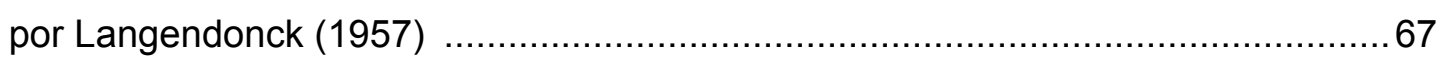

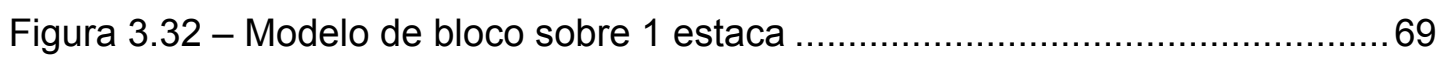

Figura 3.33 - Modelo de bloco parcialmente carregado adaptado para Modelo de Bielas e Tirantes. 
Figura 4.1 - Modelos de bielas e tirantes (Tjhin e Kuchma, 2002) ........................ 72

Figura 4.2 - Exemplos de Regiões B e D ...................................................... 75

Figura 4.3 - Aplicação do caminho de carga em blocos sobre duas estacas..........77

Figura 4.4 - Configurações típicas de campos de tensão de compressão

(Tjhin e Kuchma, 2002) …........................................................................ 78

Figura 4.5- Nós somente com força de compressão (CM - CEB-FIP, 1990) ...........81

Figura 4.6- Nós somente com ancoragem somente de barras paralelas

(CM - CEB-FIP, 1990)

Figura 4.7 - Modelo de biela e tirante estaticamente indeterminado em apoios de vigas parede(Tjhin e Kuchma, 2002)...

Figura 5.1 - Modelos de blocos sobre uma e duas estacas (medidas em centímetros)

Figura 5.2 - Modelos de blocos sobre três, quatro e cinco estacas (medidas em

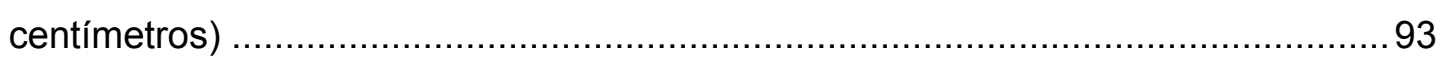

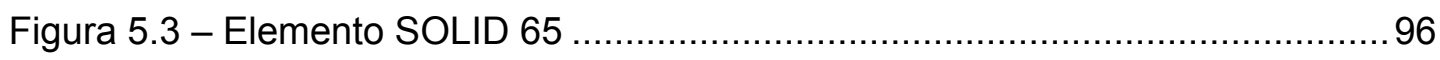

Figura 5.4 -Malha de elementos finitos utilizados........................................... 97

Figura 5.5 - Condições de contorno e solicitações impostas ao Modelo B1-1 ........98

Figura 5.6 - Campos de tensão de modelos de blocos sobre 1 estaca.................. 104

Figura 5.7 - Campos de tensão de compressão modelo A2-1h50 ........................ 105

Figura 5.8 - Campos de tensão de tração modelo A2-1h50 ................................ 106

Figura 5.9 - Campos de tensão de compressão em modelos de blocos sobre uma

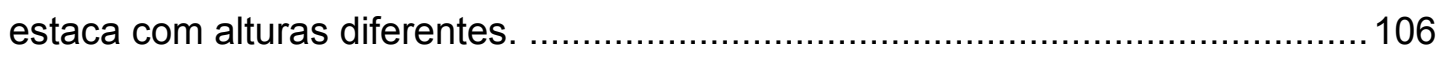

Figura 5.10 -Campos de tensão de tração em modelos de blocos sobre uma estaca

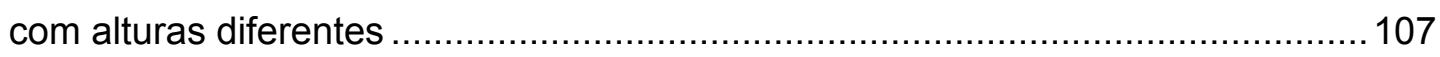

Figura 5.11 - Formação das bielas de compressão ........................................ 108

Figura 5.12 -Bielas de compressão, modelo numérico e modelo de Blévot........... 109

Figura 5.13 -Campos de tensão de compressão para modelos com diâmetro de

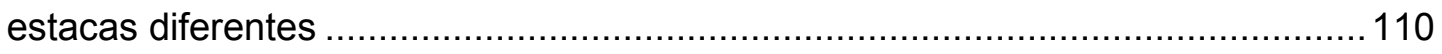

Figura 5.14-Campos de tensão de tração .....................................................110

Figura 5.15- Modelos de blocos sobre três estacas - diferentes seções adotadas para os pilares.

Figura 5.16 - Vistas esquemáticas dos modelos de blocos sobre três estacas .... 113

Figura 5.17 - Campos de tensão de compressão - blocos sobre três estacas..... 113

Figura 5.18 - Campos de tensão de tração - blocos sobre três estacas ...............114

Figura 5.19 - Campos de tensão de compressão - blocos sobre três estacas (vista de cima) 
Figura 5.20 - Campos de tensão de tração - blocos sobre três estacas (vista de baixo)

Figura 5.21 - Vistas esquemáticas dos modelos de blocos sobre quatro estacas 116

Figura 5.22 - Campos de tensão de compressão nos modelos de blocos sobre 4 estacas (corte AA)

Figura 5.23 - Campos de tensão de compressão no modelo D1-3 (corte BB) .....118

Figura 5.24 - Campos de tensão de tração no modelo D1-1 ............................... 119

Figura 5.25 - Vistas esquemáticas dos modelos de blocos sobre cinco estacas.. 120

Figura 5.26 - Campos de tensão de compressão nos modelos de blocos sobre 5 estacas (corte AA)

Figura 5.27- Campos de tensão de tração nos modelos de blocos sobre 5 estacas (vista de baixo)

Figura 5.28 - Campos de tensão de compressão nos modelos de blocos sobre 5 estacas

Figura 5.29 - Campos de tensão de tração nos modelos de blocos sobre 5 estacas

Figura 5.30 - Numeração das estacas nos modelos de blocos sobre cinco estacas

Figura 5.31 -Trajetória de Tensões Principais - Modelo A1-1h50 ...................... 128

Figura 5.32 - Trajetória de Tensões Principais ............................................... 128

Figura 5.33 - Trajetórias de tensões elástico-lineares e Modelo de Bielas e Tirantes para blocos sobre uma estaca ........................................................................ 129

Figura 5.34 -Trajetória de Tensões Principais - Modelo B1-1 ............................ 129

Figura 5.35 -Trajetórias de tensões principais. 130

Figura 5.36 - Trajetórias de tensões elástico-lineares e Modelo refinado de Bielas e Tirantes para blocos sobre duas estacas. 130

Figura 5.37 -Trajetória de Tensões Principais - Modelo C1-1

Figura 5.38 -Trajetória de Tensões Principais Direção 1 (tração) - Vista Inferior. 132 Figura 5.39 - Trajetórias de tensões de tração e sugestão para disposição de armadura dos tirantes para blocos sobre três estacas............................................133

Figura 5.40 -Trajetória de Tensões Principais - Modelo D1-1 ............................. 134

Figura 5.41 -Trajetória de tensões de tração - Vista Inferior 134

Figura 5.42 - Trajetórias de tensões de tração e sugestão para disposição de armadura dos tirantes para blocos sobre quatro estacas 135

Figura 5.43 - Bloco sobre duas estacas B1-1 ................................................. 136

Figura 5.44 - Modelo para bloco sobre duas estacas B1-1 ................................ 136

Figura 5.45 - Regiões nodais verificadas ................................................... 138 


\section{LISTA DE TABELAS}

Tabela 2.1 - Conclusões obtidas por Adebar et al. (1990) 16

Tabela 2.2 - Tipos de arranjos de armadura utilizados nos modelos ensaiados por Miguel (2000) 17

Tabela 2.3 - Principais conclusões obtidas por Miguel (2000) ............................. 18

Tabela 2.4 - Principais conclusões obtidas por Iver e Sam (1995) .........................20

Tabela 2.5 - Principais conclusões obtidas por Iturrioz et al. (2000) .......................2 21

Tabela 3.1 - Arranjo de armadura para blocos sobre quatro estacas .....................49

Tabela 3.2 - Arranjo de armadura para blocos sobre cinco estacas .......................51

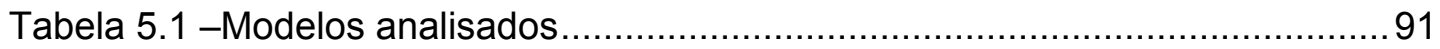

Tabela 5.2 -Parâmetros Geométricos (medidas em centímetros) .......................... 94

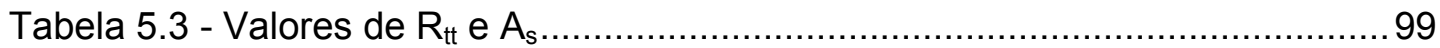

Tabela 5.4- Condições para aplicação dos métodos nos modelos estudados...... 100

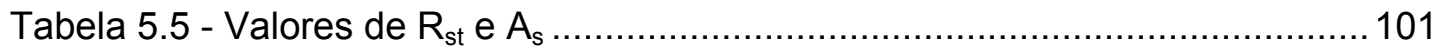

Tabela 5.6 - Tensões de compressão nas regiões nodais - modelo de Blévot (1967)

Tabela 5.7 - Tensões máximas de tração .......................................................... 111

Tabela 5.8 - Tensões máximas de tração ........................................................... 112

Tabela 5.9 - Tensões máximas de tração …..................................................... 120

Tabela 5.10 - Tensões máximas de tração ........................................................ 122

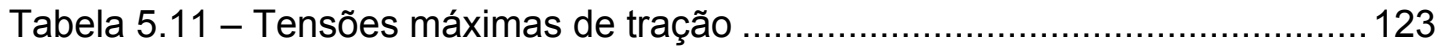

Tabela 5.12 - Reações nas estacas dos modelos numéricos de blocos sobre três

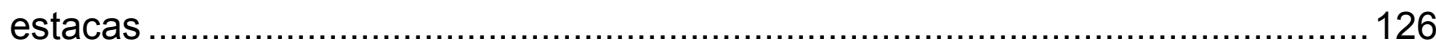

Tabela 5.13- Reações nas estacas do modelo E1-1h150 ..................................... 126 


\section{INTRODUÇÃO}

\subsection{Considerações iniciais}

A escolha do tipo de fundação para uma determinada construção é feita após estudo que satisfaça as condições técnicas e econômicas da obra. Com o conhecimento dos parâmetros do solo, da intensidade das ações, das posições das edificações limítrofes e dos tipos de fundações disponíveis no mercado do local da obra, o projetista pode escolher qual a melhor a alternativa para satisfazer técnica e economicamente o caso em questão.

Os blocos sobre estacas são elementos estruturais de fundação cuja finalidade é transmitir às estacas as ações oriundas da superestrutura (figura 1.1). $O$ uso deste tipo de fundação se justifica quando não se encontram camadas superficiais de solo local resistentes, sendo necessário atingir camadas mais profundas que sirvam de apoio à fundação.

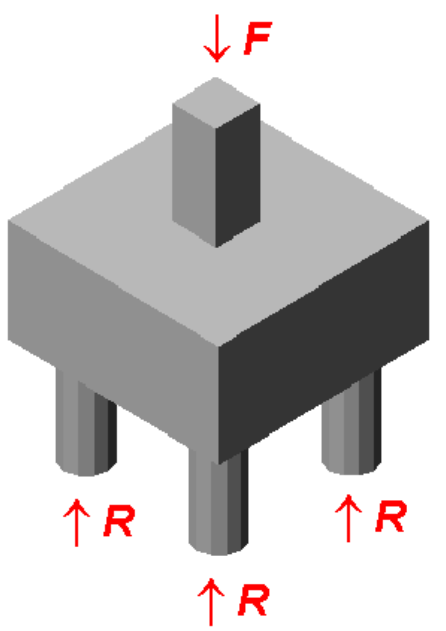

Figura 1.1 - Bloco sobre quatro estacas 
Os blocos sobre estacas são estruturas tridimensionais, ou seja, todas as dimensões têm a mesma ordem de grandeza, tornando seu funcionamento complexo. O comportamento mecânico do conjunto aço/concreto, a determinação de vinculações e a existência da interação solo/estrutura são problemas que agravam o grau de complexidade. Esses elementos estruturais, apesar de serem fundamentais para a segurança da superestrutura, geralmente, não permitem inspeção visual, quando em serviço, sendo assim, importante o conhecimento de seu real comportamento.

Os métodos para dimensionamento destes elementos utilizados até os dias atuais tratam-os de modo simplificado, além disso, há diferentes parâmetros adotados pelas normas e processos.

A norma brasileira NBR 6118:2003 considera os blocos sobre estacas como elementos estruturais especiais, que não respeitam a hipótese de seções planas, por não serem suficientemente longos para que se dissipem as perturbações localizadas. Classifica o comportamento estrutural de blocos em rígidos e flexíveis. No caso de blocos rígidos o modelo estrutural adotado para cálculo e dimensionamento deve ser tridimensional, linear ou não, e modelos de biela-tirante tridimensionais, sendo esses últimos os preferidos por definir melhor a distribuição de forças nas bielas e tirantes. A NBR 6118:2003 não fornece em seu texto um roteiro para verificações e dimensionamento destes elementos.

O código americano ACl-318 (1994) adota hipóteses bem simplificadas para o dimensionamento de blocos. Recomenda o uso da teoria da flexão e a verificação da altura mínima do bloco para resistir à força cortante.

A norma espanhola EHE (2001) fornece expressões que permitem determinar a área das barras de armadura para os casos mais freqüentes de blocos sobre estacas, conforme o modelo de treliça adotado.

Calavera (1991) define o dimensionamento de blocos conforme o recomendado pela norma espanhola $\mathrm{EH}-91$, sugerindo verificações para momento fletor e força cortante, fazendo as considerações para cálculo de blocos rígidos ou flexíveis. Define como bloco rígido aquele em que a transferência de forças se dá por meio do modelo de bielas e tirantes. Assim como Montoya (2000) e EHE (2001), não sugere verificação de tensões de compressão nas regiões nodais dos modelos.

Os métodos usuais empregados para o projeto de blocos sobre estacas, utilizado pelo meio técnico no Brasil, são o Método do CEB-FIP (1970) e o Método das Bielas.

O Método das Bielas, desenvolvido considerando análise de resultados experimentais de modelos ensaiados por Blévot (1967), considera no interior do bloco 
uma treliça composta por barras tracionadas e barras comprimidas. As forças de tração que atuam nas barras horizontais da treliça são resistidas pela armadura, as de compressão nas bielas são resistidas pelo concreto. Consiste no cálculo da força de tração e na verificação da tensão de compressão nas bielas. É recomendado para ações centradas, mas pode ser empregado no caso de ações excêntricas, desde que, se admita que todas as estacas estão submetidas à maior força transferida.

O Método do CEB-FIP (1970) é aplicável a blocos cuja distância entre a face do pilar até o eixo da estaca mais afastada varia entre um terço e a metade da altura do bloco. O método sugere um cálculo à flexão considerando uma seção de referência interna em relação à face do pilar e distante desta 0,15 da dimensão do pilar na direção considerada. Para verificações da capacidade resistente à força cortante, define-se uma seção de referência externa distante da face do pilar de um comprimento igual a metade da altura do bloco, e no caso de blocos sobre estacas vizinhas ao pilar a seção é considerada na própria face do pilar.

Uma análise criteriosa para definir o comportamento estrutural de blocos sobre estacas é a que considera o modelo de bielas e tirantes, afinal, tratam-se de regiões descontínuas, onde não são válidas as hipóteses de Bernoulli. No modelo de bielas e tirantes as verificações de compressão nas bielas podem ser feitas com as considerações do Código Modelo do CEB-FIP (1990), pois as regiões nodais têm geometria diferente das sugeridas por Blévot (1967).

O modelo de bielas e tirantes pode ser adotado considerando o fluxo de tensões na estrutura, utilizando o processo do caminho das cargas. Essas tensões podem ser obtidas por meio de uma análise elástica linear, utilizando métodos numéricos, como por exemplo, o método dos elementos finitos.

Segundo Tjhin e Kuchma (2002) a orientação mais adequada para seleção de modelos apropriadas de bielas e tirantes pode ser verificada em Schlaich et al. (1987) que propõem arranjar os elementos da treliça do modelo utilizando as trajetórias de tensões principais obtidas de uma solução elástica linear. Essas aproximações permitem verificar os estados limites último e de serviço.

O uso de trajetórias de tensões principais para guiar a construção de modelos de bielas e tirantes também foi estendido à geração automática de modelos. Um exemplo disto pode ser visto no trabalho de Harisis e Fardis (1991), que usaram uma análise estática de dados de tensão principais obtida de análise linear por elementos finitos para identificar localizações de bielas e tirantes.

Longo (2000) utilizou campos e trajetórias de tensões principais, em vigas prémoldadas, obtidas de uma análise elástica linear por meio do Método dos Elementos 
Finitos e conseguiu bons resultados iniciais para adoção de modelos de bielas e tirantes.

Autores como lyer e Sam (1991) estudaram o comportamento de blocos sobre três estacas por meio de uma análise elástica linear tridimensional e concluíram que a analogia de treliça, aplicada a blocos sobre estacas, utilizada por Blévot e Frémy (1967) não é satisfatória, pois não conferem com as localizações e magnitudes de tensões máximas com precisão.

\subsection{Justificativa}

Em virtude das diferenças encontradas nos métodos analíticos e normas utilizados para projeto de blocos sobre estacas decidiu-se estudar modelos de blocos sobre estacas. Para isto utilizaram-se modelos analíticos e numéricos, adotando-se comportamento do material como elástico linear.

Provavelmente uma análise não-linear ofereceria algumas vantagens por fornecer resultados mais realistas acerca dos efeitos de perda de rigidez dos elementos estruturais por causa da fissuração e escoamento das armaduras longitudinais. Mas com a proposta de quantificar alguns parâmetros acredita-se que a análise elástico-linear constitui-se em passo inicial imprescindível.

\subsection{Metodologia}

Para as análises feitas neste trabalho utilizaram-se resultados obtidos por meio de modelos analíticos e realizou-se análise numérica utilizando-se o programa ANSYS $^{\circledR}$, baseado no Método dos Elementos Finitos. Nos modelos adotados variaram-se os diâmetros de estacas e dimensões de pilar, a fim de se verificar as diferenças na formação dos campos e trajetórias de tensões.

Para análise numérica adotou-se comportamento do material como elástico linear. Os resultados de interesse foram os fluxos de tensões em suas direções principais, a fim de se aplicar o modelo de Bielas e Tirantes e verificar as disposições de armadura utilizadas atualmente. 


\subsection{Objetivo}

Os objetivos deste trabalho são:

I. Estudar o comportamento de blocos rígidos de concreto armado sobre uma, duas, três, quatro e cinco estacas, submetidos à ação de força centrada, para sugestão de um modelo de Bielas e Tirantes mais refinado do que o modelo de treliça utilizado atualmente em projetos;

II. Verificação da influência da variação dos diâmetros das estacas e das seções de pilares no projeto de blocos sobre estacas. Como conseqüência sugere-se revisão dos critérios para os arranjos das armaduras principais dos blocos;

III. Análise comparativa entre os processos de dimensionamento adotados em projeto.

\subsection{Estrutura da dissertação}

A dissertação se encontra dividida em seis capítulos, sendo que esse primeiro refere-se à introdução do tema e a justificativa e objetivos do trabalho.

O Capítulo 2 apresenta uma revisão bibliográfica descrevendo os principais trabalhos experimentais e numéricos desenvolvidos na área estudada, bem como, as principais conclusões obtidas pelos autores.

O Capítulo 3 refere-se a uma revisão de critérios de projeto e métodos para dimensionamento de blocos sobre estacas. São mencionadas as recomendações das principais normas utilizadas, as recomendações práticas sugeridas por alguns autores e ainda os principais métodos analíticos utilizados no projeto de blocos sobre estacas.

O Capítulo 4 apresenta uma revisão bibliográfica referente aos fundamentos e aplicações de Modelos de Bielas e Tirantes. São mostradas as recomendações de Normas e, além disso, as dificuldades e desafios que ainda devem ser vencidos para projeto de Modelos de Bielas e Tirantes.

No Capítulo 5 são apresentados os modelos analisados, que foram dimensionados por três métodos analíticos, onde pode se constatar as diferenças entre eles. Refere-se ainda, a análise numérica de modelos de blocos sobre uma, duas, três e quatro estacas. Esta análise numérica, apesar de simplificada, por não considerar efeitos de não-linearidade teve como objetivo estudar o comportamento dos modelos, observando a propagação e concentração de tensões principais. São 
apresentados os resultados obtidos bem como discussão dos mesmos. Apresenta-se também nesse capítulo sugestão generalizada para modelos de Bielas e Tirantes para blocos sobre estacas e algumas constatações a respeito da disposição das armaduras principais.

O Capítulo 6 traz as conclusões obtidas no trabalho e algumas sugestões para trabalhos futuros. Em seguida apresentam-se as Referências Bibliográficas. 


\section{REVISÃO BIBLIOGRÁFICA}

\subsection{Considerações iniciais}

Antigamente os blocos sobre estaca eram tratados como viga e não existiam teorias para peças curtas onde as zonas de perturbação envolvem praticamente todos os pontos. O esquema de comportamento considerava, obviamente, o momento fletor e a força cortante.

Em 1944 Magnel apud Mautoni (1972) apresentou um esquema de treliça para blocos sobre dois apoios, mas, foi na década de 60 que o esquema de comportamento de bloco considerando analogia de treliça ganhou importância em virtude de vários ensaios realizados principalmente na França.

Em 1957, Hobbs e Stein estudaram o comportamento de blocos sobre duas estacas por meio de análises experimentais. Ensaiaram setenta modelos e desenvolveram um modo de solução pela teoria da elasticidade bidimensional.

Blévot e Frémy (1967) realizaram ensaios em mais de cem blocos sobre estacas com a finalidade de estudar o comportamento destes elementos, verificando a teoria das bielas e a influência de diferentes arranjos de armadura.

Mautoni (1972) elaborou um apanhado geral dos trabalhos desenvolvidos até então, principalmente referente a consolos curtos e, além disso, ensaiou blocos sobre dois apoios com o objetivo de estudar a capacidade resistente.

Em 1990 Miguel estudou o comportamento de blocos rígidos sobre três estacas. Ensaiou modelos conservando a armadura principal e variando as armaduras secundárias com o objetivo de estudar o desenvolvimento de fissuras e o modo de ruína dos mesmos. 
Atualmente poucos trabalhos têm sido desenvolvidos nesta área, estes trazem algumas colaborações, mas no âmbito nacional o avanço das pesquisas tem sido relativamente lento.

Neste capítulo apresenta-se um apanhado geral das pesquisas desenvolvidas com blocos sobre estacas. É apresentado um breve histórico descrevendo os principais trabalhos desenvolvidos: experimentais (em maior parte) e numéricos. As principais conclusões obtidas pelos autores, são apresentadas como segue.

\subsection{Ensaios de Blévot (1967)}

Com a finalidade de estudar e verificar a aplicabilidade da teoria das bielas Blévot e Frémy (1967) realizaram ensaios em blocos sobre duas, três e quatro estacas. Os modelos ensaiados foram submetidos à ação de força centrada e foram variadas as disposições das armaduras. Foram analisados os estados de formação de fissuras e limite último.

Para os modelos sobre duas estacas adotaram largura dos blocos de $40 \mathrm{~cm}$, pilares de $30 \mathrm{~cm} \times 30 \mathrm{~cm}$ e inclinação da biela em relação à face inferior do bloco maior que $40^{\circ}$. Quanto à disposição da armadura, os blocos apresentavam dois tipos de arranjos diferentes: barras lisas com ganchos (figura 2.1.a) e barras com mossas ou saliências sem ganchos (figura 2.1b).

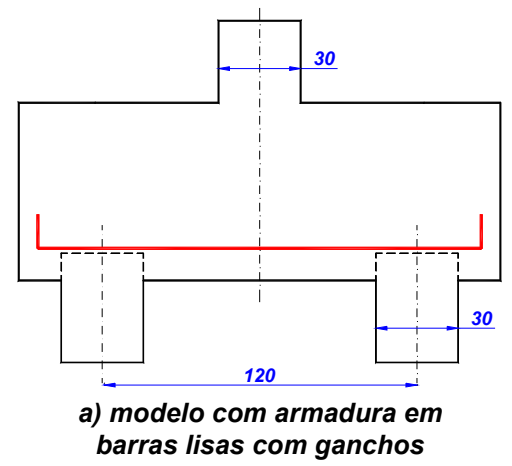

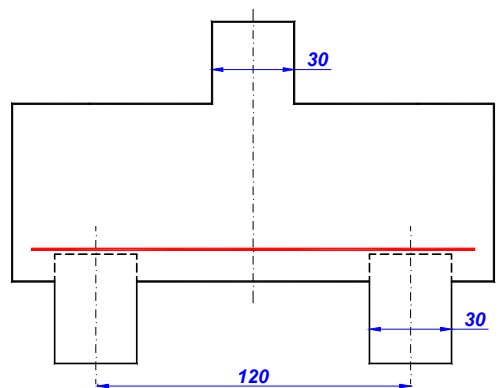

b) modelo com armadura em barras com saliências sem ganchos

Figura 2.1 - Modelos de blocos sobre duas estacas ensaiados por Blévot (1967)

A respeito dos modelos sobre duas estacas Blévot observou que houve ocorrência de várias fissuras antes da ruína que ocorreu pelo esmagamento da biela de concreto junto ao pilar ou junto à estaca, ou ainda, simultaneamente junto ao pilar e à estaca. Houve escorregamento na ancoragem para o caso dos modelos armados com barras com mossas ou saliências, sem ganchos. 
Para ensaios com modelos de blocos sobre três estacas Blévot utilizou diferentes arranjos de armadura: a) armadura segundo os lados do bloco (unindo as estacas); b) armadura em cintas contornando as estacas; c) armadura segundo as medianas; d) combinação das armaduras segundo os lados e medianas e e) armadura em malha. A figura 2.2 ilustra esses modelos.

Além de investigar a influência do tipo de arranjo de armadura e aplicabilidade do método das bielas com relação à ruína, tratou também do efeito da punção.

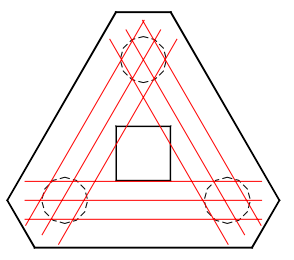

a

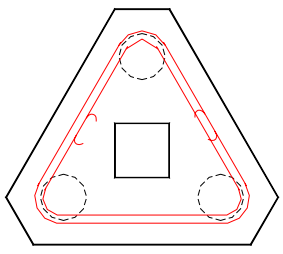

$\boldsymbol{b}$

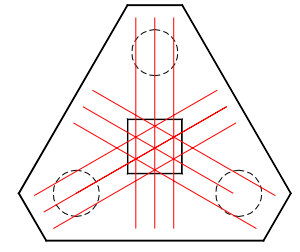

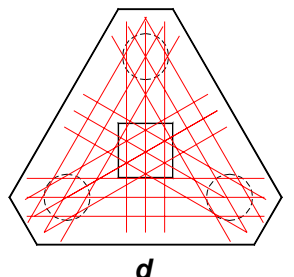

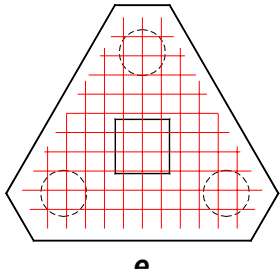

Figura 2.2 - Modelos de blocos sobre três estacas ensaiados por Blévot (1967)

Os quatro primeiros modelos apresentaram boa eficiência, desde que no modelo $d$ a armadura segundo os lados fosse preponderante. O modelo com armadura em malha (figura 2.2 e) apresentou força última cerca de $50 \%$ do valor calculado, apresentando, portanto, uma eficiência menor com relação aos outros arranjos.

Com relação à fissuração, o arranjo de armadura segundo os lados e em cintas (figura 2.2.a e b) apresentaram o melhor comportamento, com relação às faces laterais, porém ruim para a face inferior do bloco.

Freqüentemente a ruína se deu por tração do concreto e ocorreu a partir do surgimento de fissuras despontando das estacas.

Para os modelos com ângulos de inclinação das bielas entre $40^{\circ}$ e $55^{\circ}$ os valores de força de ruína obtidos pelo método das bielas é menor que os valores de ensaio. Para valores de ângulo menor que $40^{\circ}$ ou maior que $55^{\circ}$, as forças de ruína obtidas nos ensaios foram maiores do que as calculadas, portanto, contra a segurança.

Respeitando os limites recomendados para o ângulo de inclinação das bielas, também não há risco de ruína por punção.

Todos os modos de ruína se deram com ações inferiores aos indicados pelo Método das Bielas e ocorreram após o escoamento da armadura principal, e não houve ruína por punção. 
Blévot (1967) ensaiou também modelos de blocos sobre quatro estacas com cinco arranjos diferentes de armadura: a) armadura segundo os lados do bloco; b) armadura em cintas contornando as estacas; c) armadura segundo as diagonais; d) combinação das armaduras segundo as medianas com cintas e e) armadura em malha. Os modelos ensaiados são mostrados na figura 2.3.

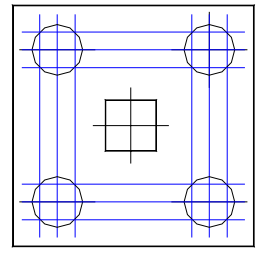

a

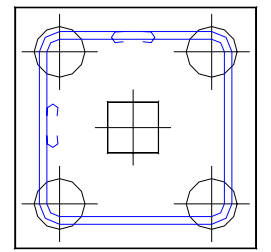

$\boldsymbol{b}$

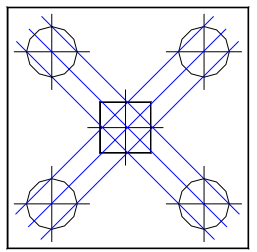

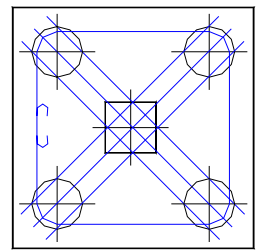

d

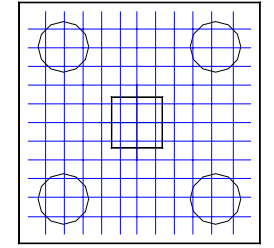

e

Figura 2.3 - Modelos de blocos sobre quatro estacas ensaiados por Blévot (1967)

As disposições de armadura dos modelos a e $d$ mostraram-se igualmente eficientes, já o modelo com armadura em malha (figura 2.3 e) apresentou eficiência de $80 \%$.

Com relação à fissuração o modelo com armadura segundo as diagonais (figura $2.3 \mathrm{c}$ ) apresentou grande número de fissuras para forças reduzidas. O modelo $b$ apresentou fissuração excessiva na parte inferior, demonstrando a necessidade de se utilizar armadura secundária em malha.

Também nestes modelos de blocos sobre quatro estacas foram observadas ruínas a partir de fissuras saindo da estaca, e não ocorreu ruína por punção. Os resultados dos modelos ensaiados foram coerentes com os teóricos dimensionados com o Método das Bielas.

\subsection{Ensaios de Mautoni (1972)}

O objetivo de Mautoni (1972) foi caracterizar os mecanismos de ruína e, além disso, determinar os valores das forças últimas, tendo em vista a ruptura das bielas.

Os modelos foram feitos para estudo de blocos sobre dois apoios, mas naturalmente se prestam ao estudo de consolos sem armadura de costura. Foram ensaiados 20 blocos com dois diferentes tipos de armadura; laçada contínua na horizontal e "armadura em bigode".

$\mathrm{Na}$ armadura "em bigode" as barras eram inclinadas, cada uma com dois trechos semicirculares, de ancoragem, contendo ainda ganchos nas extremidades. A 
armadura em laçada contínua era disposta em camadas, suas extremidades eram semicirculares separadas por um trecho central retangular.

Nos modelos ensaiados adotou-se largura de $15 \mathrm{~cm}$ e variaram-se as dimensões de altura e vão entre estacas. As características geométricas de um modelo são apresentadas na figura 2.4 .

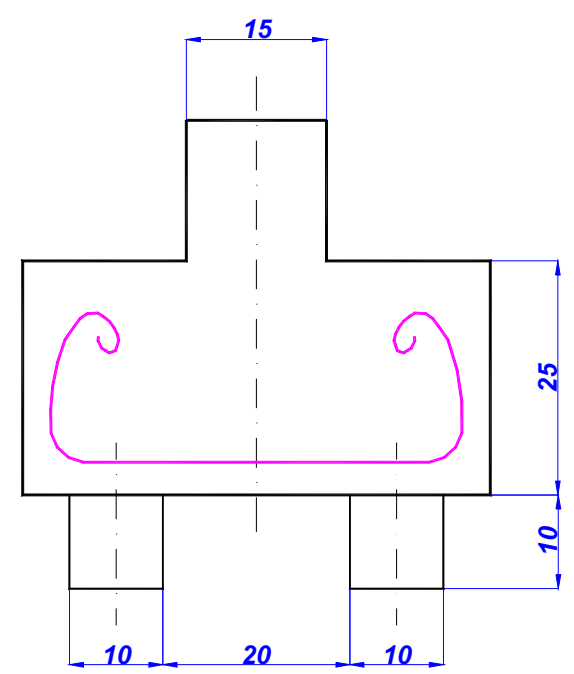

Figura 2.4 - Modelo adotado nos ensaios de Mautoni (1972) com armadura "em bigode"

Mautoni (1972) observou que o início da fissuração se deu para forças próximas de $40 \%$ das de ruína. A primeira fissura ocorreu no meio do vão, na zona inferior do bloco, junto à armadura de tração. A fissuração se estabilizou para forças em torno de $70 \%$ das de ruína, e as fissuras foram, em grande parte, paralelas às bielas comprimidas de concreto.

As principais conclusões do trabalho para um bloco sobre dois apoios com armadura conhecida foram: o estabelecimento de um método para determinar a força de ruína do bloco e a determinação do mecanismo de colapso. A ruína dos modelos ocorreu sempre por esmagamento da biela de compressão com plano de fratura entre a face interna da estaca e a face do pilar.

Mautoni (1972) também relatou as desvantagens de cada tipo de armadura empregada em seu trabalho. A armadura em "bigode" apresenta grande consumo de aço e pode apresentar inconvenientes nas ancoragens. Com relação à armadura em laçada contínua relatou dificuldades de execução e redução da altura útil do bloco. 


\subsection{Ensaios de Taylor e Clarke (1976)}

Taylor e Clarke (1976) apresentaram dados experimentais mostrando a influência do detalhamento da armadura na eficiência estrutural de blocos sobre estacas, consolo curtos contínuos, ligações de viga-pilar e ligações de laje-pilar. Ensaiaram blocos sobre quatro estacas, com espaçamento entre estacas igual a duas vezes o diâmetro da mesma. O diâmetro adotado para estacas era de $20 \mathrm{~cm}$. Dois tipos de blocos quadrados foram ensaiados de $95 \mathrm{~cm}$ e $75 \mathrm{~cm}$. A altura total dos modelos foi fixada em $45 \mathrm{~cm}$. Três disposições diferentes de armadura e quatro tipos de ancoragens foram considerados, como mostrado na figura 2.5.

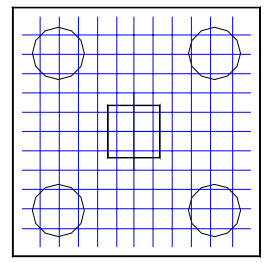

a) armadura em malha

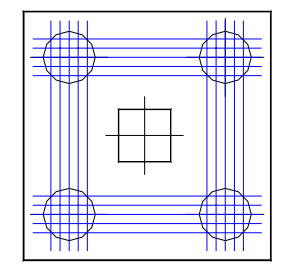

b) armadura segundo os lados

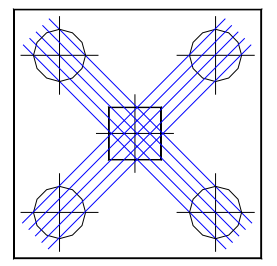

c) armadura segundo as diagonais

ARRANJOS DAS ARMADURAS

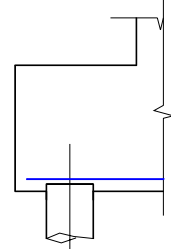

(1)

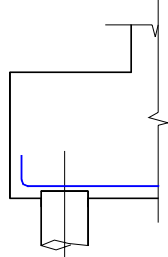

(2)

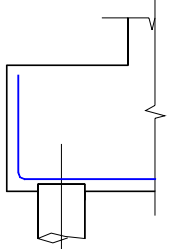

(3)

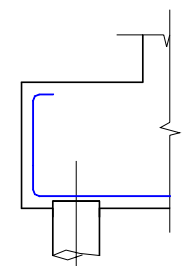

(4)

TIPOS DE ANCORAGEM

Figura 2.5 - Tipos de armadura e ancoragem utilizadas nos blocos ensaiados por Taylor e Clarke (1976)

Nas fases iniciais de carregamento todos os blocos se comportaram de maneira semelhante, com fissuras verticais que se formaram nas linhas de eixo das estacas nas quatro faces do bloco. Na maioria dos casos a ruína se deu por cisalhamento, as fissuras diagonais se formaram de repente em duas ou mais faces $e$ do bloco. Foram registradas duas formas diferentes de ruína por cisalhamento, uma delas era semelhante à ruína por cisalhamento em uma viga (figura 2.6 a) e a segunda tinha a forma mostrada na figura $2.6 \mathrm{~b}$. 

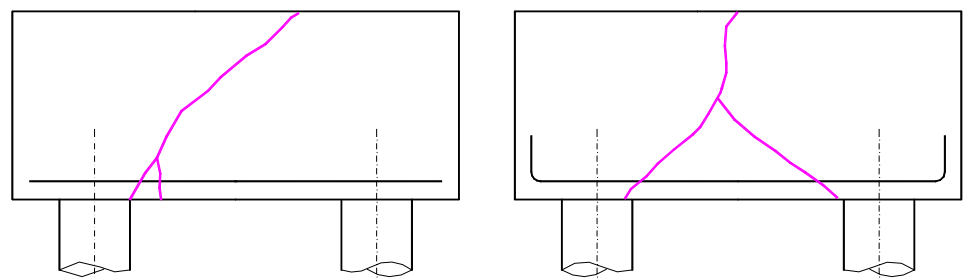

Figura 2.6 - Tipos de ruptura em blocos ensaiados por Taylor e Clarke (1976)

Os modelos com tipo de ancoragem 1 e 2 e distribuição de armadura segundo os lados apresentaram forças últimas cerca de $15 \%$ maiores que os blocos armados em malha. Os blocos com armadura segundo as diagonais tiveram praticamente a mesma força de ruína que os blocos com armadura em malha.

No caso das armaduras distribuídas em malha o tipo de ancoragem teve influência mais acentuada nas forças de ruína. A ancoragem tipos 3 aumentou a força de ruína em aproximadamente $30 \%$. Segundo Taylor e Clarke (1976) esse aumento ocorreu, provavelmente, pelo aumento da capacidade de resistência à força cortante, por causa de trabalhar com armadura de suspensão, e não pelo efeito deste trecho na ancoragem. Nenhum aumento adicional foi obtido com ancoragem tipo 4.

\subsection{Ensaios de Adebar, Kuchma e Collins (1990)}

Adebar et al. (1990) ensaiaram seis modelos diferentes de blocos sobre 4 e 6 estacas com a finalidade de examinar o modelo de bielas e tirantes tridimensional. Os modelos possuíam estacas de $20 \mathrm{~cm}$ de diâmetro e a força foi aplicada em uma área de $30 \mathrm{~cm} \times 30 \mathrm{~cm}$, a altura média dos modelos era de $60 \mathrm{~cm}$. Os diferentes modelos ensaiados são apresentados na figura 2.7 . 


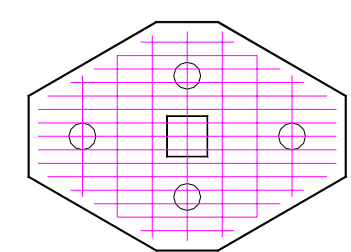

Bloco A

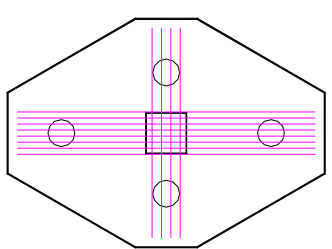

Bloco D

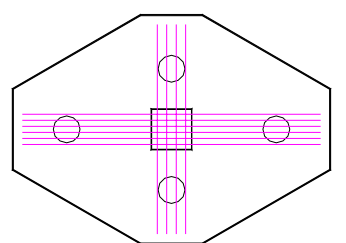

Bloco B

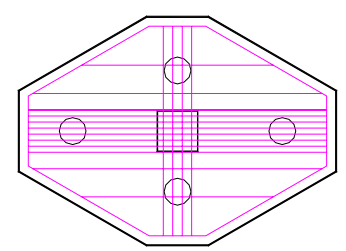

Bloco E

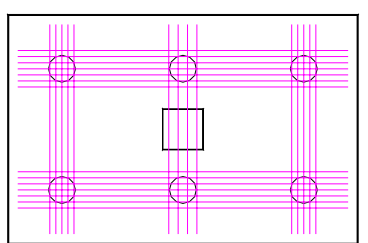

Bloco C

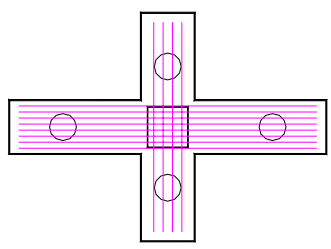

Bloco F

Figura 2.7 - Modelos de blocos ensaiados por Adebar et al. (1990)

Os modelos foram dimensionados com os critérios do ACl 318 (1983) e pelo Método das Bielas e diferenciavam-se pelo arranjo da armadura (figura 2.7). $\mathrm{O}$ modelo A foi dimensionado segundo o ACl 318 (1983); os modelo $B$, C e D foram dimensionados pelo Método das Bielas, sendo que o Bloco D possuía o dobro da armadura de $\mathrm{B}$ e o modelo $\mathrm{E}$ tinha as mesmas características de $\mathrm{D}$, mas com armadura distribuída segundo o $\mathrm{ACl}$. Bloco $\mathrm{F}$ foi construído para testar uma hipótese do código de $\mathrm{ACl}$. Era idêntico ao bloco $\mathrm{D}$ embora tenham sido omitidos os quatro cantos de concreto. Por causa desses cantos de concreto que foram retirados, o código de $\mathrm{ACl}$ sugere que o Bloco $\mathrm{F}$ teria uma força de ruína bem menor que o bloco $D$. O Método das Bielas sugere que os blocos $D$ e $F$ teriam essencialmente a mesma força.

Nos blocos $\mathrm{A}$ e $\mathrm{B}$, os menos armados, as tensões nas armaduras aumentaram muito de repente depois que a primeira fissura se formou. O Bloco $A$, que utilizou os critérios do $\mathrm{ACl}$, rompeu com aproximadamente $83 \%$ da força prevista e a ruína se deu em forma de cone, a armadura de flexão sofreu escoamento antes da ruína do concreto. O Bloco B resistiu a uma força $10 \%$ maior que a prevista, e o tirante não sofreu escoamento na direção de maior distância entre as estacas.

Nos blocos B e C o maior quinhão de força foi resistido pelas duas estacas mais próximas ao pilar, enquanto as outras estacas suportaram forças menores. Para o Bloco C a deformação do tirante entre as duas estacas centrais atingiu a deformação limite de escoamento; neste modelo a ruína ocorreu com aproximadamente $96 \%$ da força prevista.

Os blocos $\mathrm{D}$ e $\mathrm{E}$ romperam antes do escoamento do tirante; já o Bloco $\mathrm{F}$ se comportou como duas vigas interceptadas ortogonalmente pelo meio, sua ruína 
ocorreu quando a viga mais curta rompeu por cisalhamento e não houve escoamento da armadura.

Com os resultados os autores verificaram que algumas hipóteses adotadas pelo $\mathrm{ACl}$ (1983) não foram verificadas para os resultados experimentais. O ACl considera que a largura do bloco resiste uniformemente a um momento fletor aplicado, nos resultados experimentais encontrados as deformações por compressão não foram uniformes, indicando que os esforços foram resistidos como indicado pelo Método das Bielas, ou seja, as deformações por compressão alcançaram seus valores máximos no local onde o método sugere que seja o centro das bielas de compressão.

No modelo de Bloco $\mathrm{C}$ constatou-se que as bielas de compressão romperam por esmagamento do concreto. Acredita-se que a ruptura do tirante diagonal de concreto foi o mecanismo crítico envolvido nas ruínas por cisalhamento dos blocos ensaiados. A ausência de armadura para controlar a fissuração na diagonal permitiu que essa fissuração ocorresse por causa da propagação rápida de tensões nas bielas.

Com essas constatações Adebar et al. (1990) concluiu que um modelo mais refinado de bielas e tirantes deve ser adotado. A figura 2.8a mostra uma trajetória de tensões obtidas da solução pelo Método dos Elementos Finitos de um modelo elástico linear, onde se pode notar que entre os pontos de aplicação de força onde as tensões de compressão se "expandem" são produzidas tensões de tração. O autor sugeriu, então, um modelo mais refinado de biela e tirante, mostrado na figura $2.8 \mathrm{~b}$.

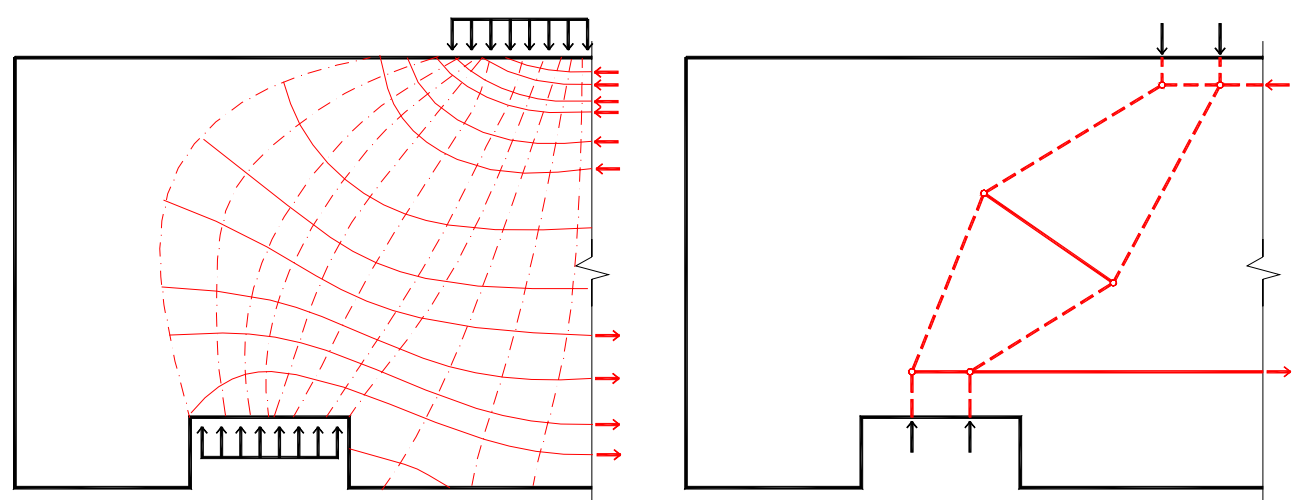

Figura 2.8 - Trajetórias de tensões elástico-lineares e Modelo refinado de Bielas e Tirantes sugerido por Adebar et al. (1990) 
Outras conclusões obtidas pelos autores são apresentadas na Tabela 2.1.

Tabela 2.1 - Conclusões obtidas por Adebar et al. (1990)

\section{Procedimentos do $\mathrm{ACl}$ (1983)}

Não foram compatíveis com resultados experimentais pelo fato do Código Americano não levar em conta a altura útil do bloco e desprezar a influência da quantidade e distribuição das barras de armadura.

\section{Blocos muito rígidos}

Blocos com grandes alturas sofreram grandes deformações pouco antes da ruína, não tiveram flexibilidade para redistribuir as forças.

\section{Comportamento de blocos sobre estaca}

Não se comportaram como vigas.

\section{Modelo de Bielas e Tirantes}

Representou melhor o comportamento estrutural dos blocos.

\section{Tipos de Ruína}

As bielas de compressão não romperam por esmagamento do concreto, a ruína ocorreu depois que uma biela sofreu cisalhamento longitudinal em decorrência das tensões transversais causadas pela expansão das tensões de compressão.

\section{Tensões nas Bielas de Compressão}

Devem ser limitadas pela resistência característica do concreto a compressão $\left(f_{c k}\right)$.

\subsection{Miguel (2000)}

Miguel (2000) estudou o comportamento de blocos sobre 3 estacas com o objetivo principal de verificar a formação de fissuras e o modo de ruína. Ensaiou modelos em escala real e realizou analise numérica pelo Método dos Elementos Finitos, considerando não linearidade, mas não considerando as armaduras.

Os modelos foram submetidos à ação de força centrada e foram igualmente projetados, conservando a armadura principal (considerada nos lados dos blocos) e variando as armaduras adicionais e o diâmetro das estacas.

Foram ensaiados um total de 9 modelos com estacas de $20 \mathrm{~cm}$ e $30 \mathrm{~cm}$. Os tipos de disposição de armadura utilizados são mostrados na Tabela 2.2. 
Tabela 2.2 - Tipos de arranjos de armadura utilizados nos modelos ensaiados por Miguel (2000)

\begin{tabular}{cl}
\hline Modelos ensaiados & \multicolumn{1}{c}{ Arranjo da armadura } \\
\hline A1 (3) & Armadura principal segundo os lados do bloco. \\
\hline A2 (2) & Armadura segundo os lados + armadura segundo as medianas \\
\hline A3 (2) & Armadura segundo os lados + armadura em malha \\
\hline A4 (2) & Armadura segundo os lados + armadura em gaiola \\
\hline
\end{tabular}

Segundo Miguel (2000) os blocos da série A2 apresentaram maiores forças de ruína, já os modelos da série $\mathrm{A} 1$ as menores. Os modelos A3 e A4 apresentaram praticamente os mesmos valores de força de ruína.

De forma geral os modelos de blocos com estacas de diâmetro de $30 \mathrm{~cm}$ apresentaram forças últimas maiores. Para os modelos A1 e A2 os blocos com diâmetro de estaca de $30 \mathrm{~cm}$ apresentaram valores de força última $21 \%$ e $28 \%$ maiores que os de diâmetro de $20 \mathrm{~cm}$. Os blocos com diâmetro de estaca menor quando atingiram a força de fissuração chegaram a ruína com forças menores do que os com diâmetro de $30 \mathrm{~cm}$. A força de fissuração correspondeu a força para a qual ocorreu a primeira perda de rigidez em qualquer uma das faces, ou quando não era possível sua determinação era considera a força para a qual surgiu a primeira fissura visível.

Uma outra constatação nos ensaios de Miguel (2000) refere-se a distribuição das forças nas estacas, percebeu-se que não houve uniformidade em nenhum dos modelos ensaiados. As estacas de número 1 (figura 2.9) receberam menores valores da ação aplicada em relação às estacas de número 2 e 3.

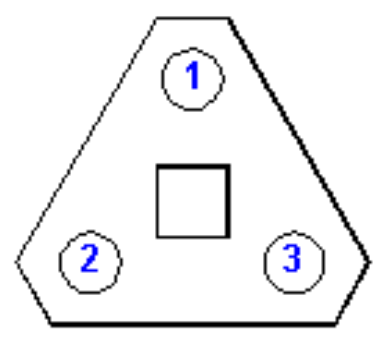

Figura 2.9 - Numeração das estacas dos modelos ensaiados por Miguel (2000)

Um resumo das principais conclusões obtidas por Miguel (2000) é apresentado na Tabela 2.3. 
Tabela 2.3 - Principais conclusões obtidas por Miguel (2000)

\section{Comportamento geral dos modelos}

- Modelos A2 resistiram a maior força aplicada;

- Método das Bielas mostrou-se conservativo.

\section{Influência do diâmetro das estacas}

- Modelos da série A1 e A2 valores de força última maior para blocos com diâmetro de estaca de $30 \mathrm{~cm}$;

- Relação entre tensão de compressão na zona nodal superior e resistência média a compressão: maior para blocos com estacas de $30 \mathrm{~cm}$ de diâmetro;

- Relação entre tensão de compressão na zona nodal superior e resistência média a compressão: maior para blocos com estaca de $30 \mathrm{~cm}$;

- Relação entre tensão de compressão na zona nodal inferior e resistência média a compressão: maior para blocos com estaca de $20 \mathrm{~cm}$;

- Deslocamentos: maiores para blocos com estaca de $30 \mathrm{~cm}$.

\section{Influência do tipo de arranjo de armadura secundária}

- Estribos verticais e horizontais: redução das aberturas de fissuras nas faces;

- Barras distribuídas na base: não contribuiu para redução das aberturas de fissuras nas faces, diminuíram o número de fissuras na base.

\section{Deformações de compressão}

- Nas bielas: maiores para blocos com estacas de $30 \mathrm{~cm}$;

- Zonas nodais inferiores: maiores para blocos com estaca de 20;

- Zona nodal superior: maiores para blocos com estaca de $30 \mathrm{~cm}$.

\section{Deformações de tração}

- Nas bielas: maiores para blocos com estacas de $20 \mathrm{~cm}$;

- Nas armaduras: maiores para modelos com estacas de $30 \mathrm{~cm}$.

\section{Modos de ruína}

"Todos os modelos romperam por fendilhamento das bielas de compressão, em função da rápida expansão do fluxo de tensões na mesma, acompanhado do escoamento das barras das armaduras principal e/ou secundária."

\subsection{Trabalhos com ênfase na análise numérica}

IYER e SAM (1991) estudaram o comportamento de blocos sobre três estacas por meio de uma análise elástica linear tridimensional. Apresentaram uma solução para as equações da teoria da elasticidade, dadas em termos de vetor de Galerkin, e as componentes deste vetor expressas em séries duplas de Fourier. No método proposto, as distribuições de tensões no bloco foram obtidas considerando as condições de contorno pela superposição de quatro soluções elásticas 
tridimensionais, para um bloco retangular sujeito a diferentes carregamentos em suas faces. O bloco analisado é mostrado na figura 2.10 .

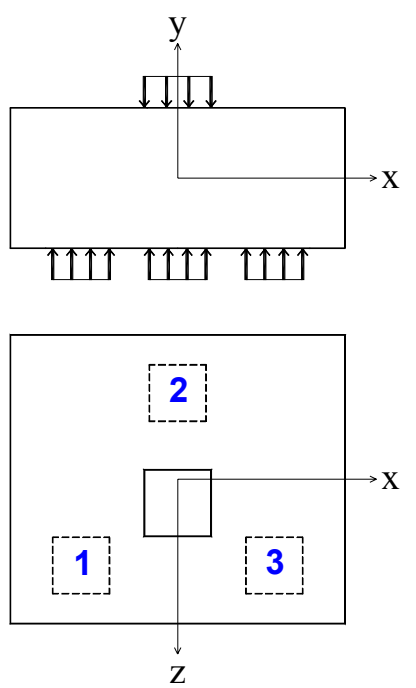

Figura 2.10 - Bloco sobre três estacas analisado por IYER e SAM (1991)

Embora um bloco seja composto de concreto armado, foram tratados linearmente como elástico, homogêneo e isotrópico, porque a distribuição de tensões pode providenciar uma solução inicial e formar uma base para estudos mais refinados.

Analisando as tensões máximas de tração na direção $x$ e $z$ (conforme figura 2.10) os autores relataram que o valor máximo na direção $x$ foi desenvolvido ao longo do plano yz com a face do bloco na região entre as estacas 1 e 3 considerando a relação entre altura e espaçamento entre estacas igual a 1, esta região mudava de posição em direção ao centro de gravidade, conforme esta relação diminuía. O mesmo ocorreu com relação a tensão de tração máxima na direção z, mas a região compreendida ficou próxima à face do pilar junto à estaca 2.

As mesmas análises foram realizadas para blocos sobre duas e quatro estacas (Iver e Sam, 1992).

Dos métodos existentes, a analogia de treliça (Blévot e Frémy) e a teoria da flexão que considera o bloco como uma viga apoiada em estacas, concluíram que nenhum deles é satisfatório, pois não conferem com as localizações e magnitudes de tensões máximas com precisão:

"No método de analogia de treliça os pontos nodais fictícios são as junções de coluna e interseções de estacas com os blocos. Por esta aproximação só é possível determinar as forças nestes elementos fictícios que conectam os pontos nodais. Dos contornos de força de tração obtidos da investigação está claro que são 
desenvolvidas tensões máximas de tração na direção $X$ e $Z$ dentro da região interna cercada por estacas. Isto mostra que os métodos de analogia de treliça estão longe de serem satisfatório".

Em 1995 os mesmos autores (Iver e Sam, 1995), com o objetivo de obter o comportamento de forças e deslocamentos, deformações na armadura, panorama de fissuração e força de ruína, fizeram uma análise numérica não-linear, considerando o Método dos Elementos Finitos, para blocos de concreto armado sobre duas e quatro estacas.

Os modelos analisados tinham a mesma geometria, resistência do concreto e taxas de armadura, embora com diferentes arranjos. Foram sujeitos a diferentes carregamentos e para consideração da não-linearidade adotaram comportamento multiaxial de compressão do concreto incluindo deformações plásticas, fissuração do concreto, escoamento da armadura e alteração do coeficiente de Poisson.

Os resultados numéricos obtidos com os modelos adotados foram comparados a resultados experimentais e dessa comparação levantaram-se algumas conclusões, que podem ser vistas na tabela 2.4 .

Tabela 2.4 - Principais conclusões obtidas por Iver e Sam (1995)

\footnotetext{
Blocos sobre duas estacas $x$ disposição da armadura

Armadura concentrada sobre estacas e armadura distribuída na largura do bloco resistiram a aproximadamente a mesma força.

\section{Blocos sobre quatro estacas $x$ disposição da armadura}

Armadura disposta segundo os lados e concentradas sobre as estacas: maior capacidade de carga quando comparados com armadura distribuída ou dispostas segundo as diagonais do bloco.

\section{Comportamento dos modelos}

- Para baixas intensidades de força, o comportamento de viga foi predominante e para altas intensidades o bloco resistiu à força pela ação da biela, indiferente ao arranjo da armadura;

- A porção de concreto, abaixo do pilar, compreendida pela região entre as faces do pilar (topo) e faces internas das estacas (base) foi esmagada e solicitada para romper por punção do pilar ou das estacas, independente do arranjo de armadura.
}

\section{Análise não-linear por elementos finitos}

Com o modelo de material e critério de ruína utilizados foi possível estimar o comportamento e a força de ruína de blocos sobre estacas com considerável rigor.

Outro trabalho numérico realizado foi desenvolvido por Iturrioz et al. (2000) que estudou o comportamento de blocos sobre duas estacas, adotando comportamento não-linear, e utilizando-se dois métodos numéricos intrinsecamente diferentes: o Método dos Elementos Finitos e o Método dos Elementos Discretos. Realizaram ainda, um estudo paramétrico sobre a influência do tipo de vinculação bloco/estaca e sua interação com o solo na determinação da capacidade de carga do conjunto. 
Foram adotados dois modelos com base em ensaios experimentais desenvolvidos por Raush et al. (1997).

As principais conclusões obtidas por Iturrioz et al. (2000) são listadas nas tabela 2.5 .

Tabela 2.5 - Principais conclusões obtidas por Iturrioz et al. (2000)

\section{Influência do tipo de vinculação no comportamento do bloco}

- Diminuição da rigidez horizontal do apoio produz uma perda de capacidade de carga do bloco;

- Quando a rigidez vertical do apoio diminui, a influência da rigidez horizontal perde a importância.

\section{Comportamento dos modelos}

- Deslocamentos obtidos pelos dois métodos numéricos são semelhantes ao modelo experimental;

- Comportamento da armadura foi diferente para cada método numérico utilizado e no ensaio experimental, o que se explica em virtude das diferentes condições de contorno adotadas.

\section{Uso de diferentes métodos}

Grande importância por permitir obtenção de resultados mais confiáveis em relação ao comportamento real. 


\section{PROJETO DE BLOCOS SOBRE ESTACA}

\subsection{Considerações iniciais}

Neste capítulo é feita uma revisão bibliográfica de critérios de projeto e métodos para dimensionamento de blocos sobre estacas.

São chamados critérios de projeto as recomendações adotadas para o projeto de blocos sobre estacas. Dentre estes critérios são mostrados desde os procedimentos gerais de projeto adotados por projetistas até recomendações de normas e autores consagrados.

Os principais métodos estudados foram o Método das Bielas (Blévot, 1967) e o Método do CEB-FIP (1970). São analisados, também, os critérios adotados por Calavera (1991), Montoya (2000) e ACl (1994).

Os métodos estudados apresentaram divergências nos valores das áreas das barras de armaduras e nas verificações de tensões de compressão, como poderá ser constatado, posteriormente, nos modelos analisados no capítulo 5 .

\subsection{Critérios de projeto para blocos sobre estacas}

\subsubsection{Procedimentos gerais de projeto}

O primeiro passo no projeto de blocos sobre estacas é a definição do tipo de estaca a ser usada. As estacas são elementos estruturais esbeltos que, instaladas no solo por cravação ou perfuração, têm a finalidade de transmitir as ações do pilar ao 
solo, seja pela resistência de ponta, seja pela resistência por atrito lateral ou pela combinação dos dois.

Conhecendo-se as ações atuantes no pilar, força normal, momentos fletores, forças cortantes, e, definido o tipo de estaca e sua carga admissível pode-se determinar o número de estacas por pilar. Outras considerações devem ser feitas nesta fase do projeto, como a consideração do efeito de grupo de estacas e estacas com forças horizontais. Fundações submetidas a forças horizontais moderadas podem ser dimensionadas com estacas verticais, distribuindo-se a força horizontal entre as estacas, desde que se respeite capacidade horizontal; se as estacas estiverem submetidas a forças horizontais elevadas, os níveis superiores do solo deverão ser capazes de resistir a estas forças sem que ocorra movimento lateral excessivo, se isto não for possível adotam-se estacas inclinadas. Os procedimentos para cálculo de forças horizontais em estacas verticais são baseados em hipóteses simplificadas, uma solução mais realista seria a consideração da interação estacasolo.

Determinado o número de estacas, faz-se a distribuição em planta em relação ao pilar. É recomendável, sempre que possível, que o centro do estaqueamento coincida com o centro do pilar. A disposição das estacas deve ser feita sempre que possível de modo a obter blocos de menor volume.

Os projetistas, de maneira geral, usam distribuições de estacas associando-os com modelos padronizados de blocos, mostrados na figura 3.1, respeitando os valores mínimos para os espaçamentos entre eixos de estacas e distâncias das faces do bloco aos eixos das estacas mais próximas. Obedecendo a essas recomendações, as dimensões dos blocos são minimizadas, e desde que a altura seja compatível, obtém-se blocos rígidos, entretanto, o espaçamento entre estacas pode ser aumentado, e se a altura não for compatível resultará em blocos flexíveis, ou seja, distâncias maiores entre estacas e alturas pequenas resultam blocos flexíveis, que têm comportamento semelhante às vigas de concreto armado.

Dependo da configuração adotada para disposição das estacas haverá deslocabilidade em relação aos eixos ortogonais dos blocos, como, no caso de bloco sobre uma ou duas estacas (ou mais, depende da disposição) deve ser empregado um elemento estrutural, por exemplo viga baldrame, para conferir indeslocabilidade horizontal. No caso de pilares de divisa deve-se recorrer ao uso de viga de equilíbrio. 

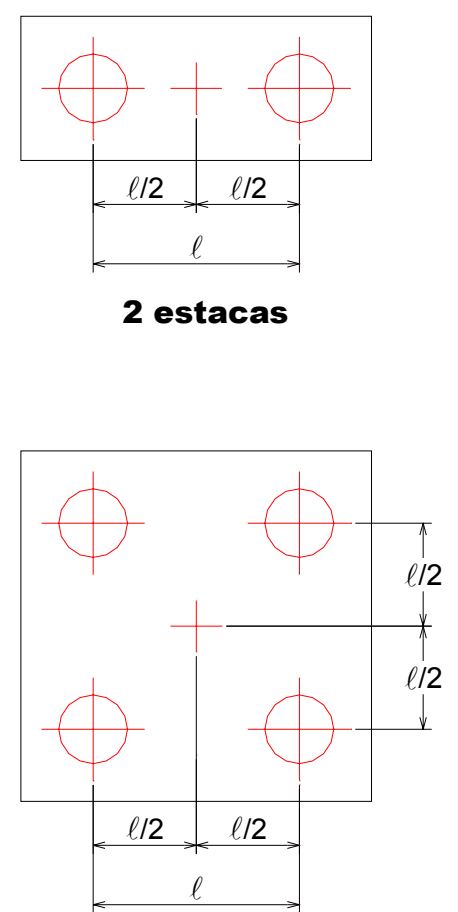

4 estacas

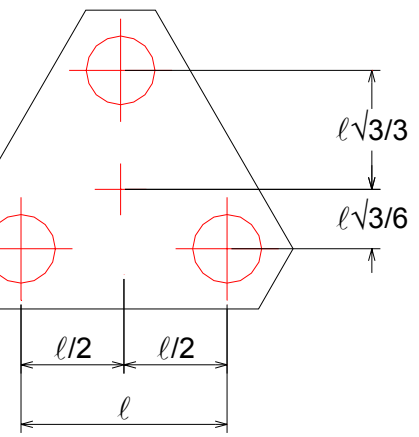

3 estacas

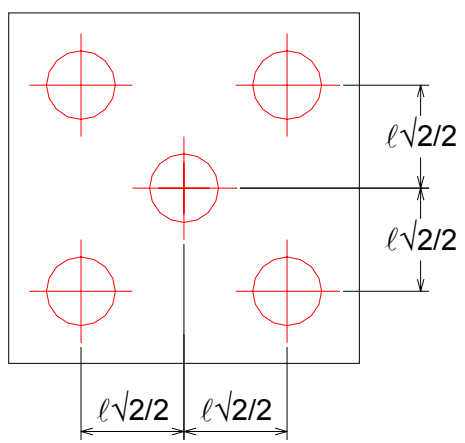

5 estacas

Figura 3.1 - Blocos padronizados sobre estacas

\subsubsection{Distância entre eixos de estacas}

A consideração de valores mínimos de espaçamento entre estacas é necessária em virtude do efeito de grupo de estacas. $O$ inchamento da superfície do solo causado pela cravação de estacas pouco espaçadas em material compacto ou incompressível deve ser minimizado e, portanto, é necessário que haja um espaçamento mínimo entre estacas.

A NBR 6118:2003 sugere que o valor de espaçamento entre eixos de estacas deva estar compreendido entre 2,5 vezes a 3 vezes o diâmetro destas.

Alguns autores adotam o espaçamento mínimo entre as estacas da ordem de 2,5 vezes o diâmetro no caso de estacas pré-moldadas e 3,0 vezes para estacas moldadas "in loco", para ambos os casos esse valor não deve ser inferior a $60 \mathrm{~cm}$.

Calavera (1991) sugere valores de separação mínima entre estacas de 2 vezes a 3 vezes o seu diâmetro. 
Montoya (2000) indica que deve ser adotado para espaçamento entre estacas o menor valor entre: 2 vezes o diâmetro da estaca, $75 \mathrm{~cm}$ ou 1,75 vez a diagonal (no caso de blocos quadrados).

\subsubsection{Método da superposição para blocos submetidos à força vertical e momento fletor}

O método da superposição consiste em calcular a reação em cada estaca somando-se separadamente os efeitos da ação vertical e dos momentos. Para ser válido o procedimento, os eixos $\mathrm{x}$ e y devem ser os eixos principais de inércia e as estacas devem ser verticais, do mesmo tipo, comprimento e diâmetro. A força resultante $\left(R_{i}\right)$ em uma estaca genérica $i$ com coordenadas $\left(x_{i}, y_{i}\right)$ é dada pela expressão 3.1 :

$$
R_{i}=\frac{F}{n_{e}} \pm \frac{M_{x} y_{i}}{\sum y_{i}^{2}} \pm \frac{M_{y} x_{i}}{\sum x_{i}^{2}}
$$

Em que, $\mathrm{F}$ é a força normal atuante, $\mathrm{M}_{\mathrm{x}}$ é o momento atuante em torno do eixo $x$ e $M_{y}$ é o momento atuante em torno do eixo y. Os momentos são considerados positivos conforme a indicação da figura 3.2.

O estaqueamento de blocos sujeitos a momentos é resolvido por tentativas, ou seja, só deve ser aceito se a reação nas estacas for no máximo igual às forças admissíveis de compressão e tração.

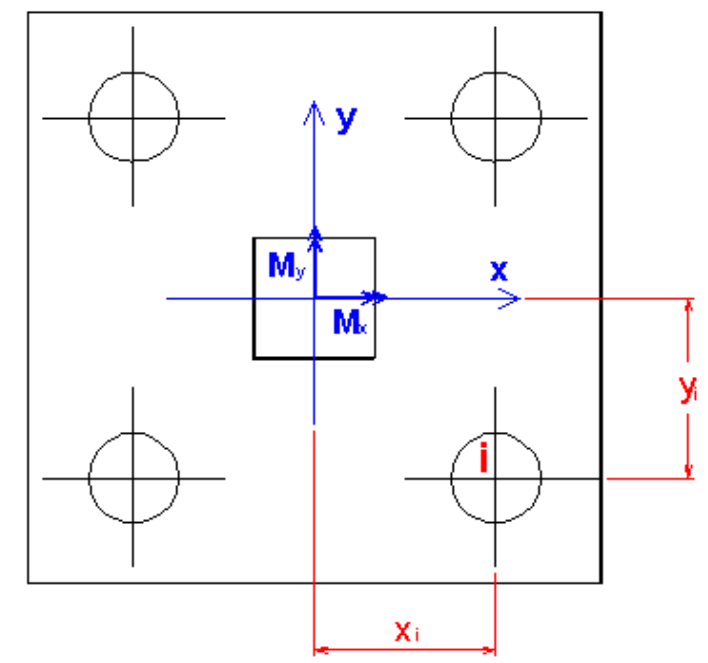

Figura 3.2 - Nomenclatura adotada para aplicação do Método da Superposição 
$\mathrm{Na}$ verdade o que este método faz nada mais é do que aplicar a fórmula de flexão composta da Resistência dos Materiais, uma vez que as hipóteses coincidem, ou seja, a consideração de bloco infinitamente rígido e as reações das estacas proporcionais aos respectivos deslocamentos (na direção do eixo da estaca), supondo ainda, todas as estacas com mesmo comprimento e desprezando-se as pressões de apoio do bloco no terreno.

\subsubsection{Classificação de blocos sobre estaca}

Os blocos sobre estacas podem ser classificados como rígidos ou flexíveis. Essa classificação se dá com relação ao comportamento estrutural do bloco. Em grande parte da literatura encontrada essa classificação é feita considerando a relação entre a altura do bloco e a distância do centro da estaca mais afastada até a face do pilar. A classificação dos blocos em rígidos e flexíveis vai definir o comportamento estrutural do modelo. Os autores e normas estudados sugerem diferentes relações para classificação dos blocos.

A NBR 6118:2003 sugere, para blocos rígidos, espaçamento mínimo entre estacas de 2,5 vezes a 3 vezes o diâmetro destas. A norma considera o mesmo critério usado para sapatas rígidas para classificar os blocos em rígidos ou flexíveis, ou seja, quando se verifica a expressão a seguir o bloco é considerado rígido:

$$
h \geq \frac{\left(a-a_{p}\right)}{3}
$$

onde:

h: é a altura do bloco;

a: é a dimensão do bloco em uma determinada direção;

$a_{p}$ : é a dimensão do pilar na mesma direção.

Segundo a NBR 6118:2003 os blocos rígidos têm comportamento estrutural caracterizado por trabalho à flexão nas duas direções com trações nas linhas sobre as estacas; as forças são transmitidas por meio de bielas de compressão com formas dimensões complexas; o trabalho ao cisalhamento também se dá nas duas direções, não apresentando ruptura por tração diagonal e sim por compressão das bielas. No caso de blocos flexíveis deve ser feita uma análise mais completa. 
Segundo CEB-FIP (1970) os blocos são classificados como flexíveis quando atender a relação: $\ell_{c} \geq 1,5 \mathrm{~h}$ (figura 3.3 ); neste caso para se determinarem os esforços solicitantes deve-se utilizar o método clássico aplicável às vigas usuais. Quando se classificam os blocos em rígidos a relação para a altura $\ell_{c} \leq 1,5 \mathrm{~h}$,deve ser atendida. O método de cálculo para blocos rígidos pode ser feito com os critérios indicados no Boletim 73 do CEB (1970) ou considerando método clássico baseado na teoria das bielas. Sugere ainda que não serão considerados no cálculo blocos com altura superior a duas vezes a distancia $\ell_{c}$, ficando necessário atender a expressão 3.3. Entende-se que no caso de blocos com alturas superiores às especificadas, o método não pode ser aplicado pois o comportamento do elemento deixaria de ser de bloco rígido e passaria a ter comportamento semelhante ao de vigas parede.

$$
\frac{2 \ell_{\mathrm{c}}}{3} \leq \mathrm{h} \leq 2 \ell_{\mathrm{c}}
$$

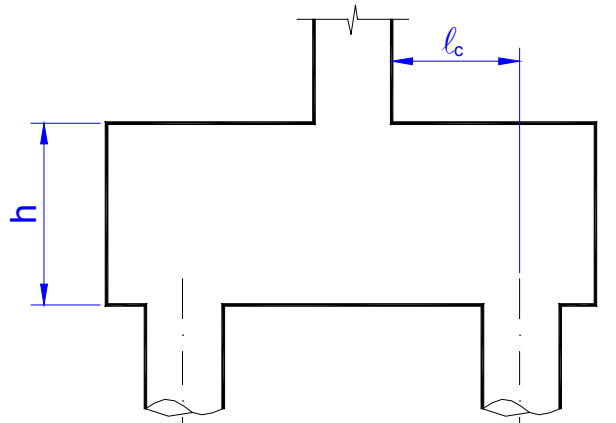

Figura 3.3 -Parâmetros para classificação do bloco

Guerrin (1980) sugere que os blocos sobre estacas podem ser dimensionados pelo método da flexão ou método das bielas. Segundo o autor, naquela época, os projetistas não estavam mais adotando o método da flexão, pois a relação $h \geq 0,5 \ell$ fornece um elemento rígido, definindo como $\ell$ o vão entre as estacas.

Calavera (1991) também adota a relação $\ell_{c} \leq 1,5 \mathrm{~h}$ admitindo que para essa relação as forças no elemento são transmitidas por meio de bielas e tirantes. Especifica ainda que não serão considerados no cálculo blocos com altura superior a uma vez e meia a distancia $\ell_{c}$. Ficando necessário atender a especificação: 


$$
\frac{\ell_{\mathrm{c}}}{1,5} \leq \mathrm{h} \leq 1,5 \ell_{\mathrm{c}}
$$

Montoya (2000) usa as mesmas especificações da norma EHE (2001) classificando os blocos sobre estacas como rígidos quando a relação $\ell_{c} \leq 2 \mathrm{~h}$ for atendida; caso contrário, quando $\ell_{c}>2 \mathrm{~h}$ em alguma das direções do bloco, ele deve ser considerado como flexível.

Silva e Giongo (2000), na análise estrutural de um modelo de biela e tirante, indicam que o modelo adotado deve ser função da geometria e ações atuantes em seu contorno. Estruturas de mesma geometria e ações diferentes não são modeladas da mesma maneira. É inadequado utilizar apenas parâmetros geométricos neste tipo de modelos, classificações do tipo $\ell / \mathrm{h}$ podem ser insuficientes.

\subsubsection{Recomendações para a altura dos blocos}

Como especificado anteriormente o CEB-FIP (1970) sugere que a altura dos blocos rígidos não deve ser superior a duas vezes a distancia $\ell_{\mathrm{c}}$.

Calavera (1991) recomenda alturas menores ou iguais a uma vez e meia o comprimento $\ell_{\mathrm{c}}$. Recomenda ainda que em qualquer caso a altura do bloco não deva ser inferior a $40 \mathrm{~cm}$ nem a uma vez e meia o diâmetro da estaca.

Montoya (2000) recomenda que a altura útil do bloco seja suficiente para não precisar de armadura para força cortante, por razões econômicas. Sugerindo a seguinte expressão:

$$
d=\frac{F_{d}}{500 b}-0,14>0,34
$$

onde:

$F_{d}$ : é a força transmitida para o bloco em kN;

b: é a largura do bloco em metros;

d: é a altura útil do bloco em metros.

Essa expressão pode ser usada para blocos de duas a seis estacas. Segundo o autor, respeitando esses valores, na maioria dos casos, resultam blocos que não precisam de armadura para resistir à força cortante, ou seja, blocos rígidos. 
Percebeu-se, para os blocos analisados neste traballho, que essa expressão fornece valores muito altos para altura útil, sendo necessário comprovar se é realmente mais econômico, aumentar a altura do bloco ou usar armadura para força cortante.

\subsubsection{Distância do eixo da estaca até a face do bloco}

Projetistas e alguns autores como Andrade (1989) e Alonso (1983) adotam que a distância mínima entre o eixo da estaca e a face do bloco deve ser de $15 \mathrm{~cm}$ somado a meio diâmetro da estaca.

Calavera (1991) e Montoya (2000) sugerem que a distância entre qualquer ponto do perímetro da estaca até a borda do bloco não deva ser inferior ao raio da estaca nem a $25 \mathrm{~cm}$.

\subsubsection{Ligação da estaca com o bloco}

Calavera (1991) e Montoya (2000), considerando recomendações práticas sugerem que a ponta superior da estaca deve ser embutida no bloco não menos que $10 \mathrm{~cm}$ e não mais que $15 \mathrm{~cm}$.

A união entre a estaca e o bloco pode variar dependendo do tipo de estaca e do processo de execução.

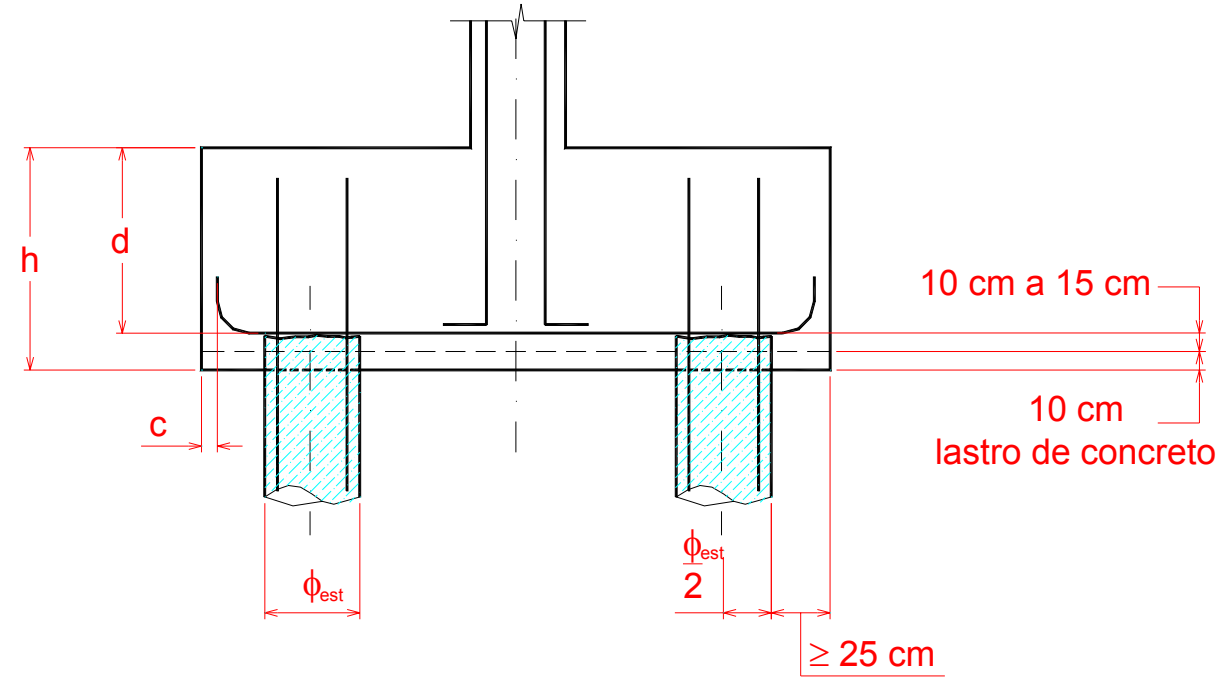

Figura 3.4 - União de bloco e estaca (Calavera, 1991) 


\subsubsection{Recomendações sobre excentricidades acidentais}

A tendência do uso de estacas de grande diâmetro, por razões econômicas, conduz muitas vezes a blocos sobre um número menor de estacas, como é o caso de blocos sobre uma ou duas estacas.

Calavera (1991) faz uma importante consideração para o caso de compressão centrada em blocos sobre uma ou duas estacas. Em virtude das incertezas na execução desses elementos sugere que se adote uma excentricidade acidental mínima, que é levada em conta no projeto do bloco.

Para os valores da excentricidade acidental pode-se adotar:

e $=5 \mathrm{~cm}$, em obras com alto controle de execução;

e $=10 \mathrm{~cm}$, em obras com controle de execução normal; e

$\mathrm{e}=15 \mathrm{~cm}$, em obras com baixo controle de execução.
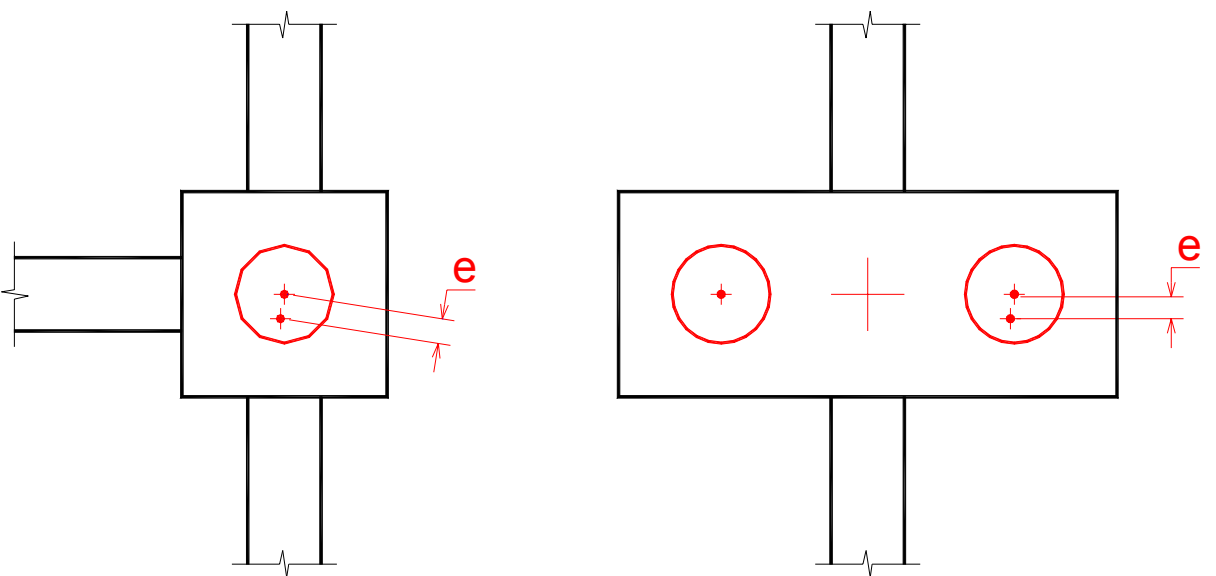

Figura 3.5 - Excentricidade acidental em blocos sobre uma e duas estacas

(Calavera, 1991)

\subsubsection{Ancoragem das barras de armadura principal dos blocos}

A NBR 6118:2003 indica que as barras de armadura dispostas nas faixas definidas pelas estacas devem se estender de face a face do bloco e terminar em gancho nas duas extremidades. A ancoragem das armaduras de cada uma dessas faixas deve ser garantida e medida a partir da face interna das estacas. Pode ser considerado o efeito favorável da compressão transversal às barras, decorrente da 
compressão das bielas. Destaca-se que esse procedimento já é adotado pelo meio técnico.

Andrade (1989) também admite que a armadura principal que deve ser mantida constante em toda a extensão do vão entre as estacas e convenientemente ancorada nas extremidades do bloco. Admite ainda que a armadura adicional longitudinal, quando constituída de barras pouco espaçadas entre si, tem o efeito de cintamento das bielas, aumentando então a capacidade resistente do bloco. Tal efeito ainda não foi estudado com cuidado. Essas afirmações são baseadas em outras análises, feitas principalmente por Burke (1978).

Considerando dados experimentais fornecidos por Minor e Jirsa (1975) e Marques e Jirsa (1975), Burke (1978) determinou a capacidade resistente das ancoragens (ganchos) de extremidade das barras para blocos de estacas alinhadas adotando uma condição favorável e admitindo que a região que envolve os ganchos esteja confinada transversalmente por barras finas (estribos). Para blocos com estacas não alinhadas admite-se uma condição muito favorável, pois o confinamento é feito com barras grossas. Definidas estas condições e o diâmetro das barras determina-se uma força resistente de cálculo de ganchos, esta força é subtraída da força a ancorar. Além disso, pode-se considerar um aumento no valor da tensão de aderência com o aumento de pressões transversais na barra ancorada.

Análise da ancoragem das barras longitudinais principais de blocos sobre estacas também pode ser encontrada em trabalho de Machado (1979), que por sua vez cita o trabalho de Burke (1978).

Calavera (1991) sugere que o comprimento de ancoragem das barras da armadura principal deve ser contado a partir do eixo da estaca. Considera ainda que o comprimento de ancoragem possa ser diminuído em $20 \%$, redução esta admitida pela boa condição de aderência produzida pela compressão transversal das barras por conta da reação nas estacas e da força da biela. Sugere, ainda que, se o comprimento de ancoragem reta não for suficiente pode-se adotar gancho sempre que:

$$
\frac{\ell_{1}}{0,7} \geq 0,8 \ell_{\mathrm{b}}
$$

Pode-se adotar também prolongamentos verticais $\left(\ell_{2}\right)$ tal que:

$$
\ell_{2}+\frac{\ell_{1}}{0,7}=0,8 \ell_{\mathrm{b}} \rightarrow \ell_{2}=0,8 \ell_{\mathrm{b}}-\frac{\ell_{1}}{0,7}
$$


Os comprimentos $\ell_{1}$ e $\ell_{2}$ estão definidos na figura 3.6, e $\ell_{\mathrm{b}}$ é o comprimento reto de ancoragem de uma barra de armadura, também chamado de comprimento básico de ancoragem.

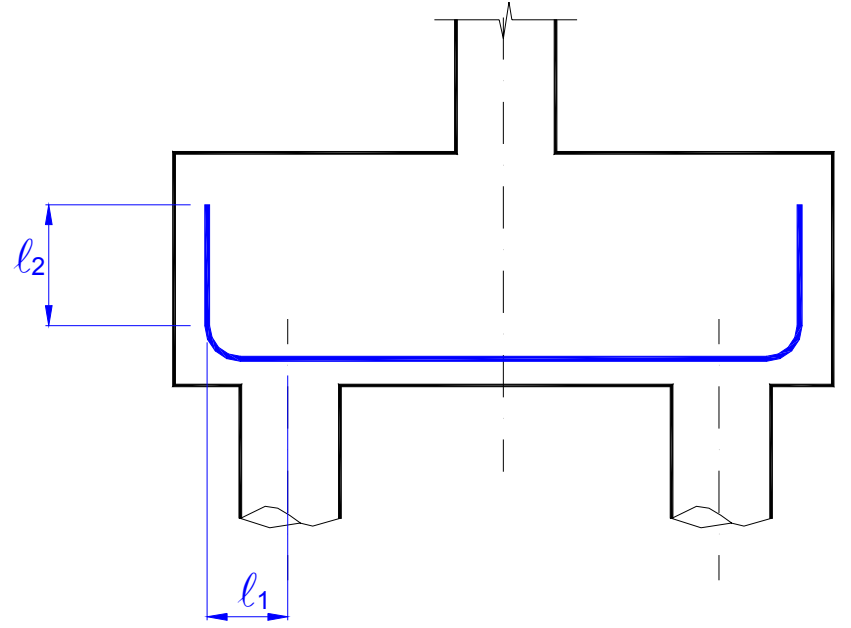

Figura 3.6 - Comprimento de ancoragem em blocos sobre estacas

(Calavera, 1991)

Calavera (1991) admite que o valor do comprimento $\ell_{\mathrm{b}}$ possa ser reduzido multiplicando-o pela relação da armadura necessária dividida pela armadura efetiva, mas deve se garantir que esta armadura seja prolongada até a face do bloco (descontando apenas o cobrimento da armadura). O comprimento $\ell_{1}$ não deve ser menor que um terço de $\ell_{\mathrm{b}}, 10$ vezes o diâmetro das barras e $15 \mathrm{~cm}$.

Montoya (2000), diferentemente de Calavera (1991), não sugere redução da seção da área de armadura, indicando que a armadura principal seja colocada em todo o comprimento do bloco. A ancoragem deve ser por prolongamento reto, ângulo reto ou com barras transversais soldadas, contadas a partir do plano vertical do eixo da estaca. Considerando o efeito benéfico da força resultante das tensões nas bielas de compressão permite reduzir a força a ser ancorada em $20 \%$. 


\subsubsection{Detalhamento das Armaduras Secundárias}

\subsubsection{Método do CEB-FIP - Boletim 73 (1970)}

Armaduras secundárias na forma de estribos na direção transversal e longitudinal são indicadas pelo CEB-FIP (1970). A princípio, elas são exigidas apenas no caso dos blocos sobre duas estacas em face de momentos fletores provenientes de excentricidades construtivas das estacas.

O CEB-FIP (1970) não contempla casos de blocos sobre uma estaca.

Em blocos sobre duas estacas uma armadura longitudinal é posicionada na parte superior, estendida sobre todo o comprimento do bloco, cuja seção transversal não deve ser inferior a 0,1 da seção da armadura longitudinal principal. Deve apresentar, nas faces laterais, uma armadura em malha, constituída por estribos transversais que devem envolver as barras longitudinais superiores e inferiores, e estribos na direção longitudinal envolvendo os estribos transversais.

A adoção desses critérios pode ser explicada, segundo Mautoni (1972) a ruína de blocos sobre duas estacas se dá quando a resistência à tração horizontal no eixo central for superada.

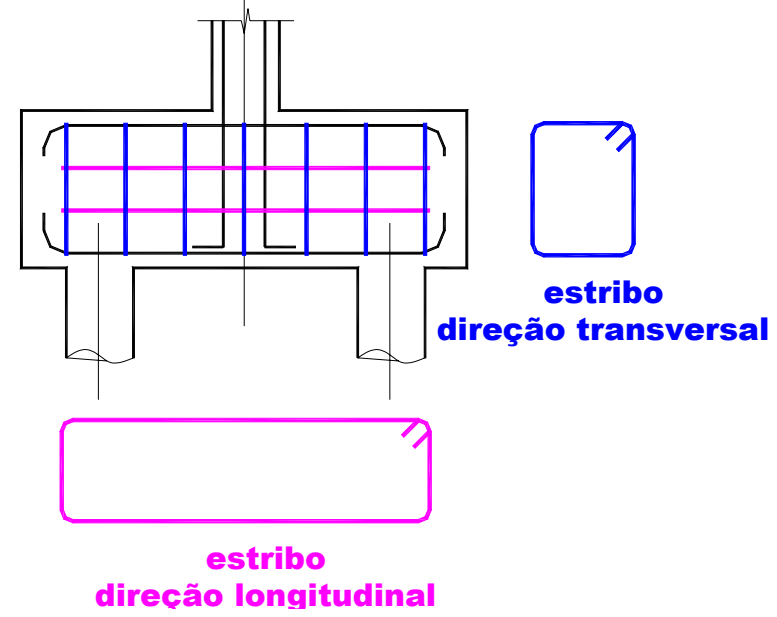

Figura 3.7 - Armaduras secundárias (CEB-FIP, 1970)

Considerando a face do bloco, mostrada na figura 3.7, a seção de uma barra da malha, formada por estribos nas duas direções, em $\mathrm{cm}^{2}$, é dada por:

$$
A_{s, w}=0,0020 \cdot b \cdot s_{h}
$$


$\mathrm{Na}$ expressão, $b$ designa a largura do bloco, em $\mathrm{cm}$, e $\mathrm{s}_{\mathrm{h}} \mathrm{o}$ espaçamento das barras da malha, em $\mathrm{cm}$. Se a largura $b$ exceder a metade da altura total $h$ do bloco, deve-se substitui-la por $h / 2$.

\subsubsection{Calavera (1991) e Montoya (2000)}

Segundo Calavera (1991) os blocos sobre duas estacas podem ter ação de momento torsor, provocado pelas excentricidades acidentais, portanto, devem-se dispor de armaduras secundárias.

A disposição e quantidade de armaduras longitudinais na face superior do bloco sugeridas por Calavera (1991) e Montoya (2000), são idênticas às sugeridas pelo CEB-FIP (1970), seguindo as mesmas orientações.

A quantidade geométrica de estribos transversais e longitudinais não deve ser menor que $0,4 \%$ da seção transversal de concreto.

Para blocos sobre mais de duas estacas os autores comentam que não é possível sugerir um critério palpável, indicando que o leitor adote seu próprio critério. Mesmo assim, comentam que para blocos submetidos a forças intensas é sempre recomendável o uso de armadura de pele.

\subsubsection{Recomendações da NBR 61182003}

A norma brasileira traz recomendações para armadura de distribuição e suspensão.

A armadura de distribuição deve ser prevista para controlar a fissuração, deve ser colocada na forma de uma malha adicional uniformemente distribuída nas duas direções para complementar a armadura principal que é distribuída em faixas sobre as estacas. Para o cálculo das áreas das barras das armaduras deve ser considerado no máximo $20 \%$ da força adotada para o dimensionamento da armadura principal. A resistência de cálculo da armadura deve ser igual a $80 \%$ de $\mathrm{f}_{\mathrm{yd}}$.

Em alguns casos, a NBR 6118:2003 sugere o uso de armadura de suspensão, nos casos em que a armadura de distribuição for prevista para mais de $25 \%$ da força adotada para o cálculo da armadura principal ou se o espaçamento entre estacas for maior que três vezes seu diâmetro. 


\subsubsection{Armadura de Suspensão}

Segundo Leonhardt e Monning (1978) é muito importante que armadura do tirante principal nos modelos de blocos sobre estacas seja o mais possível concentrada sobre as estacas e não distribuídas pela largura do bloco, pois as bielas de compressão se concentram na direção dos apoios rígidos constituídos pelas estacas e lá devem compor com esforços dos tirantes.

Para os casos em que essa armadura for disposta também entre as estacas, deve-se adotar uma armadura de suspensão. Leonhardt e Monning (1978) indicam que ensaios mostraram que, quando a armadura for disposta também entre as estacas, uma parte dos esforços das bielas de compressão atua nessa região, e pressiona o tirante para baixo, porque falta apoio nesse local (figura 3.8). Surgem então fissuras na parte inferior do bloco que podem conduzir a uma ruína prematura, porque a zona comprimida para baixo e para fora arranca a malha de armadura mesmo nas proximidades das estacas.

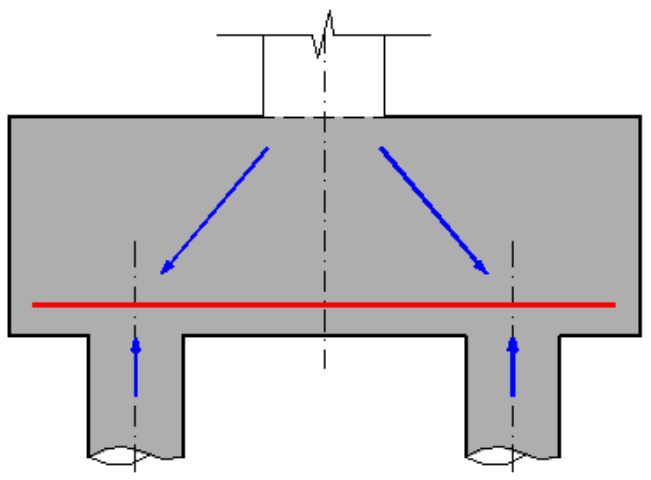

Corte passando pelas estacas

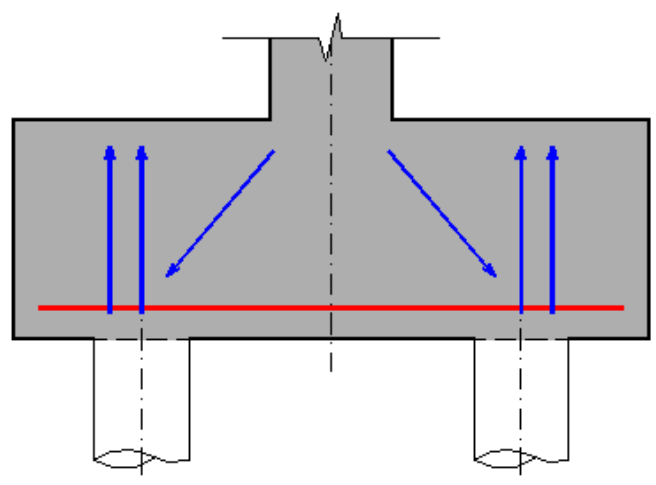

Corte passando pelo pilar

Figura 3.8 - Esquema para colocação de armadura de suspensão em casos de armadura disposta entre as estacas (Leonhardt e Monning, 1978)

No caso de distância entre as estacas maiores que três vezes o diâmetro desta, não se deixa o trecho entre as estacas sem armadura, portanto haverá a necessidade de se adotar armadura de suspensão. Essa armadura deve ser dimensionada para uma força total igual aproximadamente a $F /(1,5 . n)$, sendo $F$ a força aplicada no bloco e $n$ o número de estacas $(n \geq 3)$. 


\subsection{Métodos para dimensionamento de blocos sobre estacas}

\subsubsection{Método das Bielas}

O Método das Bielas é o método mais difundido para o dimensionamento de blocos rígidos sobre estacas. É baseado nos trabalhos experimentais realizados por Blévot e Frémy (1967).

O método das bielas consiste em admitir no interior do bloco uma treliça espacial composta por barras tracionadas e barras comprimidas.

As barras tracionadas da treliça ficam situadas no plano médio das armaduras, que é horizontal e se localiza logo acima do plano de arrasamento das estacas.

As barras comprimidas, chamadas de bielas, são inclinadas e definidas a partir da intersecção do eixo das estacas com o plano médio das armaduras com um ponto definido na região nodal do pilar (que é considerado de seção quadrada).

As forças de compressão nas bielas são resistidas pelo concreto, as de tração que atuam nas barras horizontais da treliça, pela armadura.

O método consiste no cálculo da força de tração, que defini a área necessária de armadura, e na verificação das tensões de compressão nas bielas, calculadas nas seções situadas junto ao pilar e à estaca.

As tensões limites foram determinadas experimentalmente por Blévot (1967) em ensaios e assumidas iguais junto ao pilar e estaca. É importante observar que a rigor não são iguais, junto ao pilar há o efeito favorável de confinamento do concreto. Portanto, a tensão limite junto à estaca deveria ser considerada inferior; Blévot (1967) só fez essas considerações para blocos com mais de quatro estacas.

O método das bielas é recomendado para ações centradas e todas as estacas devem estar igualmente afastadas do centro do pilar. Pode ser empregado no caso de ações que não são centradas, desde que se admita que todas as estacas estão submetidas à maior força transferida.

Os critérios usados são para pilares de seção quadrada, sendo recomendado por alguns autores que no caso de pilares retangulares se use seção quadrada equivalente.

O roteiro de dimensionamento, adaptado do Método de Blévot, que geralmente é usado pelos projetistas de concreto armado, é apresentado a seguir. 


\subsubsection{Blocos sobre duas estacas}

Para o projeto de blocos sobre duas estacas considera-se o esquema de forças internas mostrado na figura 3.9. Sendo que a treliça tem a barra tracionada localizada logo acima da cota de arrasamento das estacas, representada pela força $R_{s t}$. As diagonais comprimidas são inclinadas e representadas pela força $R_{c b}$.

A rotina de projeto segue o roteiro exposto a seguir, no qual deve-se determinar a força de tração nos tirantes e a verificação da tensão de compressão das bielas.

a) Determinação da força de tração nas barras da armadura

O ângulo de inclinação das bielas fica definido pela expressão 3.9:

$$
\theta=\operatorname{arctg}\left(\frac{d}{\frac{\ell}{2}-\frac{a_{p}}{4}}\right)
$$
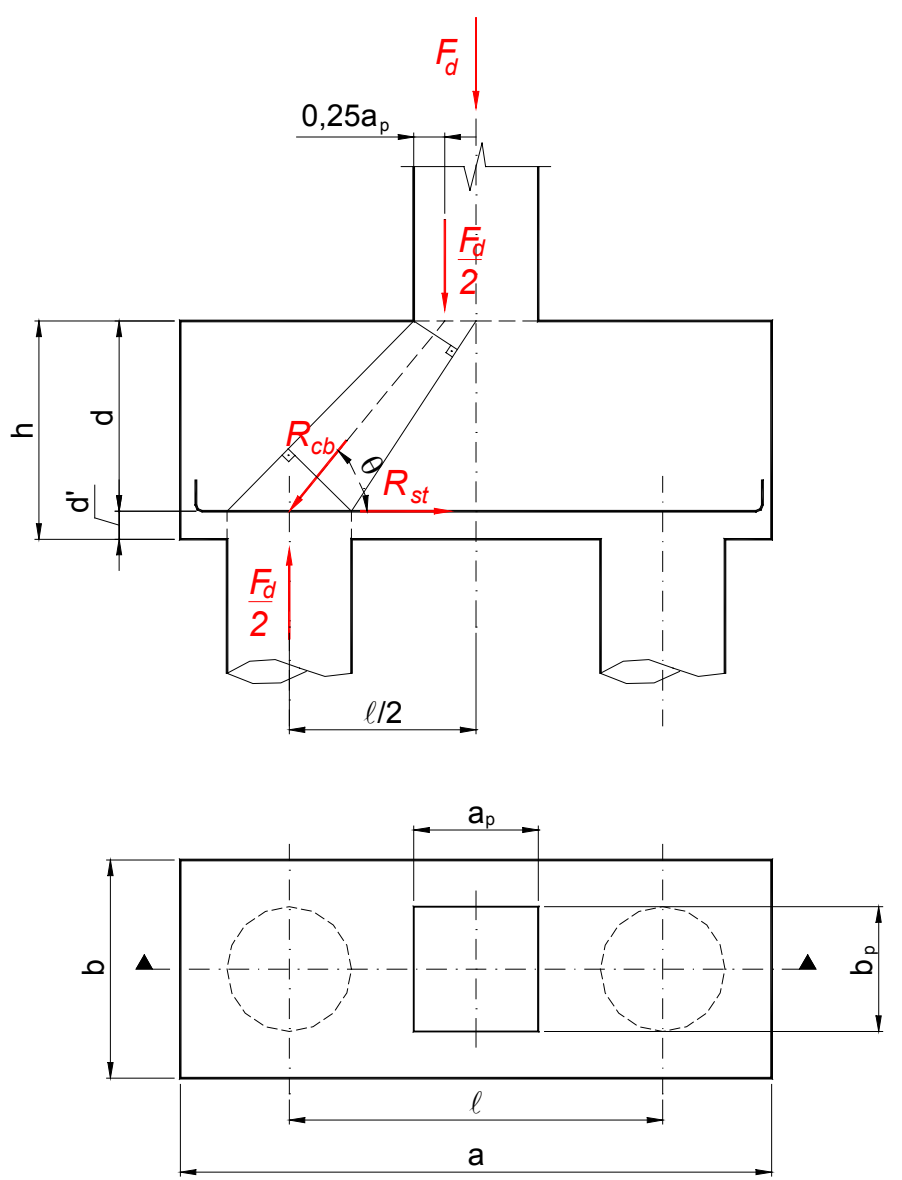

Figura 3.9 - Modelo de cálculo para blocos sobre duas estacas 
Escrevendo as expressões do polígono de forças, figura 3.10, e da tangente do ângulo de inclinação da biela de concreto, têm-se:

$$
\operatorname{tg} \theta=\frac{d}{\frac{\ell}{2}-\frac{a_{p}}{4}}
$$

e ainda, conforme figura 3.10, que representa o polígono de forças atuantes no bloco:

$$
\operatorname{tg} \theta=\frac{\frac{F_{d}}{2}}{R_{s t}}
$$

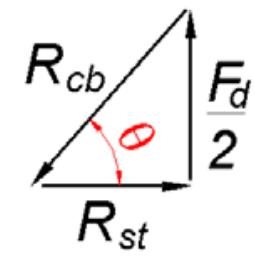

Figura 3.10 - Polígono de Forças

Igualando-se as expressões 3.10 e 3.11 determina-se a força de tração no tirante:

$$
R_{s t}=\frac{F_{d}\left(2 \ell-a_{p}\right)}{8 d}
$$

Segundo Blévot (1967) o valor da força $R_{s t}$ calculado pela expressão 3.12 deve ser majorado em $15 \%$, pois concluiu que a expressão determinada pelo polígono de forças não era a favor da segurança.

b) Recomendações para a altura útil do bloco

O ângulo de inclinação entre o tirante e as bielas deve estar entre os limites: 
Blévot (1967) assegura que utilizando esse intervalo para o ângulo de inclinação das bielas os blocos têm o comportamento adequado para a formulação sugerida. Por exemplo, no caso de se adotar blocos sobre estacas com ângulos de inclinação maiores que $55^{\circ}$, não pode mais se assegurar que o modelo tenha comportamento de bloco, tendo que se adotar outros critérios para a resolução dos mesmos.

Substituindo os valores de $\theta$ na expressão 3.10 por seus valores limites, podese determinar o intervalo de variação para a altura útil d:

$$
0,50\left(\ell-\frac{a}{2}\right) \leq d \leq 0,714\left(\ell-\frac{a}{2}\right)
$$

c) Tensão de compressão nas bielas de concreto

Do polígono de forças, da figura 2.9, pode-se escrever:

$$
\operatorname{sen} \theta=\frac{\frac{F_{d}}{2}}{R_{c c}}
$$

e portanto:

$$
\mathrm{R}_{\mathrm{cb}}=\frac{\mathrm{F}_{\mathrm{d}}}{2 \operatorname{sen} \theta}
$$

As bielas apresentam seções variáveis ao longo da altura do bloco, portanto, é necessário verificar a tensão máxima que está submetida, verificando as seções junto ao pilar e junto à estaca.

$\mathrm{c}_{1}$ ) Tensão de compressão nas bielas junto ao pilar

A relação entre as áreas da seção transversal do pilar $\left(A_{p}\right)$ e da biela na base do pilar $\left(A_{b, p}\right)$ é definida por (figura 3.9 e 3.11 ):

$$
A_{b, p}=\frac{1}{2} A_{p} \cdot \operatorname{sen} \theta
$$


A tensão normal na biela junto ao pilar é obtida pela divisão da força na biela pela sua área:

$$
\sigma_{\mathrm{cb}, \mathrm{p}}=\frac{\mathrm{R}_{\mathrm{cb}}}{\mathrm{A}_{\mathrm{b}, \mathrm{p}}}
$$

Substituindo em 3.16 as expressões 3.14 e 3.15 , tem-se:

$$
\sigma_{c b, p}=\frac{F_{d}}{A_{p} \cdot \operatorname{sen}^{2} \theta}
$$

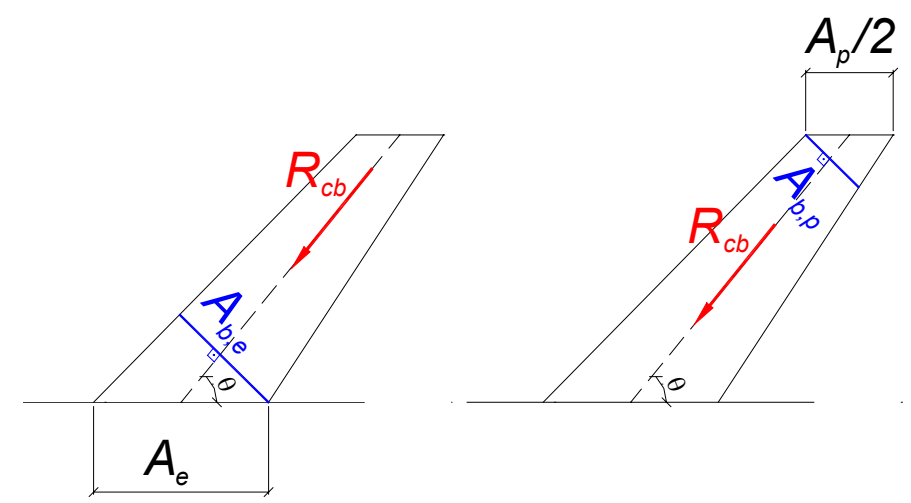

Figura 3.11 - Área de verificação das bielas, junto à estaca e junto ao pilar (bloco sobre duas estacas)

$\mathrm{C}_{2}$ ) Tensão de compressão nas bielas junto à estaca

A relação entre as áreas da seção transversal da estaca $\left(A_{e}\right)$ e da biela junto à estaca $\left(A_{b, e}\right)$ é definida:

$$
A_{b, e}=A_{e} \cdot \operatorname{sen} \theta
$$

A tensão normal na biela junto à estaca é obtida pela divisão da força na biela pela sua área:

$$
\sigma_{\mathrm{cb}, \mathrm{e}}=\frac{\mathrm{R}_{\mathrm{cb}}}{\mathrm{A}_{\mathrm{b}, \mathrm{e}}}
$$


Substituindo em 3.19 as expressões 3.14 e 3.18 , tem-se:

$$
\sigma_{\text {cb.e }}=\frac{F_{d}}{2 \cdot A_{e} \cdot \operatorname{sen}^{2} \theta}
$$

d) Verificação das tensões limites

As tensões calculadas nas bielas devem ser inferiores a um valor limite.

FUSCO (1994) sugere para a avaliação da segurança das estruturas, no estado limite último de ruptura do concreto, que no plano da seção transversal possa atuar uma tensão de compressão de cálculo de $0,85 \mathrm{f}_{\mathrm{cd}}$.

Este coeficiente de modificação $k_{\text {mod }}=0,85$ ao produto de três outros coeficientes:

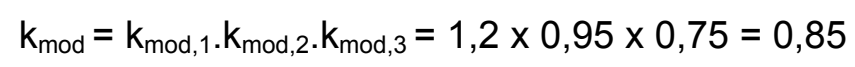

Nessa expressão 0 valor de $\mathrm{k}_{\text {mod, } 1}=1,2$ leva em conta 0 acréscimo de resistência do concreto após 28 dias de idade; o coeficiente $k_{\text {mod, } 2}=0,95$ considera a resistência medida em corpos-de-prova cilíndricos de $15 \mathrm{~cm} \times 30 \mathrm{~cm}$ em relação à resistência do concreto no elemento estrutural; e o coeficiente $k_{\text {mod, } 3}=0,75$ leva em conta o efeito deletério da ação de longa duração (Efeito Rüsch).

$\mathrm{Na}$ consideração da tensão limite na biela, leva-se em conta ainda a forma do bloco:

$$
\sigma_{\mathrm{cb}, \mathrm{lim}}=0,85 \cdot \alpha \cdot \mathrm{f}_{\mathrm{cd}}
$$

O coeficiente $\alpha$ é definido como coeficiente de ajuste entre os resultados numéricos e experimentais. Os valores adotados para $\alpha$ neste trabalho foram os sugeridos por Machado (1979) que considera o coeficiente igual a 1,4 para blocos sobre duas estacas.

e) Área das barras de armadura

A armadura é calculada por meio da força $R_{s t}$ considerando o escoamento do aço no estado limite último, ficando definida a expressão: 
$A_{s}=\frac{R_{s t}}{f_{y d}}$

Sendo: $\quad f_{y d}=\frac{f_{y k}}{\gamma_{f}}=\frac{f_{y k}}{1,15}$

\subsubsection{Blocos sobre três estacas}

A rotina de projeto para blocos sobre três estacas é praticamente o mesmo que o considerado para duas estacas, mas neste caso, a treliça é formada por três barras comprimidas. Os tirantes são representados pela armadura, que pode ter diferentes arranjos.

O esquema estático considerado é mostrado na figura 3.12 .
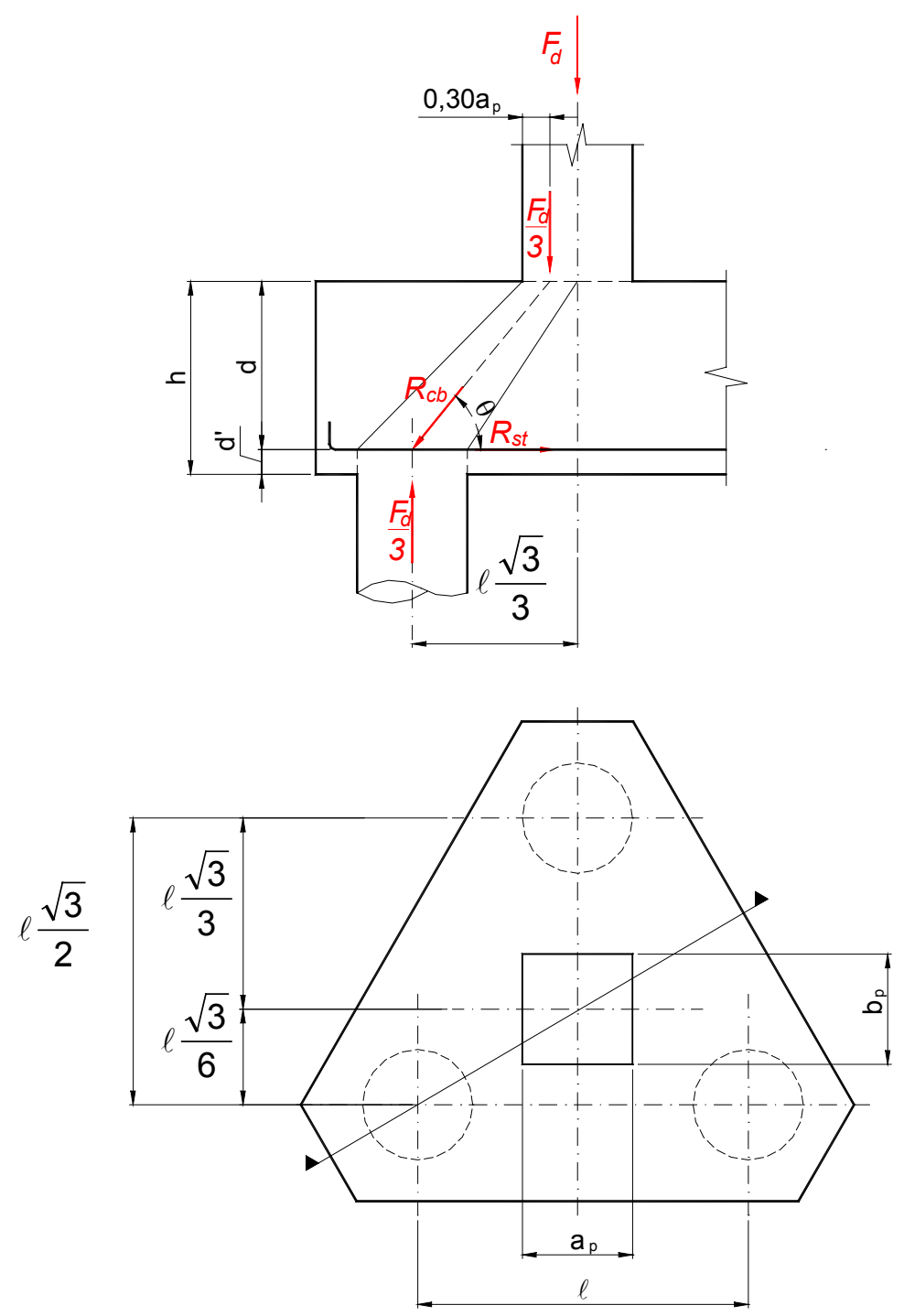

Figura 3.12 - Modelo de cálculo para blocos sobre três estacas 
a) Determinação da força de tração nas barras da armadura

Escrevendo as expressões que retratam o equilíbrio do polígono de forças e da tangente do ângulo de inclinação da biela de concreto, têm-se:

$$
\begin{aligned}
& \operatorname{tg} \theta=\frac{d}{\frac{\ell \sqrt{3}}{3}-0,3 a_{p}} \\
& \operatorname{tg} \theta=\frac{\frac{F_{d}}{3}}{R_{s t}}
\end{aligned}
$$

Igualando-se as expressões 3.24 e 3.25 determina-se a força de tração no tirante:

$$
\mathrm{R}_{\mathrm{st}}=\frac{\mathrm{F}_{\mathrm{d}}\left(\ell \sqrt{3}-0,9 \mathrm{a}_{\mathrm{p}}\right)}{9 \mathrm{~d}}
$$

b) Recomendações para a altura útil do bloco

O ângulo de inclinação entre o tirante e as bielas deve estar entre os limites:

$45^{\circ} \leq \theta \leq 55^{\circ}$

Substituindo os valores de $\theta$ na expressão 3.24 por seus valores limites, podese determinar o intervalo de variação para a altura útil d:

$$
0,577\left(\ell-0,52 a_{p}\right) \leq d \leq 0,825\left(\ell-0,52 a_{p}\right)
$$

c) Tensão de compressão nas bielas de concreto

Do polígono de forças pode-se escrever:

$$
\operatorname{sen} \theta=\frac{\frac{F_{d}}{3}}{R_{c b}}
$$


E, portanto:

$$
\mathrm{R}_{\mathrm{cb}}=\frac{\mathrm{F}_{\mathrm{d}}}{3 \operatorname{sen} \theta}
$$

$\mathrm{c}_{1}$ ) Tensão de compressão nas bielas junto ao pilar

A relação entre as áreas da seção transversal do pilar $\left(A_{p}\right)$ e da biela na base do pilar $\left(A_{b, p}\right)$ é definida:

$$
A_{b, p}=\frac{1}{3} A_{p} \cdot \operatorname{sen} \theta
$$

A tensão normal na biela junto ao pilar, obtida pelo quociente da força na biela pela sua área, é calculada pela expressão 3.16.

Substituindo em 3.16 as expressões 3.28 e 3.29 , determina-se a mesma expressão de tensão de compressão, calculada anteriormente para blocos sobre duas estacas, como indicado na expressão 3.17 .

$\mathrm{c}_{2}$ ) Tensão de compressão nas bielas junto à estaca

A relação entre as áreas da seção transversal da estaca $\left(A_{e}\right)$ e da biela junto à estaca $\left(A_{b, e}\right)$ é definida pela expressão 3.18.

A tensão normal na biela junto à estaca é obtida pela divisão da força na biela pela sua área, mostrada na expressão 3.19.

A expressão 3.30 é obtida substituindo-se em 3.19 as expressões 3.28 e 3.29 :

$$
\sigma_{\text {cb.e }}=\frac{F_{d}}{3 \cdot A_{e} \cdot \operatorname{sen}^{2} \theta}
$$

d) Verificação das tensões limites

As tensões calculadas deveram ser inferiores ao valor limite, definido na expressão 3.22 .

O valor do coeficiente $\alpha$ sugerido por Machado (1979) para blocos sobre três estacas é igual a 1,75. 
e) Área das barras de armadura

No caso de blocos sobre três estacas pode-se ter diferentes arranjos de armadura, conforme os ensaios de Blévot (1967).

$\left.\mathrm{e}_{1}\right)$ Armadura segundo as medianas

Este tipo de arranjo apresenta alguns inconvenientes, como por exemplo, a superposição de três feixes de barra no centro do bloco, além de propiciar maior número de fissuras nas faces laterais do bloco, provocadas pela falta de apoio em uma das extremidades das barras.

A força de tração definida para o dimensionamento de blocos com armaduras segundo as medianas é a mesma definida anteriormente pela expressão:

$$
R_{s t}=\frac{F_{d}\left(\ell \sqrt{3}-0,9 a_{p}\right)}{9 d}
$$

As áreas das barras de armadura para este arranjo são calculadas por meio da expressão 3.23 .
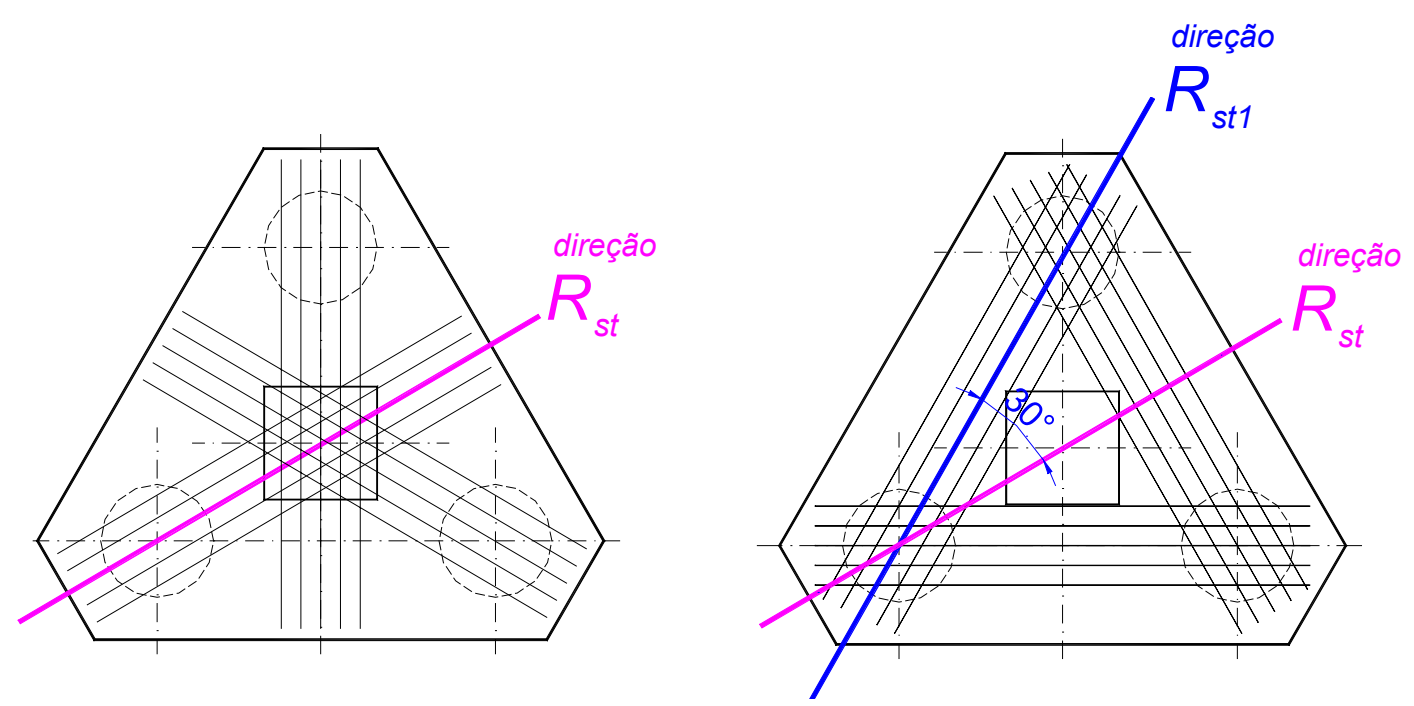

Figura 3.13 - Arranjo de armadura segundos as medianas e segundo os lados do bloco 
$\mathrm{e}_{2}$ ) Armadura segundo os lados

Os blocos com distribuição de barras segundo os lados apresentam menor número de fissuras e menor área de armadura. Quando a força atuante no pilar se distribui espacialmente entre três ou mais estacas as bielas se formam, de preferência, com as menores distâncias entre estacas. Os tirantes devem ser dispostos sobre as estacas nas direções em que a distância entre elas sejam menores. A sugestão dada por vários autores é que essas armaduras sejam concentradas sobre as estacas e não distribuídas de modo uniforme pela largura do bloco.

A força de tração para o cálculo das barras de armadura disposta segundo os lados do bloco é definida por:

$$
R_{s t 1}=R_{s t} \frac{\sqrt{3}}{3}
$$

A armadura é calculada por meio da mesma expressão definida anteriormente, mas agora a força considerada é $\mathrm{R}_{\mathrm{st1}}$.

$$
A_{s}=\frac{R_{s t 1}}{f_{y d}}
$$

$\left.\mathrm{e}_{3}\right)$ Armadura em malha

Os blocos com este tipo de arranjo de armadura são os que apresentam menor eficiência, segundo os ensaios de Blévot (1967). Além disso, há comprimentos de barras da armadura com dimensões diferentes, o que pode ser antieconômico e, além disso, dificulta a execução.

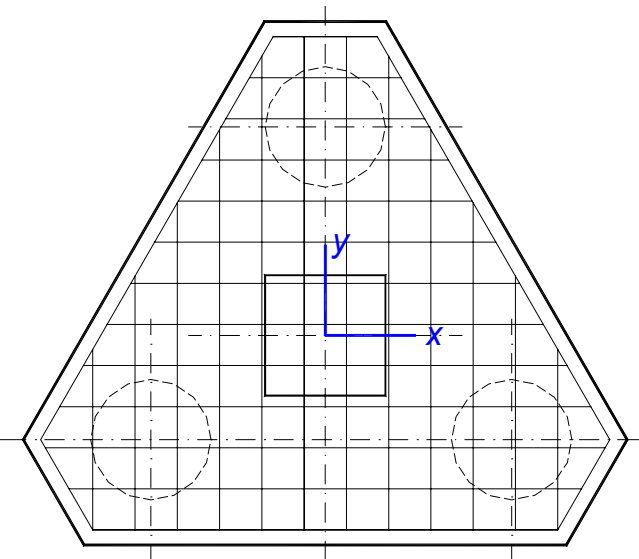

Figura 3.14 - Arranjo de armadura em malha 
A força de tração calculada para direção y é dada pela expressão 3.26. $\mathrm{Na}$ direção $x$ deve se usar a expressão:

$$
\mathrm{R}_{\mathrm{stx}}=\mathrm{R}_{\mathrm{st}} \frac{\sqrt{3}}{2}
$$

\subsubsection{Blocos sobre quatro estacas}

O funcionamento estrutural dos blocos sobre quatro estacas é mostrado na figura 3.15. A força atuante no pilar é transmitida às estacas por quatro bielas diagonais comprimidas, cujo equilíbrio é garantido pela armadura que poderá ter várias formas de distribuição.
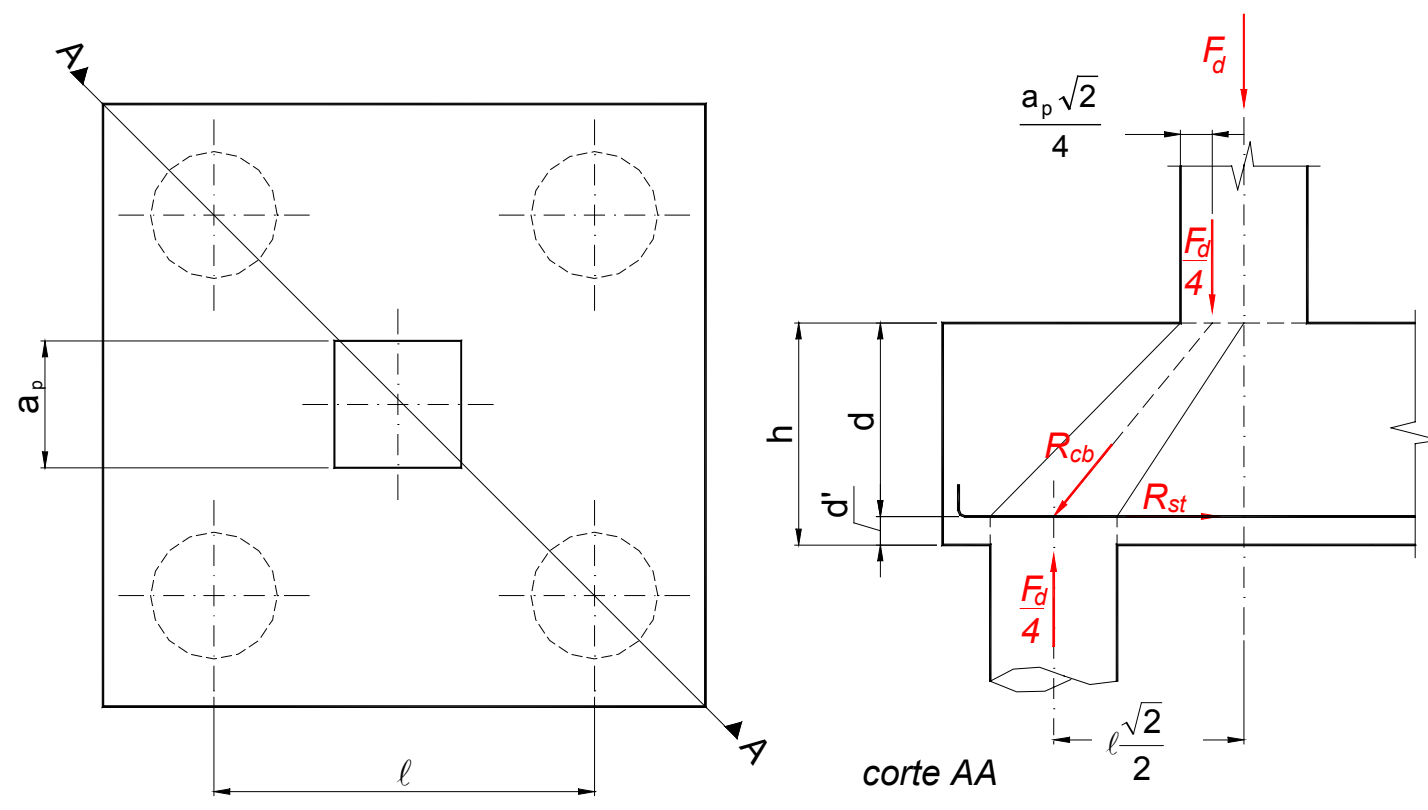

Figura 3.15 - Modelo de cálculo para blocos sobre quatro estacas

Analisando o triângulo retângulo formado pela intersecção do eixo da estaca com o eixo das barras, este com o eixo do pilar e o segmento que une o centro do pilar com o centro da estaca, pode-se escrever: 


$$
\operatorname{tg} \theta=\frac{d}{\frac{\ell \sqrt{2}}{2}-\frac{a_{p} \sqrt{2}}{4}}
$$

A expressão para cálculo da força no tirante determinada considerando o equilíbrio do polígono de forças é dada por:

$$
\operatorname{tg} \theta=\frac{\frac{F_{d}}{4}}{R_{s t}}
$$

Igualando-se as expressões 3.35 e 3.36 , a força $R_{\text {st }}$ fica definida por:

$$
R_{\mathrm{st}}=\frac{F_{d} \sqrt{2}\left(2 \ell-a_{p}\right)}{16 d}
$$

A recomendação dos intervalos de altura útil para os ângulos entre $45^{\circ}$ e $55^{\circ}$ ficam expressas por:

$$
0,707\left(\ell-\frac{a_{p}}{2}\right) \leq d \leq 1,00\left(\ell-\frac{a_{p}}{2}\right)
$$

A tensão de compressão nas bielas junto ao pilar é definida pela expressão 3.17, e a tensão junto à estaca fica definida por:

$$
\sigma_{\mathrm{cb.e}}=\frac{\mathrm{F}_{\mathrm{d}}}{4 \cdot \mathrm{A}_{\mathrm{e}} \cdot \operatorname{sen}^{2} \theta}
$$

Para verificação das tensões deve-se utilizar o valor limite definido na expressão 3.22. O valor do coeficiente $\alpha$ sugerido por Machado (1979) para blocos sobre quatro estacas é igual a 2,10.

Os diferentes arranjos de armaduras são definidos na tabela 3.1.

A primeira e a segunda configuração quando adotadas nos blocos, estes podem apresentar fissuração lateral. A disposição de armadura em malha apresenta bom desempenho com relação à fissuração, mas menor eficiência com relação à força de ruína do bloco. O ideal seria usar em conjunto as configurações 2 e 3.

As aberturas de fissuras podem ser reduzidas dispondo-se de armaduras em forma de estribos verticais e horizontais. 
Tabela 3.1 - Arranjo de armadura para blocos sobre quatro estacas

\begin{tabular}{lll}
\hline \multicolumn{1}{c}{ Armadura } & Configuração & Força $\mathbf{R}_{\mathbf{s t}}$ \\
\hline 1) Segundo as diagonais & $\frac{F_{d} \sqrt{2}\left(2 \ell-a_{p}\right)}{16 d}$ & \\
\hline & & $\frac{F_{d}\left(2 \ell-a_{p}\right)}{16 d}$ \\
\hline
\end{tabular}

\subsubsection{Blocos sobre cinco estacas}

Os blocos sobre cinco estacas podem ter dois tipos de disposição das estacas, estacas dispostas segundo os vértices de um pentágono ou estacas dispostas nos vértices e no centro de um quadrado.

Neste item serão tratados os blocos sobre cinco estacas distribuídas segundo um quadrado e uma estaca no seu centro geométrico, conforme figura 3.16. Os blocos sobre cinco estacas com este tipo de disposição são mais utilizados, em virtude da maior facilidade de execução.

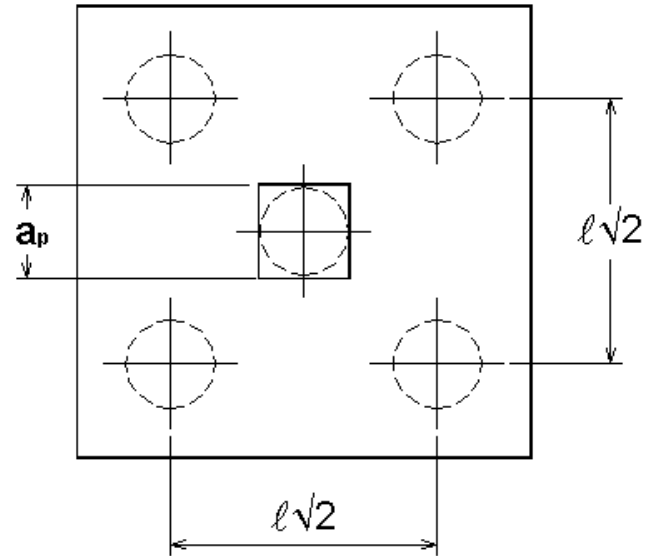

Figura 3.16 - Modelo de cálculo para blocos sobre cinco estacas 
Para o projeto deste tipo de bloco Blévot recomenda que se utilizem as mesmas expressões sugeridas para blocos sobre quatro estacas, a treliça é montada considerando a reação em cada estaca igual a $1 / 5$ da força aplicada no pilar. As expressões são obtidas substituindo-se a força $F$ por 4/5F.

$O$ valor do ângulo de inclinação das bielas também deve ficar entre os limites de $45^{\circ}$ e $55^{\circ}$ e os valores limites para altura útil podem ser definidos com a mesma expressão utilizada para blocos sobre quatro estacas (expressão 3.38).

A tensão de compressão na região nodal próxima ao pilar pode ser calculada por meio da expressão 3.17 , e junto à estaca fica definida por:

$$
\sigma_{c b . e}=\frac{F_{d}}{5 \cdot A_{e} \cdot \operatorname{sen}^{2} \theta}
$$

Para verificação das tensões de compressão nas bielas, nos casos anteriores (blocos sobre duas, três e quatros estacas) considerou-se o valor limite sendo o mesmo, tanto na região nodal próxima ao pilar, como próxima à estaca. Como dito anteriormente isso é uma aproximação, pois na região próxima as estacas as tensões são menores do que próxima ao pilar. Para blocos sobre cinco estacas Blévot (1967) considerou esta diferença e adotou valores distintos para o coeficiente $\alpha$. Os valores sugeridos por Machado (1979) para blocos sobre cinco estacas são:

$\alpha=2,6$ para o cálculo da tensão limite junto ao pilar, e,

$\alpha=2,1$ para o cálculo da tensão limite junto à estaca.

Para a obtenção das tensões limites devem-se substituir os valores de $\alpha$ na expressão 3.22 .

Os diferentes arranjos de armaduras são definidos na tabela 3.2. 
Tabela 3.2 - Arranjo de armadura para blocos sobre cinco estacas

\begin{tabular}{lll}
\hline \multicolumn{1}{c}{ Armadura } & Configuração & Força $\mathbf{R}_{\mathbf{s t}}$ \\
\hline 1) Segundo as diagonais & $\frac{F_{d} \sqrt{2}\left(2 \ell-a_{p}\right)}{20 d}$ & \\
\hline 2) Segundo os lados & $\frac{F_{d}\left(2 \ell-a_{p}\right)}{20 d}$ & \\
\hline 3) Em malha & & \\
\hline
\end{tabular}

\subsubsection{Processo do CEB-FIP - Boletim 73 (1970)}

O projeto de blocos sobre estacas considerando o Processo do CEB-FIP (1970) indica verificações de segurança para tensões normais e tangenciais com os esforços solicitantes determinados em seções transversais particulares.

A rotina de projeto é aplicada a blocos considerados rígidos, com distância entre a face do pilar até o eixo da estaca mais afastada, variando entre um terço e a metade da altura do bloco, conforme a figura 3.17 , ou seja:

$$
\frac{2}{3} \ell_{\mathrm{c}} \leq \mathrm{h} \leq 2 \ell_{\mathrm{c}}
$$

Caso essa recomendação não seja atendida as recomendações do método não são aplicáveis. 


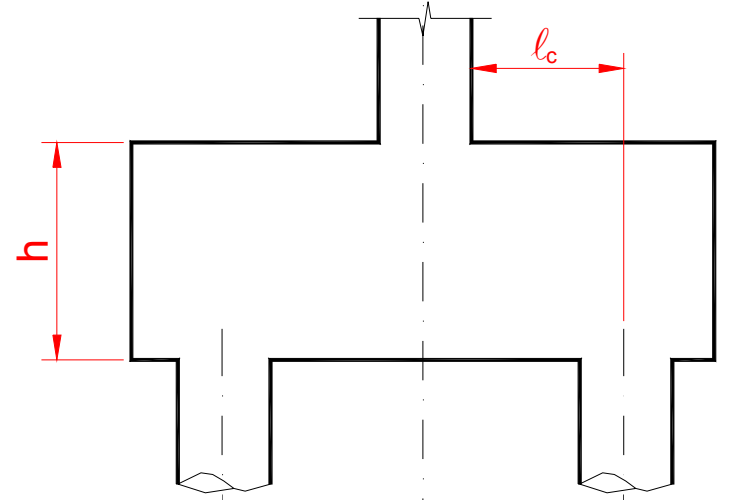

Figura 3.17 - Relação entre a aba $\ell_{c}$ e altura h.

A altura do bloco pode ser variável, decrescendo linearmente da face do pilar até a extremidade livre do bloco, desde que as condições de resistência à força cortante sejam verificadas em todas as seções e que os cobrimentos sejam suficiente nas zonas de ancoragem.

O procedimento de projeto de blocos sobre estacas por meio deste método deve seguir a rotina de cálculo descrita a seguir.

\subsubsection{Dimensionamento da armadura inferior}

Para o dimensionamento da armadura principal do bloco o método sugere uma verificação à flexão considerando uma seção de referência interna plana, normal à superfície do bloco. Esta seção definida como $S_{1}$ está situada entre as faces do pilar a uma distância de $0,15 a_{p}$, onde $a_{p}$ designa a medida do lado do pilar no sentido perpendicular à seção considerada.

Essa recomendação é pelo fato de que, no caso de pilares com seção alongada, o valor do momento fletor pode crescer sensivelmente além da seção situada na face do pilar, esta é a justificativa para que se verifique a seção $S_{1}$ na posição $0,15 a_{p}$ (figura 3.18).

A altura útil da seção $S_{1}$ é tomada igual à altura útil da seção paralela a $S_{1} e$ situada na face do pilar, salvo se esta altura exceder 1,5 vez a aba $\ell_{c}$ do bloco, medida perpendicularmente a $S_{1}$, limitando-se, portanto a altura útil a $1,5 \ell_{c}$ :

$$
\mathrm{d}_{1}=\mathrm{d} \leq 1,5 \ell_{\mathrm{c}}
$$


No caso de blocos sobre muitas estacas, a aba $\ell_{c}$ é avaliada a partir do eixo da estaca mais afastada da face do pilar.

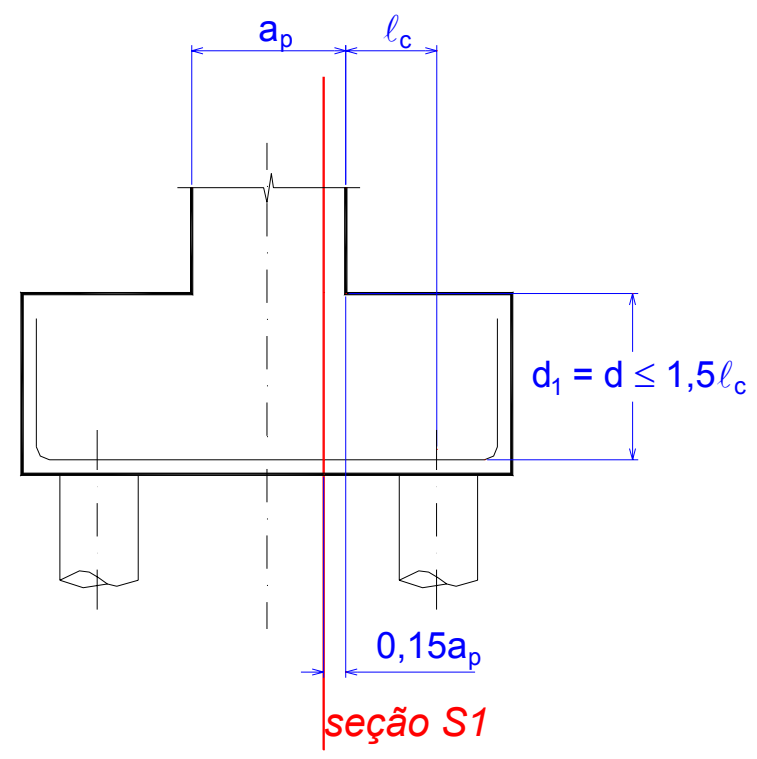

Figura 3.18 - Seção de Referência $S_{1}$

O cálculo da área da seção transversal da armadura inferior do bloco é feito por meio da consideração do momento fletor relativo à seção de referência $S_{1}$. Este momento é calculado levando-se em conta a totalidade da reação das estacas agindo na parte do bloco limitada por essa seção, ou seja, o produto da reação das estacas e a distância dessa a seção de referência. As reações computadas para o cálculo são das estacas localizadas entre a seção $S_{1}$ e a face lateral do bloco, paralela a essa seção, e que não atravessa o centro do pilar.

Em casos, como em blocos sobre duas estacas, em que a armadura é predominante em uma das direções, a armadura na outra direção deve ser considerada com área igual a $20 \%$ da área da armadura principal.

\subsubsection{Disposição da armadura inferior}

\section{A) Caso Geral}

A armadura inferior requerida para resistir a força de tração necessária para equilibrar o momento fletor pode ser, em parte, constituída por barras distribuídas em faixas sobre as estacas. As disposições de armadura sugeridas na figura 3.19 podem 
ser adotadas no caso em que as estacas são dispostas segundo os vértices de um polígono regular centrado em relação ao eixo do pilar.
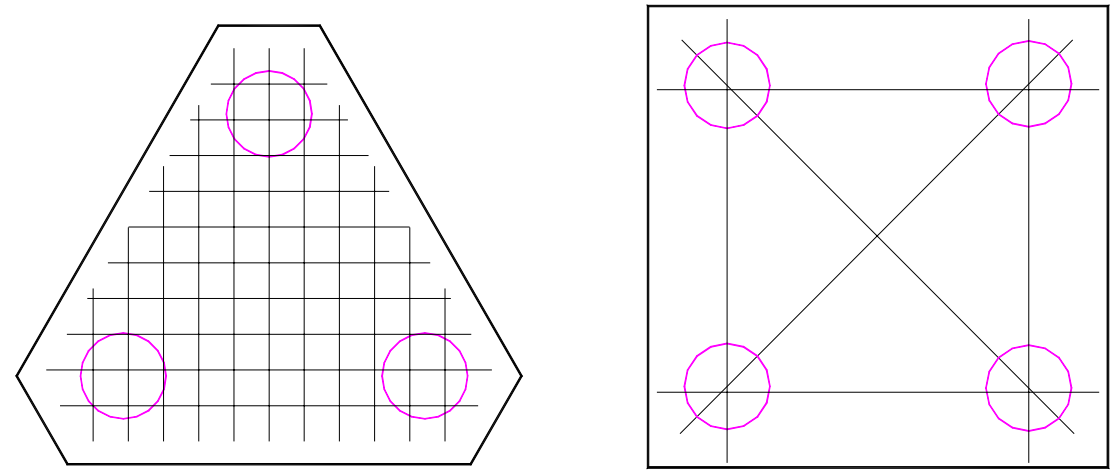

Figura 3.19 - Disposição das armaduras

Em todos os casos as armaduras devem ser dispostas de maneira que sejam satisfeitas as condições de ancoragem além das estacas periféricas. Pode-se considerar que isto se dá quando a armadura inferior que atravessa a superfície cilíndrica axial sobre a estaca, pode equilibrar uma força igual a 0,8 vez a reação da estaca, nesta avaliação, só as barras totalmente ancoradas além do plano axial da estaca que é perpendicular a elas podem ser consideradas.

B) Blocos sobre duas estacas

A armadura principal deve ser prolongada, sem redução de seção transversal ao longo de todo o comprimento do bloco. Ela deve ser ainda ancorada além do plano vertical do eixo das estacas para uma força de tração igual a 0,8 da força máxima para a qual ela foi calculada. $A$ armadura inferior pode ser disposta em várias camadas e a qualidade da ancoragem pode ser melhorada enlaçando a armadura horizontal além das estacas, conforme a figura 3.20.

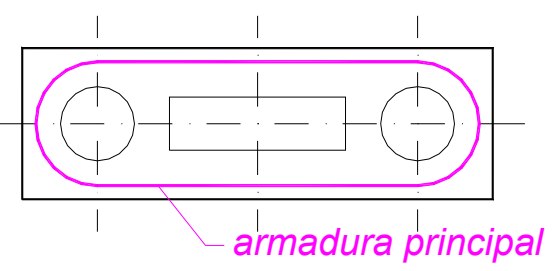

Figura 3.20 - Recomendação para ancoragem da armadura principal em blocos sobre duas estacas (CEB-FIP, 1970) 


\subsubsection{Condição de aderência das barras da armadura principal}

É uma condição que deve ser verificada para não haver escorregamento da armadura, com a força cortante de cálculo relativa à seção de referência $S_{1}$, por unidade de largura, que não deve ultrapassar o valor limite dado pela expressão que segue.

$$
V_{d 1} \leq 0,9 \cdot d \cdot n \cdot \pi \cdot \phi \cdot f_{b d}
$$

onde:

$\mathrm{n}$ : número de barras por unidade de largura;

$\phi$ : diâmetro da barra de aço;

$\mathrm{d}$ : altura útil na seção $\mathrm{S}_{1}$;

$f_{b d}$ : resistência de aderência de cálculo na ancoragem de armaduras passivas, definida pela expressão, conforme NBR 6118:2003:

$$
f_{b d}=\eta_{1} \cdot \eta_{2} \cdot \eta_{3} \cdot f_{c t d}
$$

em que:

$\eta_{1}=1,0$ para barras lisas $(\mathrm{CA}-25)$;

$\eta_{1}=1,4$ para barras entalhadas (CA-60);

$\eta_{1}=2,25$ para barras nervuradas $(C A-50)$;

$\eta_{2}=1,0$ para situações de boa aderência,

$\eta_{2}=0,7$ para situações de má aderência;

$\eta_{3}=1,0$ para $\phi<32 \mathrm{~mm}$;

$\eta_{3}=\frac{132-\phi}{100}$ para $\phi \geq 32 \mathrm{~mm} ;$

onde $\phi$ é o diâmetro da barra.

$$
f_{c t d}=\frac{f_{c t k, i n f}}{\gamma_{c}}, f_{c t k, i n f}=0,7 . f_{c t m} \text { e } f_{c t m}=0,3 \cdot f_{c k}{ }^{2 / 3}
$$

É importante observar que os critérios utilizados são os indicados no Boletim 73 do CEB-FIP (1970), mas decidiu-se atualizar algumas verificações, como neste caso, utilizando a norma brasileira NBR 6118:2003. 


\subsubsection{Resistência à força cortante}

Para verificações da resistência à força cortante, define-se uma seção de referência $S_{2}$ distante da face do pilar de um comprimento igual à metade da altura do bloco, figura 3.21 , e, no caso de blocos sobre estacas vizinhas ao pilar, em que algumas estacas ficam situadas a uma distância da face do pilar inferior a metade da altura útil do bloco, a seção é considerada na própria face. A força de referência $V_{d}$ é igual a componente normal à superfície de apoio da resultante das forças aplicadas sobre uma ou outra das partes do bloco limitadas pela seção de referência $S_{2}$.

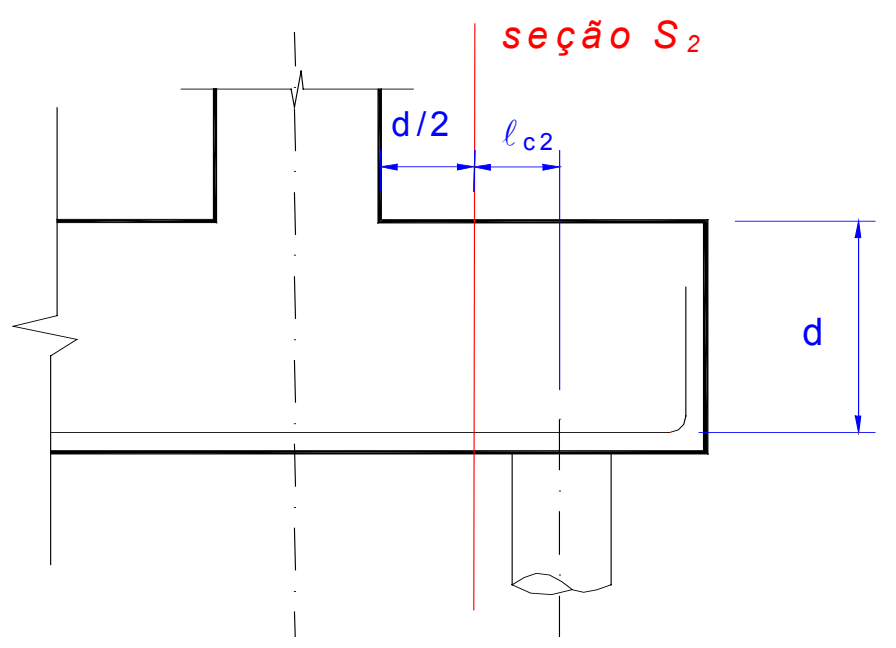

Figura 3.21 - Seção de Referência $S_{2}$

Define-se a largura da seção de referência $S_{2}$ como a soma da dimensão do pilar medida segundo a horizontal e altura útil do bloco, conforme figura 3.22:

$$
b_{2}=b_{p}+d
$$




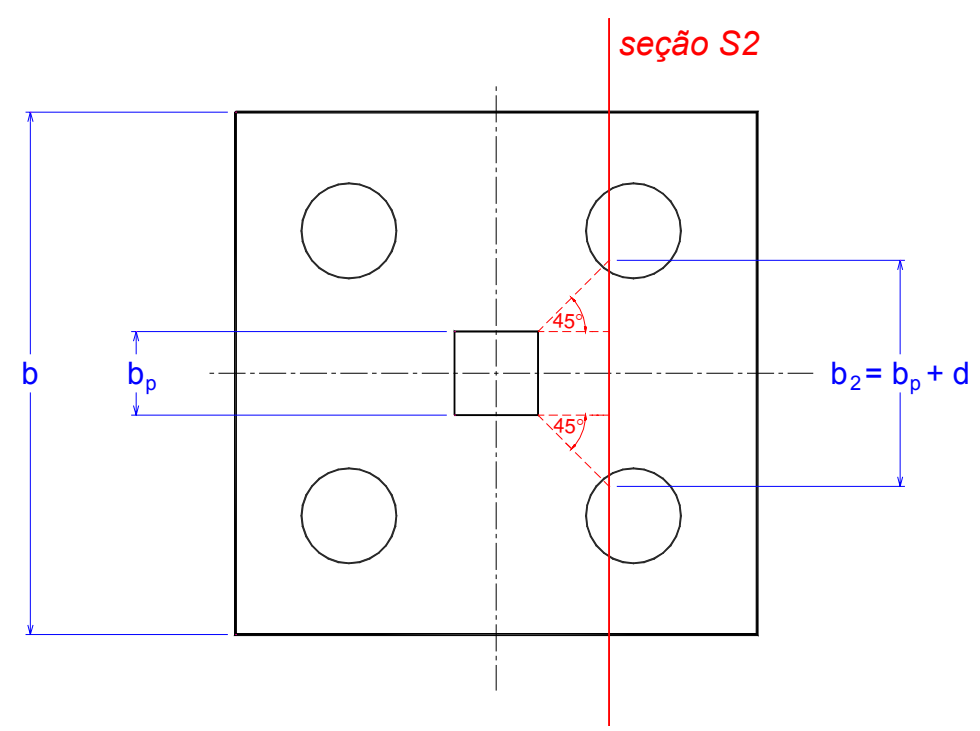

Figura 3.22 - Largura da seção de Referência $S_{2}$

A altura útil $d_{2}$ da seção $S_{2}$ é igual à altura útil do bloco medida na própria seção. Se essa altura $d_{2}$ exceder uma vez e meia a medida da aba $\ell_{\mathrm{c} 2}$ do bloco fica limitada a esse valor:

$$
\mathrm{d}_{2} \leq 1,5 \ell_{\mathrm{c} 2}
$$

A aba $\ell_{\mathrm{c} 2}$ no caso de blocos sobre muitas estacas é medida a partir da seção $\mathrm{S}_{2}$ ao eixo da estaca mais afastada.

A força cortante de referência $V_{d}$, avaliada na seção de referência $S_{2}$, deve ser inferior ou no mínimo igual à força cortante limite dada pela expressão:

$$
V_{\mathrm{d}, \mathrm{lim}}=\frac{0,25}{\gamma_{\mathrm{c}}} \cdot\left(1-\frac{\ell_{\mathrm{c}}}{5 \cdot \mathrm{d}}\right) \cdot \mathrm{b}_{2} \cdot \mathrm{d}_{2} \cdot \sqrt{\mathrm{f}_{\mathrm{ck}}} \quad \text { com } \mathrm{f}_{\mathrm{ck}} \mathrm{em} \mathrm{kN} / \mathrm{cm}^{2}
$$

Onde $\ell_{c}$ é a aba do bloco, medida a partir do eixo da estaca mais afastada da seção de referência $S_{2} ; d$ é altura útil da seção; $d_{2}$ a altura útil da seção $S_{2} ; b_{2}$ é a largura da seção de referência $S_{2}$. 


\subsubsection{Resistência local a força cortante}

A resistência à força cortante deve ser verificada em qualquer seção do bloco onde as condições geométricas da seção e a intensidade ou a localização das reações podem provocar circunstâncias desfavoráveis que aquelas relativas às seções de referências como, por exemplo, na vizinhança das estacas de canto dos blocos, conforme figura 3.23 .

Neste caso, a força cortante que solicita a seção é igual à reação da estaca de canto.

A seção que deve ser objeto de verificação a força cortante fica situada a uma distância da face da estaca igual à metade da altura útil $\mathrm{d}_{1}$ do bloco, medida junto à face da estaca. Sua largura $b_{2}^{\prime}$ é igual a altura útil $d_{1}$ acrescida da largura da estaca e a altura útil $d_{2}^{\prime}$ é a altura efetiva da seção $S_{2}^{\prime}$.

A reação da estaca deve ser no máximo igual a reação limite definida pela expressão:

$$
R_{\mathrm{d}, \mathrm{lim}}=\frac{0,12}{\gamma_{\mathrm{c}}} \cdot \mathrm{b}_{2}^{\prime} \cdot \mathrm{d}_{2}^{\prime} \cdot \sqrt{\mathrm{f}_{\mathrm{ck}}} \quad \quad \text { com } \mathrm{f}_{\mathrm{ck}} \mathrm{em} \mathrm{kN/ \textrm {cm } ^ { 2 }}
$$
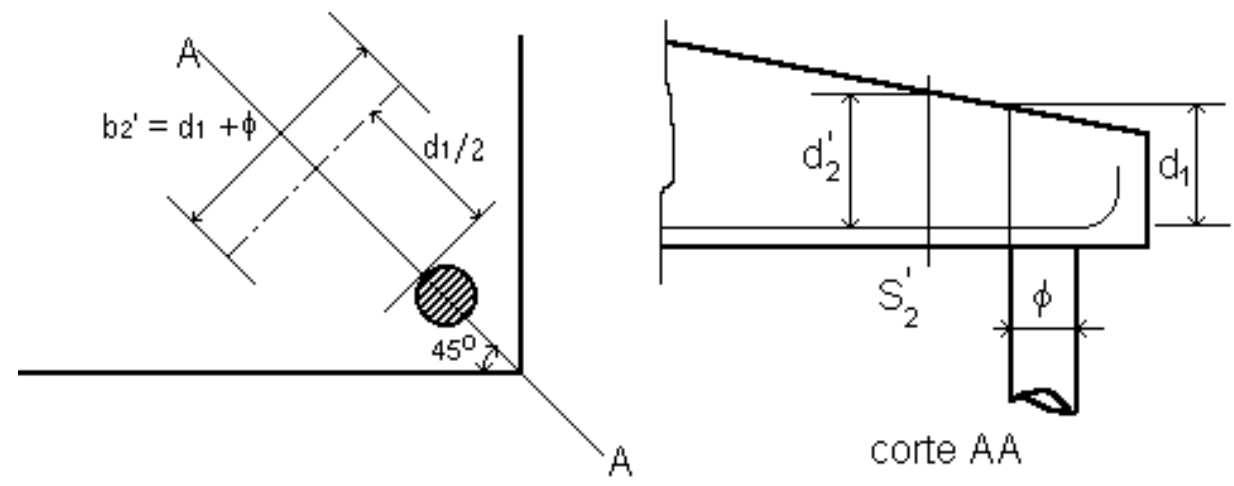

corte AA

Figura 3.23 - Verificação da força cortante em regiões próximas às estacas de canto

\subsubsection{Critérios adotados por Calavera (1991)}

O modelo adotado por Calavera (1991) diverge um pouco quando comparado ao indicado pela Norma Espanhola EHE (2001). A maior diferença é o modelo de cálculo para blocos sobre duas estacas, os blocos com mais de duas estacas 
divergem com relação a uma diferença na consideração da altura das bielas, ou seja, a distância do ponto onde se forma a biela diagonal ao tirante.

Calavera (1991) sugere as especificações da Norma Espanhola EH (1991) para o dimensionamento de blocos rígidos. No caso de blocos sobre duas estacas especifica um cálculo à flexão e a força cortante adotando seções de referência semelhantes às especificadas no Boletim 73 do CEB (1970).

A seção de referência para o cálculo do momento fletor em blocos com duas estacas é definida a uma distância de $0,15 a_{p}$ da face do pilar, sendo $a_{p}$ a dimensão do pilar medida na direção ortogonal à seção de referência. Já para verificação da força cortante, se as estacas estão parcial ou totalmente situadas a uma distância menor que $d / 2$ da face do pilar, a seção de referência é tomada na face do pilar, caso contrário, toma-se uma seção de referência distante $d / 2$ da face do pilar.

Ainda para bloco sobre duas estacas especifica que atendendo às condições para blocos rígidos, vista anteriormente, a transmissão de forças se dá por meio de bielas e tirantes. Mesmo assim, a armadura é dimensionada a partir do momento fletor que solicita a seção correspondente e não por meio da força de equilíbrio no tirante.

Em todos os modelos é considerado pilar de seção quadrada, no qual o centro coincide com o centro geométrico da disposição das estacas.

Para blocos flexíveis o autor sugere dimensionamento semelhante às vigas de concreto armado, porém indica que a verificação a força cortante é feita em uma seção de referência distante $h$ da face do pilar. Deve-se ainda fazer a verificação ao puncionamento.

No caso de blocos sobre três estacas especifica que a condição $\ell \leq 2$,6h deve ser assegurada para que o bloco seja rígido. Deduz-se que para chegar a esse valor ele fez a seguinte consideração:

Recordando à condição para blocos rígidos, $\ell_{\mathrm{c}} \leq 1,5 \mathrm{~h}$, tomando o valor:

$$
\ell_{\mathrm{c}}=\frac{\ell \sqrt{3}}{3} \text { e substituindo na expressão tem se que } \ell \leq 2,6 \mathrm{~h}
$$

Observa-se que, para blocos sobre duas estacas a distância $\ell_{c}$ era considerada do eixo da estaca à face do pilar, e agora se considerou uma distância do eixo da estaca ao eixo do pilar.

Calavera (1991) adota para o dimensionamento da armadura principal uma treliça semelhante à sugerida por Blévot (1967), porém a biela de compressão tem 
início em um ponto $A$, situado a uma distância de $7 / 8 d$, medida na vertical tomando como referência o eixo do tirante, $0,15 a_{p}$ a partir da face do pilar, medida na horizontal. Esses detalhes são mostrados na figura 3.24.
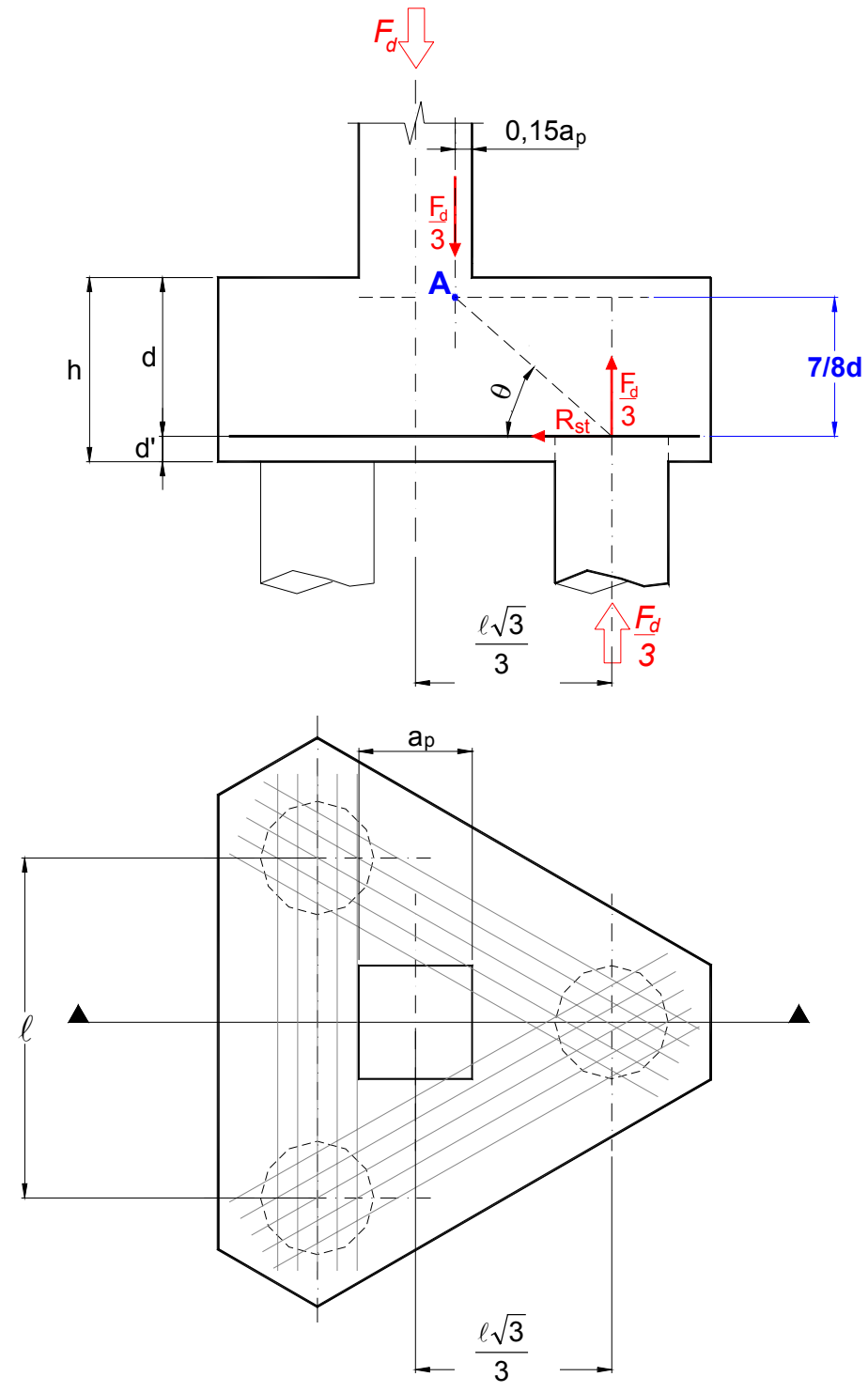

Figura 3.24 - Modelo de cálculo para blocos sobre três estacas sugerido por Calavera (1991).

A força no tirante é calculada considerando o equilíbrio dos momentos e forças internas em relação ao ponto $A$, deduzindo-se à expressão 3.50 .

$$
\mathrm{R}_{\mathrm{st}}=\frac{8 \mathrm{~F}_{\mathrm{d}}}{21 \mathrm{~d}}\left(\frac{\ell \sqrt{3}}{3}-0,35 \mathrm{a}_{\mathrm{p}}\right)
$$


Como se distribui as barras da armadura sobre as estacas, paralelas aos lados do bloco a área deve ser calculada com a força $\mathrm{R}_{\mathrm{st}}$ :

$$
\mathrm{R}_{\mathrm{st}}^{\prime}=\frac{8 \sqrt{3} \mathrm{~F}_{\mathrm{d}}}{63 \mathrm{~d}}\left(\frac{\ell \sqrt{3}}{3}-0,35 \mathrm{a}_{\mathrm{p}}\right)
$$

A verificação da força é feita em uma seção de referência situada a $d_{1} / 2$ da face da estaca, conforme a figura 3.25. Essa seção tem largura igual a soma do diâmetro da estaca com a altura $d_{1}$, sendo $d_{1}$ a altura da seção considerada.

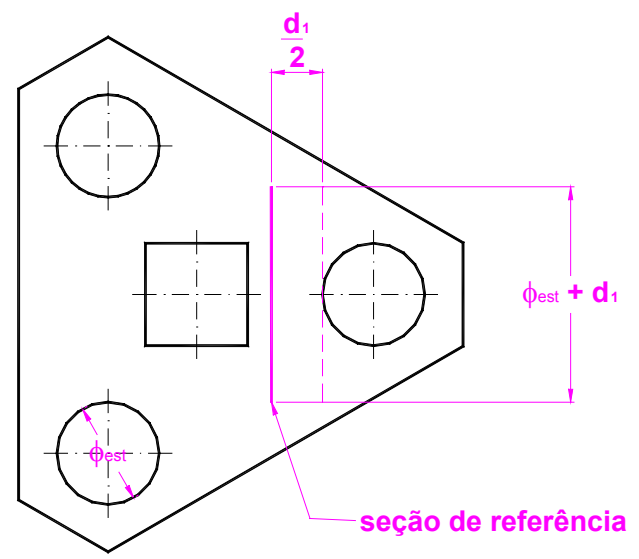

Figura 3.25 - Seção de referência para verificação à força cortante (Calavera, 1991)

Para blocos sobre quatro estacas a área de armadura do tirante é calculada conforme a configuração apresentada na figura 3.26. As barras são distribuídas conforme os lados do bloco e calculadas por meio da força $R_{\text {st, }}$ que para este caso é especificada pela expressão 3.52 .

$$
\mathrm{R}_{\mathrm{st}}=\frac{2 \mathrm{~F}_{\mathrm{d}}}{7 \mathrm{~d}}\left(\frac{\ell}{2}-0,35 \mathrm{a}_{\mathrm{p}}\right)
$$

Para a verificação da força cortante deve-se adotar o mesmo critério usado para blocos sobre três estacas. 


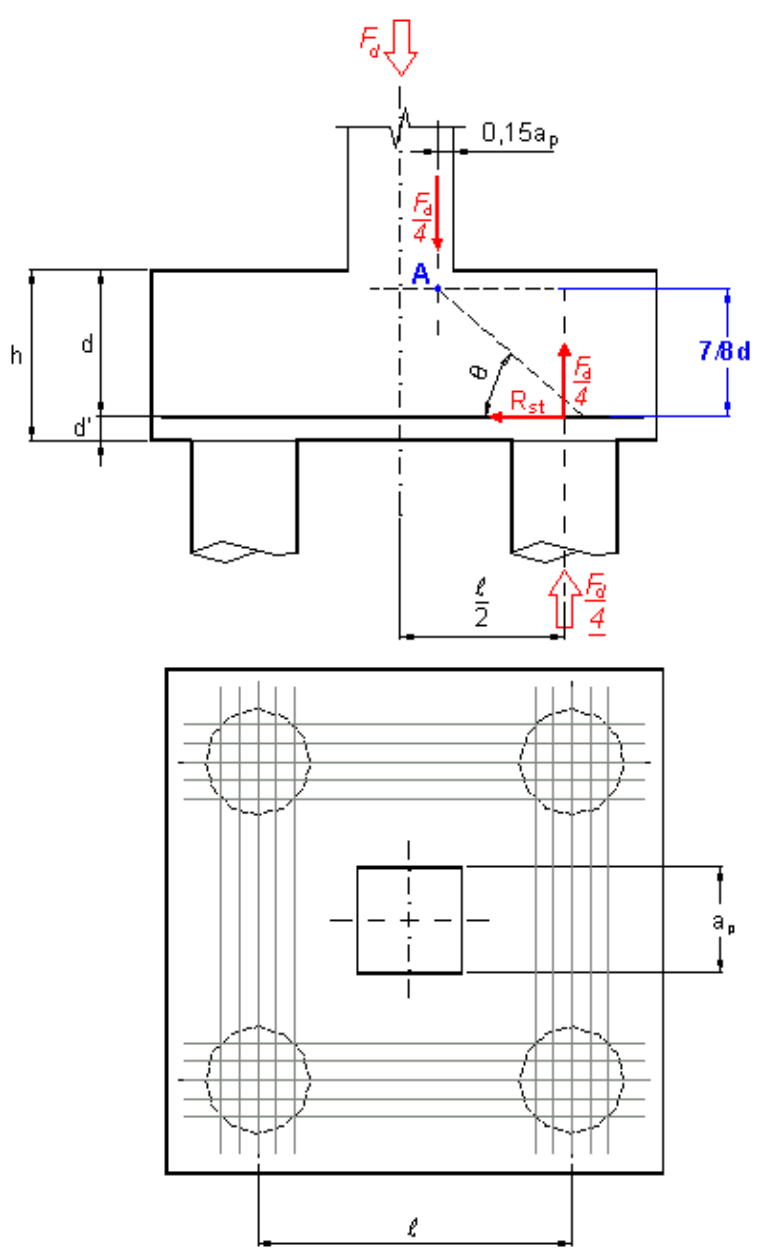

Figura 3.26 - Modelo de cálculo para blocos sobre quatro estacas sugerido por Calavera (1991)

\subsubsection{Critérios adotados por Montoya (2000)}

Montoya (2000) adota as especificações da Norma Espanhola EHE (2001) que indica que a área de armadura necessária para blocos rígidos sobre estacas é determinada a partir das forças de tração atuantes nos tirantes do modelo adotado para cada bloco.

A diferença básica entre os critérios adotados por Montoya (2000) e Blévot (1967) está na adoção da altura da treliça, já que, Montoya adota a altura de 0,85d e Blévot considera a altura $d$. A altura $z=0,85 d$ pode ser entendida como o braço de alavanca, ou seja, a distância entre o centro do banzo comprimido e o tracionado.

Para os casos mais freqüentes de blocos sobre estaca a norma indica as expressões que permitem determinar a área das barras de armadura.

A verificação da resistência do concreto nos nós do modelo, em geral, não é necessária, ou seja, se as estacas são executadas "in loco" e se a resistência 
característica do concreto destas e do pilar forem iguais a do bloco. Nos outros casos devem se realizar verificações. Por outro lado, a verificação dos nós está implícita na verificação das bielas.

Para os blocos sobre duas estacas a área de armadura é calculada conforme a expressão 3.52 e o modelo utilizado é mostrado na figura 3.27.

$$
R_{s t}=\frac{F_{d}}{2} \cdot \frac{\left(\ell_{c}+0,25 a_{p}\right)}{0,85 d}=A_{s} \cdot f_{y d}
$$

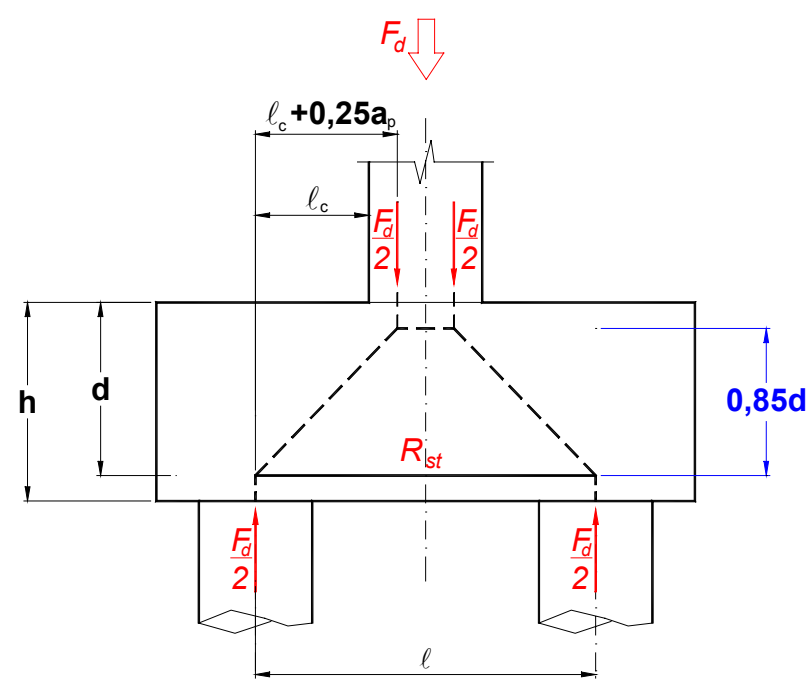

Figura 3.27 - Modelo de cálculo para blocos sobre duas estacas (EHE, 2001)

No caso de blocos sobre várias estacas a norma define que as barras da armadura principal devem ser distribuídas em faixas sobre as estacas, na região em que o eixo une os centros das estacas. A largura dessa faixa é definida pelo diâmetro da estaca somado a duas vezes a distância da face da estaca ao centro de gravidade da armadura do tirante. Além disso, é definida uma armadura secundária distribuída nos espaços restantes.

Para blocos sobre três estacas é definida a expressão da força $R_{s t}$ 'para o cálculo da armadura segundo os lados do bloco, conforme a figura 3.28:

$$
R^{\prime}{ }_{s t}=\frac{0,68 F_{d}}{3 d}\left(0,58 \ell-0,25 a_{p}\right)=A_{s} f_{y d}
$$




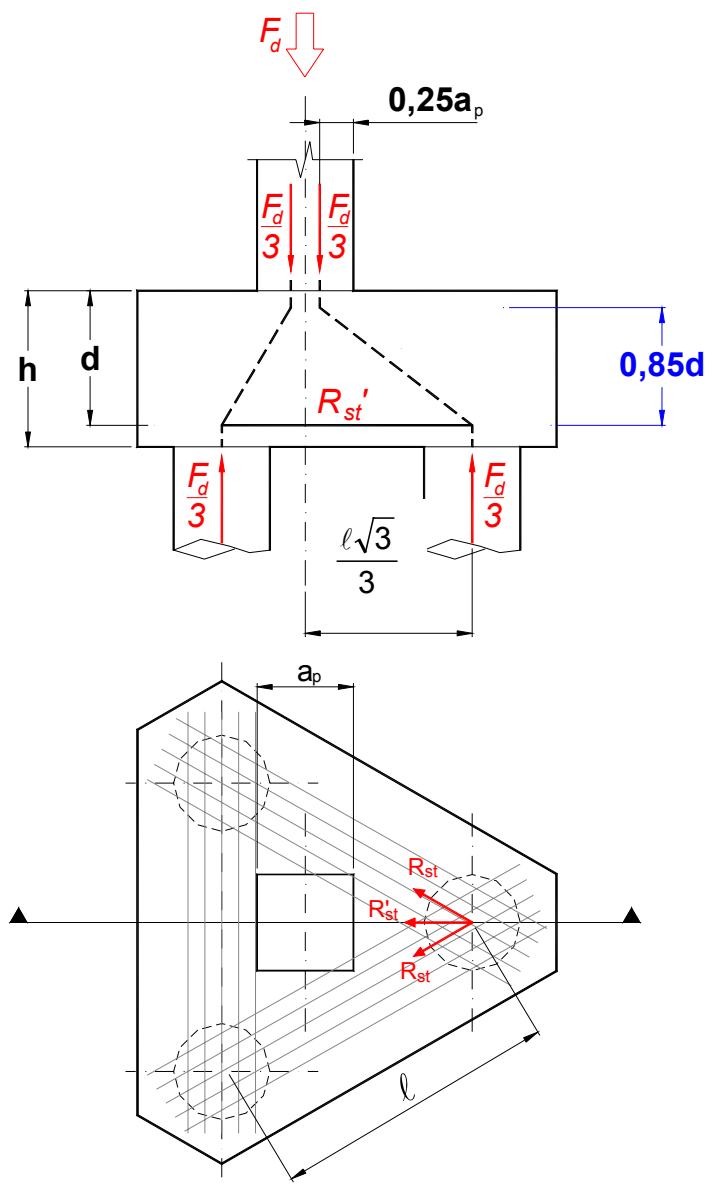

Figura 3.28 - Modelo de cálculo para blocos sobre três estacas (EHE, 2001).

No caso de blocos sobre quatro estacas a EHE (2001) define a força no tirante para cada direção. A distância da face do pilar ao ponto de aplicação da força também é considerada de $0,25 \mathrm{a}_{\mathrm{p}}$ e a altura das bielas inclinadas é igual a 0,85d.

As expressões 3.55 e 3.56 definem os cálculos das áreas das barras das armaduras dos tirantes:

$$
\begin{aligned}
& R_{s t x}=\frac{F_{d}}{4} \cdot \frac{\left(0,50 \ell_{x}-0,25 a_{p}\right)}{0,85 d}=A_{s} f_{y d} \\
& R_{s t y}=\frac{F_{d}}{4} \cdot \frac{\left(0,50 \ell_{y}-0,25 b_{p}\right)}{0,85 d}=A_{s} f_{y d}
\end{aligned}
$$

As direções das forças $R_{\text {stx }}$ e $R_{\text {sty }}$ são consideradas conforme a figura 3.29. 


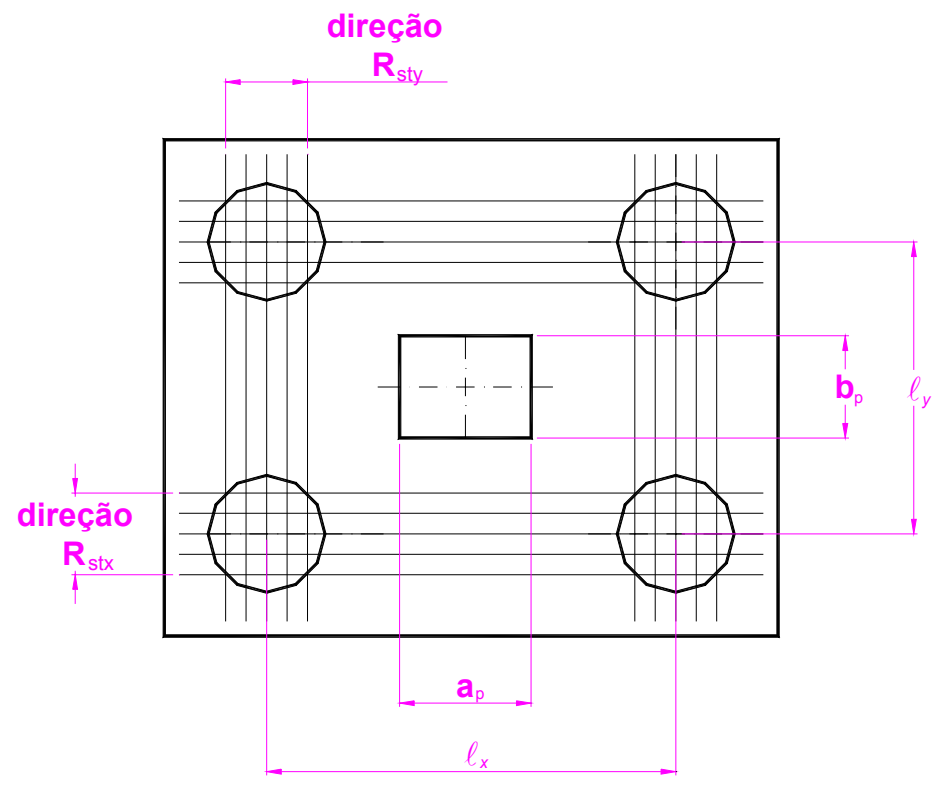

Figura 3.29 - Disposição de armadura em blocos sobre quatro estacas (EHE, 2001)

\subsubsection{Critérios adotados pelo $\mathrm{ACl}$ (1994)}

O código americano ACl-318 (1994) adota hipóteses bem simplificadas para o dimensionamento de blocos.

Admite os blocos sobre estacas como um elemento semelhante a uma viga apoiada sobre estacas. Os procedimentos para o dimensionamento sugerido são verificações pertinentes a momento fletor e à força cortante em seções críticas. $O$ momento fletor máximo é o que atua em um plano perpendicular ao bloco e localizado na face do pilar. A quantidade de armadura longitudinal é determinada pelos procedimentos usuais às vigas de concreto armado. $O$ código indica como essa armadura deve ser distribuída. Recomenda-se o valor de $30 \mathrm{~cm}$ para altura mínima de blocos sobre estacas.

A verificação à força cortante em blocos sobre estacas, segundo o código americano, deve ser feita em uma seção crítica que é medida a partir da face do pilar, com a localização definida conforme o comportamento do bloco; ou seja, quando ocorre comportamento de viga, o bloco é considerado uma viga extensa e a seção crítica é definida por um plano que dista $d$ da face do pilar, sendo $d$ a altura útil do bloco. Quando ocorre comportamento por "dois caminhos" cisalhantes, a ruína se dá em forma de um cone, e, a superfície crítica é definida a partir de $d / 2$ do perímetro do pilar. 


\subsubsection{Critérios para blocos sobre 1 estaca}

Este tipo de bloco também chamado de bloco de transição tem a função de um elemento de ligação entre o pilar e o elemento de fundação, que pode ser uma estaca ou um tubulão.

Em obras de pequeno porte, onde as intensidades das ações são pequenas e se utilizam estacas de diâmetro pequeno, os projetistas, na maioria dos casos, consideram que a transmissão de força é direta, quando estacas e pilares têm seções transversais com dimensões semelhantes, concluem que não é necessário calcular a armadura. Adotam-se hipóteses bem simplificadas:

- altura do bloco deve ter ordem de grandeza de 1,1 vez o diâmetro da estaca e no mínimo igual ao comprimento de ancoragem das barras de armadura dos pilares;

- adota-se uma armadura construtiva constituída por estribos verticais e horizontais.

O tratamento de blocos sobre uma estaca de maiores diâmetros e conseqüentemente carregamentos maiores é levado com maior cuidado e são tratados como blocos parcialmente carregados.

Nos blocos sobre uma estaca as tensões de compressão atuantes no pilar são transmitidas até o topo da estaca por meio da altura do bloco, em trajetórias curvas, como mostrado na figura 3.30. Na direção transversal ocorrem tensões de tração que podem causar o fendilhamento, portanto, mesmo em blocos com dimensões e forças atuantes pequenas essas tensões devem ser verificadas.

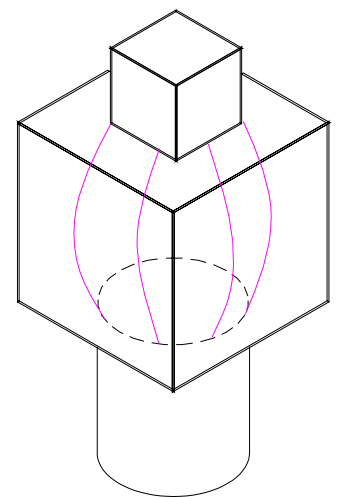

Figura 3.30 - Trajetória de Tensões Principais de Compressão

As trajetórias e campos de tensões foram verificados em modelos de blocos sobre uma estaca como pode ser visto no capítulo 5. 
Langendonck (1957) e Fusco (1995) estudaram o comportamento de blocos parcialmente carregados e concluíram que em virtude de ação em área reduzida ao longo da altura do modelo em um determinado comprimento a distribuição de tensões não é uniforme.

Pelo fato da força ser aplicada em área parcial, o bloco fica sujeito a um estado múltiplo de tensões. Ao longo do eixo da peça, na direção longitudinal, as tensões são de compressão, nas outras duas direções (transversais) as tensões serão de compressão apenas nas proximidades da face de carregamento e de tração no restante do comprimento de perturbação. As tensões de compressão serão resistidas por bielas de compressão e, para o equilíbrio das bielas, considera-se armadura transversal, que deve resistir ao fendilhamento causado pelas forças transversais de tração.

Para o cálculo da armadura transversal deve-se determinar a força de tração transversal, que pode causar fendilhamento, por meio do modelo simplificado sugerido por Langendonck (1957), mostrado na figura 3.31.

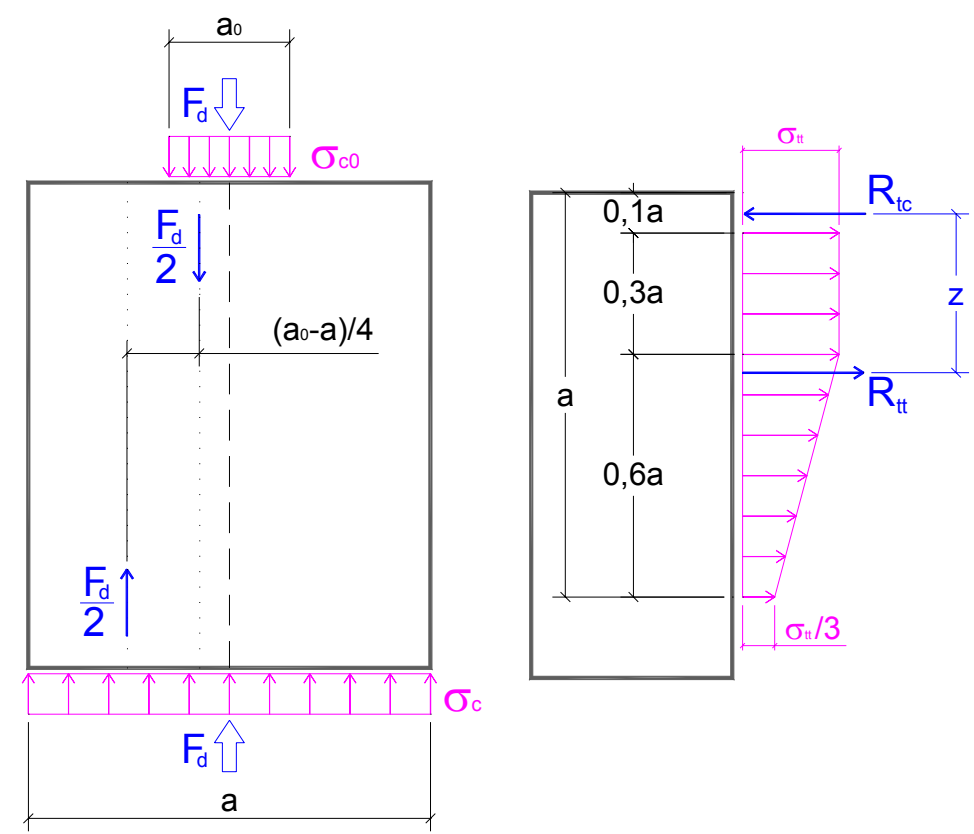

Figura 3.31 - Modelo para determinação de força transversal de tração $\left(R_{t t}\right)$ proposto por Langendonck (1957)

O equacionamento para determinação da força $R_{\mathrm{tt}}$ é feito partindo do equilíbrio dos momentos no modelo: 


$$
\frac{F_{d}}{2} \cdot \frac{\left(a-a_{0}\right)}{4}=R_{t t} \cdot z
$$

O braço de alavanca ( $z$ ) entre as forças de compressão transversal $\left(R_{t c}\right)$ e a de tração transversal $\left(R_{t t}\right)$ é igual a 0,445a. Substituindo esse valor na expressão 3.57 obtém-se a força $R_{t t t}$ :

$$
\mathrm{R}_{\mathrm{tt}}=0,28\left(1-\frac{\mathrm{a}_{0}}{\mathrm{a}}\right) \mathrm{F}_{\mathrm{d}}
$$

A força $R_{t t}$ determinada na expressão 3.58 deve ser absorvida pela armadura, que é determinada dividindo-se o valor de cálculo de $R_{t t}$ pela resistência de escoamento de cálculo do aço.

Essa expressão 3.58 utilizada para blocos parcialmente carregados pode ser adaptada para blocos sobre uma estaca, conforme definido nas expressões 3.59 e 3.60.

$$
\begin{aligned}
& \mathrm{R}_{\mathrm{ttdx}}=0,28 \frac{\left(\phi_{\text {est }}-a_{\mathrm{p}}\right)}{\phi_{\text {est }}} \mathrm{F}_{\mathrm{d}} \\
& \mathrm{R}_{\mathrm{ttdy}}=0,28 \frac{\left(\phi_{\text {est }}-\mathrm{b}_{\mathrm{p}}\right)}{\phi_{\text {est }}} \mathrm{F}_{\mathrm{d}}
\end{aligned}
$$

As notações utilizadas na expressão 3.59 e 3.60 estão definidas na figura 3.32 . 

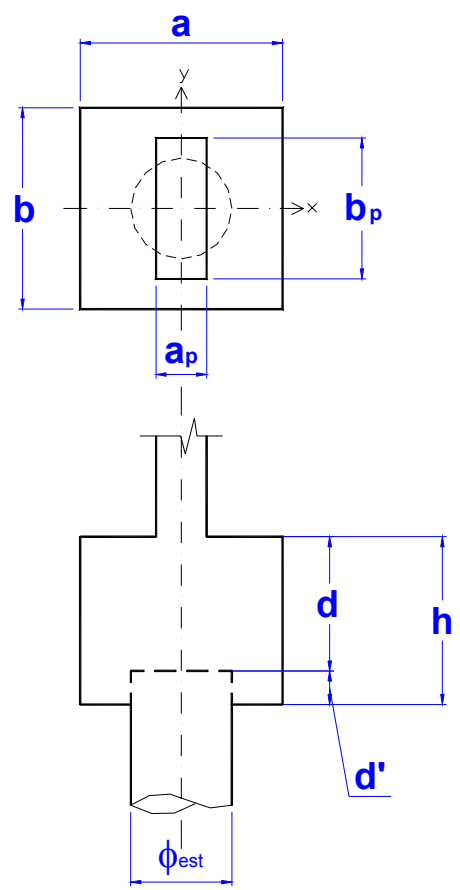

Figura 3.32 - Modelo de bloco sobre 1 estaca

As áreas de armadura são calculadas com as expressões 3.61 e 3.62 . É recomendado que a menor área de armadura, calculada para cada direção, não deve ser inferior a $1 / 5$ da área de maior armadura.

$$
A_{s x}=\frac{R_{t t d x}}{f y d} \text { e } A_{s y}=\frac{R_{t t d y}}{\text { fyd }}
$$

Uma outra verificação que deve ser feita, em blocos parcialmente carregados, é a pressão de contato em área reduzida. Segundo a NBR 6118:2003 quando uma força atuar em área menor do que a da superfície do elemento estrutural, pode-se considerar aumentada a resistência do concreto não ultrapassando o valor resistente de cálculo correspondente ao esmagamento, dado pela expressão 3.63.

$$
F_{R D}=A_{c 0} \cdot f_{c d} \cdot \sqrt{\frac{A_{c 1}}{A_{c 0}}} \leq 3,3 \cdot f_{c d} \cdot A_{c 0}
$$

em que:

$A_{c 0}$ : área reduzida carregada uniformemente;

$A_{c 1}$ : área máxima de mesmo centro de gravidade de $A_{c 0}$. 
Voltando a questão dos blocos parcialmente carregados, uma importante constatação foi feita por Fusco (1994) apud Schafer e Schlaich (1988), que se refere ao caso elementar de blocos parcialmente carregados adaptando-os ao modelo de Bielas e Tirantes, como é mostrado na figura 3.33.

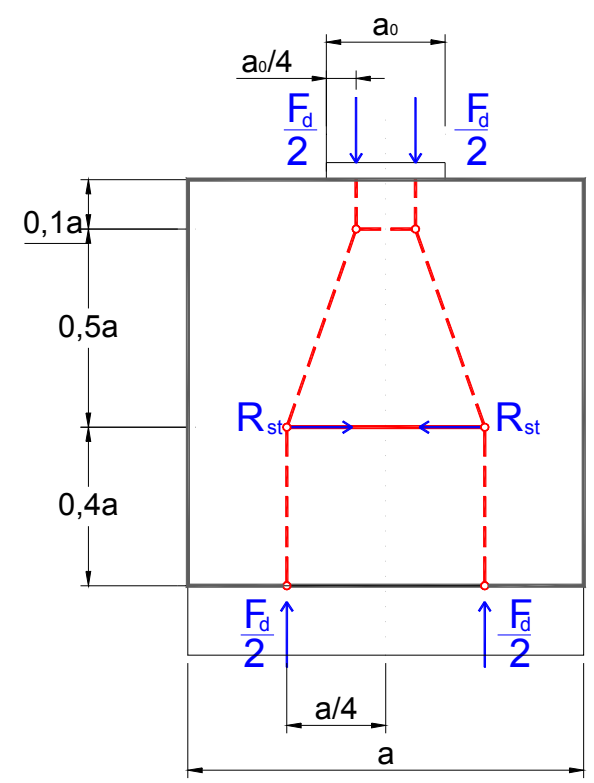

Figura 3.33 - Modelo de bloco parcialmente carregado adaptado para Modelo de Bielas e Tirantes 


\section{MODELO DE BIELAS E TIRANTES}

\subsection{Considerações Iniciais}

A idéia do modelo de bielas e tirantes teve início na analogia de treliça introduzida há aproximadamente 100 anos por Ritter e Mörsch. O método faz a analogia entre a viga de concreto armado fissurada e a uma treliça de banzos paralelos. Após várias décadas de estudos foram sugeridos modificações e aperfeiçoamentos ao modelo proposto, porém, a hipótese básica continua válida. $\mathrm{O}$ método é conhecido também com o nome Escoras e Tirantes; a diferença entre escoras e bielas é que as bielas são inclinadas e as escoras são inclinadas ou não em relação aos tirantes.

$\mathrm{Na}$ concepção de um projeto estrutural em concreto armado, é apropriado classificar regiões da estrutura em regiões contínuas e descontínuas. As contínuas, denominadas B, são regiões da estrutura onde são válidas as hipóteses de Bernoulli, ou seja, há uma variação linear na tensão atuante na seção transversal. Nas descontínuas, regiões $\mathbf{D}$, a distribuição de tensões é não-linear, há uma variação complexa de tensão, elas são produzidas por descontinuidades estáticas (forças concentradas e reações) e geométricas (mudanças abruptas na geometria).

Tjhin e Kuchma (2002) citam que a maior parte dos problemas em estruturas de concreto armado ocorre em regiões $\mathrm{D}$. Isso acontece, pois, ainda hoje, os tipos mais familiares de regiões $\mathrm{D}$, como por exemplo, vigas paredes, consolos, nós de pórticos e blocos sobre estacas são projetados por meio de aproximações com base em análise experimental ou em considerações consagradas pela prática da engenharia. Para maior parte de outros tipos de regiões $D$, as normas fornecem pequenas orientações para projetos. 
O método de Blévot (1967) utilizado como rotina para cálculo de blocos sobre estacas, apesar de ser chamado de Método das Bielas, é um pouco diverso do modelo de biela e tirante. Isso porque o método de Blévot, não define as regiões nodais e as tensões que nelas devem ser verificadas, ou seja, faz uma verificação apenas da tensão de compressão nas bielas, e não nas regiões nodais, como sugere o modelo de bielas e tirantes. Além disso, não define dimensão de bielas e tirantes, portanto, está mais próximo de um modelo de treliça, ao invés de um modelo de biela e tirante.

\subsection{Fundamentos do Modelo}

O modelo de bielas e tirantes é uma representação discreta de campos de tensões nos elementos estruturais de concreto armado. É idealizado o fluxo de forças internas nas regiões sob a consideração de uma treliça que leva as ações impostas no contorno para seus apoios. Esta treliça é composta por uma estrutura de barras comprimidas e tracionadas interconectadas por nós.

As bielas são idealizações dos campos de tensão de compressão, são simbolizadas normalmente usando uma linha tracejada. Os tirantes são campos de tensão de tração, que normalmente são absorvidas pela armadura; em alguns casos podem ser absorvidas pelo concreto, em locais onde não se posicionam barras de armadura, são supostos tirantes de concreto. Os tirantes são representados por linhas contínuas. Na figura 4.1 pode-se observar alguns exemplos de regiões modeladas com bielas e tirantes.
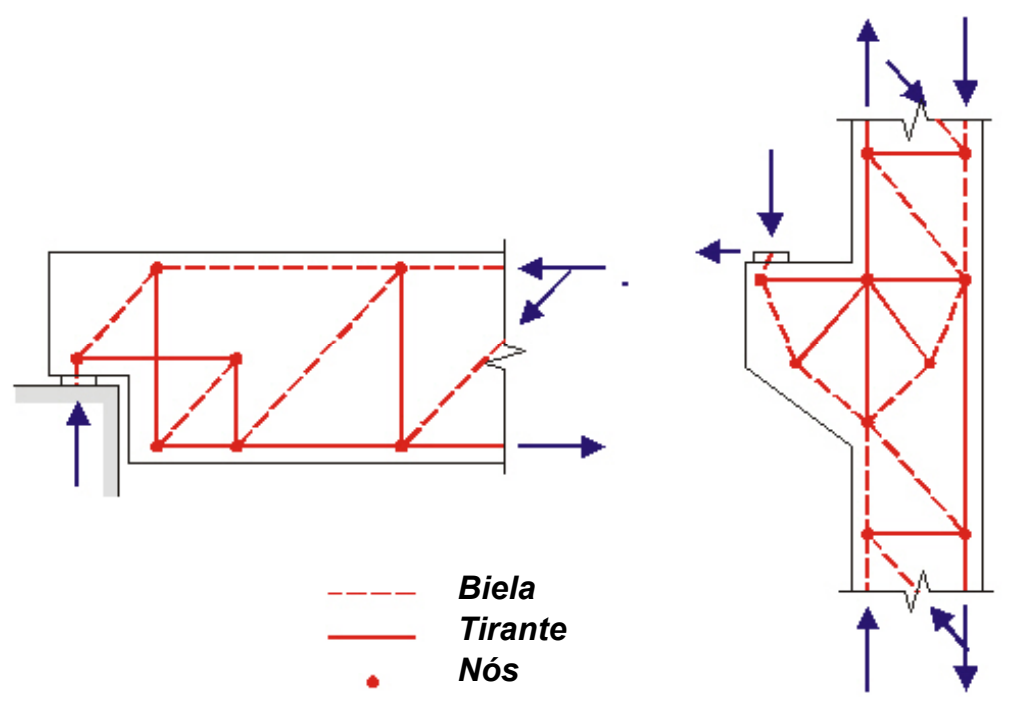

Figura 4.1 - Modelos de bielas e tirantes (Tjhin e Kuchma, 2002) 
Os nós são análogos às articulações de uma treliça, são regiões onde são transferidas forças entre bielas e tirantes. Como resultado, estas regiões estão sujeitas a um estado de tensão multidirectional. São classificados pelos tipos de forças que recebem.

Conhecido o modelo adequado para determinada região da estrutura, as forças nas bielas e tirantes são calculadas por meio do equilíbrio das forças internas e externas. O dimensionamento dos tirantes e a verificação das bielas e nós são feitos de modo a absorver as forças atuantes.

Silva e Giongo (2000), semelhante a outros autores, descrevem que o modelo de bielas e tirantes pode ser adotado considerando o fluxo de tensões na estrutura, usando o processo do caminho de carga. Dispondo-se das tensões elásticas e suas direções principais, obtidas por meio de análise elástica linear, o desenvolvimento do modelo é imediato. Esta análise pode ser feita utilizando métodos numéricos, como por exemplo, o método dos elementos finitos.

Tjhin e Kuchma (2002) concluem que as trajetórias de tensões principais obtidas de uma solução elástica linear satisfazem os estados limites de serviço e últimos, mas advertem ser uma aproximação.

O uso de trajetórias de tensão principais para guiar a construção de modelos de biela e tirante também foi estendido à geração automática de modelos. Um exemplo disto pode ser visto no trabalho de Harisis e Fardis (1991), que usaram uma análise estática de dados de tensão principais obtida de análise linear por elementos finitos para identificar localizações de biela e tirantes.

Longo (2000) utilizou campos e trajetórias de tensões principais em vigas prémoldadas obtidas por meio do Método dos Elementos Finitos, em programa computacional para obter modelos de bielas e tirantes. Observou também, que os campos de tensões principais mostram as regiões de descontinuidade e os lugares geométricos da posição das bielas.

\subsubsection{Aplicação de Modelos de Bielas e Tirantes}

O modelo de bielas e tirantes é uma representação discreta de campos de tensões nos elementos estruturais de concreto armado. É idealizado o fluxo de forças internas nas regiões sob a consideração de uma treliça que leva o carregamento imposto no contorno para seus apoios. Esta treliça é composta por uma estrutura de barras comprimidas (bielas) e tracionadas (tirantes) interconectadas por nós. 
Os modelos de Bielas e Tirantes são fundamentados no Teorema do Limite Inferior da Teoria da Plasticidade. Uma das hipóteses para se aplicar esse teorema é o material exibir comportamento elasto-plástico perfeito, ou seja, para fins de determinação da capacidade limite de carga de uma estrutura, é possível dispensar uma análise evolutiva das tensões e das deformações, admitindo-se, simplificadamente, que o material tenha comportamento elasto-plástico perfeito.

O projeto de regiões, utilizando o modelo de bielas e tirantes, pode oferecer mais do que uma treliça possível representando campos de tensões estaticamente em equilíbrio e plasticamente admissíveis, sendo cada solução garantida pelo Teorema do Limite Inferior (ou teorema estático) da Teoria da Plasticidade (Análise limite).

Machado (1998) apresentou modelos de consolos curtos e muito curtos sem utilizar de maneira formal a Teoria da Plasticidade (Análise Limite), mas baseado em Modelos de Bielas e Tirantes.

Os modelos propostos neste trabalho também não usam de maneira formal esta análise, embora o modelo sugerido seja baseado em um Modelo de Bielas e Tirantes, o qual tem solução garantida pelo Teorema do Limite Inferior.

Como orientação inicial deve-se seguir de perto os contornos e as trajetórias de tensões elásticas na peça, que são obtidas, inicialmente, empregando-se um programa de análise em Elementos Finitos Linear (regime elástico linear, sem a consideração da fissuração).

O Método dos Elementos Finitos pode ser usado em sua versão linear, a mais simplificada, em conjunto com Método das Bielas e Tirantes, fornecendo trajetória das tensões para facilitar a definição dos modelos de treliça, os campos tensões possíveis, ou poderá ser usado na construção efetiva de um modelo para a análise aproximada, desconsiderando a fissuração da peça.

O programa CAST, desenvolvido recentemente, por Tjhin e Kuchma (2002), para projeto de regiões $D$ utiliza contornos de tensão e trajetórias de tensões principais obtidas de uma análise elástica linear para a seleção da treliça do modelo. Schlaich et al. (1987) explicam que este método de orientar o modelo de bielas e tirantes ao longo dos caminhos de forças indicados pela teoria da elasticidade negligencia um pouco a capacidade última de carga que poderia ser utilizada por uma aplicação da teoria de plasticidade. Por outro lado, tem a vantagem principal que o mesmo modelo usado para o estado limite último e de serviço. Se por alguma razão o propósito da análise é achar a força última, o modelo pode ser adaptado facilmente a esta fase de carregamento trocando suas bielas e tirantes para obter um valor 
maior e mais real da resistência da estrutura. Neste caso, porém, a capacidade de rotação não elástica do modelo tem que ser considerada.

\subsection{Projeto considerando o Modelo de Bielas e Tirantes}

A rotina de projeto para modelos de bielas e tirantes pode ser dividida em vários passos, conforme definido a seguir:

\section{I) Definição dos limites das regiões $D$}

Por meio da divisão da estrutura em regiões B e D pode-se aplicar o modelo de biela e tirante.

A subdivisão da estrutura pode ser feita considerando as trajetórias de tensão nas proximidades das regiões descontínuas. Baseado no princípio de Saint Venant, a extensão de uma região $D$ tem aproximadamente a mesma dimensão da altura das regiões $B$ adjacentes, contada a partir da descontinuidade (geométrica ou estática). Exemplos de regiões B e D são ilustradas na figura 4.2.

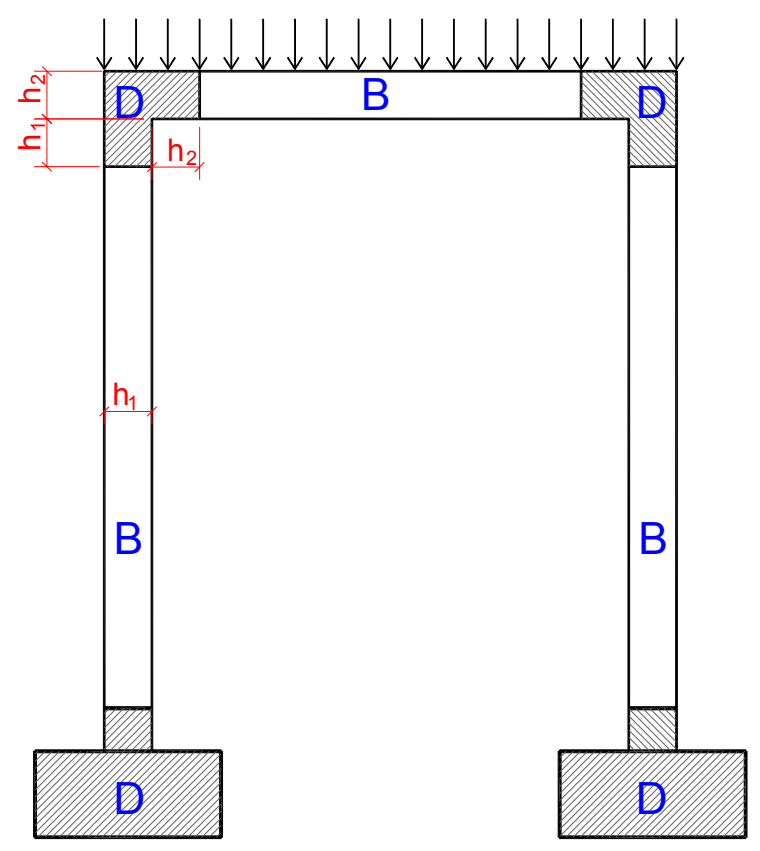

Figura 4.2 - Exemplos de Regiões B e D 


\section{II) Análise Estrutural}

Após a divisão da estrutura em regiões $B$ e $D$ deve-se isolar a região $D$. Para o projeto das regiões $D$, deve-se conhecer os esforços solicitantes no contorno dessas regiões. Esses esforços são obtidos da análise estrutural e do projeto das regiões $B$ adjacentes.

O modelo adotado para a estrutura é função da geometria e das ações atuantes em seu contorno. Estruturas de mesma geometria e ações diferentes são modeladas de maneiras diferentes. Portanto, fica claro que parâmetros geométricos não são suficientes, assim como, o uso de relações como $\ell / h$ na classificação de elementos como consolos e vigas-parede podem ser insuficientes.

Estruturas tridimensionais podem ser subdivididas em planos individuais e tratadas separadamente. Mesmo que, em geral apenas modelos bidimensionais sejam considerados, a interação de modelos em planos diferentes deve ser levada em consideração por meio de condições de contorno apropriadas.

\section{III) Processo do Caminho das Cargas em Blocos sobre Estacas}

Após a verificação do equilíbrio externo e determinação de todos os esforços atuantes no contorno, é possível desenvolver o modelo de bielas e tirantes por meio do fluxo de forças dentro da estrutura pelo processo de caminho de carga.

O caminhamento das forças no interior da estrutura ocorre por meio de campos de tração e compressão que serão representados por bielas e tirantes

O processo do caminho das cargas deve seguir os seguintes passos:

- Forças distribuídas no contorno devem ser substituídas por forças concentradas equivalentes;

- Todos os caminhos de carga devem ser desenhados, alinhados e não podem se interceptar;

- Ações opostas devem ser interligadas por caminhos de carga os mais curtos possíveis;

- Linhas curvas devem ser substituídas por linhas retas, que representam as bielas e tirantes;

- Se necessário, bielas e tirantes devem ser adicionados para equilibrar os nós. 

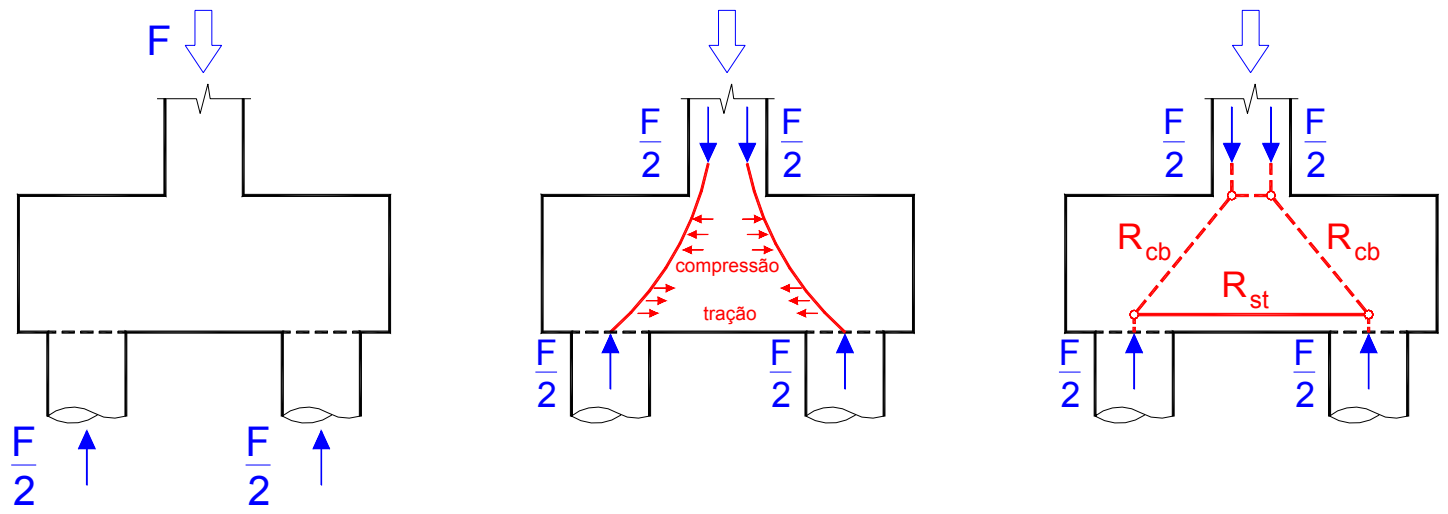

Figura 4.3 - Aplicação do caminho de carga em blocos sobre duas estacas

\section{IV) Escolha do melhor modelo para blocos sobre estacas}

O projeto de regiões, utilizando o modelo de bielas e tirantes, pode oferecer mais do que uma treliça possível para cada caso de força, contanto que a treliça selecionada esteja em equilíbrio e dentro de limites aceitáveis. Mas, segundo Tjhin e Kuchma (2002) em virtude da ductilidade limitada no concreto estrutural, há um número pequeno de soluções viáveis para cada região de projeto.

A orientação que é mais utilizada é fornecida por Schlaich et al. (1987). Baseado no caminho das mínimas forças ou deformações, sugerem selecionar uma treliça na qual os comprimentos de tirantes sejam mais curtos, os tirantes, que normalmente são formados por barras de armadura, são muito mais deformáveis que as bielas de concreto, portanto esse modelo seria melhor.

O caminho das mínimas forças é baseado no Princípio da Energia de Deformação Mínima para comportamento elástico-linear de bielas e tirantes após a fissuração. A contribuição das bielas pode geralmente ser omitida porque as deformações delas são usualmente muito menor do que aquelas dos tirantes.

\section{V) Dimensionamento de bielas}

As bielas são representações discretas de campos de tensão de compressão. Dependendo da forma como as tensões de compressão se distribuem por meio da estrutura, têm-se campos de tensão de compressão diferentes, sendo três configurações típicas como mostrado na figura 4.4 . 


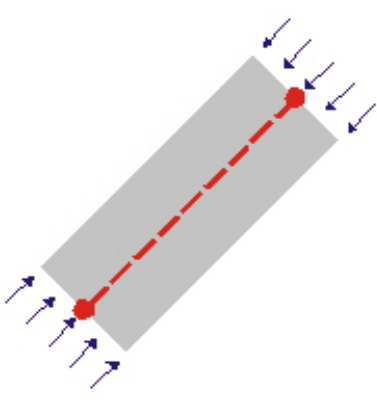

(a)

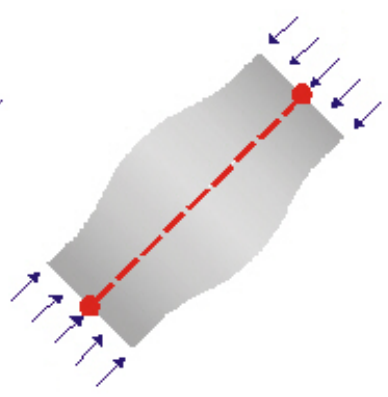

(b)

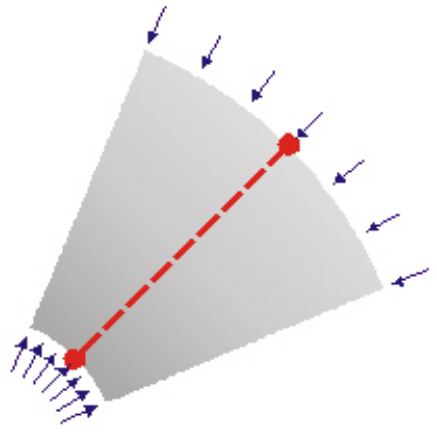

(c)

Figura 4.4 - Configurações típicas de campos de tensão de compressão (Tjhin e Kuchma, 2002)

a) Distribuição paralela de tensões: ocorre quando as tensões se distribuem uniformemente sem perturbação. Este campo é típico de regiões $B$.

b) Distribuição de tensões em linhas curvilíneas com afunilamento da seção: forças concentradas são introduzidas e propagadas por meio de curvaturas acentuadas. A difusão dessas tensões provoca compressão biaxial ou triaxial abaixo da força e trações transversais, que combinada com a compressão longitudinal pode provocar fissuras longitudinais. Como a resistência do concreto à tração é muito baixa, normalmente se dispõem barras de aço na direção transversal.

c) Distribuição radial de tensões: forças concentradas são introduzidas e propagadas de maneira suave. Não se desenvolvem trações transversais.

A resistência à compressão do concreto depende do seu estado multiaxial de tensões e das perturbações causadas pelas fissuras e armaduras.

Schafer e Schlaich (1988) propõem os seguintes valores de resistência para as bielas de compressão:

- $\quad 0,85 \mathrm{f}_{\mathrm{cd}}$ - para um estado de tensão uniaxial e sem perturbação;

- $0,68 f_{c d}$ - para campos de compressão com fissuras paralelas às tensões de compressão;

- $0,51 \mathrm{f}_{\mathrm{cd}}$ - para campos de compressão com fissuras inclinadas. 
Em outro artigo Schlaich e Schafer (1991) propõem que os valores limites de resistência para as bielas de compressão sejam:

- $1,0 f_{c d}$ - para um estado de tensão uniaxial e sem perturbação;

- $0,8 \mathrm{f}_{\mathrm{cd}}$ - para campos de compressão com fissuras paralelas às tensões de compressão;

- $0,6 \mathrm{f}_{\mathrm{cd}}$ - para campos de compressão com fissuras inclinadas.

O FIB (1999) mantém os mesmos valores sugeridos pelo Código Modelo CEB-FIP (1990), ou seja, que a tensão média nas bielas, para valores de $f_{c k}$ em MPa, é calculada pela expressão:

$$
\begin{aligned}
& f_{c d 1}=0,85\left[1-\frac{f_{c k}}{250}\right] f_{c d}, \quad \text { para zonas não fissuradas } \\
& f_{c d 2}=0,60\left[1-\frac{f_{c k}}{250}\right] f_{c d}, \quad \text { para zonas fissuradas }
\end{aligned}
$$

Em zonas fissuradas a resistência do concreto à compressão pode ser reduzida pelo efeito de tração transversal da armadura e pela necessidade de transmitir forças por meio das fissuras.

Os valores de tensão sugeridos são válidos, desde que a deformação de compressão máxima no concreto seja:

$$
\varepsilon_{\text {cu }}=0,004-0,002 \cdot \frac{f_{c k}}{100} \quad\left(f_{c k} \text { em MPa }\right)
$$

\section{VI) Dimensionamento de tirantes}

As forças nos tirantes devem, usualmente, ser absorvidas pela armadura; a reta que contém o centro de gravidade das barras da armadura deve coincidir com o eixo do tirante no modelo. A área de armadura necessária é obtida diretamente por meio da força no tirante e da resistência de escoamento do aço considerando o estado limite último dada por:

$$
A_{s}=\frac{\gamma_{f} \cdot R_{s t}}{f_{y d}}
$$


Em alguns casos surgem tirantes de concreto, pois, o equilíbrio em alguns modelos só pode ser obtido se forças de tração forem consideradas em locais onde não se pode colocar armaduras. Nestes casos deve ser verificada a resistência à tração do concreto. Apesar da dificuldade de se obter um critério de projeto adequado nestes casos, pode-se considerar, simplificadamente, a resistência à tração do concreto para equilíbrio das forças, apenas quando se espera ruptura frágil ou zonas de ruptura local.

\section{VII) Dimensionamento de regiões nodais}

Uma região nodal pode ser definida como um volume de concreto que envolve as intersecções das bielas comprimidas com forças de ancoragem e/ou forças de compressão externa. No modelo de bielas e tirantes os nós são análogos às articulações de uma treliça, e é onde há mudança de direção e são transferidas forças entre bielas e tirantes. Como resultado, estas regiões estão sujeitas a um estado triplo de tensão. Os nós são classificados pelos tipos de forças que neles agem.

Os nós são uma idealização simplificada, no modelo o nó representa uma mudança brusca de direção, enquanto que no elemento estrutural real esta mudança ocorre com certas dimensões, ou seja, comprimento e largura.

Segundo o Código Modelo CEB-FIP (1990) normalmente as tensões de compressão dos nós precisam ser verificadas somente onde forças concentradas são aplicadas à superfície do elemento estrutural. Uma verificação das tensões nos nós dentro da estrutura pode tornar-se necessária no caso de descontinuidades. Um dos fatores que afetam a resistência das regiões nodais são a existência de armadura tracionada e o modo como são distribuída e ancorada, assim como, o tipo de confinamento existente. O Código apresenta quatro exemplos típicos de regiões nodais:

> Nós somente com forças de compressão;

> Nós com ancoragem somente de barras paralelas;

$>$ Nós com barras dobradas;

$>$ Nós com tirantes em direções ortogonais.

Em princípio serão comentados apenas os dois primeiros tipos de regiões nodais, que serão de maior importância para a análise da segurança de blocos sobre estaca. 
Os nós somente com forças de compressão ocorrem sob forças concentradas, acima de apoios intermediários de vigas contínuas em apoios com cabos protendidos ancorados. A região do nó pode ser suposta limitada por um polígono não necessariamente com ângulos retos, e as tensões ao longo da superfície do nó podem ser consideradas distribuídas.

Exemplos de nós somente com força de compressão são mostrados na figura 4.5 .

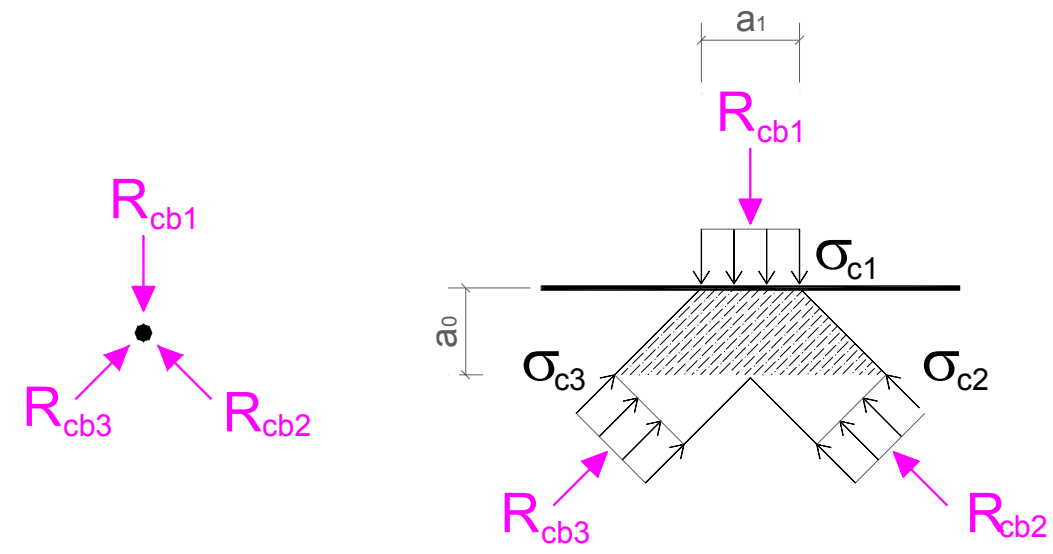

Figura 4.5- Nós somente com força de compressão (CM - CEB-FIP, 1990)

Neste caso deve se verificar a tensão $\sigma_{\mathrm{c} 1}$ :

$$
\sigma_{\mathrm{c} 1}=\frac{\mathrm{R}_{\mathrm{cb} 1}}{\mathrm{a}_{1} \cdot \mathrm{b}}
$$

No caso da altura do nó ser limitado por uma fissura ou pela largura das bielas que o formam, uma tensão $\sigma_{\mathrm{c} 0}$ localizada na direção ortogonal ao apoio também deve ser verificada.

Os nós com ancoragem somente de barras paralelas ocorrem quando um tirante encontra duas ou mais bielas. Alguns exemplos desse tipo de região nodal são apoios extremos de vigas-parede e abaixo de forças concentradas que são aplicadas a consolos. 

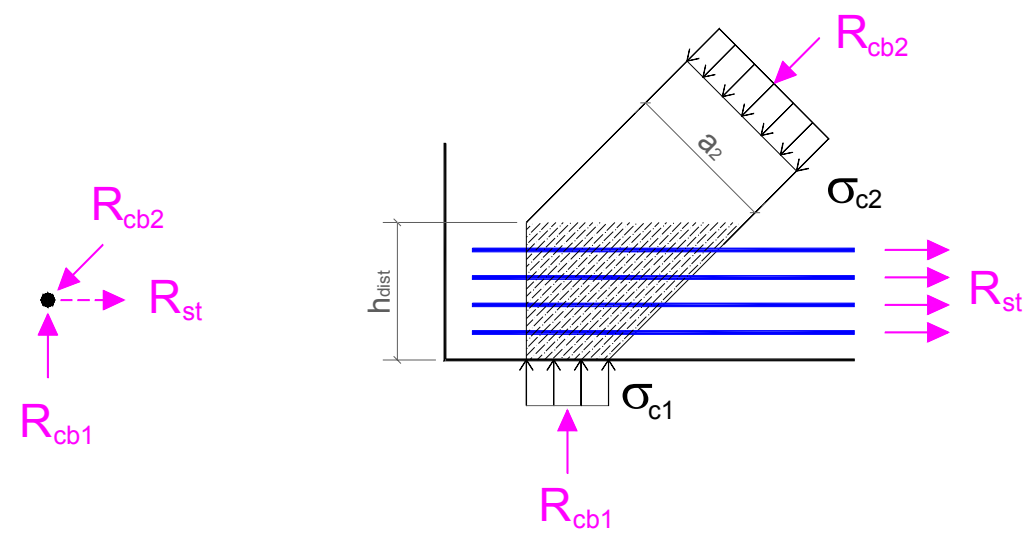

$\mathrm{a}_{1}$

Figura 4.6- Nós somente com ancoragem somente de barras paralelas (CM - CEB-FIP, 1990)

Schlaich e Schafer (1991) indicam algumas expressões para verificação das tensões neste tipo de região nodal:

$$
\sigma_{c 1}=\frac{R_{c b 1}}{a_{1} \cdot b} \quad \text { e } \quad \sigma_{c 2}=\frac{R_{c b 2}}{a_{2} \cdot b}=\frac{R_{c b 1}}{a_{2} \cdot b \cdot \operatorname{sen} \theta}
$$

Sendo, a largura $a_{2}$ definida:

$$
a_{2}=\left(a_{1}+h_{\text {dist }} \cdot \cot g \theta\right) \operatorname{sen} \theta=a_{1}\left(1+\frac{h_{\text {dist }}}{a_{1}} \cot g \theta\right) \operatorname{sen} \theta
$$

Arrumando a expressão de $\sigma_{\mathrm{c} 2}$ :

$$
\sigma_{c 2}=\frac{R_{c b 1}}{a_{1}\left(1+\frac{h_{\text {dist }}}{a_{1}} \operatorname{cotg} \theta\right) \operatorname{sen} \theta \cdot b \cdot \operatorname{sen} \theta} \rightarrow \sigma_{c 2}=\frac{\sigma_{c 1}}{\left(1+\frac{h_{\text {dist }}}{a_{1}} \operatorname{cotg} \theta\right) \operatorname{sen}^{2} \theta}
$$

A altura onde dever ser distribuída as barras de armadura do tirante pode ser calculada com a expressão:

$$
\mathrm{h}_{\text {dist }}=\mathrm{n} \cdot \phi+2 \mathrm{c}+(\mathrm{n}-1) \cdot \mathrm{s}
$$


Em que $\mathbf{n}$ é o número de camadas de armadura, $\phi$ é o diâmetro da armadura e s o espaçamento.

O Código Modelo CEB-FIP (1990) sugere que seja obrigatória a verificação da tensão $\sigma_{\mathrm{c} 2}$ em apoios extremos de vigas parede em que:

$$
\mathrm{h}_{\text {dist }}<\mathrm{a}_{1} \cdot \cot \mathrm{g} \theta
$$

Os limites para as tensões médias de compressão nos contornos dos nós sugeridos por Schafer e Schlaich (1988) são:

- $0,935 \mathrm{f}_{\mathrm{cd}}$ - em nós onde só se encontram bielas comprimidas, criando estado de tensão biaxial ou triaxial.

- $0,68 \mathrm{f}_{\mathrm{cd}}-\mathrm{em}$ nós onde a armadura é ancorada

Schlaich e Schafer (1991) sugerem valores um pouco diversos para os limites de tensões:

- $1,1 \mathrm{f}_{\mathrm{cd}}-\mathrm{em}$ nós onde só se encontram bielas comprimidas, criando estado de tensão biaxial ou triaxial.

- $0,8 \mathrm{f}_{\mathrm{cd}}-\mathrm{em}$ nós onde a armadura é ancorada.

O Código Modelo CEB-FIP (1990) indica como parâmetros de resistência média das regiões nodais os mesmos que os indicados para bielas de compressão, que podem ser aplicados às regiões nodais em estado multiaxial de tensão. Ficando, portanto, definido como limites para as tensões médias em qualquer superfície ou seção de um nó singular, os seguintes parâmetros:

- $\mathrm{f}_{\mathrm{cd} 1}$ - para nós onde só chegam bielas de compressão;

- $\mathrm{f}_{\mathrm{cd} 2}$ - para nós onde barras tracionadas são ancoradas.

A tensão limite $\mathrm{f}_{\mathrm{cd} 1}$ também pode ser aplicada a outros nós se o ângulo entre os tirantes e bielas não for inferior a $55^{\circ}$ e se a armadura for detalhada com cuidado especial na região do nó; isto é disposta em várias camadas com tirantes transversais. 
O FIB (1999) adota os mesmos valores que o Código Modelo CEB-FIP (1990), e além disso, acrescenta um valor intermediário para verificação das tensões nas regiões nodais:

$$
\mathrm{f}_{\mathrm{cd} 3}=0,70\left[1-\frac{\mathrm{f}_{\mathrm{ck}}}{250}\right] \mathrm{f}_{\mathrm{cd}}
$$

$O$ valor de tensão intermediário $\mathrm{f}_{\mathrm{cd} 3}$ é definido para nós com tirantes ancorados apenas em uma direção.

Silva e Giongo (2000) advertem sobre a divergência para valores dos parâmetros de resistência existente, citando que em uma mesma referência podem surgir dúvidas em relação a que valor adotar para cada caso. Os autores recomendam que, na dúvida, se usem os critérios do o Código Modelo do CEB-FIP (1990).

\section{VIII) Detalhamento das armaduras}

Concluídos os passos anteriores definem-se o tipo de ancoragem e os comprimentos das barras das armaduras, fazendo assim, o arranjo das mesmas.

Deve-se dar atenção especial à ancoragem das barras da armadura nas extremidades das regiões nodais. Uma ancoragem adequada contribui na definição da geometria e, conseqüentemente, na resistência das bielas e regiões nodais.

O detalhamento da armadura é importante para limitar a abertura e distribuição de fissuras. A norma canadense CSA-A23.3-94 (1994) sugere que os elementos estruturais ou regiões projetadas pelo modelo de bielas e tirantes devem conter uma malha ortogonal de armadura mínima em cada face. A relação entre a área de armadura e a área de concreto não deve ser menor que 0,002 em cada direção e seu espaçamento não deve ser maior que $30 \mathrm{~cm}$.

Tjhin e Kuchma (2002) também sugerem que uma armadura distribuída deve ser colocada para aumentar a dutilidade da região $D$, mas não explicitam como essa armadura deve ser dimensionada e detalhada.

\subsection{Dificuldades e Desafios em Modelos de Bielas e Tirantes}

Segundo Tjhin e Kuchma (2002) embora o modelo de bielas e tirantes seja conceitualmente simples, numerosas complicações podem dificultar o processo de 
projeto, isso tem motivado muitos pesquisadores para o desenvolvimento de programas computacionais. Os autores descrevem brevemente algumas destas complicações como segue.

a) Seleção de modelos de biela e tirante apropriado:

Como descrita anteriormente a orientação mais usada para escolha de um modelo adequado é a baseada no caminho das mínimas forças ou deformações, proposto por Schlaich et al. (1987). Esta direção é muito útil, mas nem sempre são fáceis de se obter as soluções.

\section{b) Ajuste de geometria da treliça}

A geometria inicial da treliça, inclusive as bielas e as dimensões de nós, deve ser ajustada freqüentemente para satisfazer as tensões limites, ajustar as bielas e nós dentro dos limites da região $\mathrm{D}$, investigar outras configurações, e aperfeiçoar o projeto.

\section{c) Geometria e dimensões de tirantes e nós}

Para determinar as dimensões e forma de um nó, é necessário saber as larguras das bielas e tirantes que chegam nele. Normalmente é selecionada a largura de uma biela particular conforme a norma que esta sendo seguida de maneira que o valor limite de tensão não seja excedido. Está menos claro, porém, como definir a largura efetiva de tirantes, como também, as dimensões e forma de zonas nodais.

d) Modelos de biela e tirante indeterminados estaticamente

Há uma pequena orientação para a avaliação de modelos de biela e tirante estaticamente indeterminados. Como resultado, o projetista fica inseguro na determinação da distribuição de forças nestes tipos de treliça.

O método sugerido por Schlaich e Schafer (1991), é decompor a treliça indeterminada estaticamente em várias treliças determinadas estaticamente. Isso requer, como resultado, as exigências de compatibilidade de tensões e deformações, esta técnica requer uma estimativa razoável da rigidez e a imposição da distribuição de carregamento de cada treliça determinada estaticamente.

e) Casos de combinações de ações

A necessidade para considerar casos de combinações de ações pode aumentar o tempo exigido para completar um projeto no qual se usa o modelo de biela e tirante. Isto porque se deve resolver diferentes modelos para cada situação de 
ações diferentes. Normalmente não podem ser sobrepostos diretamente casos de ações para formar combinações por causa das exigências de compatibilidade de tensões.

Tjhin e Kuchma (2002), além de enumerarem as dificuldades para o projeto de regiões com modelos de bielas e tirantes, enumeram também as incertezas que ainda existem para determinação do modelo, sugerindo assim que estas incertezas devem ser estudadas em pesquisas futuras.

Algumas destas incertezas são descritas a seguir:

\section{a) Capacidade das bielas}

Ainda há muita discussão sobre a força de compressão efetiva de uma biela. Isto é refletido nos valores de força diferentes especificados em Normas. Não obstante, geralmente concorda-se que a força de uma biela é uma fração da força uniaxial do concreto a compressão como obtido do teste de corpo-de-prova cilíndrico. Os seguintes fatores foram identificados como influências à capacidade última de tensão de compressão de bielas:

$a_{1}$. Forma da biela - Se as trajetórias de tensão em uma biela fossem paralelas, a força da biela estaria perto da força de compressão do corpo-de-prova cilíndrico. A forma de distribuição de tensões em linhas curvilíneas com afunilamento da seção, pode conduzir ao fendilhamento de uma biela para uma tensão de compressão que é consideravelmente menor que a resistência do concreto.

$a_{2}$. Perturbações nas bielas - Outros fatores que influenciam a força de fendilhamento de uma biela incluem fissuras iniciais paralelas ou inclinadas ao eixo da biela e tensão transversal elástica ou deformação induzidas por um tirante cruzando ou outro efeito;

$a_{3}$. Armadura distribuída - O uso de armadura distribuída pode controlar o fendilhamento da biela por causa de propagações ou perturbações de tensões. Também pode aumentar a dutilidade estrutural global e assim ajudar a melhorar o desempenho de uma região $D$ projetada com uma treliça que não seja ideal;

$a_{4}$. Confinamento - O desempenho da biela também pode ser melhorado por confinamento fornecido por uma outra armadura ou por meio de uma massa de concreto armado envolvendo a biela; e 
$a_{5}$. Ângulo de biela - é sabido que a força de compressão do concreto decresce tanto quanto a intensidade que se aumenta a tensão elástica transversal. A implicação para modelo de bielas e tirantes é que, como o ângulo entre a biela e o tirante, que está em uma região nodal, decresça, é esperado que a força de compressão da biela decresça. Assim, acredita-se que uma biela mais inclinada seja mais resistente que uma biela horizontal.

Enquanto muitos dos fatores que podem influenciar a força de compressão das bielas de concreto foram identificados, o efeito, destes fatores tem que ainda ser quantificado adequadamente. Isto acontece pela limitação de pesquisas experimentais que foram realizados para entender como definir forma, rigidez, e características de força de bielas.

b) Resposta de carga-deformação de bielas e tirantes

Outro desafio primordial é calcular a resposta de carga-deformação de bielas e tirantes com precisão. Por estas importantes razões explicitadas a seguir:

$b_{1}$. Caso as propriedades de rigidez das bielas e tirantes sejam conhecidas, a distribuição de força em modelos de bielas e tirantes estaticamente indeterminados pode ser prevista. A figura 4.7 mostra um detalhe de apoio, onde é considerado que a força concentrada é transferida ao apoio por meio de dois caminhos de carga distintos:

i) uma biela direta do ponto de carregamento ao apoio; e

ii) um caminho formado por duas bielas mais inclinadas interligadas por um tirante. A quantidade de força levada por cada caminho estará em proporção com a rigidez relativa destes caminhos;

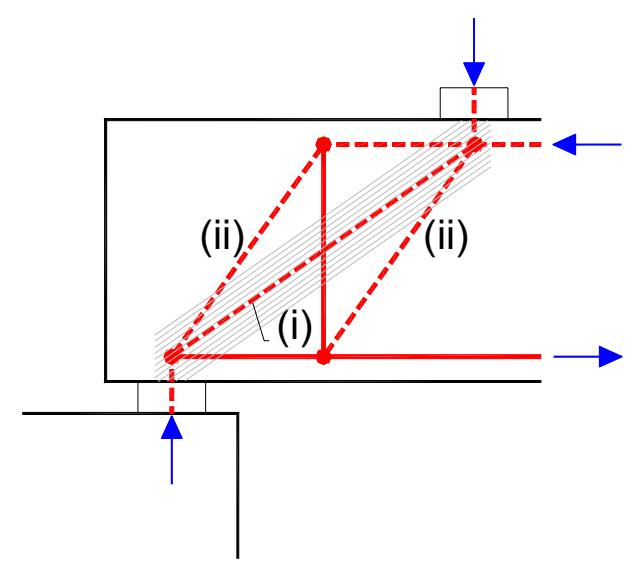

Figura 4.7 - Modelo de biela e tirante estaticamente indeterminado em apoios de vigas parede(Tjhin e Kuchma, 2002). 
$\mathrm{b}_{2}$. Caso as propriedades de rigidez das bielas e tirantes para forças de serviço sejam conhecidas, a resposta de carga-deformação equivalente pode ser prevista para a avaliação de estado de limite de serviço; e

$b_{3}$. Como mostrado na figura 4.7, um tirante pode cruzar o caminho de uma biela. A deformação e a fissuração induzidas nesta situação podem influenciar a força da biela. Examinando esses fatores a capacidade e resposta das bielas podem ser melhor entendidas.

\section{c) Ancoragem e distribuição de armadura de tirante}

No modelo de bielas e tirantes, a armadura do tirante pode desenvolver forças que só são transferidas para os nós se os tirantes são ancorados corretamente nos nós. Ainda há incertezas, porém, sobre as exigências de ancoragem e a necessidade de distribuir a armadura do tirante ao longo da região nodal. A distribuição e ancoragem da armadura do tirante influenciam a capacidade de transferir uma componente horizontal de uma biela diagonal para o tirante ao término de um elemento simplesmente apoiado.

d) Tamanho, forma, e força de zonas nodais complexas

O detalhe de ancoragem pode oferecer complexidades de transferência de força em regiões nodais. Como mencionadas anteriormente, estas regiões podem ter uma variação grande em suas configurações e assim podem ficar bastante difícil entender.

Tjhin e Kuchma (2002) sugerem que, mais pesquisas nesta área são essenciais. Fatores sugeridos para estudar o dimensionamento de zonas nodais podem incluir o tipo de elemento de treliça (biela ou tirante), número de intersecções dos elementos de treliça, distribuição de armadura de tirante, confinamento, e uso de fibras, intensidade de tração transversal, volume e condição de concreto adjacente, e condições de ancoragem de tirantes. Para obter simplicidade no modelo de bielas e tirantes, estes estudos deveriam enfocar a determinação da forma de zonas nodais nas quais se encontram bielas e tirantes.

\section{e) Estado limite de serviço}

É reconhecido que o projeto de concreto estrutural deveria considerar ambos o estado limites, o último e o de serviço. Até agora, foi enfocado o desenvolvimento de modelos de bielas e tirantes no estado limite último; o estado limite de serviço é implícito na consideração da seleção de modelos apropriados de bielas e tirantes. A 
avaliação de deslocamentos para cargas de serviço pelo modelo requer a seleção do modelo de bielas e tirantes configurado a estimativa de rigidez dos elementos que dão resposta equivalente, para o deslocamento real estrutura. A avaliação de larguras de fissuras para cargas de serviço requer estimativa razoável da área de concreto efetiva ao redor dos tirantes da armadura. 


\section{ANÁLISE DE BLOCOS SOBRE ESTACAS}

\subsection{Considerações Iniciais}

A rotina de projeto de blocos sobre estacas utilizada pelo meio técnico é a adaptada do trabalho de Blévot (1967). Outro procedimento que tem sido utilizado por alguns projetistas de estruturas de concreto é o processo sugerido pelo CEB (1970) publicado no Boletim de Informação 73. Esses dois métodos baseiam-se em hipóteses um pouco diferentes uma da outra, pois, o primeiro adota modelo de treliça e verifica tensões de compressão considerando as áreas do pilar e das estacas projetadas na direção perpendicular ao eixo da biela; o segundo indica verificações de segurança para tensões normais e tangenciais com esforços solicitantes determinados em seções transversais particulares.

A norma espanhola EHE (2001) adota um modelo semelhante ao proposto por Blévot (1967), mas com a geometria da treliça um pouco diferente, ou seja, altura menor, o que conduz a forças maiores nos tirantes, e conseqüentemente, áreas de barras de armaduras maiores. Para os casos mais comuns não recomenda verificações de tensões de compressão. Outros autores como Calavera (1991) e Montoya (2000) também não sugerem verificações de tensões.

Neste trabalho modelos de blocos sobre duas, três, quatro e cinco estacas foram analisados, e, concluiu-se que os vários métodos analíticos para dimensionamento conduzem a diferentes resultados, o dimensionamento da armadura pode fornecer valores com diferenças da ordem de até $30 \%$.

Os modelos foram dimensionados por três métodos analíticos, de Blévot (1967), CEB-FIP (1970) e EHE (2001) e, foram submetidos à análise numérica 
utilizando o programa computacional $\mathrm{ANSYS}^{\circledR}$, baseado no Método dos Elementos Finitos, considerando-se comportamento elástico linear.

Foram desenvolvidos também modelos de blocos sobre uma estaca, que foram verificados por meio das expressões para blocos parcialmente carregados e foram submetidos à análise numérica.

Os resultados numéricos de interesse foram os fluxos de tensões em suas direções principais, a fim de se aplicar o Modelo de Bielas e Tirantes.

Foram adotados modelos semelhantes variando-se os diâmetros de estacas e as dimensões dos pilares. A justificativa para a adoção desses modelos se deve ao interesse em estudar a influência de estacas e pilares, com dimensões diferentes em modelos de blocos com mesma geometria, no comportamento do fluxo de tensões. Nos modelos de blocos sobre uma e cinco estacas, variou-se também a altura, para a análise da distribuição das tensões ao longo da altura do modelo.

\subsection{Modelos adotados}

Foram analisados 33 modelos de blocos sobre uma, duas, três e quatro estacas, submetidos à ação de força centrada, os modelos foram agrupados em cinco séries conforme a quantidade de estacas e força aplicada, como pode ser visto na tabela 5.1:

Tabela 5.1-Modelos analisados

\begin{tabular}{cccc}
\hline Tipo de Bloco & Série & $\begin{array}{c}\text { Número de } \\
\text { modelos }\end{array}$ & $\begin{array}{c}\text { Força } \\
\text { aplicada (kN) }\end{array}$ \\
\hline 1 estaca & A & 4 & 400 \\
2 estacas & B & 9 & 710 \\
3 estacas & C & 7 & 1000 \\
4 estacas & D & 7 & 1400 \\
5 estacas & E & 6 & 1900 \\
\hline
\end{tabular}


A fim de se estudar a formação dos campos de tensões, foram adotados modelos variando-se o diâmetro das estacas $(30 \mathrm{~cm}, 35 \mathrm{~cm}$ e $40 \mathrm{~cm})$ e as dimensões de pilares para blocos com a mesma geometria e carregamento. Para blocos sobre uma e cinco estacas alteraram-se também as alturas dos modelos.

Foram adotados resistência característica do concreto de $20 \mathrm{MPa}$ e aço CA-50. A ligação do bloco com a estaca foi considerada de $10 \mathrm{~cm}$ e as demais condições geométricas são apresentadas nas figuras 5.1. e 5.2.
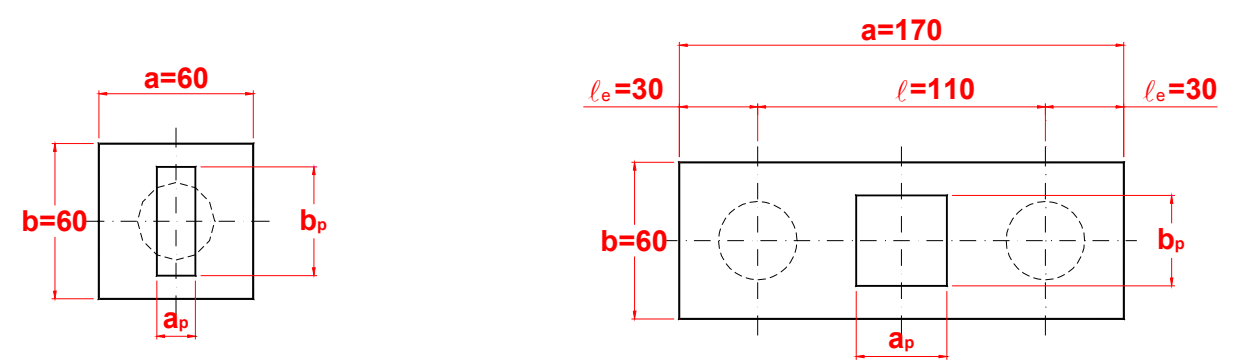

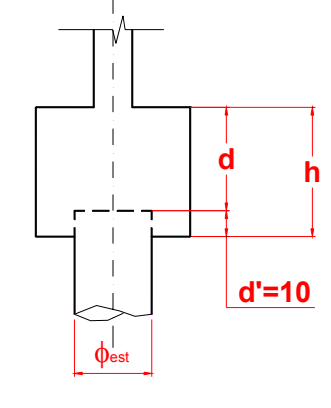

Série A - uma estaca

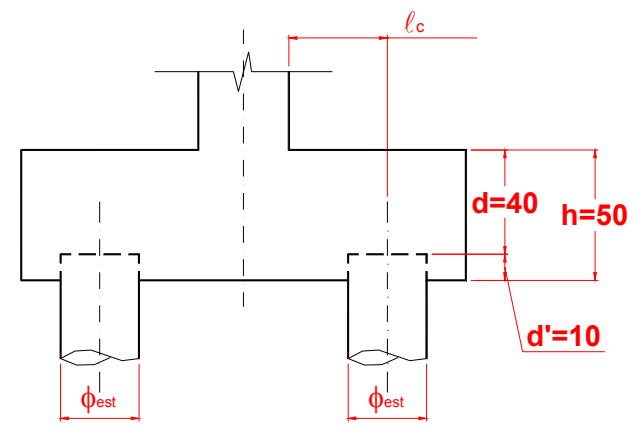

Série B - duas estacas

Figura 5.1 - Modelos de blocos sobre uma e duas estacas (medidas em centímetros) 

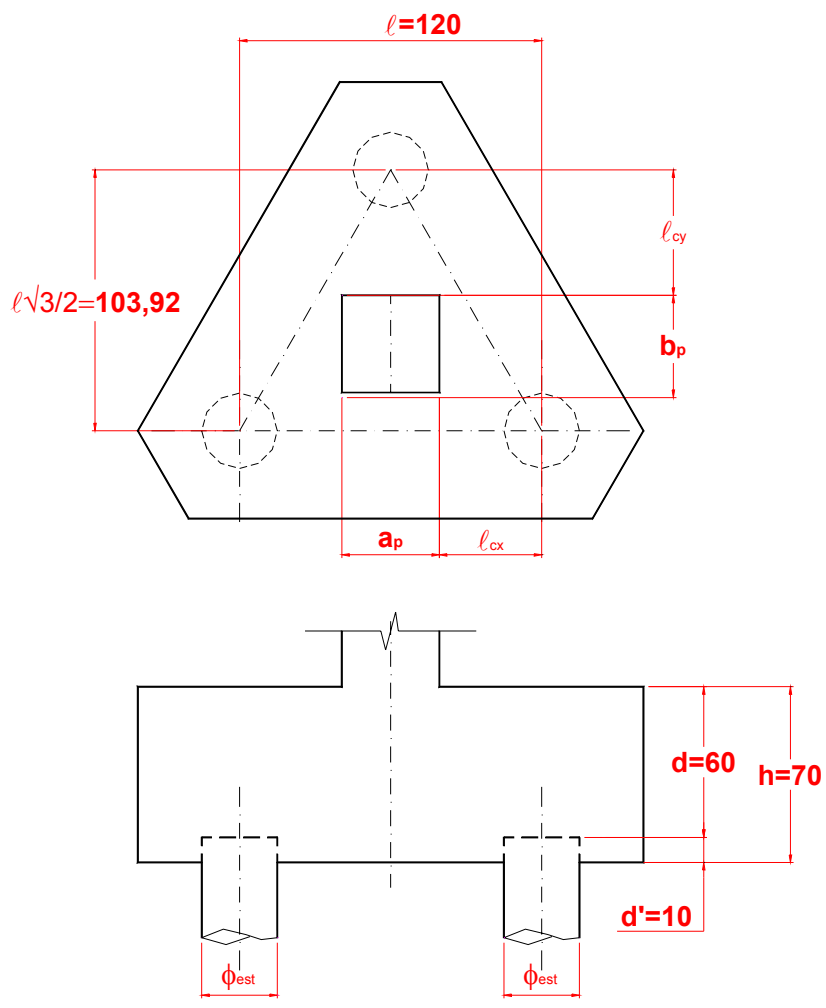

Série $\mathrm{C}$ - três estacas
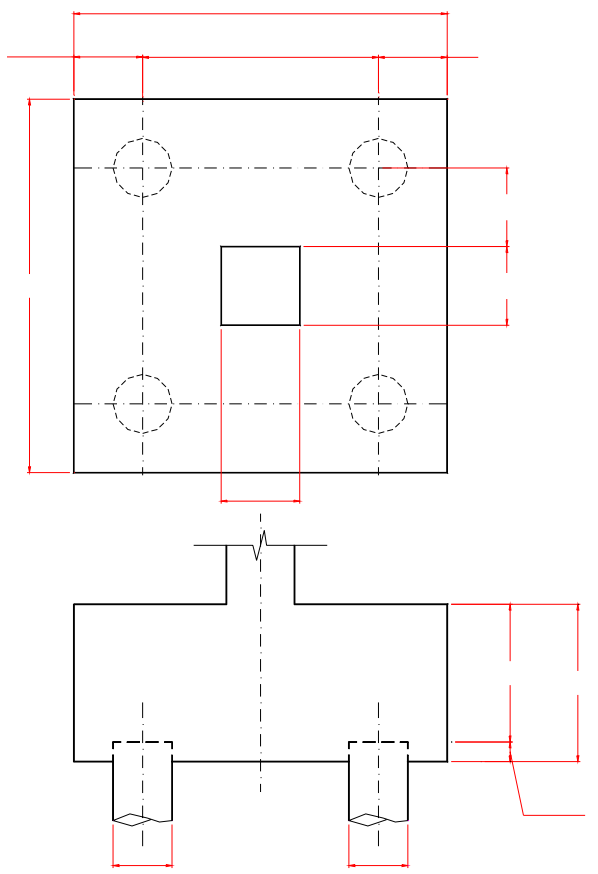

Série D - quatro estacas
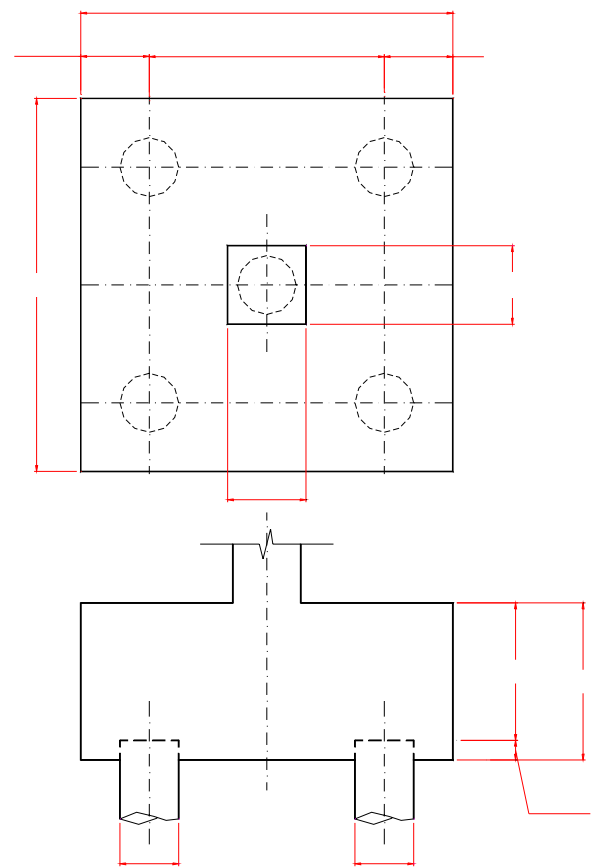

Série $\mathrm{E}$ - cinco estacas

Figura 5.2 - Modelos de blocos sobre três, quatro e cinco estacas (medidas em centímetros) 
Na tabela 5.2 são apresentados os parâmetros geométricos de cada modelo, ou seja, dimensões do bloco $(a, b)$, altura útil (d), distância entre eixos de estacas $(\ell)$, distância da face do pilar ao eixo da estaca mais afastada $\left(\ell_{c}\right)$, dimensões de pilares $\left(a_{p}\right.$ e $\left.b_{p}\right)$ e diâmetro das estacas $\left(\phi_{\text {est }}\right)$.

Tabela 5.2 -Parâmetros Geométricos (medidas em centímetros)

\begin{tabular}{|c|c|c|c|c|c|c|c|c|c|c|}
\hline \multirow{2}{*}{ Série } & \multirow{2}{*}{ Modelos } & \multicolumn{3}{|c|}{ Bloco } & \multicolumn{3}{|c|}{ Distâncias } & \multicolumn{3}{|c|}{ Pilar e estaca } \\
\hline & & $\mathbf{a}$ & b & d & $\ell$ & $\ell_{c x}$ & $\ell_{c y}$ & $a_{p}$ & $b_{p}$ & $\phi_{\text {est }}$ \\
\hline \multirow{4}{*}{ A } & A1-1h50 & 60 & 60 & 40 & - & - & - & 25,00 & 25,00 & 30 \\
\hline & $\mathrm{A} 1-1 \mathrm{~h} 60$ & 60 & 60 & 50 & - & - & - & 25,00 & 25,00 & 30 \\
\hline & A1-3h50 & 60 & 60 & 40 & - & - & - & 25,00 & 25,00 & 40 \\
\hline & A2-1h50 & 60 & 60 & 40 & - & - & - & 15,00 & 42,00 & 30 \\
\hline \multirow{9}{*}{ B } & B1-1 & 170 & 60 & 40 & 110 & 37,68 & - & 34,64 & 34,64 & 30 \\
\hline & B1-2 & 170 & 60 & 40 & 110 & 37,68 & - & 34,64 & 34,64 & 35 \\
\hline & B1-3 & 170 & 60 & 40 & 110 & 37,68 & - & 34,64 & 34,64 & 40 \\
\hline & B2-1 & 170 & 60 & 40 & 110 & 25,00 & - & 60,00 & 20,00 & 30 \\
\hline & B2-2 & 170 & 60 & 40 & 110 & 25,00 & - & 60,00 & 20,00 & 35 \\
\hline & B2-3 & 170 & 60 & 40 & 110 & 25,00 & - & 60,00 & 20,00 & 40 \\
\hline & B3-1 & 170 & 60 & 40 & 110 & 20,00 & - & 70,00 & 20,00 & 30 \\
\hline & B3-2 & 170 & 60 & 40 & 110 & 20,00 & - & 70,00 & 20,00 & 35 \\
\hline & B3-3 & 170 & 60 & 40 & 110 & 20,00 & - & 70,00 & 20,00 & 40 \\
\hline \multirow{7}{*}{ C } & C1-1 & - & - & 60 & 120 & 41,63 & 50,95 & 36,74 & 36,74 & 30 \\
\hline & C1-2 & - & - & 60 & 120 & 41,63 & 50,95 & 36,74 & 36,74 & 35 \\
\hline & C1-3 & - & - & 60 & 120 & 41,63 & 50,95 & 36,74 & 36,74 & 40 \\
\hline & C2-1 & - & - & 60 & 120 & 51,00 & 31,82 & 18,00 & 75,00 & 30 \\
\hline & C2-3 & - & - & 60 & 120 & 51,00 & 31,82 & 18,00 & 75,00 & 40 \\
\hline & C3-1 & - & - & 60 & 120 & 22,50 & 60,32 & 75,00 & 18,00 & 30 \\
\hline & C3-3 & - & - & 60 & 120 & 22,50 & 60,32 & 75,00 & 18,00 & 40 \\
\hline \multirow{7}{*}{ D } & D1-1 & 190 & 190 & 70 & 120 & 40,00 & 40,00 & 40,00 & 40,00 & 30 \\
\hline & D1-2 & 190 & 190 & 70 & 120 & 40,00 & 40,00 & 40,00 & 40,00 & 35 \\
\hline & D1-3 & 190 & 190 & 70 & 120 & 40,00 & 40,00 & 40,00 & 40,00 & 40 \\
\hline & D2-1 & 190 & 190 & 70 & 120 & 50,00 & 20,00 & 20,00 & 80,00 & 30 \\
\hline & D2-2 & 190 & 190 & 70 & 120 & 50,00 & 20,00 & 20,00 & 80,00 & 35 \\
\hline & D2-3 & 190 & 190 & 70 & 120 & 50,00 & 20,00 & 20,00 & 80,00 & 40 \\
\hline & D3-1 & 190 & 190 & 70 & 120 & 50,00 & 15,00 & 20,00 & 90,00 & 30 \\
\hline \multirow{6}{*}{ E } & E1-1h80 & 190 & 190 & 70 & 120 & 40,00 & 40,00 & 40,00 & 40,00 & 30 \\
\hline & E1-3h80 & 190 & 190 & 70 & 120 & 40,00 & 40,00 & 40,00 & 40,00 & 40 \\
\hline & E1-1h95 & 190 & 190 & 85 & 120 & 40,00 & 40,00 & 40,00 & 40,00 & 30 \\
\hline & E1-1h110 & 190 & 190 & 100 & 120 & 40,00 & 40,00 & 40,00 & 40,00 & 30 \\
\hline & E2-1h80 & 190 & 190 & 70 & 120 & 50,00 & 20,00 & 20,00 & 80,00 & 30 \\
\hline & $\mathrm{E} 2-3 \mathrm{~h} 80$ & 190 & 190 & 70 & 120 & 50,00 & 20,00 & 20,00 & 80,00 & 40 \\
\hline
\end{tabular}

As siglas adotadas para representar os nomes dos blocos têm o seguinte significado: $W x-y, W$ relaciona a série do modelo (ver tabela 5.1), que foi dividida conforme o número de estacas, $x$ está relacionada com a seção do pilar, $y$ está 
relacionado com a seção da estaca $\left(y=1\right.$ para $\phi_{\text {est }}=30 \mathrm{~cm}, y=2$ para $\phi_{\text {est }}=35 \mathrm{~cm}, y=3$ para $\phi_{\text {est }}=40 \mathrm{~cm}$ ) em alguns modelos com as mesmas iniciais $x$ e $y$ e variação da altura, acrescentou-se a letra $h$ e o valor da altura em centímetros. Citando como exemplo o bloco B1-1, B significa que ele pertence à série $\mathrm{B}$ (blocos sobre duas estacas), o primeiro 1 significa que ele tem a mesma seção que os demais modelos da mesma série com $x=1$, e o outro 1 significa estacas com diâmetro de $30 \mathrm{~cm}$.

Para os modelos B1-x e C1-x $a_{p}$ e $b_{p}$ são as medidas do lado de um quadrado com uma área equivalente a do retângulo que foi adotado para os demais modelos da mesma série, por isso têm valores com números com mais casas decimais.

Para a modelagem numérica dos modelos de blocos sobre duas, três, quatro e cinco estacas adotaram-se estacas com seção quadrada, mas com área equivalente aos referidos diâmetros.

\subsection{Modelagem numérica}

Os modelos teóricos foram submetidos a uma análise elástica linear via Método dos Elementos Finitos utilizando o programa computacional ANSYS ${ }^{\circledR}$. Para a análise seguiram-se algumas etapas: definição das propriedades dos materiais, do tipo de elemento finito a se utilizar, da malha, das ações e condições de contorno.

Em quase todos os modelos foi possível aproveitar a simetria para a modelagem, apenas para os modelos de blocos sobre três estacas não foi possível. Para os modelos de blocos sobre uma, quatro e cinco estacas aproveitaram-se a simetria em uma direção, modelando-se metade do bloco; no caso de blocos sobre duas estacas aproveitou-se a simetria nas duas direções, modelando-se 1/4 dos blocos.

Como citado anteriormente, nos modelos da série $B, C, D$ e $E$ as estacas foram definidas retangulares, mas com área equivalente a seção circular usada no cálculo dos modelos analíticos. Essa medida foi tomada para facilitar a construção da malha numérica, e foi muito útil, já que não interferiu nos resultados de interesse. Para os modelos da série A (blocos sobre uma estaca) adotoram-se estacas circulares, já que eram modelos bem menores, houve a possibilidade de adotar uma malha mais refinada, e com isso conseguiu-se a construção de estacas circulares. Os pilares e estacas foram modelados com a mesma altura do bloco, procedimento este, normalmente adotado em ensaios experimentais. 
As propriedades dos materiais, considerando avaliação global dos modelos, foram adotadas conforme a NBR 6118:2003, coeficiente de Poisson ( $v$ ) de 0,2 e módulo de elasticidade tangente do concreto conforme a expressão 5.1:

$$
E_{c}=5600 \sqrt{f_{c k}} \rightarrow E_{c}=2504 \mathrm{kN} / \mathrm{cm}^{2}
$$

O programa ANSYS ${ }^{\circledR}$ possui uma vasta biblioteca de elementos finitos com a finalidade de fornecer ao usuário condições para resolver problemas diversos. Neste trabalho o elemento SOLID 65, mostrado na figura 5.3, foi utilizado para discretizar o bloco, pilar e estacas. Este elemento é tridimensional, constituído por oito nós, cada nó possuindo três graus de liberdade, referentes às translações das coordenadas $\mathrm{x}, \mathrm{y}$ e z.

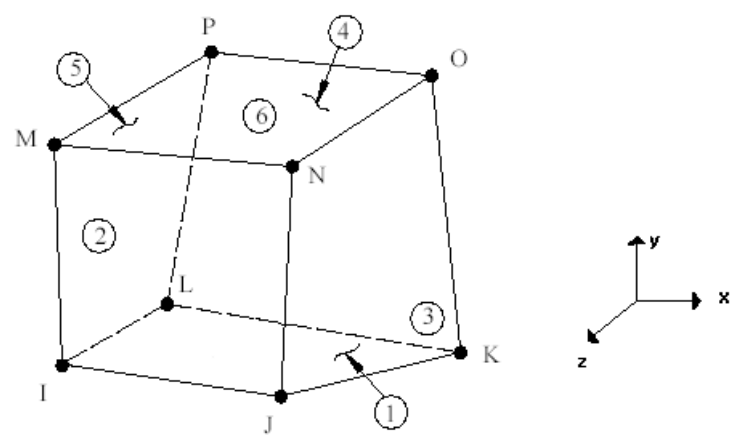

Figura 5.3 - Elemento SOLID 65

Para discretização dos elementos adotou-se uma malha com espaçamento entre nós de aproximadamente $5 \mathrm{~cm}$ para os modelos da série $A$ e $B, 10 \mathrm{~cm}$ para modelos da série $D$ e E e $14 \mathrm{~cm}$ para os modelos C. Não foi possível utilizar uma malha mais refinada, pois com o aumento do número de elementos inviabilizou o processamento do modelo numérico. Os modelos da série $C$ (blocos sobre três estacas) foram os mais difíceis de modelar, por não ter simetria utilizou-se uma malha grande, além disso, optou-se por excluir da modelagem os elementos triangulares que foram gerados na malha nas periferias, já que, nestes locais não havia tensões significativas. Isso se justifica, pois, na modelagem inicial esses elementos triangulares não foram excluídos e causaram dificuldades no processamento dos modelos, já que exigiram uma malha mais refinada.

A figura 5.4 explicita as malhas utilizadas em um modelo de cada série de blocos analisados. 


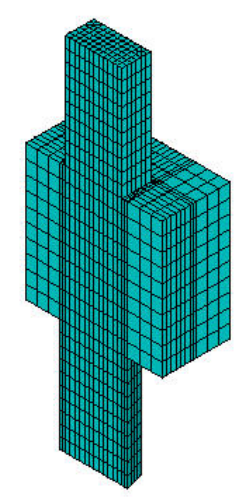

Série A - uma estaca

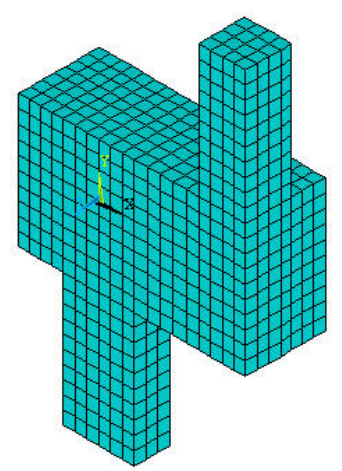

Série B - duas estacas

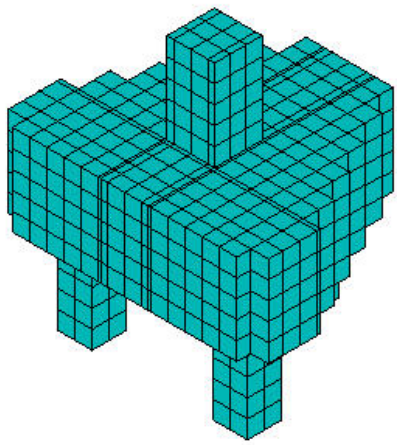

Série $\mathrm{C}$ - três estacas

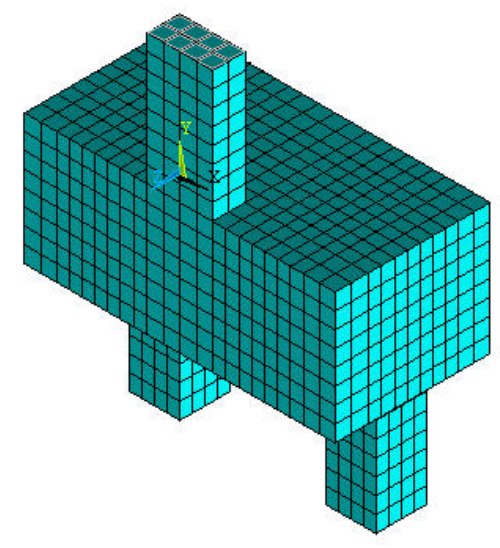

Série D - quatro estacas

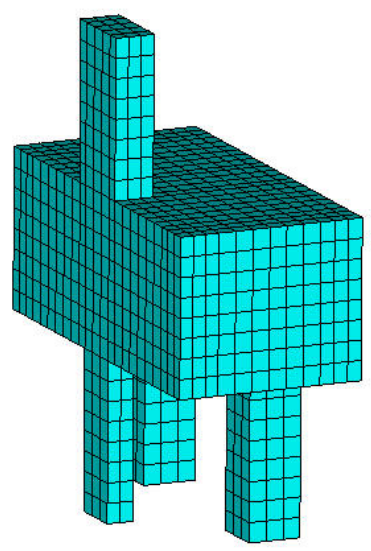

Série $\mathrm{E}$ - cinco estacas

Figura 5.4 -Malha de elementos finitos utilizados

A ação foi aplicada como pressão na área referente ao pilar.

Como condições de contorno restringiram-se todos os nós na face das estacas no plano xz, nas duas direções e na direção normal a este plano, ou seja, restringiram-se as três direções. A intenção de impedir a rotação dos modelos devese ao fato de querer estudar o comportamento do bloco, mantendo condições coerentes a de um ensaio experimental.

O uso da simetria foi indispensável para a modelagem, pois sem esse recurso o número de elementos aumentaria, o que aumentaria o tempo e o trabalho computacional. A condição de simetria foi aplicada referente aos planos que foram cortados.

Todas as condições de contorno e solicitações aplicadas em um modelo da série B são mostradas na figura 5.5 . 


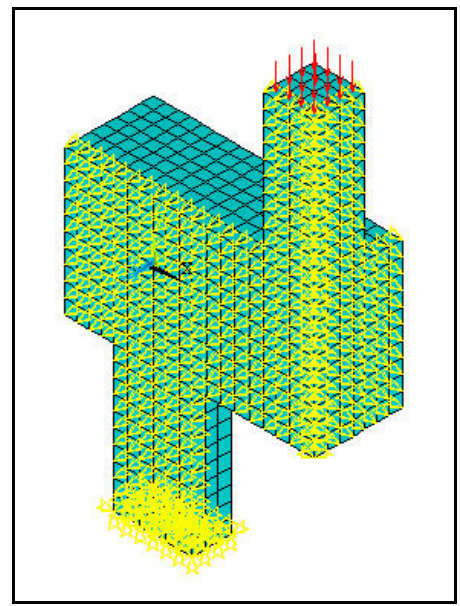

Figura 5.5 - Condições de contorno e solicitações impostas ao Modelo B1-1

\subsection{Análise de resultados}

As análises realizadas foram divididas em duas etapas. Primeiramente os modelos foram verificados por meio de três métodos analíticos, Blévot (1967), CEBFIP (1970) e norma espanhola EHE (2001). Nesta etapa verificou-se principalmente a diferença com relação à aplicabilidade de cada método, ou seja, em alguns casos o mesmo modelo pode ser calculado por um determinado método e por outro não. Ocorreram também diferenças nas áreas das barras das armaduras que foram calculadas.

$\mathrm{Na}$ segunda etapa deste trabalho consideraram-se os resultados obtidos pela análise numérica. Foi feita análise gráfica dos campos de tensão de compressão e com isso foram possíveis algumas comparações com os modelo analítico. Além disso, observaram-se as divergências, tanto na formação do campo de tensão de compressão, quanto nos valores de tensão máxima de tração, quando se variam dimensões de pilares e estacas.

\subsubsection{Resultados analíticos}

\subsubsection{Blocos sobre uma estaca}

Os modelos de blocos sobre uma estaca foram dimensionados conforme as recomendações fornecidas no Capítulo 3. Estas recomendações são fundamentadas na teoria de blocos parcialmente carregados, além de algumas recomendações de 
ordem prática. Não foram encontradas, nas referências pesquisadas, outras metodologias de cálculo, ficando, portanto, os resultados analíticos encontrados sem parâmetros de comparação.

Para adoção da geometria dos modelos, considerou-se o diâmetro de estacas de $30 \mathrm{~cm}$, mesmo tendo adotado alguns modelos com estacas de $40 \mathrm{~cm}$. A altura útil foi adotada considerando ordem de grandeza de 1,1 vez o diâmetro da estaca, ou seja, para diâmetro de $30 \mathrm{~cm}$, o menor valor seria $33 \mathrm{~cm}$. Adotou-se para os modelos alturas de 50 e $60 \mathrm{~cm}$.

As armaduras foram calculadas por meio da determinação da força $R_{t t}$ (força de tração transversal) utilizando as expressões 3.59 e 3.60 (Capítulo 3). As áreas de armadura foram calculadas com as expressões 3.61 e 3.62. A tabela 5.3 apresenta os valores da força $R_{t t}$ e os valores de área de armadura equivalentes.

Tabela 5.3 - Valores de $R_{t t}$ e $A_{s}$

\begin{tabular}{|c|c|c|}
\hline Modelos & $R_{t t}(k N)$ & $A_{s}\left(\mathrm{~cm}^{2}\right)$ \\
\hline A1-1h50 & 19,3 & 0,38 \\
\hline A1-1h60 & 19,3 & 0,38 \\
\hline A1-3h50 & 43,5 & 0,87 \\
\hline $\mathrm{A} 2-1 \mathrm{~h} 50^{(1)}$ & 58,0 & 1,16 \\
\hline \multicolumn{3}{|c|}{$\begin{array}{l}\text { (1) Este modelo possui pilar retangular, a força e a armadura foram } \\
\text { calculadas nas duas direções, mas adotou-se a maior delas para } \\
\text { as duas direções. }\end{array}$} \\
\hline
\end{tabular}

Para os modelos de blocos sobre uma estaca verificou-se ainda a pressão de contato em área reduzida, segundo as recomendações da NBR 6118:2003 para blocos parcialmente carregados. Esta verificação foi feita por meio da expressão 3.63 (Capítulo 3) e para nenhum dos modelos analisados foi ultrapassado valor resistente de cálculo.

\subsubsection{Blocos sobre duas, três, quatro e cinco estacas}

Os blocos sobre duas, três, quatro e cinco estacas foram dimensionados por três métodos analíticos, de BLÉVOT (1967), CEB-FIP(1970) e EHE (2001).

Todos esses métodos empregados são aplicáveis apenas a blocos rígidos, e cada um deles tem sua peculiaridade, ou seja, só podem ser aplicados em modelos que respeitem determinada condição para ser um bloco rígido.

O método das Bielas (Blévot, 1967) só deve ser aplicado em blocos cujo ângulo entre biela e tirante esteja entre os valores de $45^{\circ}$ e $55^{\circ}$. O método do CEB 
(1970) deve ser aplicado somente em blocos que respeitem a relação $2 \ell_{\mathrm{c}} / 3 \leq \mathrm{h} \leq 2 \ell_{\mathrm{c}}$, sendo $\ell_{\mathrm{c}}$ a distância medida da face do pilar ao eixo da estaca mais afastada e h a altura total do bloco. Para a norma espanhola EHE só são considerados rígidos os blocos que atendem a relação $\ell_{c} \leq 2 \mathrm{~h}$. Tomando como exemplo, os modelos de blocos sobre duas estacas B1-1, B1-2 e B1-3 o ângulo entre bielas e tirantes calculado é de $40^{\circ}$, portanto, não estaria dentro dos valores permitidos pelo Método das Bielas, em compensação as tensões de compressão verificadas nas regiões nodais ficaram dentro do valor limite permitido. Os mesmos modelos atenderam as condições de blocos rígidos para os outros métodos. A tabela a seguir mostra melhor estas constatações:

Tabela 5.4- Condições para aplicação dos métodos nos modelos estudados

\begin{tabular}{|c|c|c|c|c|c|c|}
\hline \multirow{3}{*}{\begin{tabular}{|c|} 
Condição \\
$\mathrm{B} 1-1$ \\
$\mathrm{~B} 1-2$ \\
$\mathrm{~B} 1-3$
\end{tabular}} & \multicolumn{2}{|c|}{ Método das Bielas } & \multicolumn{2}{|c|}{ Método CEB-FIP } & \multicolumn{2}{|c|}{ Método EHE } \\
\hline & \multicolumn{2}{|c|}{$45^{\circ} \leq \theta \leq 55^{\circ}$} & \multicolumn{2}{|c|}{$2 \ell_{c} / 3 \leq h \leq 2 \ell_{c}$} & \multicolumn{2}{|c|}{$\mathrm{h} \geq \ell_{\mathrm{c}} / 2$} \\
\hline & $46,3 \leq d \leq 66,2$ & $\begin{array}{c}\mathrm{d}=40 \\
\text { Não OK! }\end{array}$ & $25,1 \leq \mathrm{h} \leq 75,4$ & $\begin{array}{c}\mathrm{h}=50 \\
\mathrm{OK} !\end{array}$ & $h \geq 18,8$ & $\begin{array}{c}\mathrm{h}=50 \\
\text { OK! }\end{array}$ \\
\hline $\begin{array}{l}\text { B2-1 } \\
\text { B2-2 } \\
\text { B2-3 }\end{array}$ & $40,0 \leq d \leq 57,1$ & $\begin{array}{c}\mathrm{d}=40 \\
O K !\end{array}$ & $16,7 \leq \mathrm{h} \leq 50,0$ & $\begin{array}{c}\mathrm{h}=50 \\
\mathrm{OK} !\end{array}$ & $h \geq 12,5$ & $\begin{array}{c}\mathrm{h}=50 \\
\mathrm{OK!}\end{array}$ \\
\hline $\begin{array}{l}\text { B3-1 } \\
\text { B3-2 } \\
\text { B3-3 }\end{array}$ & $37,5 \leq d \leq 53,6$ & $\begin{array}{c}\mathrm{d}=40 \\
\mathrm{OK} !\end{array}$ & $13,3 \leq h \leq 40,0$ & $\begin{array}{c}\mathrm{h}=50 \\
\text { Não OK! }\end{array}$ & $h \geq 10,0$ & $\begin{array}{c}\mathrm{h}=50 \\
\mathrm{OK} !\end{array}$ \\
\hline $\begin{array}{l}\text { C1-1 } \\
\text { C1-2 } \\
\text { C1-3 }\end{array}$ & $58,2 \leq d \leq 83,2$ & $\begin{array}{c}d=60 \\
O K !\end{array}$ & $27,8 \leq h \leq 83,3$ & $\begin{array}{c}\mathrm{h}=70 \\
\mathrm{OK} !\end{array}$ & $h \geq 26,0$ & $\begin{array}{c}\mathrm{h}=70 \\
\mathrm{OK} !\end{array}$ \\
\hline $\begin{array}{l}\text { C2-1 } \\
\text { C2-3 }\end{array}$ & $63,8 \leq d \leq 91,3$ & $\begin{array}{c}\mathrm{d}=60 \\
\text { Não OK! }\end{array}$ & $34,0 \leq \mathrm{h} \leq 102,0$ & $\begin{array}{c}\mathrm{h}=70 \\
\mathrm{OK} !\end{array}$ & $h \geq 25,5$ & $\begin{array}{c}\mathrm{h}=70 \\
\mathrm{OK} !\end{array}$ \\
\hline $\begin{array}{l}\text { C3-1 } \\
\text { C3-3 }\end{array}$ & $46,7 \leq d \leq 66,8$ & $\begin{array}{c}d=60 \\
O K !\end{array}$ & $40,2 \leq \mathrm{h} \leq 120,6$ & $\begin{array}{c}\mathrm{h}=70 \\
\mathrm{OK} !\end{array}$ & $h \geq 30,0$ & $\begin{array}{c}\mathrm{h}=70 \\
\text { OK! }\end{array}$ \\
\hline $\begin{array}{l}\text { D1-1 } \\
\text { D1-2 } \\
\text { D1-3 } \\
\end{array}$ & $70,7 \leq d \leq 100$ & $\begin{array}{c}d=70 \\
O K !\end{array}$ & $26,7 \leq \mathrm{h} \leq 80,0$ & $\begin{array}{c}\mathrm{h}=80 \\
\mathrm{OK} !\end{array}$ & $h \geq 20,0$ & $\begin{array}{c}\mathrm{h}=80 \\
\mathrm{OK!}\end{array}$ \\
\hline $\begin{array}{l}\text { D2-1 } \\
\text { D2-2 }\end{array}$ & $77,8 \leq d \leq 110$ & $\begin{array}{c}\mathrm{d}=70 \\
\text { Não OK! }\end{array}$ & $33,3 \leq h \leq 100,0$ & $\begin{array}{c}\mathrm{h}=80 \\
\mathrm{OK}\end{array}$ & $h \geq 25,0$ & $\begin{array}{c}\mathrm{h}=80 \\
\mathrm{OK} !\end{array}$ \\
\hline $\begin{array}{l}\text { D2-3 } \\
\text { D3-1 }\end{array}$ & $77,8 \leq d \leq 110$ & $\begin{array}{c}\mathrm{d}=70 \\
\text { Não OK! }\end{array}$ & $33,3 \leq h \leq 100,0$ & $\begin{array}{c}\mathrm{h}=80 \\
\mathrm{OK}\end{array}$ & $h \geq 25,0$ & $\begin{array}{c}\mathrm{h}=80 \\
\mathrm{OK} !\end{array}$ \\
\hline $\begin{array}{l}\text { E1-1h80 } \\
\text { E1-3h80 }\end{array}$ & $70,7 \leq d \leq 100$ & $\begin{array}{c}d=70 \\
O K !\end{array}$ & $26,7 \leq \mathrm{h} \leq 80,0$ & $\begin{array}{c}\mathrm{h}=80 \\
\mathrm{OK}\end{array}$ & $h \geq 20,0$ & $\begin{array}{c}\mathrm{h}=80 \\
\mathrm{OK} !\end{array}$ \\
\hline E1-1h95 & $70,7 \leq d \leq 100$ & $\begin{array}{c}d=85 \\
O K !\end{array}$ & $26,7 \leq \mathrm{h} \leq 80,0$ & $\begin{array}{c}\mathrm{h}=95 \\
\text { Não OK }\end{array}$ & $h \geq 20,0$ & $\begin{array}{c}\mathrm{h}=95 \\
\mathrm{OK!}\end{array}$ \\
\hline E1-1h110 & $70,7 \leq d \leq 100$ & $\begin{array}{c}d=100 \\
O K !\end{array}$ & $26,7 \leq \mathrm{h} \leq 80,0$ & $\begin{array}{c}\mathrm{h}=110 \\
\text { Não OK }\end{array}$ & $h \geq 20,0$ & $\begin{array}{c}h=110 \\
\text { OK! }\end{array}$ \\
\hline $\begin{array}{l}\text { E2-1h80 } \\
\text { E2-3h80 }\end{array}$ & $77,8 \leq d \leq 110$ & $\begin{array}{c}d=70 \\
O K !\end{array}$ & $33,3 \leq h \leq 100,0$ & $\begin{array}{c}\mathrm{h}=80 \\
\mathrm{OK}\end{array}$ & $h \geq 25,0$ & $\begin{array}{c}\mathrm{h}=80 \\
\mathrm{OK!}\end{array}$ \\
\hline
\end{tabular}


Para as áreas de armaduras calculadas, é importante observar que neste trabalho, não se verificou a ancoragem das mesmas, em nenhum dos modelos. Os valores das forças nos tirantes $\left(R_{\mathrm{st}}\right)$ e das áreas de armadura calculadas pelos métodos utilizados, por meio das expressões fornecidas no Capítulo 3 são apresentados na Tabela 5.5. O CEB-FIP não fornece o valor da força $R_{\text {st }}$, por não ser baseado em modelo de Biela e Tirante, o cálculo da armadura foi feito com expressões utilizadas para cálculo de flexão em vigas.

Para os modelos de blocos sobre três, quatro e cinco estacas a armadura foi calculada segundo os lados dos blocos, portanto os valores fornecidos na tabela 5.5 referem-se à área de armadura que deve ser colocada em cada lado. O procedimento do CEB-FIP sugere verificações em duas direções, então, adotou-se a mesma armadura para as duas direções, escolhendo-se a maior delas.

Tabela 5.5 - Valores de $\mathrm{R}_{\mathrm{st}}$ e $\mathrm{A}_{\mathrm{s}}$

\begin{tabular}{|c|c|c|c|c|c|c|}
\hline & \multirow{2}{*}{ Modelos } & \multicolumn{2}{|c|}{ BLÉVOT } & \multirow{2}{*}{$\begin{array}{l}\text { CEB-FIP } \\
A_{s}\left(\mathrm{~cm}^{2}\right)\end{array}$} & \multicolumn{2}{|c|}{ EHE } \\
\hline & & $R_{s t}(k N)$ & $A_{s}\left(\mathrm{~cm}^{2}\right)$ & & $R_{s t}(k N)$ & $A_{s}\left(\mathrm{~cm}^{2}\right)$ \\
\hline \multirow{3}{*}{ 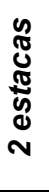 } & B1-1/ B1-2/ B1-3 & 473,0 & 9,46 & 8,00 & 483,8 & 9,68 \\
\hline & B2-1/ B2-2/ B2-3 & 408,3 & 8,17 & 6,28 & 417,7 & 8,35 \\
\hline & B3-1/ B3-2/ B3-3 & 382,7 & 7,65 & 5,61 & 391,5 & 7,83 \\
\hline \multirow{3}{*}{ 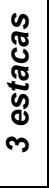 } & $C 1-1 / C 1-2 / C 1-3$ & 186,9 & 3,74 & 3,66 & 228,2 & 4,56 \\
\hline & $\mathrm{C} 2-1 / \mathrm{C} 2-3$ & 204,9 & 4,10 & 4,01 & 245,9 & 4,92 \\
\hline & C3-1/ C3-3 & 150,05 & 3,00 & 4,09 & 192,1 & 3,84 \\
\hline \multirow{3}{*}{ 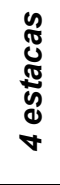 } & D1-1/ D1-2/ D1-3 & 250,0 & 5,00 & 4,65 & 294,0 & 5,88 \\
\hline & D2-1/ D2-2/ D2-3 & 275,0 & 5,50 & 5,36 & 323,5 & 6,47 \\
\hline & D3-1 & 275,0 & 5,50 & 5,36 & 323,5 & 6,47 \\
\hline \multirow{4}{*}{$\begin{array}{l}\mathscr{y} \\
\mathbb{J} \\
\mathbb{J} \\
\mathbb{J} \\
0\end{array}$} & E1-1h80/E1-3h80 & 271,4 & 5,43 & 5,05 & 235,3 & 4,71 \\
\hline & E1-1h95 & 223,5 & 4,47 & 4,14 & 193,8 & 3,88 \\
\hline & E1-1h110 & 190,0 & 2,80 & 3,52 & 167,7 & 3,29 \\
\hline & E2-1h80/ E2-3h80 & 298,6 & 5,97 & 5,83 & 258,8 & 5,18 \\
\hline
\end{tabular}

Os métodos analíticos para dimensionamento também conduziram a diferentes resultados, de armadura, fornecendo valores com diferenças que chegaram até $30 \%$ para modelos de blocos sobre duas estacas. Para os blocos sobre duas, três e quatros estacas o método da EHE (2001) apresentou as maiores áreas de armadura, e o Método do CEB (1970) as menores, ou seja, as diferenças foram maiores entre esses dois métodos. Entre os Métodos de Blévot (1967) e CEB (1970) 
também ocorreram diferenças grandes, nos modelos de blocos sobre duas estacas chegaram a mais de $30 \%$, para um dos modelos de blocos sobre três estacas houve uma diferença um pouco maior (Armadura pelo CEB foi 36\% maior que Blévot), isso ocorreu por causa do posicionamento do pilar e das diferentes considerações dos dois métodos. Para os modelos de blocos sobre cinco estacas, de modo geral, o método que apresentou maiores áreas de armadura foi o de Blévot e as maiores diferenças ocorreram entre Blévot (1967) e EHE (2001), essa diferença foi da ordem de $15 \%$.

Foram feitas verificações das tensões de compressão nas regiões nodais conforme o modelo de Blévot. A tabela 5.6 mostra os valores destas tensões calculadas para blocos de duas, três, quatro e cinco estacas.

Tabela 5.6 - Tensões de compressão nas regiões nodais - modelo de Blévot (1967)

\begin{tabular}{|c|c|c|c|c|c|}
\hline & Modelos & $\begin{array}{c}\sigma_{\mathrm{cb}, \mathrm{e}} \\
(\mathrm{MPa})\end{array}$ & $\begin{array}{c}\sigma_{\mathrm{cb}, \mathbf{p}} \\
(\mathrm{MPa})\end{array}$ & \multicolumn{2}{|c|}{$\begin{array}{l}\sigma_{\mathrm{cb}, \mathrm{lim}} \\
(\mathrm{MPa})\end{array}$} \\
\hline \multirow{9}{*}{ 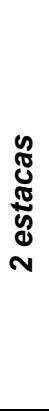 } & B1-1 & 11,8 & \multirow{3}{*}{13,9} & \multirow{9}{*}{\multicolumn{2}{|c|}{17,0}} \\
\hline & B1-2 & 8,6 & & & \\
\hline & B1-3 & 6,6 & & & \\
\hline & B2-1 & 10,1 & & & \\
\hline & B2-2 & 7,4 & 11,8 & & \\
\hline & B2-3 & 5,7 & & & \\
\hline & B3-1 & 9,4 & \multirow{3}{*}{9,5} & & \\
\hline & B3-2 & 6,9 & & & \\
\hline & B3-3 & 5,3 & & & \\
\hline \multirow{7}{*}{ 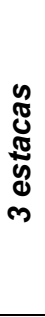 } & C1-1 & 9,2 & \multirow{3}{*}{14,4} & \multirow{7}{*}{\multicolumn{2}{|c|}{21,3}} \\
\hline & C1-2 & 6,7 & & & \\
\hline & C1-3 & 5,2 & & & \\
\hline & C2-1 & 10,1 & \multirow{2}{*}{15,8} & & \\
\hline & C2-3 & 5,7 & & & \\
\hline & C3-1 & 7,6 & \multirow{2}{*}{11,9} & & \\
\hline & C3-3 & 4,3 & & & \\
\hline \multirow{7}{*}{$\begin{array}{l}\mathscr{y} \\
\mathbb{J} \\
\mathbb{J} \\
\mathbb{J} \\
\mathbb{\forall}\end{array}$} & D1-1 & 10,0 & \multirow{3}{*}{17,7} & \multirow{7}{*}{\multicolumn{2}{|c|}{25,5}} \\
\hline & D1-2 & 7,40 & & & \\
\hline & D1-3 & 5,60 & & & \\
\hline & D2-1 & 11,1 & \multirow{3}{*}{19,6} & & \\
\hline & D2-2 & 8,10 & & & \\
\hline & D2-3 & 6,20 & & & \\
\hline & D3-1 & 11,1 & 17,4 & & \\
\hline \multirow{6}{*}{ 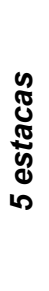 } & E1-1h80 & 10,9 & 240 & \multirow{6}{*}{$\begin{array}{c}25,5 \\
\text { (estaca) }\end{array}$} & \multirow{6}{*}{$\begin{array}{c}31,6 \\
\text { (pilar) }\end{array}$} \\
\hline & E1-3h80 & 6,10 & & & \\
\hline & E1-1h95 & 9,10 & 20,1 & & \\
\hline & E1-1h110 & 8,10 & 17,8 & & \\
\hline & E2-1h80 & 12,0 & \multirow{2}{*}{26,6} & & \\
\hline & E2-3h80 & 6,8 & & & \\
\hline
\end{tabular}


As verificações de tensões apresentadas na tabela anterior foram feitas por meio das expressões apresentadas no Capítulo 3. Foram verificadas tensões de compressão junto à estaca $\left(\sigma_{c b, e}\right)$, junto ao pilar $\left(\sigma_{c b, p}\right)$ e comparadas com as tensões limites sugeridas por Blévot (1967). É importante lembrar que para blocos sobre cinco estacas Blévot (1967) adotou valores diferentes para tensão limite junto à estaca e junto ao pilar, como observa o Capítulo 3. Essa diferença para verificação da tensão limite nas regiões nodais próximas aos pilares e próximas às estacas deveriam ser adotadas sempre, já que, as tensões limite de compressão próximas às estacas são sempre menores do que na região próxima ao pilar.

Para os modelos adotados pode-se constatar que não houve problemas nas verificações das bielas sugeridas por Blévot (1967), pois, as tensões calculadas tiveram valores abaixo dos valores limites.

\subsubsection{Resultados numéricos}

Os resultados numéricos de interesse neste trabalho são os campos de tensões com valores máximos e mínimos nas direções principais, que fornecem uma noção do funcionamento das estruturas.

Por meio das trajetórias de tensões principais é possível montar um modelo de bielas e tirantes. As trajetórias mínimas principais (tensão principal direção 3), geralmente de compressão podem orientar as posições das bielas comprimidas. As trajetórias máximas principais (tensão principal direção 1) podem orientar o posicionamento dos tirantes. No item 5.4 .3 serão apresentadas essas trajetórias para os modelos analisados, e são por meio delas, em conjunto com a análise dos campos de tensão, que serão apresentados algumas sugestões para modelos de bielas e tirantes, mais refinados, para blocos sobre uma, duas, três, quatro e cinco estacas.

Analisaram-se os campos de tensões principais máximas e mínimas. As tensões máximas representadas pelas tensões na direção 1 (tração) e as mínimas são representadas pelas tensões na direção 3 (compressão).

Para cada série de modelos de estacas foram feitas algumas constatações quando se variam os diâmetros das estacas ou a dimensão dos pilares ou a altura dos blocos. 


\subsubsection{Blocos sobre uma estaca}

a) Análise de modelos de blocos com mesma geometria de pilar variando-se diâmetro das estacas

Foram analisados neste item os modelos $\mathrm{A} 1-1 \mathrm{~h} 50$ e $\mathrm{A} 1-3 \mathrm{~h} 50$, que possuem mesma geometria e diâmetros de estacas de 30 e $40 \mathrm{~cm}$ respectivamente.

A figura 5.6 mostra os campos de tensão, de compressão e tração, obtidos nos modelos de blocos sobre uma estaca, analisados neste item.
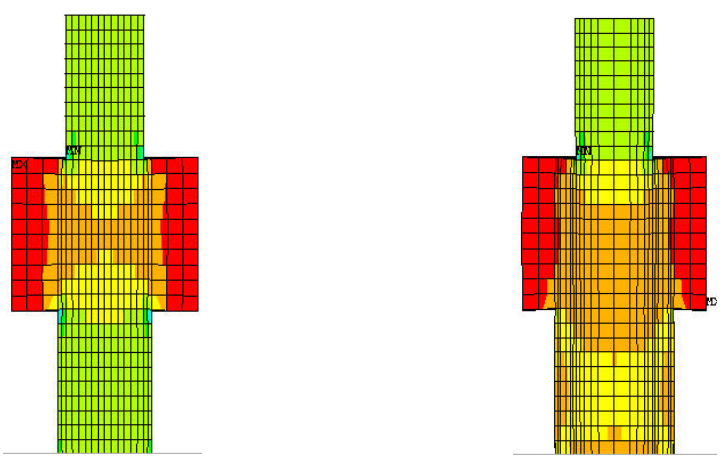

TENSÕES DE COMPRESSÃO
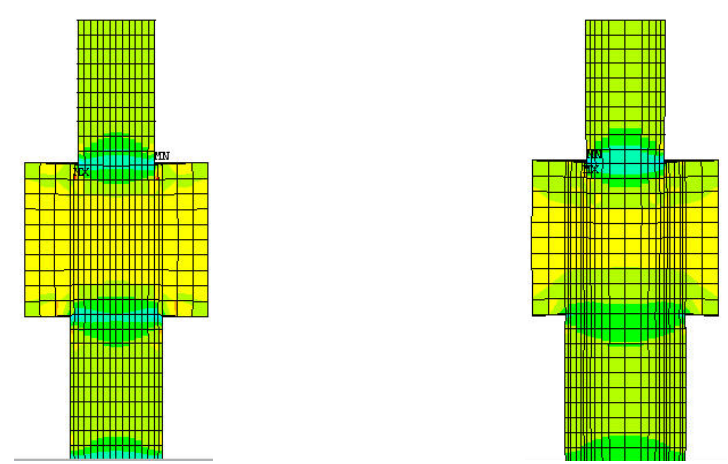

TENSÕES DE TRAÇÃO

$\mathrm{A} 1-1 \mathrm{~h} 50\left(\phi_{\mathrm{est}}=30 \mathrm{~cm}\right)$

$\mathrm{A} 1-3 \mathrm{~h} 50\left(\phi_{\mathrm{est}}=40 \mathrm{~cm}\right)$

Figura 5.6 - Campos de tensão de modelos de blocos sobre 1 estaca

Os campos de tensão de compressão apresentaram uma diferença significativa de um modelo para o outro, como pode ser constatado na figura 5.6. Os valores de tensão máxima de compressão foram praticamente iguais para os dois modelos, as diferenças ocorreram na distribuição de tensão pelo bloco.

Com relação às máximas tensões de tração, com o aumento do diâmetro da estaca estas aumentaram. No cálculo analítico a armadura do modelo A1-3h50 ( $\phi_{\text {est }}=$ $40 \mathrm{~cm}$ ) é maior que $50 \%$ do valor calculado para A1-1h50 $\left(\phi_{\mathrm{est}}=30 \mathrm{~cm}\right)$, os resultados 
numéricos para tensão de tração máxima apresentaram uma diferença de $8 \%$ de um modelo para o outro.

b) Análise de modelos de blocos com mesma geometria e mesmo diâmetro das estacas variando-se dimensão de pilares

Neste item são analisados os modelos A1-1h50 e A2-1h50, que possuem mesma geometria e seções de pilares diferentes, mas com área equivalente, sendo o primeiro deles quadrado $(25 \mathrm{~cm} \times 25 \mathrm{~cm})$ e o outro retangular $(15 \mathrm{~cm} \times 42 \mathrm{~cm})$.As figuras 5.6 e 5.7 mostram campos de tensão de compressão destes modelos.
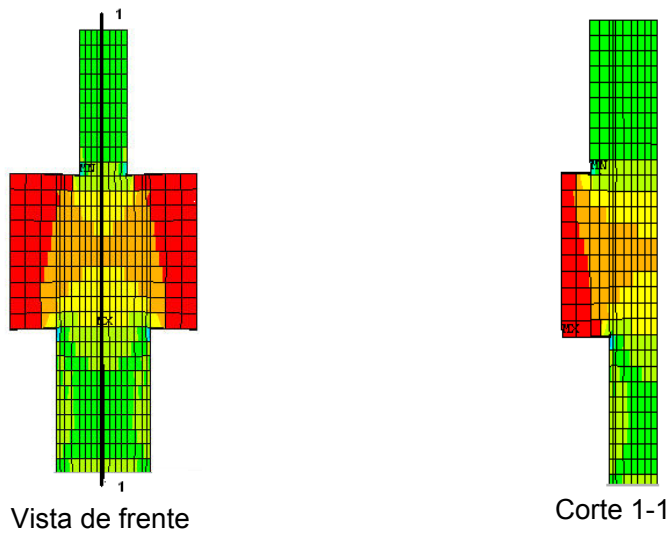

A2-1h50(15x42)

Figura 5.7 - Campos de tensão de compressão modelo A2-1h50

As tensões máximas de compressão, ao longo da altura do bloco, foram maiores no modelo $\mathrm{A} 1-1 \mathrm{~h} 50$. As formações dos campos de tensão foram bem distintas, analisando a figura 5.6 e 5.7 notou-se que o modelo com pilar de seção alongada teve uma distribuição de tensão de compressão próxima a um cone, analisando a outra direção (maior dimensão do pilar), deste modelo A2-1h50 observou-se um cone ao contrario, mostrado no corte 1-1 na figura 5.7.

Os campos de tensão de tração apresentaram distribuição diferente, como pode ser comparado nas figuras 5.6 e 5.8, os valores máximos de tensão de tração foram maiores para o modelo A2-1h50 (pilar alongado). Observando-se uma vista de frente (menor direção do pilar) as tensões se concentram mais no centro, no corte 1-1 (maior direção) as tensões são mais expandidas, como pode ser visto na figura 5.8. É importante ressaltar que para todos os modelos as tensões máximas ocorreram no centro do bloco, visto de frente, representada pela cor amarela nas figuras. 


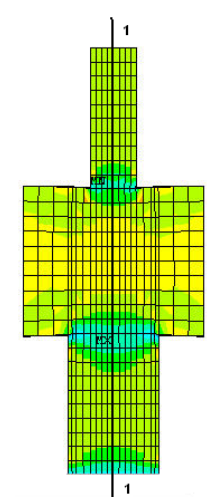

Vista de frente

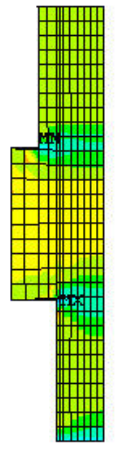

Corte 1-1

A2-1h50(15x42)

Figura 5.8 - Campos de tensão de tração modelo A2-1h50

c) Análise de modelos de blocos com alturas diferentes

As expressões utilizadas para o cálculo de armadura para blocos sobre uma estaca (expressões 3.59 e 3.60 - Capítulo 3) são adaptadas da teoria aplicada para blocos parcialmente carregados. Estas expressões são função da área de aplicação da força, da força aplicada e do diâmetro da estaca, não levando em conta a variação de altura, que pode tornar um bloco mais ou menos rígido.

Neste item analisaram-se os modelos A1-1h50 e A1-1h60, e observou-se que com uma diferença de apenas $10 \mathrm{~cm}$ na altura dos modelos, de mesma geometria, há mudanças na distribuição dos campos de tensão e nos valores de tensão máxima.

Os campos de tensão de compressão e tração são mostrados na figura 5.9. e 5.10 , respectivamente.
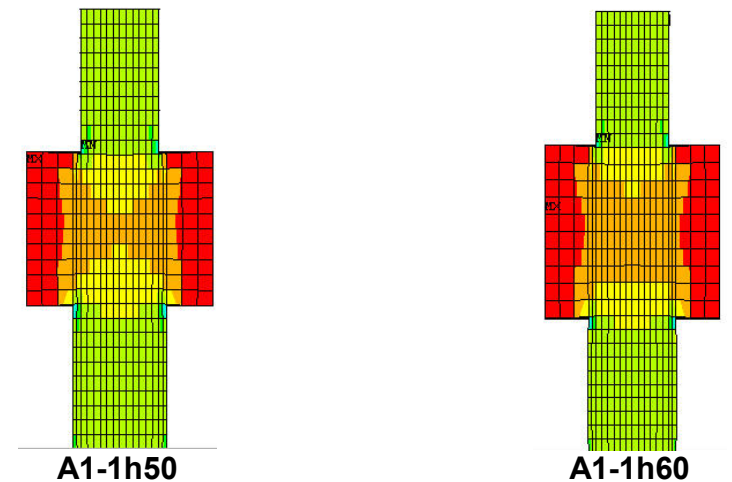

Figura 5.9 - Campos de tensão de compressão em modelos de blocos sobre uma estaca com alturas diferentes. 

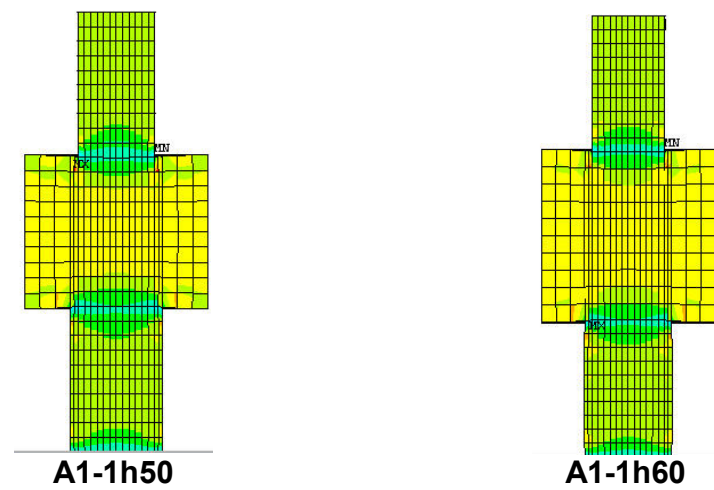

Figura 5.10 -Campos de tensão de tração em modelos de blocos sobre uma estaca com alturas diferentes

Como era esperado, as tensões de compressão ao longo da altura do bloco foram melhores distribuídas com o aumento desta altura, portanto, menores valores de tensão. O mesmo ocorreu com as tensões na outra direção (tração), o valor máximo foi maior no modelo com altura menor, o que não é considerado no cálculo analítico, ou seja, para esses dois modelos, pelo cálculo analítico, a área de armadura é a mesma, como pode ser verificado na tabela 5.3.

\subsubsection{Blocos sobre duas estacas}

a) Análise de modelos de blocos com mesma geometria de pilar variando-se diâmetro das estacas

Neste item foram feitas comparações entre os modelos em que se variou o diâmetro das estacas, ou seja, dividindo-se os modelos em três grupos: (1) B1-1, B12 e B1-3; (2) B2-1, B2-2 e B2-3 e (3) B3-1, B3-2 e B3-3.

As constatações que seguem são as mesmas para os três grupos distintos, já que, nas análises feitas ocorreram as mesmas situações.

Analisando primeiramente os campos de tensão na direção principal 3, que representam as tensões de compressão, pode-se observar a formação das bielas de compressão, como pode ser visto na figura 5.11. Além disso, observou-se a grande concentração de tensões nas regiões nodais, próximas ao pilar e próximas às estacas. 


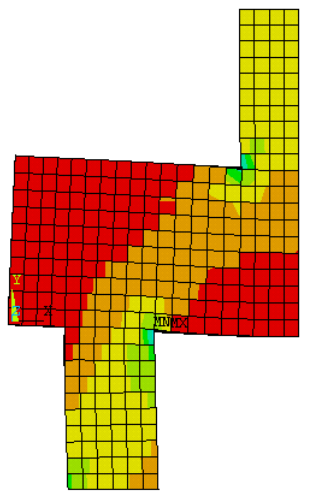

B1-1 $\left(\phi_{\text {est }}=30 \mathrm{~cm}\right)$

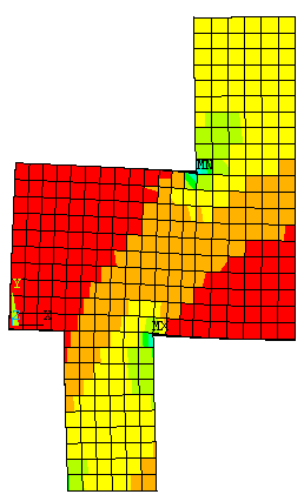

B2-1 $\left(\phi_{\text {est }}=30 \mathrm{~cm}\right)$

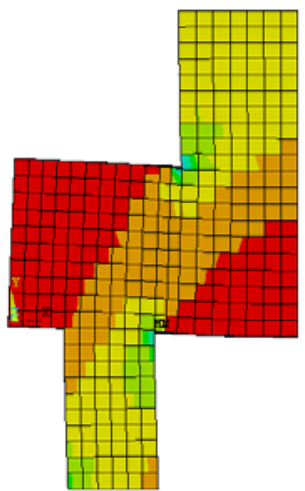

B3-1 $\left(\phi_{\text {est }}=30 \mathrm{~cm}\right)$

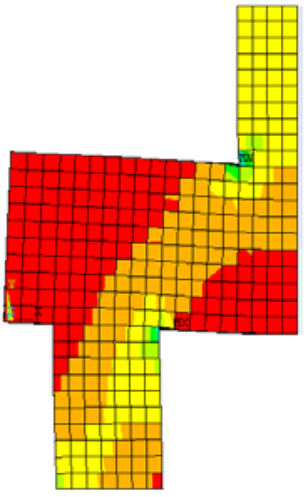

B1-2 $\left(\phi_{\text {est }}=35 \mathrm{~cm}\right)$

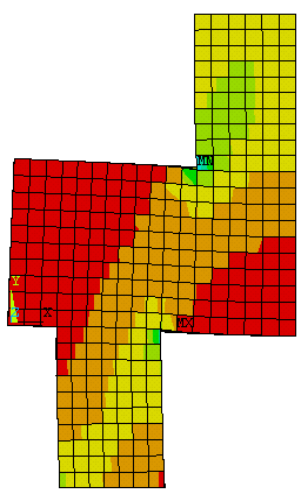

B2-2 $\left(\phi_{\text {est }}=35 \mathrm{~cm}\right)$

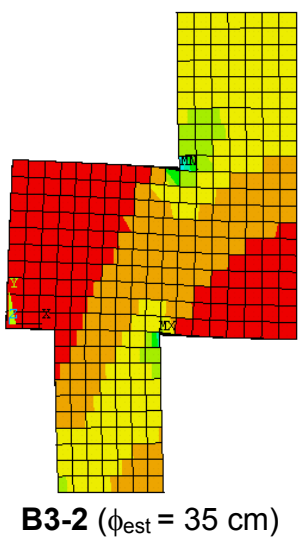

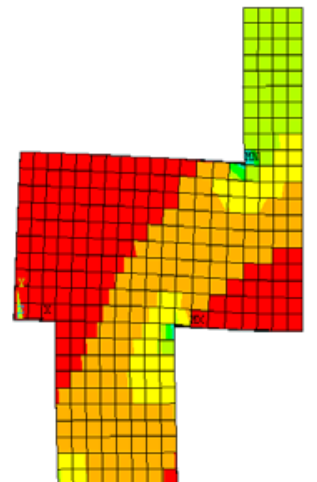

B1-3 $\left(\phi_{\text {est }}=40 \mathrm{~cm}\right)$

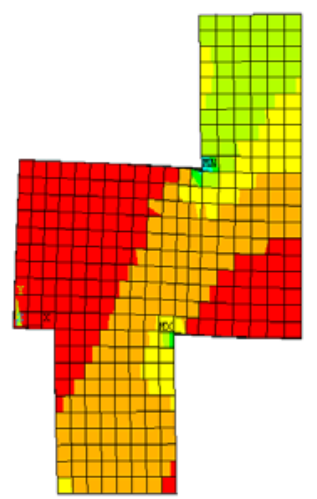

B2-3 $\left(\phi_{\text {est }}=40 \mathrm{~cm}\right)$

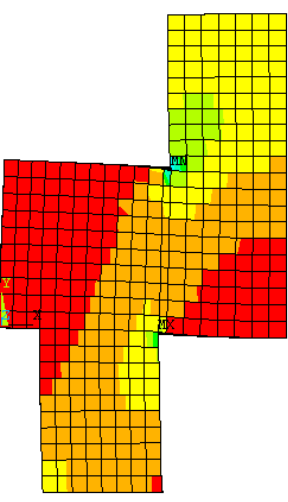

B3-3 $\left(\phi_{\text {est }}=40 \mathrm{~cm}\right)$

Figura 5.11 - Formação das bielas de compressão

Uma importante constatação refere-se à formação das bielas de compressão. Os campos de tensão de compressão na região nodal superior, obtidos com a análise numérica, se formaram além da seção do pilar, como pode ser observado na figura 5.11. Conforme o Modelo de Blévot (1967) a biela se forma partindo da área do pilar, e não foi isso que ocorreu. Por meio de uma aproximação gráfica pode-se notar melhor, as diferenças que ocorreram entre o modelo numérico e o analítico, conforme figura 5.12 . 


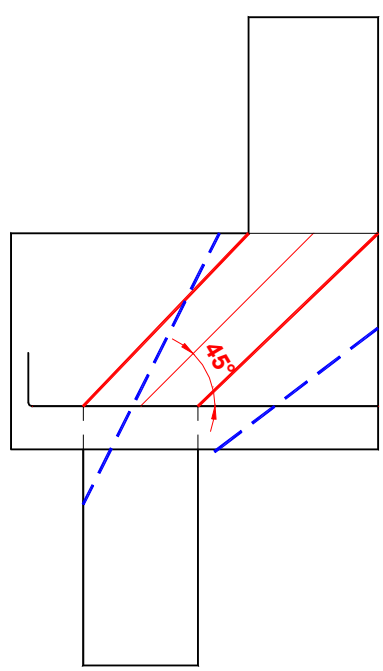

Figura 5.12 -Bielas de compressão, modelo numérico e modelo de Blévot

Na figura 5.12 as linhas contínuas em vermelho mostram a formação das bielas proposta pelo modelo de Blévot. As linhas em azul mostram uma idealização dos campos de compressão obtidos por análise numérica. Observa-se que o ângulo das bielas formado pelas linhas azuis tracejadas (modelo numérico) seria bem maior que o formado pelas linhas vermelhas contínuas. Além disso, conforme o modelo numérico a região nodal logo abaixo do pilar tem uma altura bem maior. É lógico que essas conclusões baseadas em análises gráficas são bem aproximadas, mas, mesmo assim são válidas.

Uma outra constatação relaciona os campos de tensão de compressão com o diâmetro das estacas. Observou-se que a tensão de compressão ao longo da biela diminuiu conforme se aumentou o diâmetro da estacas, essa diferença foi notada entre os blocos com estacas de diâmetros de $30 \mathrm{~cm}$ e $40 \mathrm{~cm}$. Além disso, foi feita, graficamente, uma comparação da formação dos campos de tensão de compressão nos modelos iguais e com diâmetros de estacas diferentes, isso pode ser observado na figura 5.13. 


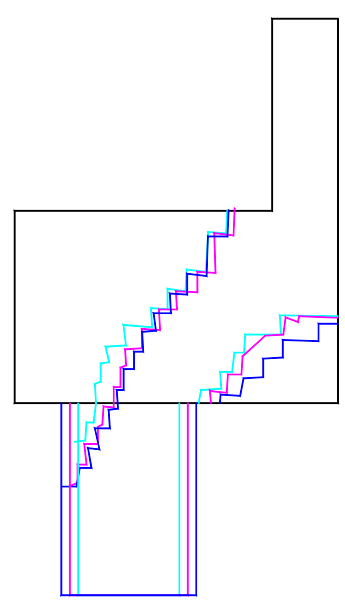

Grupo (1)

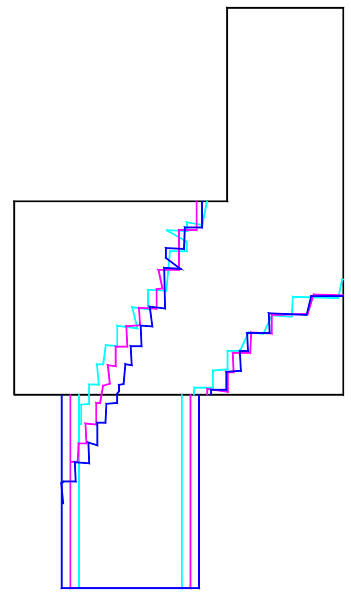

Grupo (2)

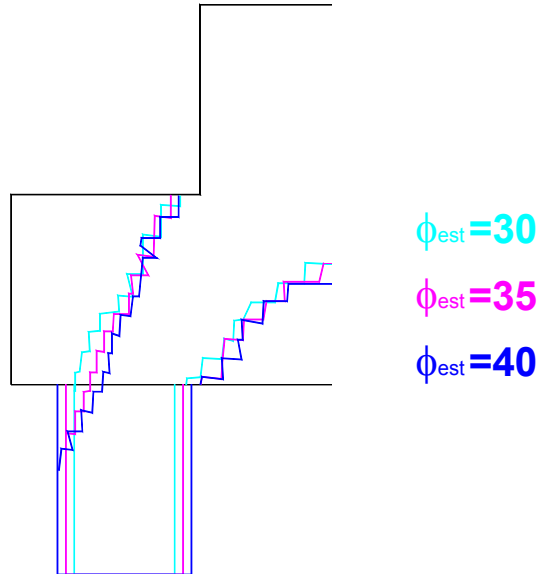

Grupo (3)

Figura 5.13 -Campos de tensão de compressão para modelos com diâmetro de estacas diferentes

Com relação às tensões principais na direção 1 , observou-se que essas máximas tensões de tração ocorrem na face inferior do bloco, como era esperado, no local onde se posiciona a armadura principal do bloco. A figura 5.14 ilustra os campos de tensão máxima, em um dos modelos adotados.

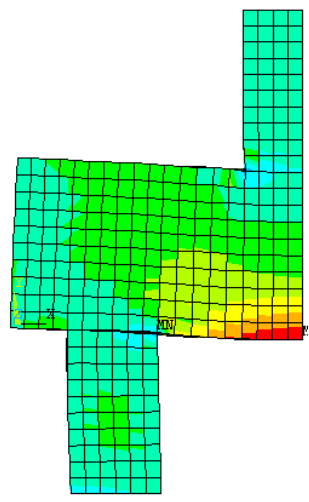

Figura 5.14-Campos de tensão de tração

Relacionando as tensões máximas de tração com os diâmetros das estacas, observou-se que as tensões aumentaram conforme se diminui os diâmetros das estacas. A tabela 5.7 traz os valores de tensão máxima de tração obtidos para cada grupo de blocos analisados. 
Tabela 5.7 - Tensões máximas de tração

\begin{tabular}{cccc}
\hline Grupos & Modelos & $\phi_{\text {est }}(\mathbf{c m})$ & $\begin{array}{c}\text { Tensão de tração } \\
\text { máxima (MPa) }\end{array}$ \\
\hline \multirow{2}{*}{1} & B1-1 & 30 & 4,8 \\
& B1-2 & 35 & 4,4 \\
& B1-3 & 40 & 4,0 \\
\hline \multirow{2}{*}{2} & B2-1 & 30 & 4,0 \\
& B2-2 & 35 & 3,6 \\
& B2-3 & 40 & 3,3 \\
\hline \multirow{2}{*}{3} & B3-1 & 30 & 3,6 \\
& B3-2 & 35 & 3,4 \\
& B3-3 & 40 & 3,0 \\
\hline
\end{tabular}

As diferenças entre os valores de tensão máxima chegaram a $20 \%$. No cálculo analítico isso não aconteceria, pois a força no tirante, com a qual se calcula a área de armadura, independe do diâmetro da estaca.

b) Análise de modelos de blocos com mesma geometria e mesmo diâmetro das estacas variando-se a dimensão de pilares

Esta análise refere-se aos modelos de blocos com mesmas dimensões e mesmo diâmetro de estaca, mas com dimensões de pilares diferentes. Os grupo de blocos analisados refere-se aos modelos: (1) B1-1, B2-1 e B3-1, (2) B1-2, B2-2 e B23 e (3) B1-3, B2-3 e B3-3.

Os modelos B1-x e B2-x têm pilares com área equivalente, sendo o primeiro com área quadrada e o segundo retangular, já o modelo B3-x tem pilar com área retangular mais alongada. A importância desta análise deve-se ao fato de que, a maioria dos métodos de cálculo são aplicados somente para blocos sobre estacas com pilares de seção quadrada. Ocorreu que em um modelo de bloco com mesma geometria e seção de pilar diferente as tensões de tração são distintas, portanto, não é muito realista a consideração que muitos métodos fazem utilizando-se seções quadradas equivalentes para pilares retangulares. Estas constatações podem ser observadas na tabela 5.8, que mostra os valores de tensões máximas de tração para cada grupo de modelos analisados. 
Tabela 5.8 - Tensões máximas de tração

\begin{tabular}{cccc}
\hline Grupos & Modelos & $\begin{array}{c}\text { Seção Pilar } \\
(\mathbf{c m x c m})\end{array}$ & $\begin{array}{c}\text { Tensão de tração } \\
\text { máxima (MPa) }\end{array}$ \\
\hline \multirow{3}{*}{1} & B1-1 & $34,64 \times 34,64$ & 4,8 \\
& B2-1 & $20,00 \times 60,00$ & 4,0 \\
& B3-1 & $20,00 \times 70,00$ & 3,6 \\
\hline \multirow{2}{*}{2} & B1-2 & $34,64 \times 34,64$ & 4,4 \\
& B2-2 & $20,00 \times 60,00$ & 3,6 \\
& B3-2 & $20,00 \times 70,00$ & 3,4 \\
\hline \multirow{3}{*}{3} & B1-3 & $34,64 \times 34,64$ & 4,0 \\
& B2-3 & $20,00 \times 60,00$ & 3,3 \\
& B3-3 & $20,00 \times 70,00$ & 3,0 \\
\hline
\end{tabular}

Observou-se que as máximas tensões de tração diminuem conforme se alonga a seção do pilar. Tomando como exemplo o modelo B2-1, aplicando o Método das Bielas e considerando uma seção quadrada equivalente a armadura adotada seria a mesma que para o modelo B1-1, portanto, talvez seja conservativo adotar esta estratégia de seções equivalentes para blocos sobre duas estacas.

\subsubsection{Blocos sobre três estacas}

Para análise de bloco sobre três estacas adotou-se modelos com estacas de diâmetro diferente, e pilares de seção retangular e seção quadrada equivalente, ou seja, os modelos C1-1, C1-2 e C1-3 têm pilares de seção quadrada; os modelos C2-1 e C2-3 pilares de seção retangular, com a mesma área que os anteriores, e, os modelos C3-1 e C3-3 a mesma seção retangular que os anteriores, mas agora no outro sentido, conforme pode ser visto na figura 5.15. A intenção é observar os campos de tensão nestes modelos e notar as diferenças que existem nestes casos.

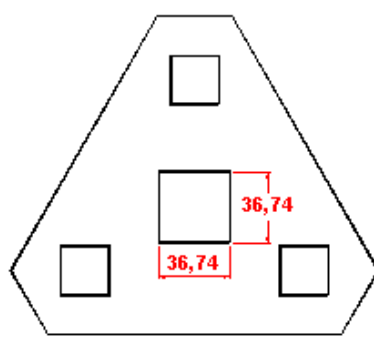

C1-1, C1-2, C1-3

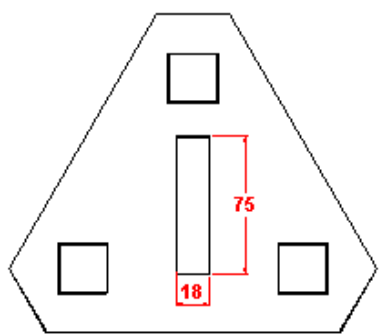

C2-1. $C 2-3$

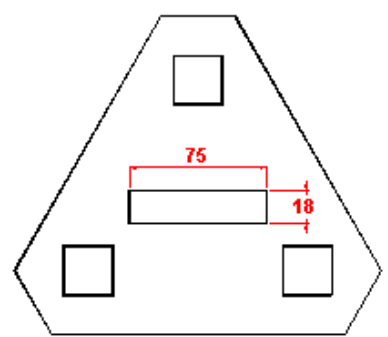

C3-1, C3-3

Figura 5.15- Modelos de blocos sobre três estacas - diferentes seções adotadas para os pilares. 
Foram analisadas vistas e cortes pré-determinados para os modelos de blocos sobre três estacas, para melhor visualização dos campos de tensão, conforme a figura 5.16 .

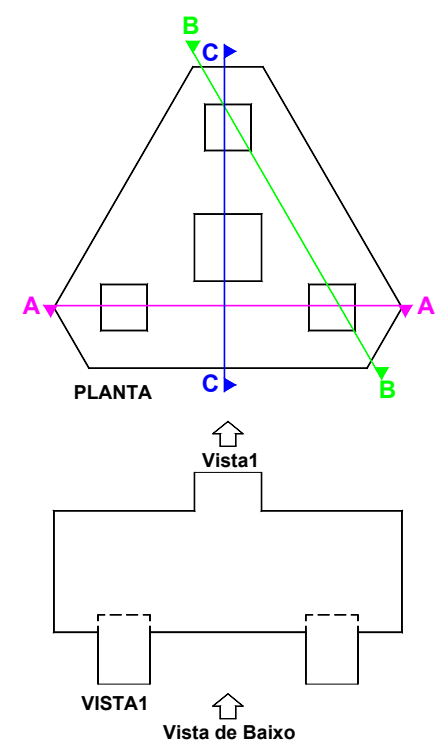

Figura 5.16 - Vistas esquemáticas dos modelos de blocos sobre três estacas

a) Análise de modelos de blocos com mesma geometria de pilar variando-se o diâmetro das estacas

Neste item analisaram-se modelos de blocos com diferentes diâmetros de estacas, dividindo-se os modelos em três grupos distintos: (1) C1-1, C2-1 e C3-1, (2) C1-2 e C2-3 e (3) C1-3 e C3-3. A figura 5.17 mostra os campos de tensão dos modelos do grupo (1).
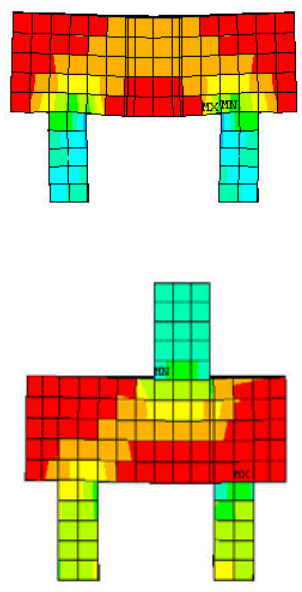

$\mathbf{C} 1-1\left(\phi_{\text {est }}=30 \mathrm{~cm}\right)$

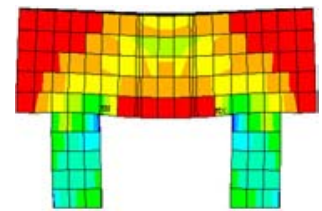

CORTE AA

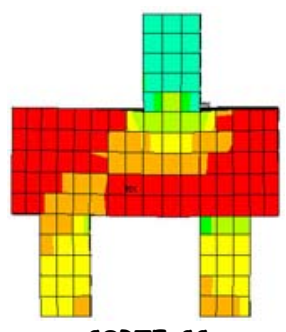

CORTE CC

$\mathbf{C} 1-2\left(\phi_{\text {est }}=35 \mathrm{~cm}\right)$
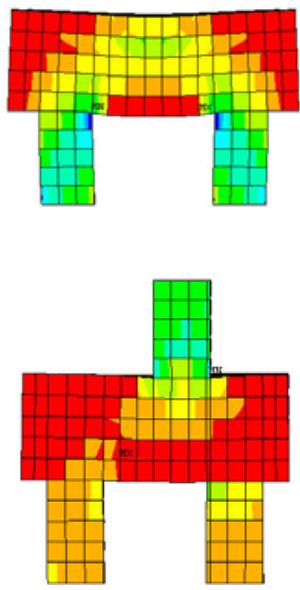

$\mathbf{C} 1-3\left(\phi_{\text {est }}=40 \mathrm{~cm}\right)$

Figura 5.17 - Campos de tensão de compressão - blocos sobre três estacas 
Analisando os campos de tensão para os modelos do grupo (1) constatou-se que a distribuição das forças de compressão é bem coerente com o modelo de Blévot (1967), mas as regiões nodais são bem distintas. Como era esperado, com o aumento do diâmetro das estacas, a tensão de compressão ao longo da biela diminuiu, isto se justifica afinal com o aumento da área da biela ocorre uma diminuição de tensão. Estas mesmas constatações foram feitas para os grupos (2) e (3).

Por meio da figura 5.18 pode se observar as formações dos campos de tensão de tração (direção principal) para os modelos de blocos sobre três estacas.
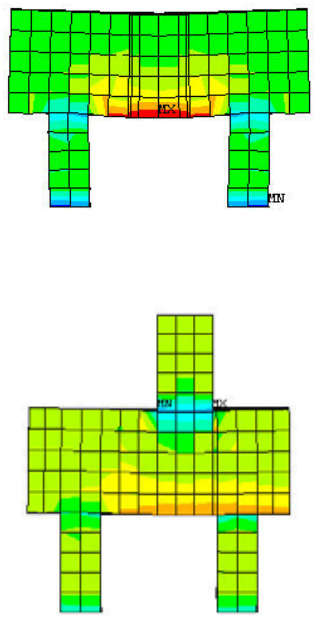

$\mathbf{C} 1-1\left(\phi_{\text {est }}=30 \mathrm{~cm}\right)$

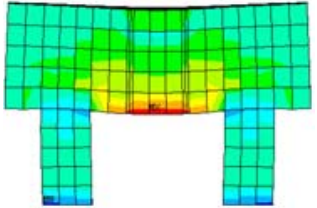

CORTE AA

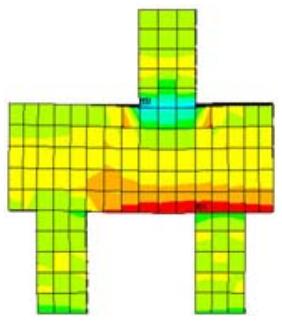

CORTE CC

$\mathbf{C} 1-2\left(\phi_{\text {est }}=35 \mathrm{~cm}\right)$
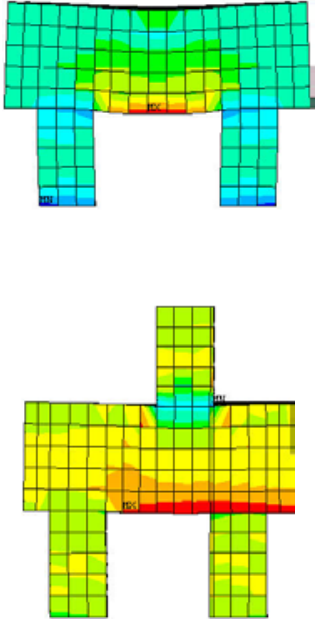

$\mathbf{C} 1-3\left(\phi_{\text {est }}=40 \mathrm{~cm}\right)$

Figura 5.18 - Campos de tensão de tração - blocos sobre três estacas

As tensões de tração máximas para os modelos com pilares retangulares (grupo 1) constatou-se que as tensões aumentaram conforme se diminuiu os diâmetros das estacas, as diferenças entre os valores máximos, de forma geral não foram significativas. Estas observações também se aplicam ao grupo 3; para o grupo 2 as tensões diminuíram conforme se diminuiu o diâmetro das estacas. Essas constatações têm sua validade, mas é importante ressaltar que os grupos de modelos têm seções diferentes de pilar, e essa variação na seção tem grande importância na formação dos campos de tensão, conforme será visto no item seguinte. 
b) Análise de modelos de blocos com mesma geometria e mesmo diâmetro das estacas variando-se a dimensão de pilares

Neste item analisou modelos de blocos com diferentes seções de pilares, dividindo-se os modelos em dois grupos distintos: (1) C1-1, C2-1, C3-1 e (2) C1-3, C2-3, C3-3.

A figura 5.19 apresenta os campos de tensões de compressão dos grupos de modelos estudados neste item. Ë mostrado uma vista de cima (face superior) dos modelos onde pode se observar as diferentes formas de distribuição de um modelo para o outro.
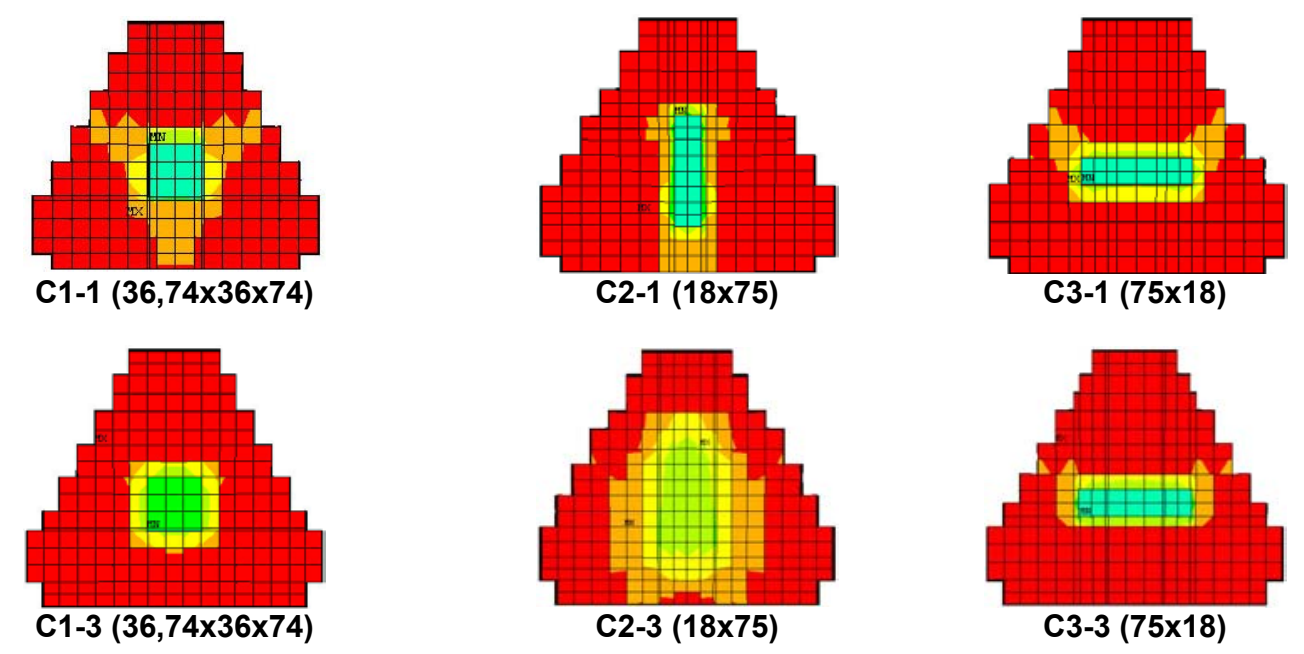

Figura 5.19 - Campos de tensão de compressão - blocos sobre três estacas (vista de cima)

A figura 5.20 apresenta os campos de tensões de tração dos grupos de modelos estudados neste item. É mostrado uma vista da parte inferior dos modelos, onde pode se observar os contornos dos campos de tensão de tração para os modelos com diferentes seções de pilares. 

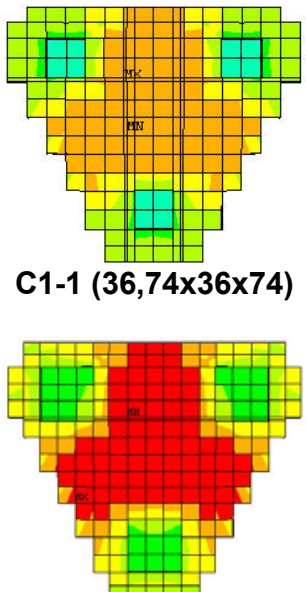

C1-3 $(36,74 \times 36 \times 74)$

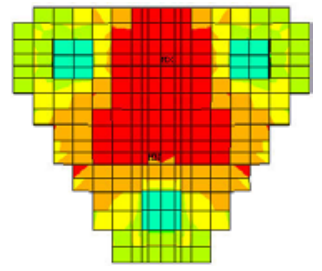

C2-1 (18x75)

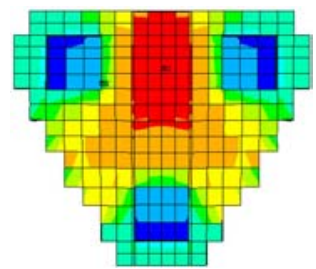

C2-3 (18x75)

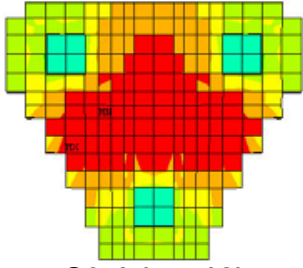

C3-1 (75x18)

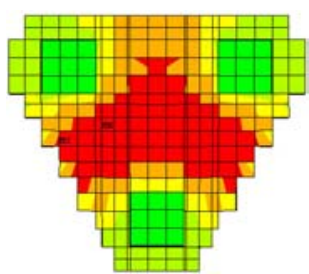

C3-3 (75x18)

Figura 5.20 - Campos de tensão de tração - blocos sobre três estacas (vista de baixo)

Com relação às tensões de tração os valores máximos para todos os modelos estudados ocorreram aproximadamente no centro do bloco, mas sua formação, como era esperado, diferiu muito conforme houve mudanças nas seções dos pilares.

\subsubsection{Blocos sobre quatro estacas}

Para melhor visualização dos campos de tensão foram analisados vistas e cortes pré-determinados para os modelos de blocos sobre quatro estacas, a figura 5.21 ilustra quais foram as vistas e cortes feitos nos modelos.

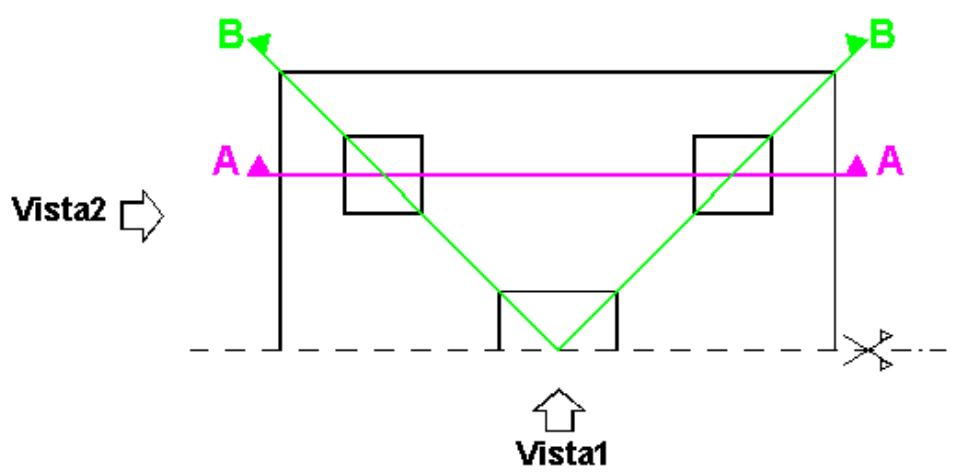

Figura 5.21 - Vistas esquemáticas dos modelos de blocos sobre quatro estacas 
a) Análise de modelos de blocos com mesma geometria de pilar variando-se diâmetro das estacas

Neste item foi feita análise dos campos de tensão de compressão (tensão principal na direção 3) para modelos de blocos sobre quatro estacas e comparada com o modelo analítico que utiliza analogia de treliça. Além disso, observaram-se as divergências, tanto na formação do campo de tensão de compressão, quanto nos valores de tensão máxima de tração (tensão principal na direção 1 ), quando se variam dimensões de estacas.

Para esta analise utilizou apenas 6 dos 7 modelos dividindo-os em dois grupos: (1) D1-1, D1-2 e D1-3 e (2) D2-1, D2-2 e D2-3.

Observando-se os elementos mostrados no corte AA obteve-se as configurações de campos de tensão de compressão mostrados na figura 5.22 , as diferenças nas formações das bielas, deve-se às diferentes geometrias dos pilares.

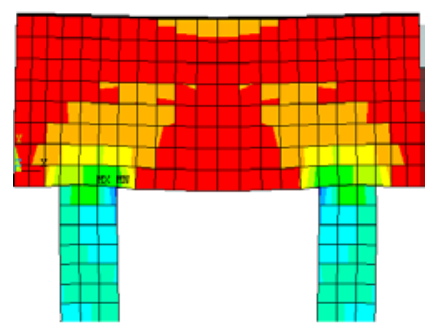

D1-1 $\left(\phi_{\text {est }}=30 \mathrm{~cm}\right)$

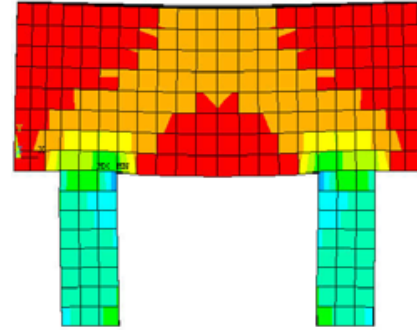

D2-1 $\left(\phi_{\mathrm{est}}=30 \mathrm{~cm}\right)$

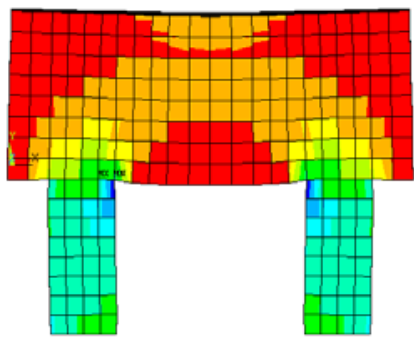

D1-2 $\left(\phi_{\text {est }}=35 \mathrm{~cm}\right)$

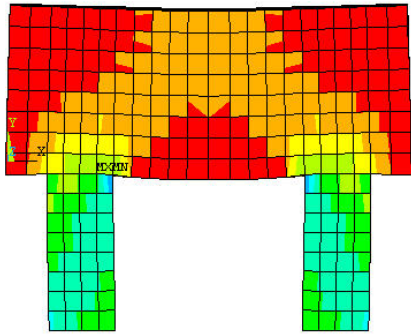

D2-2 $\left(\phi_{\text {est }}=35 \mathrm{~cm}\right)$

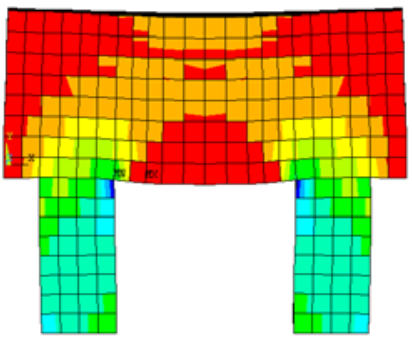

D1-3 $\left(\phi_{\text {est }}=40 \mathrm{~cm}\right)$

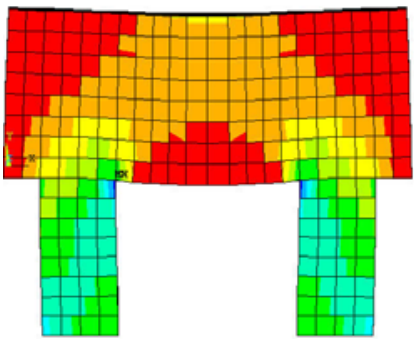

D2-3 $\left(\phi_{\text {est }}=40 \mathrm{~cm}\right)$

Figura 5.22 - Campos de tensão de compressão nos modelos de blocos sobre 4 estacas (corte AA)

Da mesma forma que para os blocos sobre duas estacas, constatou-se que os campos de tensão de compressão nas regiões nodais se formam além da seção do pilar e estacas, conforme é considerado no Modelo de Blévot (1967).Observou-se ainda que com o aumento do diâmetro das estacas as intensidades das tensões de compressão diminuíram, isso era esperado e se justifica, pois há uma dissipação maior das tensões de compressão, portanto, maiores intensidades. 
A intenção de passar um corte em diagonal como o corte BB, era a verificação de como se formam os campos de tensões de compressão, ou melhor, como era a formação das bielas, mas não foi possível essa visualização, sendo o aspecto neste corte como o mostrado na figura 5.23 .

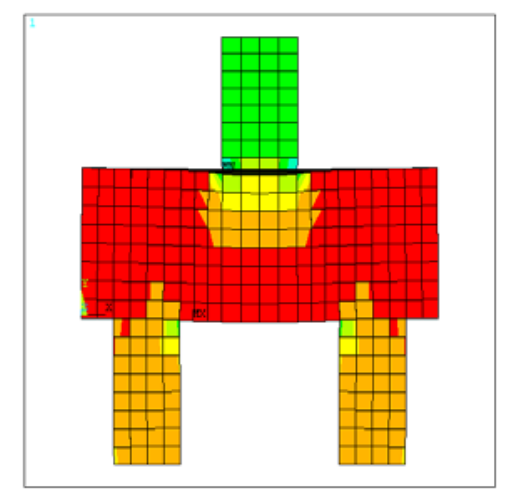

Figura 5.23 - Campos de tensão de compressão no modelo D1-3 (corte BB)

É importante ressaltar que no Método das Bielas, as bielas são consideradas traçando-se um corte diagonal, como pode ser visto no esquema apresentado no Capítulo 3, figura 3.14, nos modelos numéricos, apesar da difícil análise, em virtude das três dimensões, os campos de tensões tiveram uma distribuição um pouco diferente do que considerado no método analítico citado. O que ocorreu nos modelos numéricos foi a formação de um bulbo de tensões abaixo do pilar e, após uma certa altura essas tensões foram distribuídas para estacas, por isso só é possível a constatação de bielas de compressão quando se observa o corte AA. É válido destacar que esse fato ocorreu para esse tipo de carregamento, pode ser que um carregamento bem maior geraria outra configuração de tensões.

Com relação às tensões de tração houve diferenças nos valores de tensões máximas de tração conforme se aumentou os diâmetros das estacas, mas não foram significativas como nos modelos de blocos sobre duas estacas. Os campos de tensão de tração apresentaram aspecto semelhante em todos os modelos, como é mostrado na figura 5.24 . 


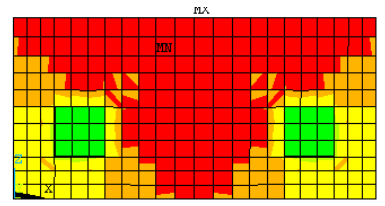

Vista de Baixo

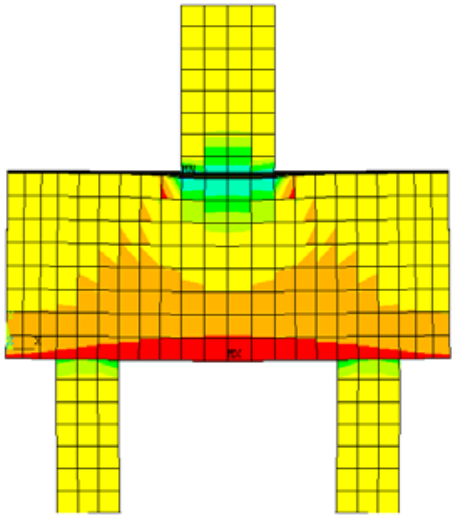

Vista 1

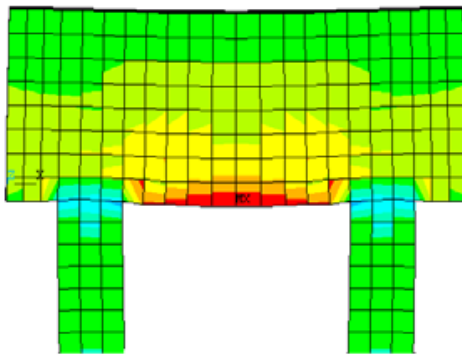

Corte AA

Figura 5.24 - Campos de tensão de tração no modelo D1-1

b) Análise de modelos de blocos com mesma geometria e mesmo diâmetro das estacas variando-se a dimensão de pilares

Os modelos D1-x e D2-x têm pilares com área equivalente, sendo o primeiro com área quadrada e o segundo retangular, já o modelo B3-x tem pilar com área retangular mais alongada.

Observando-se figura 5.22 pode-se ver que conforme se mudou a geometria do pilar houve diferença na distribuição de tensões de compressão. Houve diferenças significativas entre os modelos de blocos com pilares quadrados e retangulares. $A$ intensidade da tensão de compressão ao longo da biela de compressão foi maior para os modelos com pilares quadrados e diminuíram conforme se alongou a seção do pilar.

Comparando-se os modelos de blocos sobre quatro estacas com pilar retangular de área $20 \mathrm{~cm} \times 80 \mathrm{~cm}$ e com pilar quadrado de área equivalente $40 \mathrm{~cm} \times$ $40 \mathrm{~cm}$ obteve-se valores máximos de tensões de tração muito próximas, o que não ocorreu nos modelos de blocos sobre duas estacas. Neste caso, seria possível a utilização de seções quadradas de área equivalente para blocos com pilares de seção retangular. Logicamente para o modelo B3-1, com seção um pouco mais alongada $(20 \mathrm{~cm} \times 90 \mathrm{~cm})$, os valores foram um pouco menores, como era esperado. Estas constatações podem ser observadas na tabela 5.9, que mostra os valores de tensões máximas de tração para o grupo de modelos analisados. 
Tabela 5.9 - Tensões máximas de tração

\begin{tabular}{cccc}
\hline Grupos & Modelos & $\begin{array}{c}\text { Seção Pilar } \\
(\mathbf{c m x c m})\end{array}$ & $\begin{array}{c}\text { Tensão de tração } \\
\text { máxima (MPa) }\end{array}$ \\
\hline \multirow{3}{*}{1} & D1-1 & $40 \times 40$ & 1,898 \\
& D2-1 & $20 \times 80$ & 1,890 \\
& D3-1 & $20 \times 90$ & 1,540 \\
\hline
\end{tabular}

\subsubsection{Blocos sobre cinco estacas}

Os modelos de blocos sobre cinco estacas, geralmente, são considerados no cálculo analítico, como um bloco de quatro estacas com mais uma estaca central. As análises numéricas efetuadas, apesar de simplificadas, mostraram que não é bem isso que ocorre, já que há diferenças significativas na distribuição de tensões, de um modelo para o outro, principalmente quando se tem diferença na rigidez dos blocos, alterando sua altura.

Como para os modelos de blocos sobre quatro estacas os campos e trajetórias de tensões para os blocos sobre cinco estacas foram analisados em determinados cortes e vistas dos modelos, como mostrado na figura 5.25.

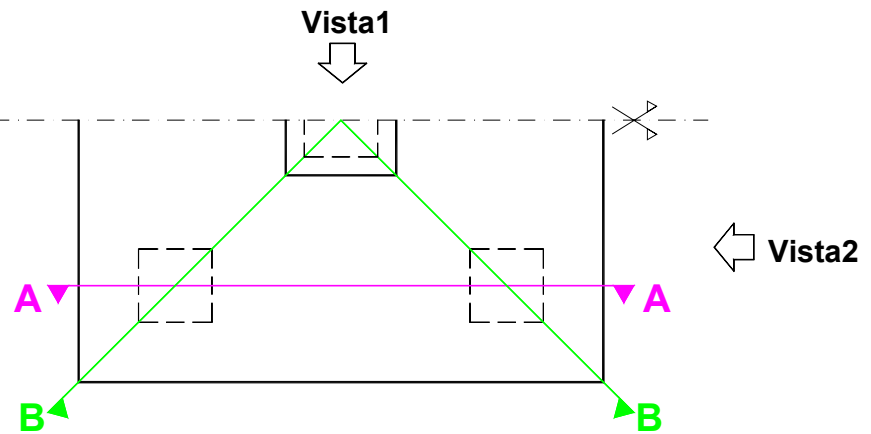

Figura 5.25 - Vistas esquemáticas dos modelos de blocos sobre cinco estacas

a) Análise de modelos de blocos com mesma geometria de pilar variando-se diâmetro das estacas

Neste item são analisados os modelos E1-1h80 e E1-3h80, E2-1h80 e E213h80, que possuem diâmetros de estacas de $30 \mathrm{~cm}$ e $40 \mathrm{~cm}$, foram excluídos os modelos de blocos com diâmetro de estacas de $35 \mathrm{~cm}$ por haver poucas diferenças quando comparados com os de $30 \mathrm{~cm}$ ou $40 \mathrm{~cm}$.

A figura 5.26 mostra as configurações de campos de tensão de compressão selecionados os elementos por meio do corte $A A$, onde se podem notar diferenças 
significativas nas formações dos campos por causa dos diferentes diâmetros de estacas.
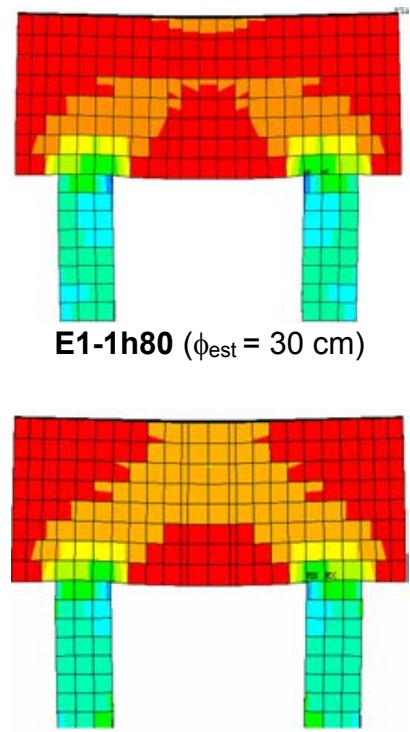

E2-1h80 $\left(\phi_{\text {est }}=30 \mathrm{~cm}\right)$

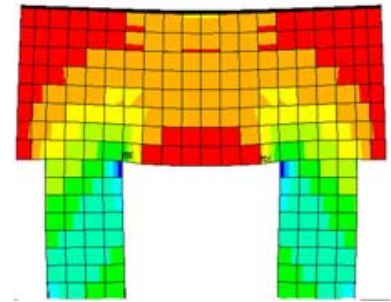

$\mathrm{E} 1-3 \mathrm{~h} 80\left(\phi_{\mathrm{est}}=40 \mathrm{~cm}\right)$

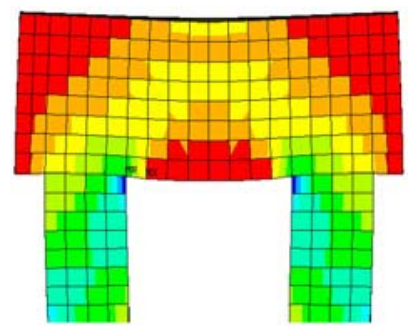

$\mathrm{E} 2-3 \mathrm{~h} 80\left(\phi_{\mathrm{est}}=40 \mathrm{~cm}\right)$

Figura 5.26 - Campos de tensão de compressão nos modelos de blocos sobre 5 estacas (corte AA)

Do mesmo modo que ocorreu para os modelos de blocos sobre quatro estacas com o aumento de seus diâmetros as intensidades das tensões de compressão diminuíram, mas nestes modelos as mudanças foram mais bruscas. Comparando os modelos E1-1h80 ( $\left.\phi_{\text {est }}=30 \mathrm{~cm}\right)$ e E1-3h80 $\left(\phi_{\text {est }}=40 \mathrm{~cm}\right)$ observou-se que as tensões foram melhores distribuídas no modelo com diâmetro de $40 \mathrm{~cm}$, o modelo E1-1h80 tem maiores concentrações de tensões, ou seja, valores mais elevados de tensão de compressão do que o modelo E1-3h80. Essas constatações são muito importantes para a verificação das regiões nodais, já que diminuindo o diâmetro das estacas há concentrações de tensões maiores, sendo da ordem de duas vezes maior para diâmetro de $30 \mathrm{~cm}$. O mesmo ocorreu comparando os modelos E21h80 e E2-3h80, ou seja, os valores máximos de tensão de compressão são maiores no modelo com diâmetro de $30 \mathrm{~cm}$.

A formação dos campos de tensão de compressão também difere do modelo analítico.

Com relação às tensões de tração, comparando os modelos E1-1h80 e E1$3 \mathrm{~h} 80$, os valores máximos de tensão não diferiram muito (ver tabela 5.10 ), mas no modelo $\mathrm{E} 1-3 \mathrm{~h} 80$ as tensões máximas ocorreram mais concentradas na estaca central 
do bloco. A figura 5.27 mostra uma vista por baixo dos modelos de blocos e, pode explicitar melhor essa constatação, sendo que as tensões máximas (com praticamente mesma intensidade) têm a mesma cor.

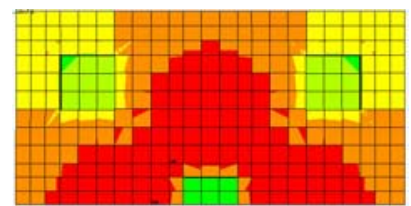

$\mathrm{E} 1-1 \mathrm{~h} 80\left(\phi_{\mathrm{est}}=30 \mathrm{~cm}\right)$

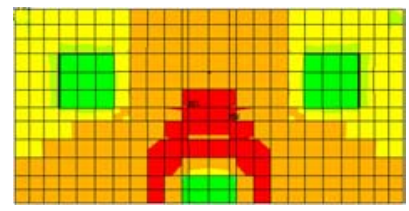

$\mathrm{E} 2-1 \mathrm{~h} 80\left(\phi_{\mathrm{est}}=30 \mathrm{~cm}\right)$

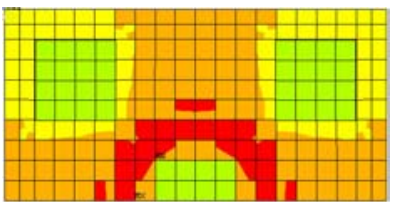

$\mathrm{E} 1-3 \mathrm{~h} 80\left(\phi_{\mathrm{est}}=40 \mathrm{~cm}\right)$

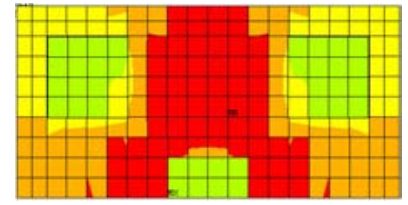

$\mathrm{E} 2-3 \mathrm{~h} 80\left(\phi_{\mathrm{est}}=40 \mathrm{~cm}\right)$

Figura 5.27- Campos de tensão de tração nos modelos de blocos sobre 5 estacas (vista de baixo)

Já nos modelos E2-1h80 e E2-3h80, que tem seções de pilares alongadas, no modelo com estaca de $30 \mathrm{~cm}$ ocorreu maior concentração de tensões de tração em torno da estaca central, sendo os valores de tensão de tração máxima, maiores do que para o modelo de estaca de $40 \mathrm{~cm}$ de diâmetro (figura 5.27). A tabela a seguir mostra os valores de tensão máxima de tração para esses modelos.

Tabela 5.10 - Tensões máximas de tração

\begin{tabular}{ccc}
\hline Modelos & $\phi_{\text {est }}(\mathbf{c m})$ & $\begin{array}{c}\text { Tensão de tração } \\
\text { máxima (MPa) }\end{array}$ \\
\hline E1-1h80 & 30 & 1,40 \\
E1-3h80 & 40 & 1,47 \\
\hline E2-1h80 & 30 & 1,76 \\
E2-3h80 & 40 & 1,13 \\
\hline
\end{tabular}

b) Análise de modelos de blocos com mesma geometria e mesmo diâmetro das estacas variando-se a dimensão de pilares

Os dois grupos de modelos analisados: (1) E1-1h80 e E2-1h80 e (2) E1-3h80 e E2-3h80 possuem pilares de seção quadrada e retangular, têm pilares com área equivalente, sendo o primeiro de cada grupo com área quadrada e o segundo retangular. 
Observando-se a Figura 5.26 pode se analisar que conforme se mudou a geometria do pilar houve diferença na distribuição de tensões de compressão. Da mesma maneira que ocorreu para modelos de blocos sobre quatro estacas houve diferenças significativas entre os modelos de blocos com pilares quadrados e retangulares. A tensão máxima de compressão ao longo da biela de compressão foi maior para os modelos com pilares quadrados e diminuíram conforme se alongou a seção do pilar.

Comparando-se os modelos de blocos sobre cinco estacas com pilar retangular de área $20 \mathrm{~cm} \times 80 \mathrm{~cm}$ e com pilar quadrado de área equivalente $40 \mathrm{~cm} \times$ $40 \mathrm{~cm}$ obteve-se valores máximos de tensões de tração divergiram um pouco. Neste caso, não seria possível a utilização de seções quadradas de área equivalente para blocos com pilares de seção retangular. Na tabela 5.11 são mostrados os valores de tensões máximas de tração para o grupo de modelos analisados.

Tabela 5.11 - Tensões máximas de tração

\begin{tabular}{cccc}
\hline Grupos & Modelos & $\begin{array}{c}\text { Seção Pilar } \\
(\mathbf{c m x c m})\end{array}$ & $\begin{array}{c}\text { Tensão de tração } \\
\text { máxima (MPa) }\end{array}$ \\
\hline \multirow{2}{*}{1} & E1-1h80 & $40 \times 40$ & 1,40 \\
& E2-1h80 & $20 \times 80$ & 1,76 \\
\hline \multirow{2}{*}{2} & E1-3h80 & $40 \times 40$ & 1,47 \\
& E2-3h80 & $20 \times 80$ & 1,13 \\
\hline
\end{tabular}

Observando-se a tabela conforme se alongou a seção para o grupo 1 a tensão máxima aumentou e para o grupo 2 diminuiu. Este resultado não era esperado, pois em outros casos (modelos de duas e quatro estacas) as tensões de tração diminuem conforme se alonga a seção. Essas comparações são válidas, mas ocorre que entre os dois grupos há diferença no diâmetro das estacas também, portanto há distribuições diferentes de tensões. O modelo E2-1h80 têm estacas de $30 \mathrm{~cm}$ de diâmetro já o modelo E2-3h80 têm estacas de $40 \mathrm{~cm}$, os modelos com diâmetro de $40 \mathrm{~cm}$ tiveram uma melhor distribuição nas tensões, portanto uma diminuição do valor máximo.

c) Análise de modelos de blocos com alturas diferentes

Foram analisados modelos de blocos sobre cinco estacas com mesma geometria variando-se a altura. Esta analise tem a intenção de mostrar que conforme se aumenta a altura há diferenças na formação dos campos de tensão, principalmente nos campos de tensão de compressão, mostrados na figura 5.28. 


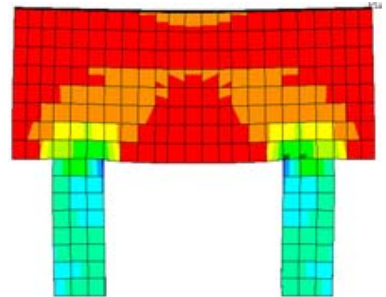

E1-1h80

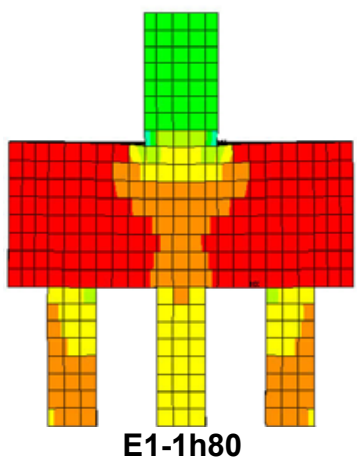

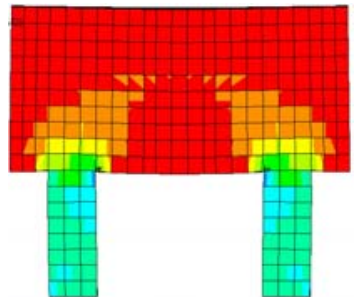

E1-1h95

CORTE AA

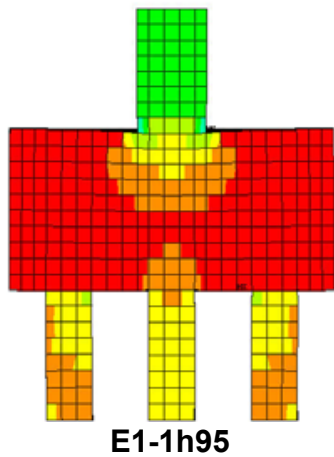

VISTA 1

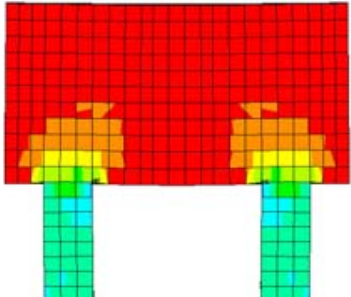

E1-1h110

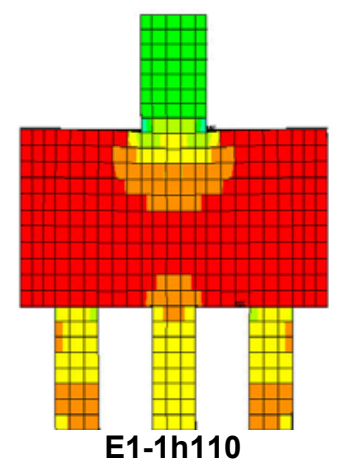

E1-1h110

Figura 5.28 - Campos de tensão de compressão nos modelos de blocos sobre 5 estacas

Os modelos foram adotados conforme o ângulo de inclinação das bielas,

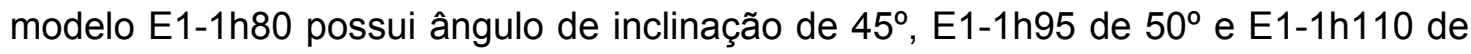
$55^{\circ}$. Estes ângulos estão contidos no intervalo sugerido pelo Método das Bielas $\left(45^{\circ} \mathrm{a}\right.$ $\left.55^{\circ}\right)$

A figura 5.28 mostra que quando o ângulo de inclinação das bielas está em seu limite inferior $\left(45^{\circ}\right)$ uma parcela maior de tensões de compressão se dirigem para a estaca central. Conforme se aumenta este ângulo as tensões são melhores distribuídas para as demais estacas. Esta constatação pode ser melhor conferida quando se compara as reações obtidas em cada estaca, conforme pode ser visto no próximo item.

Os campos de tensão de tração se formam de forma semelhante para todos os modelos analisados neste item, conforme pode ser visto na figura 5.29. 


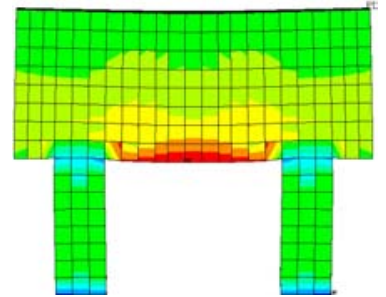

E1-1h80

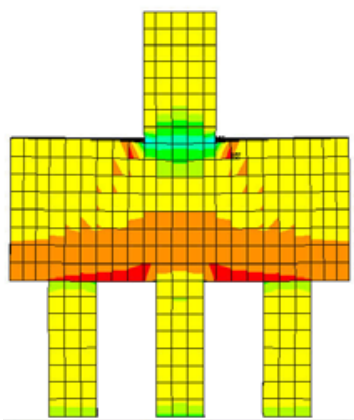

E1-1h80

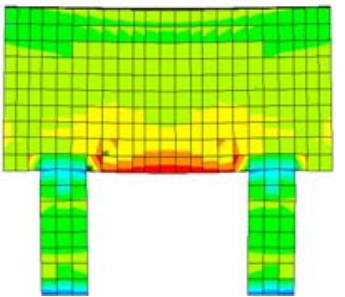

E1-1h95

CORTE AA

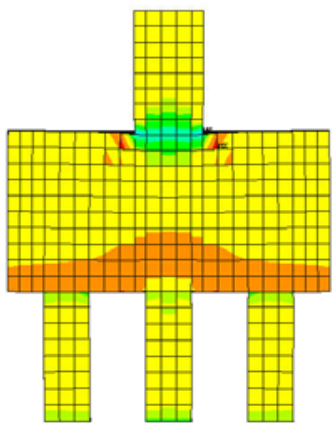

E1-1h95

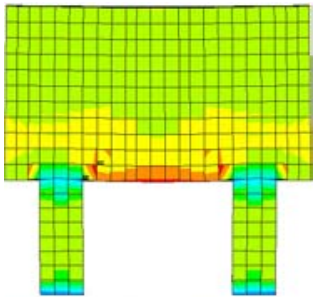

E1-1h110

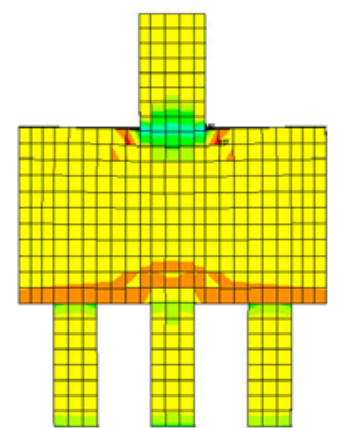

E1-1h110

VISTA 1

Figura 5.29 - Campos de tensão de tração nos modelos de blocos sobre 5 estacas

d) Análise das reações nas estacas

Em cada um dos modelos de blocos sobre cinco estacas foi aplicada uma força centrada de 1900 kN. Portanto, a reação em cada estaca, considerada no modelo analítico, é igual a $380 \mathrm{kN}$, já que, para modelos de blocos com ação de força centrada a reação em cada estaca é considerada o valor da força aplicada dividido pelo número de estacas.

A figura 5.30 mostra como foi considerada a numeração das estacas no modelo.

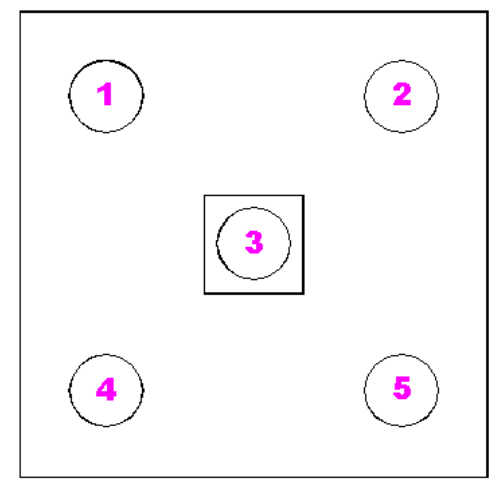

Figura 5.30 - Numeração das estacas nos modelos de blocos sobre cinco estacas 
Nos modelos numéricos a reação obtida em cada estaca divergiu dos modelos analíticos, como é mostrado na tabela 5.12. É importante ressaltar que os modelos adotados têm ângulo de inclinação entre as bielas dentro do intervalo sugerido pelo método analítico de Blévot (1967).

Tabela 5.12 - Reações nas estacas dos modelos numéricos de blocos sobre três estacas

\begin{tabular}{ccccccc}
\hline \multirow{2}{*}{ Modelos } & $\theta^{\circ}$ & $\mathbf{6}$ & $\mathbf{2}$ & $\mathbf{3}$ & $\mathbf{4}$ & $\mathbf{5}$ \\
\hline E1-1h80 & 45 & 360,01 & 360,01 & 459,96 & 360,01 & 360,01 \\
E1-1h95 & 50 & 367,41 & 367,41 & 430,36 & 367,41 & 367,41 \\
E1-1h110 & 55 & 371,84 & 371,84 & 412,64 & 371,84 & 371,84 \\
E1-3h80 & 45 & 344,10 & 344,10 & 523,60 & 344,10 & 344,10 \\
E2-1h80 & 45 & 361,66 & 361,66 & 453,36 & 361,66 & 361,66 \\
E2-3h80 & 45 & 347,09 & 347,09 & 511,64 & 347,09 & 347,09 \\
\hline \multicolumn{7}{l}{ Sendo: $\theta=$ ângulo de inclinação das bielas } \\
\hline \multicolumn{7}{l}{}
\end{tabular}

Conforme a tabela 5.12 nos modelos numéricos a reação na estaca central (estaca 3) foi muito maior do que nas outras estacas. Percebeu-se, analisando os modelos E1-1h80, E1-1h95 e E1-1h110 que conforme se aumenta a altura do bloco o valor da reação na estaca 3 é menor, ou seja, esse modelo de bloco sobre cinco estaca teria que ser muito mais rígido para que a distribuição de força normal fosse coerente com o modelo analítico. O modelo E1-1h110 tem o ângulo de inclinação das bielas de $55^{\circ}$, ou seja, o valor máximo que é permitido pelo Método de Blévot (1967) para que se garanta que a transmissão de forças se dê pelo Modelo de Bielas e Tirantes.

Mediante as constatações decidiu-se pela modelagem de mais um modelo de blocos sobre cinco estacas. Esse modelo teve a mesma geometria que o modelo E1$1 \mathrm{~h} 80$, mas agora a altura adotada foi de $150 \mathrm{~cm}$, esse novo modelo foi nomeado de E1-1h150 (d= $140 \mathrm{~cm}$ ). Para essa altura adotada no novo modelo o ângulo de inclinação das bielas é de aproximadamente $63^{\circ}$, ou seja, bem maior que o intervalo permitido. A tabela a seguir mostra as reações encontradas para estacas do bloco E1-1h150.

Tabela 5.13 - Reações nas estacas do modelo E1-1h150

\begin{tabular}{ccccccc}
\hline \multirow{2}{*}{ Modelo } & $\theta^{\circ}$ & $\mathbf{5}$ & $\mathbf{2}$ & $\mathbf{3}$ & $\mathbf{4}$ & $\mathbf{5}$ \\
\hline E1-1h150 & 63 & 377,23 & 377,23 & 391,08 & 377,23 & 377,23 \\
\hline
\end{tabular}


As reações nas estacas obtidas no modelo E1-1h150 foram valores bem mais próximos do modelo numérico, mas ainda assim a estaca 3 (central) apresentou maior valor do que as demais.

Após essas verificações pode-se constatar que esse modelo de bloco sobre cinco estacas não é confiável, já que teria que atingir ângulos maiores que $63^{\circ}$ para a inclinação das bielas. Aumentando muito a altura ficaria descaracterizado o tratamento desse modelo como bloco sobre estacas, devendo talvez, ser tratado como viga-parede. Além disso, não seria vantagem utilizar um bloco de fundação com uma altura muito elevada. Sendo assim, o mais correto seria adotar outra disposição de estacas, quando se houver a necessidade de utilizar blocos sobre cinco estacas.

\subsection{Modelagem utilizando Bielas e Tirantes}

É fato que para a definição de um modelo de Bielas e Tirantes deve-se seguir como orientação inicial os contornos e as trajetórias elásticas de tensões na peça, que são obtidas inicialmente empregando-se um programa de análise em Elementos Finitos Linear.

Como foi citado anteriormente Longo (2000) utilizou modelos numéricos obtidos do Método dos Elementos Finitos para obtenção de modelos de Bielas e Tirantes; os modelos dele foram desenhados na própria tela do computador sobre os desenhos de trajetórias de tensão.

Da mesma maneira que Longo (2000) com os modelos obtidos neste trabalho procurou-se sugerir um modelo mais refinado do que os modelos analíticos existentes, mas não se pode generalizar, já que, o modelo adotado é função da geometria e das ações atuantes em seu contorno; estruturas com mesmas ações e geometrias diferentes são modeladas de maneira diferente. Portanto, nos modelos sugeridos não se definiu, por exemplo, espessura das bielas já que isso dependeria da seção de estacas e pilares adotados.

Neste item não foram analisados os modelos de blocos sobre cinco estacas, já que, concluiu-se que este tipo de disposição de estacas não é adequada. 


\subsubsection{Blocos sobre uma estaca}

A figura 5.31 apresenta as trajetórias de tensão nas direções principais 1 (tração) e 3 (compressão) obtidas para um dos modelos.
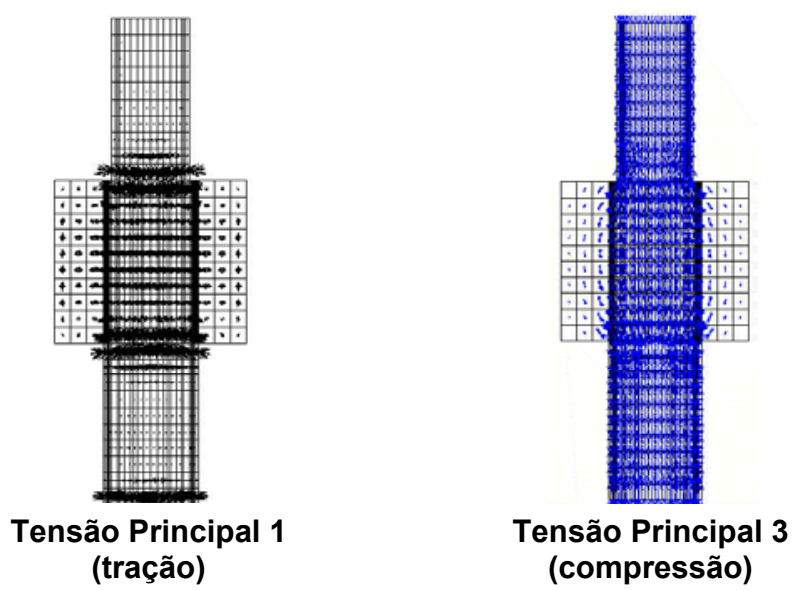

Figura 5.31 -Trajetória de Tensões Principais - Modelo A1-1h50

A figura 5.32 mostra as trajetórias de tensões na direção 3 (compressão) para os modelos de blocos sobre uma estaca.
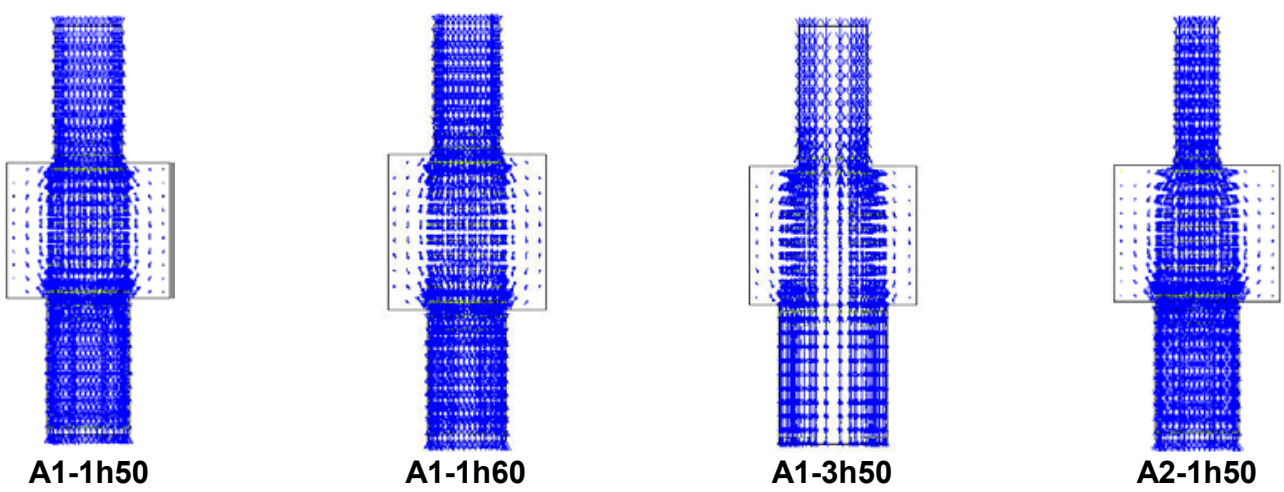

Figura 5.32 - Trajetória de Tensões Principais

Nos modelos de blocos sobre uma estaca houve variações nos campos e trajetórias de tensões, principalmente quando se reduz a seção do pilar em uma das direções. Mesmo assim pode-se constatar que o modelo de Bielas e Tirantes, sugerido por Fusco (1994), mostrado no capítulo 3, para blocos parcialmente carregados, seria uma boa solução, adaptado a blocos sobre uma estaca, como é mostrado na figura 5.33 . 

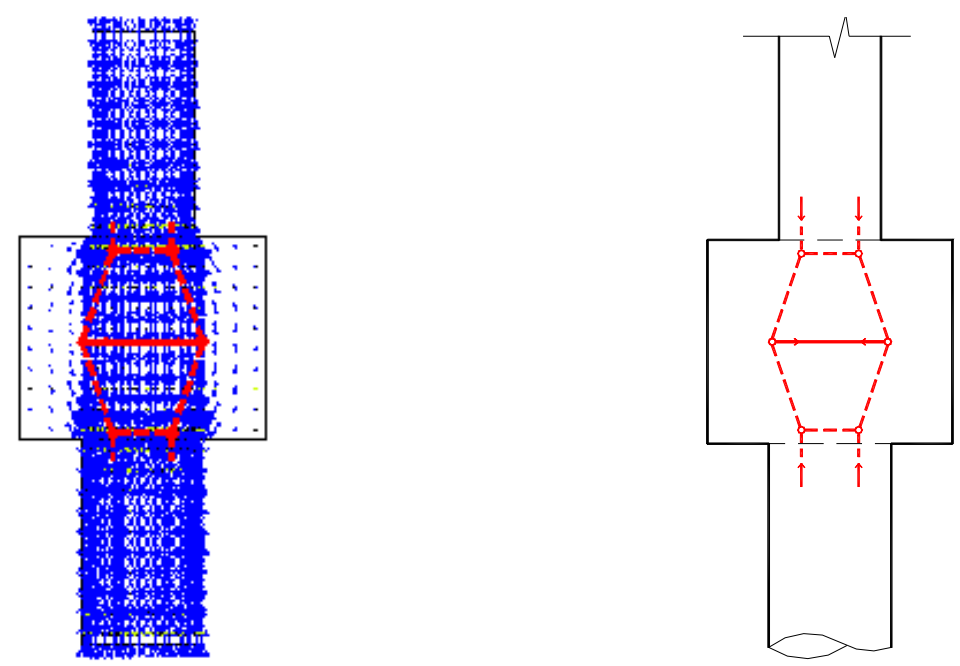

-mBIELAS

TIRANTES

Trajetórias de tensões elástico-lineares

Proposta de Modelo de Bielas e Tirantes para blocos sobre uma estaca

Figura 5.33 - Trajetórias de tensões elástico-lineares e Modelo de Bielas e Tirantes para blocos sobre uma estaca

O arranjo da armadura fica definido pelo tirante localizado ao centro, porém esse arranjo das barras de armadura deve ser feito em várias camadas. As regiões nodais serão verificadas conforme os critérios do CEB-FIP (1990).

\subsubsection{Blocos sobre duas estacas}

A figura 5.34 apresenta as trajetórias de tensão nas direções principais 1 (tração) e 3 (compressão) obtidas para um dos modelos.

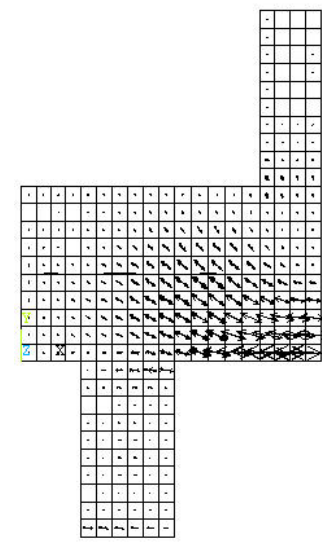

Tensão Principal 1 (tração)

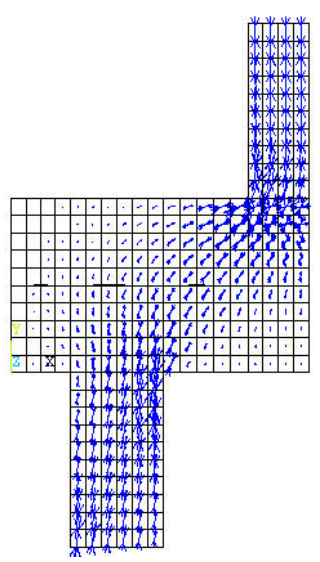

Tensão Principal 2 (compressão)

Figura 5.34 -Trajetória de Tensões Principais - Modelo B1-1 
Nos modelos adotados para blocos sobre duas estacas, apesar das diferentes seções adotadas para estacas e pilares a trajetórias de tensão é semelhante, divergindo obviamente nas regiões nodais. A figura 5.35 mostra as trajetórias de tensões em todas as direções obtidas para alguns dos modelos.

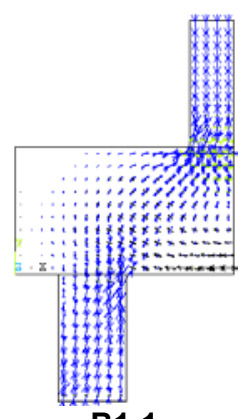

B1-1

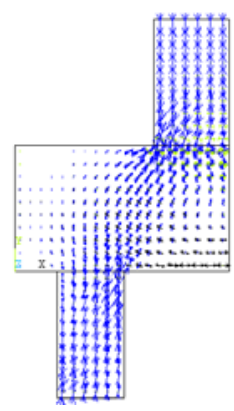

B2-1

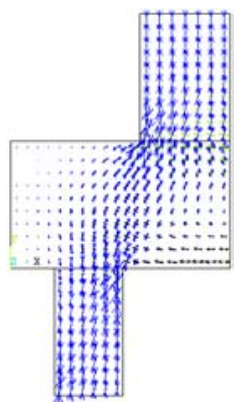

B3-1

Figura 5.35 -Trajetórias de tensões principais

Fazendo uma análise conjunta dos campos de tensão e das trajetórias de tensões obtidas, conclui-se que o modelo sugerido por Adebar et al.(1990), mostrado no Capítulo 2, seria bem coerente com os modelos estudados e utilizando-se para esses modelos obteria-se a treliça mostrada na figura 5.36. O modelo refinado sugerido pelo autor sugere um tirante onde os campos de tensão de compressão se expandem e são produzidas tensões de tração, essa constatação pode ser feita para os modelos estudados observando-se as trajetórias de tensão principal na direção 1.

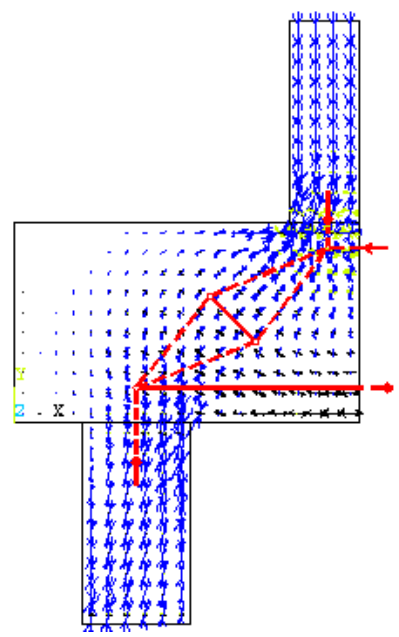

Trajetórias de tensões elástico-lineares

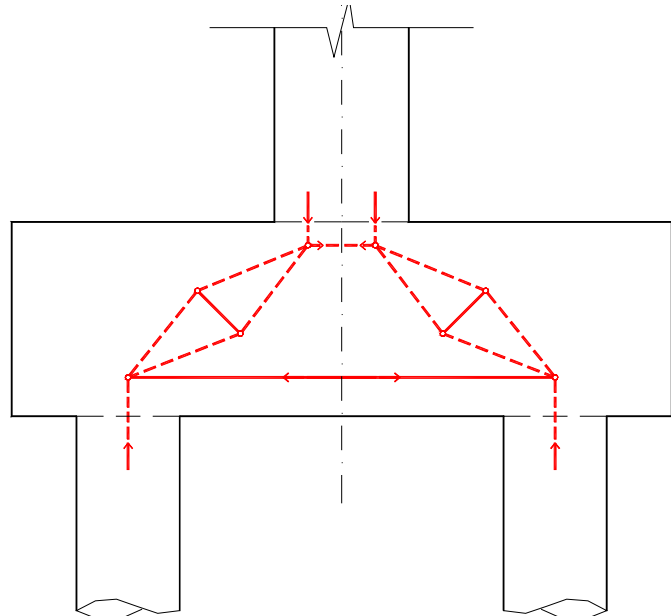

-m=-BIELAS

TIRANTES

Proposta de Modelo de Bielas e Tirantes para blocos sobre duas estaca

Figura 5.36 - Trajetórias de tensões elástico-lineares e Modelo refinado de Bielas e Tirantes para blocos sobre duas estacas 
Para a treliça apresentada é necessária a verificação das regiões nodais, conforme as recomendações do Código Modelo do CEB-FIP (1990), para isto, é preciso a definição das larguras das bielas que chegam nos nós. $O$ arranjo da armadura fica definido pelo tirante localizado na parte inferior do modelo. $O$ tirante inclinado pode ser considerado de concreto, e deve ser feita a verificação da resistência à tração do concreto.

\subsubsection{Blocos sobre três estacas}

A figura 5.37 apresenta as trajetórias de tensão nas direções principais 1 (tração) e 3 (compressão) obtidas para um dos modelos de blocos sobre três estacas.

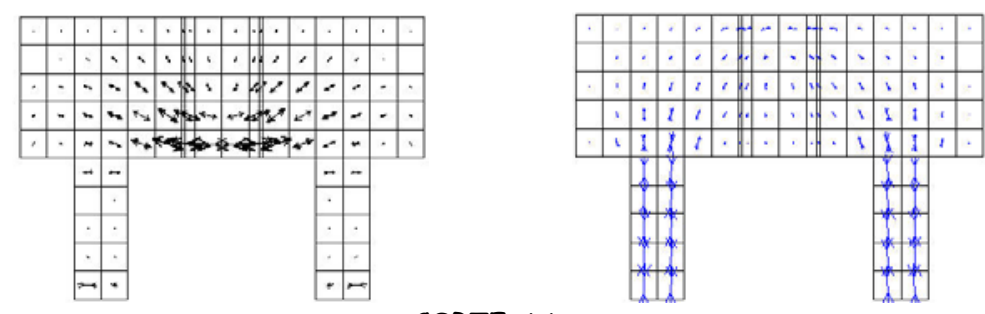

CORTE AA

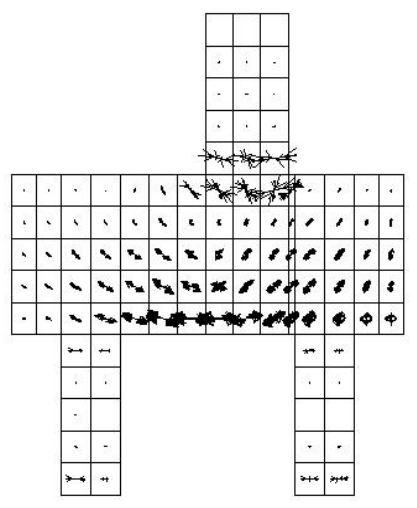

CORTE CC

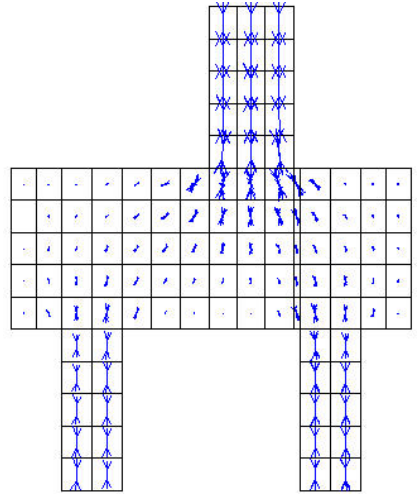

Tensão Principal 3 (compressão)

Figura 5.37 -Trajetória de Tensões Principais - Modelo C1-1

De forma geral a distribuição de tensão de compressão (formação das bielas) foi semelhante para todos os modelos, podendo-se adotar uma solução semelhante. As trajetórias de tensões de tração, da mesma forma que para os blocos sobre duas estacas, foram mais intensas na parte superior do bloco, apresentando tensões inclinadas ao longo da altura. Portanto para adoção de um modelo de bielas e tirantes 
poderia se utilizar a mesma treliça, utilizada para blocos sobre duas estacas, mudando, logicamente o posicionamento do tirante inferior. A forma das bielas e o tirante inclinado no meio seriam iguais aos sugerido na figura 5.36.

A posição dos tirantes na face inferior dos blocos deve ser estudada para cada caso. É mostrado na figura 5.38 uma vista de baixo das trajetórias de tensões principais de tração.
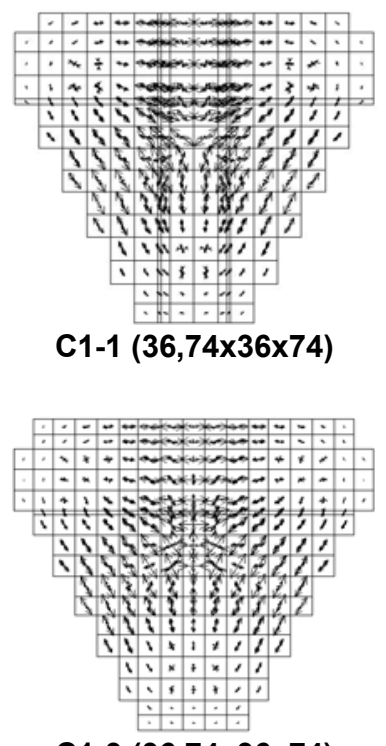

C1-3 $(36,74 \times 36 \times 74)$

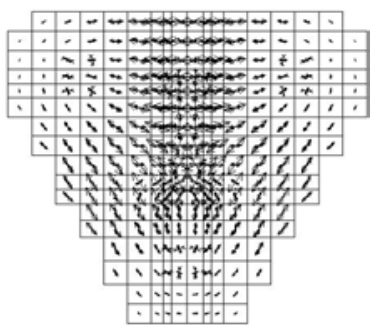

C2-1 (18x75)

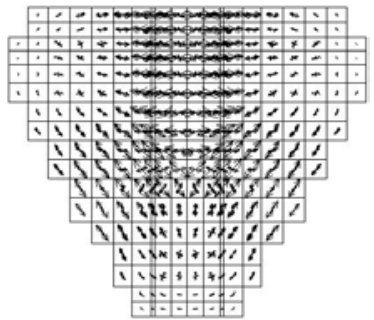

C2-3 (18x75)

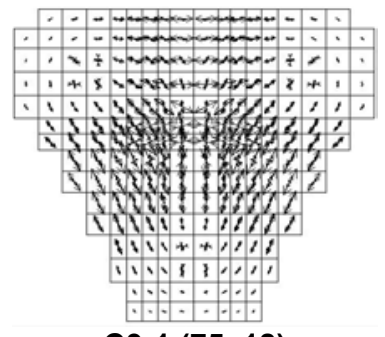

C3-1 (75x18)

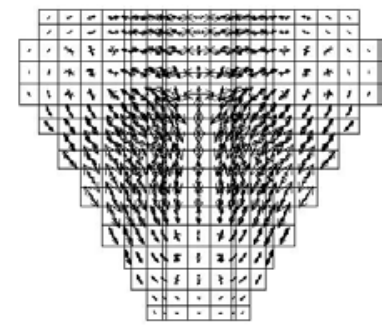

C3-3 (75x18)

Figura 5.38 -Trajetória de Tensões Principais Direção 1 (tração) - Vista Inferior

É possível imaginar como deve ser a disposição das armaduras dos tirantes com as trajetórias de tensão mostradas na figura 5.38. Para todos os modelos com a melhor disposição de armadura encontrada, que atenderia a distribuição das trajetórias de tensões seria segundo os lados dos blocos (ligando as estacas). Havia dúvidas sobre se no caso de pilares alongados a disposição de armadura seria a mesma que para pilares quadrados, mas concluiu-se que essa disposição pode atender aos dois modelos. Talvez, em conjunto com uma armadura de distribuição, os modelos trabalhariam melhor, já que as tensões máximas ocorrem no centro do bloco, essa armadura distribuiria melhor para armadura principal disposta segundo os lados. O uso desse tipo de distribuição se justifica também, aos ensaios experimentais feitos por Miguel (2000) que utilizou em um de seus modelos uma disposição de armadura segundo os lados do bloco, somadas a uma armadura em malha, e, constatou que o uso de barras distribuídas diminui as fissuras na base do bloco. 
A figura 5.39 mostra as trajetórias de tensões principais de tração e a sugestão para disposição das armaduras dos tirantes para os modelos de blocos sobre três estacas estudados.

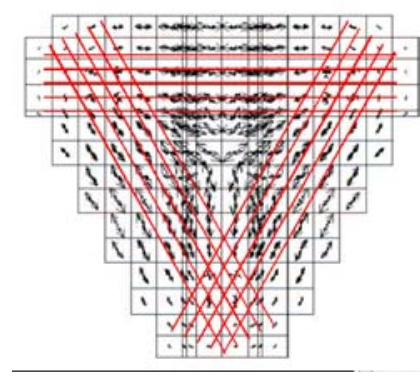

C1-1 $(36,74 \times 36 \times 74)$

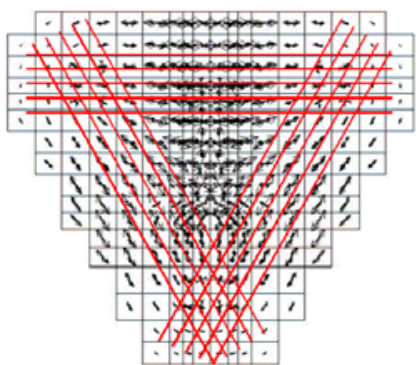

C2-1 (18x75)

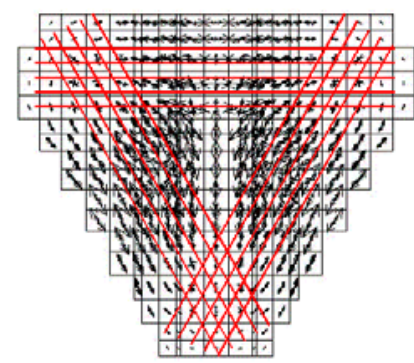

C3-1 (75x18)

Figura 5.39 - Trajetórias de tensões de tração e sugestão para disposição de armadura dos tirantes para blocos sobre três estacas

Uma outra solução para a distribuição da armadura principal, em blocos sobre três estacas, é a utilização de uma combinação de armaduras dispostas segundo os lados do bloco, somadas a armaduras dispostas segundo as medianas, já que nos modelos ensaiados por Miguel (2000) para essa forma de distribuição os modelos resistiram a maior força aplicada, como pode ser constatado no Capítulo 2.

\subsubsection{Blocos sobre quatro estacas}

A figura 5.40 apresenta as trajetórias de tensão nas direções principais 1 (tração) e 3 (compressão) obtidas para um dos modelos de blocos sobre quatro estacas. 


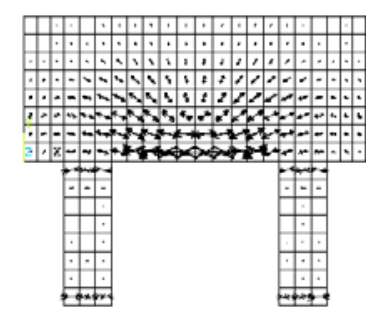

CORTE AA
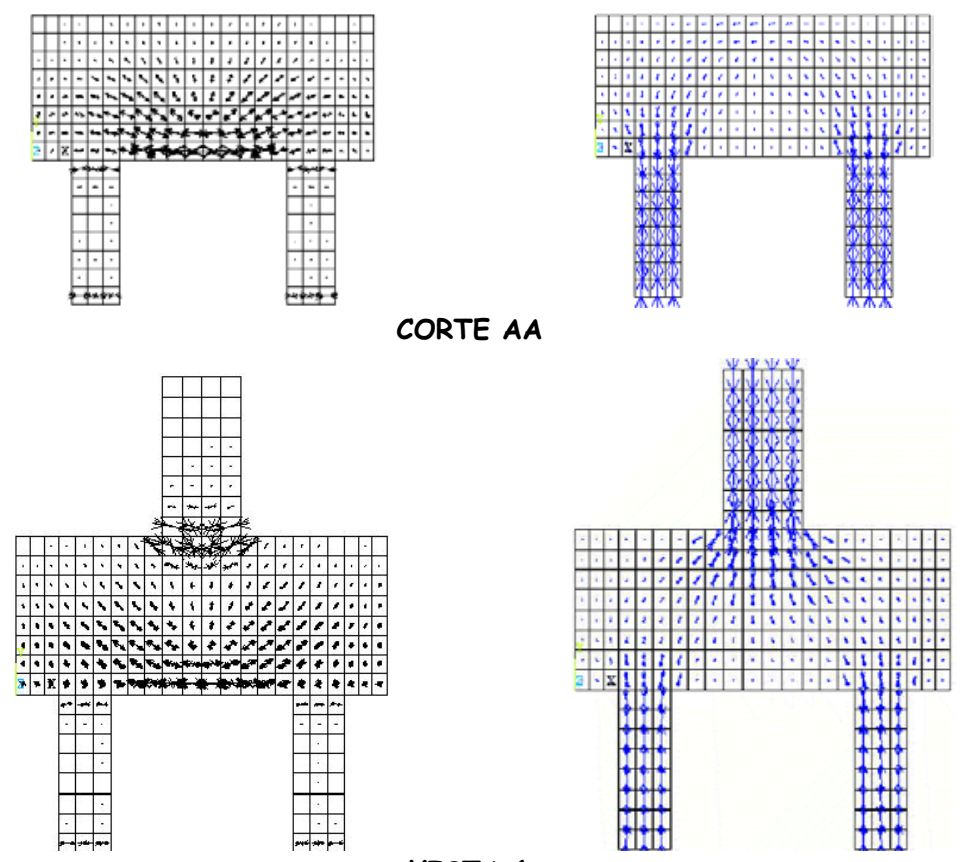

VISTA 1

Tensão Principal 1 (tração)

Tensão Principal 3 (compressão)

Figura 5.40 -Trajetória de Tensões Principais - Modelo D1-1

Como era esperada, a trajetória de tensões principais nos modelos de blocos sobre quatro estacas foi semelhante para todos os modelos. Para o modelo de bielas e tirantes pode se adotar uma treliça semelhante a que foi adotada pra blocos sobre duas estacas, mas equilibrada agora para quatro estacas.

As tensões principais de tração ocorreram no centro do bloco. A figura 5.41 mostra a configuração das trajetórias de tensões principais na direção 1 (tração), vista de baixo, para alguns modelos adotados.

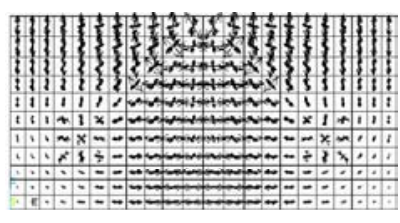

D1-1

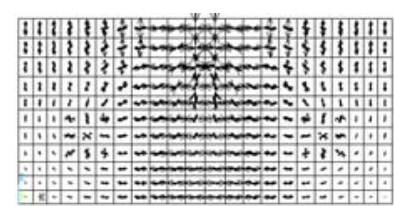

D2-1

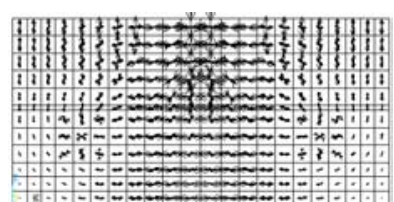

D3-1

Figura 5.41 -Trajetória de tensões de tração - Vista Inferior

Com as trajetórias de tensões mostradas na figura 5.41 é possível a sugestão de uma disposição adequada para as armaduras dos tirantes inferiores. Para todos 
os modelos adotados notou-se que uma distribuição bem coerente seria armar o bloco segundo os lados (unindo as estacas), como pode ser visto na figura 5.42 .

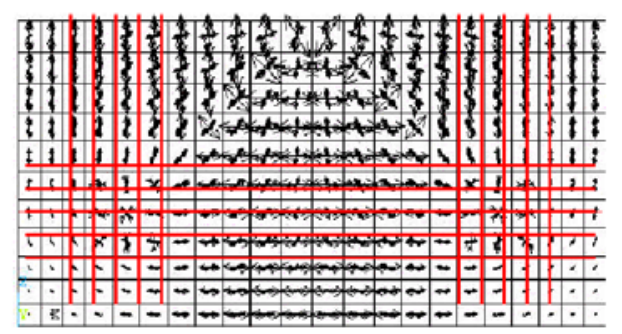

Figura 5.42 - Trajetórias de tensões de tração e sugestão para disposição de armadura dos tirantes para blocos sobre quatro estacas

Da mesma maneira que para blocos sobre três estacas é interessante a adoção de uma armadura de distribuição em conjunto com a armadura principal distribuída segundo os lados.

A sugestão desse tipo de disposição de armadura atende os requisitos propostos na NBR 6118:2003, que sugere a armadura principal dos blocos deva ser disposta essencialmente em faixas definidas pelas estacas em proporção de equilíbrio com as bielas.

\subsection{Exemplo de Aplicação para blocos sobre duas estacas}

Um exemplo de aplicação do Modelo de Biela e Tirante para blocos sobre duas estacas foi resolvido por meio da sugestão feita no item 5.4.

É importante salientar que esse modelo resolvido só é aplicado para este caso, ou seja, um bloco sobre duas estacas, submetido à ação de força centrada, com pilar quadrado de seção $34,64 \mathrm{~cm} \times 34,64 \mathrm{~cm}$ e estacas $26,58 \mathrm{~cm} \times 26,58 \mathrm{~cm}$. Trata-se do modelo chamado de B1-1, mostrado na figura 5.43. São dados ainda: concreto C20 e aço CA-50. 


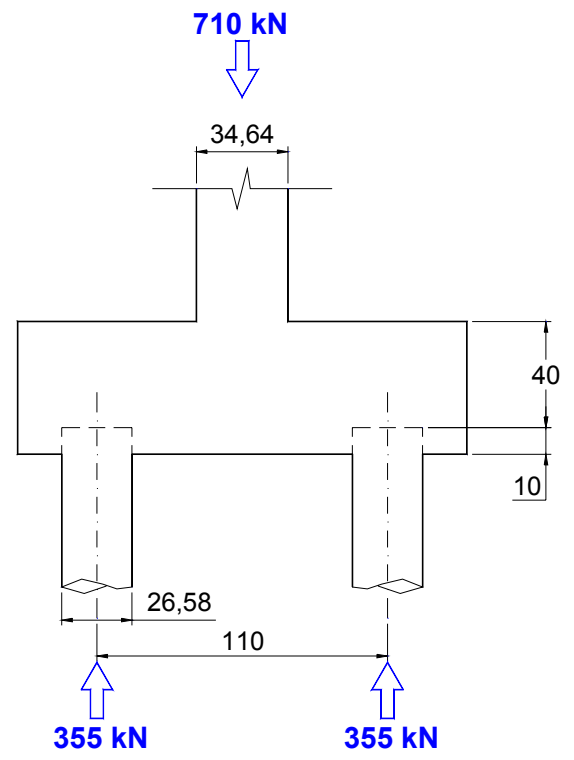

Figura 5.43 - Bloco sobre duas estacas B1-1

\subsubsection{Modelo de Bielas e Tirantes}

Para o modelo sugerido foi necessário acrescentar duas barras (bielas) para que houvesse equilíbrio dos nós, e por meio disso, determinaram-se as forças de compressão e tração, conforme é mostrado na figura 5.44 .

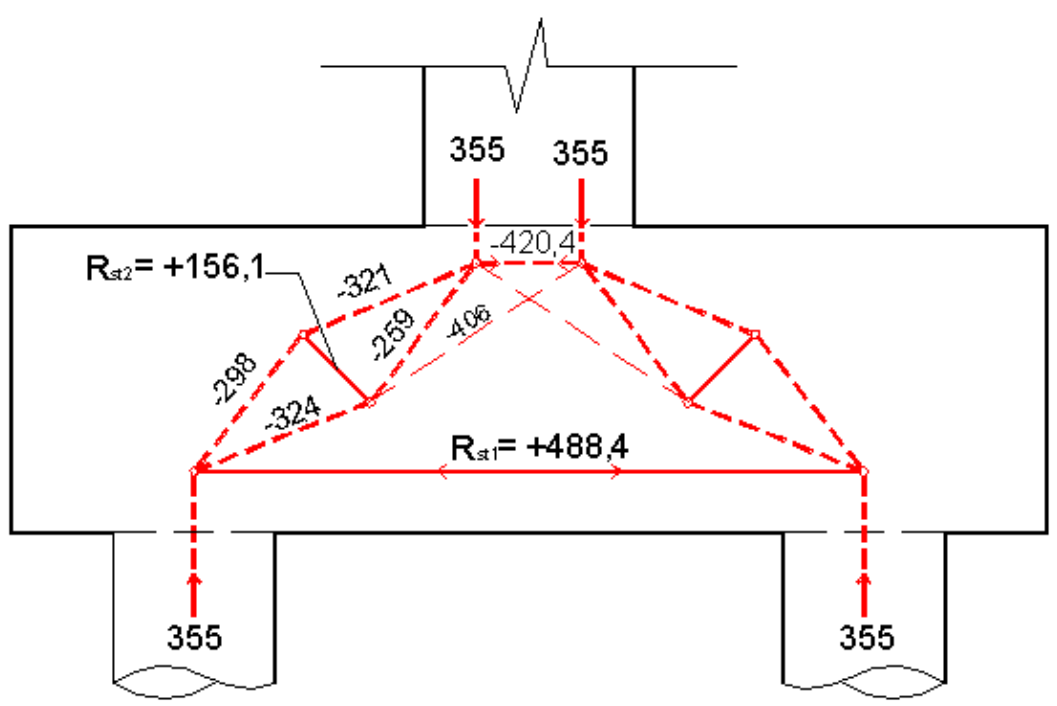

Figura 5.44 - Modelo para bloco sobre duas estacas B1-1 


\subsubsection{Dimensionamento dos Tirantes}

O cálculo da área de armadura de tração para armadura principal é feito com a força de cálculo $R_{\mathrm{st} 1}$, dividindo-a pela resistência de cálculo à tração do aço, resultando:

$$
A_{s 1}=\frac{R_{s t 1}}{f_{y d}}=\frac{488,4}{50 / 1,15}=11,23 \mathrm{~cm}^{2}
$$

Para essa área de armadura pode-se adotar $9 \phi 12,5\left(11,25 \mathrm{~cm}^{2}\right)$.

Para o tirante em diagonal com força $R_{\text {st2 }}$, deve-se verificar a resistência à tração do concreto, ou adotar uma armadura que resista a essa força.

Segundo a NBR 6118:2003 a resistência à tração do concreto é obtida por meio das equações:

$$
\begin{aligned}
& \mathrm{f}_{\mathrm{ct}, \mathrm{m}}=0,3 \mathrm{f}_{\mathrm{ck}}^{2 / 3}=2,21 \mathrm{MPa} \mathrm{e}, \\
& \mathrm{f}_{\mathrm{ctk}, \text { inf }}=0,7 \mathrm{f}_{\mathrm{ctm}}=1,55 \mathrm{MPa}
\end{aligned}
$$

Para adoção de tirante de concreto seria necessária a consideração da seguinte área:

$$
A_{c t}=\frac{R_{s t 2}}{f_{c t d}}=\frac{156,1}{1,55 / 1,4}=141 \mathrm{~cm}^{2}
$$

Uma outra solução seria adoção de uma armadura com a área:

$$
A_{s 2}=\frac{R_{s t 2}}{f_{y d}}=\frac{156,1}{50 / 1,15}=2,72 \mathrm{~cm}^{2}
$$

\subsubsection{Verificações das Tensões}

A tensão $\sigma_{\mathrm{c} 2}$ foi verificada na região nodal próxima à estaca, onde se encontra uma região nodal com ancoragem das barras do tirante, sendo o tirante ancorado apenas em uma direção. Seu valor deve ser menor que a tensão limite $f_{c d 3}$. A tensão 
$\sigma_{\mathrm{c} 1}$ é calculada na região nodal próximo ao pilar e seu valor limite deve ser a tensão $f_{c d 1}$.

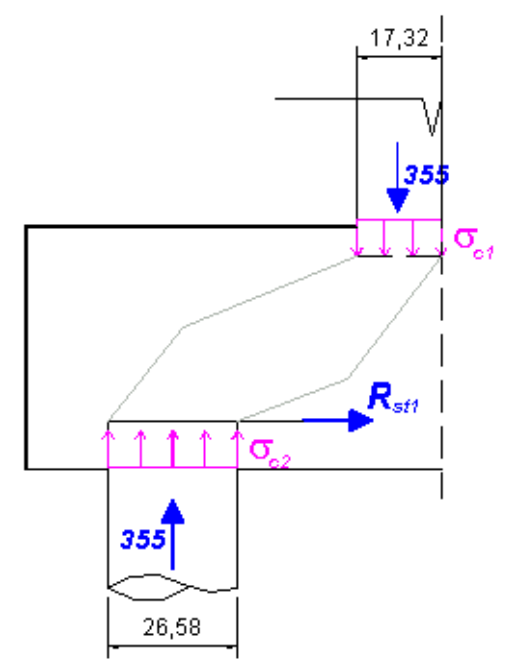

Figura 5.45 - Regiões nodais verificadas

As tensões limites são calculadas conforme as formulações do CEB-FIP(1990) e FIP (1999), mostradas no Capítulo 4.

Para nós onde só chegam bielas de compressão a tensão média não deve exceder:

$$
f_{c d 1}=0,85\left[1-\frac{f_{c k}}{250}\right] f_{c d}=1,12 \mathrm{kN} / \mathrm{cm}^{2}
$$

A tensão nodal na região do pilar é definida por:

$$
\sigma_{\mathrm{c} 1}=\frac{355}{17,32 \cdot 34,64}=0,59 \mathrm{kN} / \mathrm{cm}^{2}<\mathrm{f}_{\mathrm{cd} 1} \rightarrow \text { condição satisfeita }
$$

Para nós com tirantes ancorados apenas em uma direção, a tensão média não deve exceder o valor da tensão $f_{c d 3}$, fornecida pelo FIB (1999)

$$
\mathrm{f}_{\mathrm{cd} 3}=0,70\left[1-\frac{\mathrm{f}_{\mathrm{ck}}}{250}\right] \mathrm{f}_{\mathrm{cd}}=0,92 \mathrm{kN} / \mathrm{cm}^{2}
$$

A tensão nodal na região da estaca é definida por:

$$
\sigma_{\mathrm{c} 2}=\frac{355}{26,58 \cdot 26 \cdot 58}=0,50 \mathrm{kN} / \mathrm{cm}^{2}<\mathrm{f}_{\mathrm{cd} 3} \rightarrow \text { condição satisfeita }
$$




\subsubsection{Comentários sobre o exemplo}

O tirante que fornece a área da armadura principal do bloco teve um valor semelhante ao adotado pela EHE (2001). No cálculo feito pela Norma Espanhola obteve-se uma força de $483,8 \mathrm{kN}$, e no modelo adotado $488,4 \mathrm{kN}$. No modelo de Blévot (1967) o valor era de 411,3 kN.

A semelhança entre os valores do modelo adotado e da EHE (2001) ocorreu em virtude da distância adotada entre o centro do banzo comprimido e o tracionado, pois no modelo esse valor foi próximo a $0,85 d$, mesmo valor que adota a norma EHE (2001). Já o modelo de Blévot (1967) adota uma treliça com altura $d$ o que fornece valores para forças nos tirantes menores.

Essa foi a solução mais coerente para o modelo em questão, já que as bielas e tirantes foram posicionada em cima dos campos e trajetórias de tensões obtidos do modelo numérico. 


\section{CONCLUSÃO}

\subsection{Preâmbulo}

A importância deste trabalho foi mostrar que os métodos utilizados para projeto de blocos sobre estacas apresentam divergências entre si. Esta constatação pôde ser feita em virtude dos diferentes resultados encontrados no cálculo das áreas de barras de armadura e para as verificações de tensões de compressão.

Os modelos numéricos apresentaram os resultados esperados demonstrando a importância em se adotar um modelo analítico mais refinado que leve em consideração parâmetros como diâmetro de estacas e seções de pilares, além disso, deve-se adotar uma verificação de compressão nas regiões nodais, próximo ao pilar e próximo às estacas, semelhantes ás feitas para Modelos de Bielas e Tirantes.

Ficou comprovado que adoção de uma análise numérica simplificada, considerando comportamento elástico linear, era necessária, já que existem poucos trabalhos tratando desse assunto, e, além disso, é o primeiro passo para adoção de um modelo de Bielas e Tirantes.

Constatou-se que a treliça adotada pelo Método das Bielas (Blévot, 1967) é um modelo coerente para projeto de blocos sobre estacas, e é o mais simples. Por meio das trajetórias de tensões e com os contornos de tensão obtidos para cada modelo foi possível posicionar bielas e tirantes e sugerir um modelo mais refinado, além disso, foi possível a verificação da influência do diâmetro das estacas e das seções de pilares no projeto de blocos sobre estacas e pode-se sugerir arranjos de armadura. 


\subsection{Comportamento dos modelos}

\subsubsection{Blocos sobre uma estaca}

A análise de blocos sobre uma estaca foi importante para a verificação de que este tipo de elemento deve receber mais importância do que se tem dado na prática.

A adaptação da teoria de blocos parcialmente carregados pode nem sempre fornecer bons resultados no caso de blocos sobre uma estaca, principalmente quando se têm variações de seções de pilares e estacas.

Pode se verificar também que quando ocorrem variações na altura há grande mudança nos campos de tensão o que não é considerado na metodologia utilizada.

O uso de um modelo de Bielas e Tirantes e imprescindível para esse tipo de elemento e pode trazer bons resultados.

\subsubsection{Blocos sobre duas, três e quatro estacas}

O modelo de Biela e Tirante sugerido não é nenhuma novidade, já que outros autores já tinham constatado em trabalhos experimentais que as bielas de compressão romperam por esmagamento do concreto; acreditando-se que a ruptura do tirante diagonal de concreto era o mecanismo crítico envolvido nas ruínas por cisalhamento dos blocos ensaiados.

Por isso entende-se a importância em se adotar a treliça sugerida, fazendo-se a verificação do tirante diagonal, se não for possível a adoção de tirante de concreto (fazendo-se a verificação à tração do concreto) deve-se adotar uma armadura diagonal.

Outro ponto importante é a geometria da treliça, que deve ser diferente conforme a seção do pilar; a maior parte dos métodos analíticos considera para blocos com pilares de seção retangular com uma seção quadrada equivalente, e essa pode ser uma solução conservativa, em alguns casos, portanto, deve-se estudar caso a caso. A seção da estaca também deve ser considerada, já que, nos modelos analisados, quando se aumenta a seção, as tensões nas bielas diminuem, e, conseqüentemente, diminuem as tensões nos tirantes. 


\subsubsection{Blocos sobre cinco estacas}

A adoção de modelos de blocos sobre cinco estacas distribuídas segundo os vértices de um quadrado e uma estaca no centro geométrico trouxe conclusões importantes; com o uso de uma estaca central pode se perceber que o comportamento do modelo não é exatamente como considerado na prática. Considerando fatores como a fissuração os resultados poderiam ser ainda piores, ou seja, a distribuição de tensão seria ainda mais distinta.

Como já foi dito anteriormente com as analises efetuadas pôde-se constatar que o modelo de bloco sobre cinco estacas, adotado neste trabalho, não é confiável, já que teria que atingir ângulos maiores que $63^{\circ}$ para a inclinação das bielas. Aumentando muito a altura ficaria descaracterizado o tratamento desse modelo como bloco sobre estacas, devendo-se talvez, ser tratado como viga-parede. Além disso, não é vantagem econômica utilizar um bloco de fundação com uma altura muito elevada. Sendo assim, o mais correto é adotar outra disposição de estacas, quando houver a necessidade de utilizar blocos sobre cinco estacas, como por exemplo, blocos com estacas dispostas nos vértices de um pentágono.

\subsection{Sugestões para trabalhos futuros}

Com a finalidade de contribuir para a orientação de trabalhos futuros, envolvendo o tema, sugerem-se alguns temas como segue.

Análise de modelos numéricos considerando não-linearidade, estudando a influência dos efeitos de perda de rigidez dos elementos estruturais por causa da fissuração e escoamento das armaduras longitudinais na formação dos campos e trajetórias de tensões.

Realização de análise experimental com modelos de blocos sobre cinco estacas (com a mesma disposição de estacas adotadas neste trabalho), adotando-se modelos com diferentes ângulos de inclinação das bielas, para um estudo mais aprofundado do comportamento real desse modelo, já que é muito utilizado na prática de projeto de blocos sobre estacas, visto que a disposição de estacas em pentágono causa algumas dificuldades na execução.

Estudos mais aprofundados no comportamento de modelos de blocos sobre uma estaca, pois, na maioria dos casos, principalmente em obras de pequeno porte, projetistas não efetuam cálculos para este tipo de elemento, considerando que a 
transmissão de força é direta, quando estacas e pilares têm seções transversais com dimensões semelhantes.

Análises numéricas e experimentais de modelos de blocos sobre estacas com disposição diferentes das adotadas neste trabalho.

E finalmente elaboração de critérios para aplicação de modelos de Bielas e Tirantes sugeridos para formulação de roteiro para dimensionamento de blocos sobre estacas. 


\section{REFERÊNCIAS BIBLIOGRÁFICAS}

ADEBAR, P.; KUCHMA, D.; COLLINS, M. P. (1990). Strut-and-tie models for design of pile caps: an experimental study. ACI Structural Journal, v.87, p. 81-92, Jan-Feb.

ALONSO, U.R. (1983). Exercícios de Fundações, São Paulo, Edgard Blücher.

ANDRADE, J. R. L. (1989). Dimensionamento estrutural de elementos de fundação. São Carlos, EESC-USP. (Notas de Aula).

ANSYS User's Manual. Theory Manual. 1998. ANSYS revision 5.5.

ASSOCIAÇÃO BRASILEIRA DE NORMAS TÉCNICAS. NBR 6118:2003 - Projeto de estruturas de concreto. Rio de Janeiro

ASSOCIAÇÃO BRASILEIRA DE NORMAS TÉCNICAS. NBR 6122:1986 - Projeto e execução de fundações. Rio de Janeiro

AMERICAN CONCRETE INSTITUTE (1983). Design Handbook, v.1: Beam, oneway slabs, brackets, footings and pile caps. (ACI 340. IR-84) ACI SP-17, Detroit, USA.

AMERICAN CONCRETE INSTITUTE (1989). ACI 318-89 - Building code requeriments for reinforced concrete and commentary (ACI 318 R-89). Detroit, USA.

AMERICAN CONCRETE INSTITUTE (1994). ACI 318M - Building code requeriments for reinforced concrete. Detroit, USA. 
BLÉVOT, J.; FRÉMY, R. (1967). Semelles sur pieux. Annales d'Institut Technique du Bâtiment et des Travaux Pulblics, Paris, v.20, n. 230, p. 223-295, fev.

BURKE JR., J.U. (1978). Blocos rígidos sobre apoios diretos. São Paulo, Maubertec.

CALAVERA, J. (1991). Calculo de estructuras de cimentacion. Instituto Tecnico de Materiales y Construcciones. $3^{\text {a }}$ Edição. Madrid, Espanha.

CARVALHO, I. H. (1994). Análise experimental de blocos sobre grupos de estacas escavadas de pequeno diâmetro. Dissertação (Mestrado) - Escola de Engenharia de São Carlos, Universidade de São Paulo;

CLARKE, J. L. (1973). Behaviour and design of pile caps with four piles. London, Cement and Concrete Association. 19p. (Technical Report, n. 42489)

COMITÉ EURO-INTERNATIONAL DU BÉTON (1970). CEB-FIP Recommandations particulières au calcul et à l'exécution dês semelles de fondation. Bulletin D'Information, Paris, n.73.

COMITÉ EURO-INTERNATIONAL DU BÉTON (1990). CEB-FIP model code for concrete structures. Bulletin D'Information, Paris, n. 203-205, July.

COMISIÓN PERMANENTE DEL HORMIGÓN (1991). Ministerio de Fomento. Centro de Publicaciones. Instrucción española de hormigón armado (EH), Madrid.

COMISIÓN PERMANENTE DEL HORMIGÓN (2001).Ministerio de Fomento. Centro de Publicaciones. Instrucción de hormigón estructural (EHE), Madrid.

COMMISSON OF THE EUROPEAN COMMUNITIES (1989). Eurocode 2 - Design of concrete strutures. Brussels.

FÉDÉRATION INTERNATIONALE DU BÉTON (1999). Structural concrete. Fib Bulletin, Lausanne, n. 1-3. (3 volumes)

FUSCO, P.B. (1994). Técnica de armar as estruturas de concreto. São Paulo, Editora Pini Ltda. 
GOGATE, A. B.; SABNIS, G. M. (1980). Design of thick pile caps. ACl Journal, v, 77, p. 18-22.

GUERRIN, A. (1980). Tratado de concreto armado. São Paulo, Hemus, v.2.

HARISIS, A., FARDIS, M. N. (1991). Computer-Aided Automatic Construction of Strutand-Tie Models. Structural Concrete, IABSE Colloquium, Stuttgart, International Association for Bridge and Structural Engineering, Zürich, p. 533-538, Março.

ITURRIOZ, I.; D'AVILA, V. M. R.; RAUSH, A. (2000). Análise experimentalcomputacional de um bloco de estacas de concreto armado. XXXIX Jornadas SulAmericanas de engenharia estrutural, In: CD-ROOM;

IYER, P. K.; SAM, C. (1991). 3-D elastic analysis of three-pile caps. Journal of Engineering Mechanics, ASCE, v. 117, n. 12, p. 2862-2883, Dec.

IYER, P. K.; SAM, C. (1992). Three-dimensional analysis of pile caps. Computers and Structures, v. 42, n. 3, p. 395-411, Feb.

IYER, P. K.; SAM, C. (1995 - Part a). Nonlinear finite element analysis of reinforced concrete four-pile caps. International Journal of Structures, v. 15, n. 1, p. 18-34, Jan/Jun.

IYER, P. K.; SAM, C. (1995 - Part b). Nonlinear finite element analysis of reinforced concrete two-pile caps. Computers and Structures, v. 57, p. 605-622, Nov.

LANGENDONCK, T. (1957). Cálculo de concreto armado. São Paulo, v.1-2.

LEONHARDT, F.; MONNING, E. (1978). Construções de Concreto. Rio de Janeiro, Interciência, v.2-3.

LONGO, H. I. (2000). Modelagem de estruturas de concreto pelo modelo de bielas e tirantes utilizando o método dos elementos finitos. XXIX Jornadas Sul-Americanas de Engenharia Estrutural, In: CD-ROOM.

MACHADO, C. P. (1979). Elementos especiais estruturais de concreto armado. São Paulo, FDTE- EPUSP - IPT. (Notas de Aula), v1. 
MACHADO, C. P. (1998). Consolos curtos e muito curtos de concreto armado. Tese (Doutorado) - Escola Politécnica, Universidade de São Paulo.

MARQUES, J.; JIRSA, J. (1975). A study of a Hooked Bar Anchorages in Beam Joints, ACl Journal, May.

MAUTONI, M. (1972). Bloco sobre dois apoios. São Paulo, Grêmio Politécnico.

MIGUEL, M. G. (2000). Análise experimental e numérica de blocos sobre três estacas. Tese (Doutorado) - Escola de Engenharia de São Carlos, Universidade de São Paulo.

MINOR, J.; JIRSA, J. (1975). Behaviour of Bent Bar Anchorages, ACI Journal, p.141149, April.

MONTOYA, P. J.; MESEgueR, A.; CABRE, M. (2000). Hormigon Armado. $14 .^{\text {a }}$ Edición Basada em EHE ajustada al Código Modelo y Eurocódig. Barcelona, Gustavo Gili.

OLIVEIRA, R. (1998). Determinação de Modelos de Bielas e Tirantes com utilização de Técnicas de Otimização Topológica. Dissertação (Mestrado) - Departamento de Engenharia Civil, Pontifica Universidade Católica do Rio de Janeiro.

RAUSH, A.; D'ASCENSO, N.; GOLDSCHMIDT, P.; NATALINI, M. (1997). Analisis experimental sobre cabezales de pilotes sometidos a cargas verticals. XXVIII Jornadas Sul-Americanas de engenharia estrutural, v. 1, p. 309-318, São Carlos;

SANTOS, L. M. (1981). Cálculo de concreto armado. Volume 2. Editora LMS Ltda. São Paulo.

SCHAFER, K., SCHLAICH, J. (1988). Consistent design of structural concrete using strut and tie modesI. In: COLÓQUIO SOBRE COMPORTAMENTO E PROJETO DE ESTRUTURAS, 5., Rio de Janeiro. Anais. PUC/RJ.

SCHLAICH, J., SCHAFER, K. (1991). Design and detailing of structural concrete using strut-and-tie models. The Structural Engineer, v.69, n.6, p.113-125, March. 
SCHLAICH, J., SCHAFER, K., JENNEWEIN, M. (1987). Towards a consistent design of structural concrete. PCl Journal, v.32, n.3, p.74-150, May-June.

SILVA, R. C.; GIONGO, J. S. (2000). Modelos de bielas e tirantes. Projeto REENGE, São Carlos, EESC - USP.

TAYLOR, H. P. J., CLARKE, J. L. (1976). Some detaililng problems in concrete frame structures. The Structural Engineer, London, v.54, n. 1, p. 19-32, January.

TJHIN, T. N.; KUCHMA, D. (2002). Computer-Based Tools for Design by Strut-andTie Method: Advances and Challenges. ACI Structural Journal, p. 586-594, SeptmberOctober. 